\title{
Fetal inflammatory injury as origin of long term disease : lessons from animal models
}

Citation for published version (APA):

Gantert, M. B. D. F. (2014). Fetal inflammatory injury as origin of long term disease : lessons from animal models. [Doctoral Thesis, Maastricht University]. Shaker Verlag GmbH. https://doi.org/10.26481/dis.20140131mg

Document status and date:

Published: 01/01/2014

DOI:

10.26481/dis.20140131mg

Document Version:

Publisher's PDF, also known as Version of record

\section{Please check the document version of this publication:}

- A submitted manuscript is the version of the article upon submission and before peer-review. There can be important differences between the submitted version and the official published version of record.

People interested in the research are advised to contact the author for the final version of the publication, or visit the DOI to the publisher's website.

- The final author version and the galley proof are versions of the publication after peer review.

- The final published version features the final layout of the paper including the volume, issue and page numbers.

Link to publication

\footnotetext{
General rights rights.

- You may freely distribute the URL identifying the publication in the public portal. please follow below link for the End User Agreement:

www.umlib.nl/taverne-license

Take down policy

If you believe that this document breaches copyright please contact us at:

repository@maastrichtuniversity.nl

providing details and we will investigate your claim.
}

Copyright and moral rights for the publications made accessible in the public portal are retained by the authors and/or other copyright owners and it is a condition of accessing publications that users recognise and abide by the legal requirements associated with these

- Users may download and print one copy of any publication from the public portal for the purpose of private study or research.

- You may not further distribute the material or use it for any profit-making activity or commercial gain

If the publication is distributed under the terms of Article $25 \mathrm{fa}$ of the Dutch Copyright Act, indicated by the "Taverne" license above, 


\title{
Fetal inflammatory injury as origin of long term disease: lessons from animal models
}

\author{
DISSERTATION \\ To obtain the degree of Doctor \\ at Maastricht University, \\ on authority of the Rector Magnificus, \\ Prof. Dr. L.L.G. Soete,
} in accordance with the decision of the Board of Deans, to be defended in public on Friday $31^{\text {st }}$ of January 2014 at 12:00 a.m.

by

Markus Bodo Paul Friedrich Gantert

Born the $12^{\text {th }}$ of January 1973 in Donaueschingen (Germany) 
Promoters and copromoter

Prof. Dr. Boris W. Kramer, MUMC+

Prof. Dr. Luc Zimmermann, MUMC+

Dr. Danilo Gavilanes, MUMC+

Evaluation committee:

Prof. Dr. Bernd Kremer, Chairman, MUMC+

Prof. Dr. Sidarto Bambang Oetomo, MMC, Veldhoven

Prof. Dr. Thorsten Orlikowsky, University Hospital Aachen, Germany

Prof. Dr. Hans Vles, MUMC+

Prof. Dr. Marc Spaanderman, MUMC+ 


\title{
Berichte aus der Medizin
}

\author{
Markus Gantert
}

Fetal inflammatory injury as origin of long term disease: lessons from animal models 
Bibliographic information published by the Deutsche Nationalbibliothek The Deutsche Nationalbibliothek lists this publication in the Deutsche Nationalbibliografie; detailed bibliographic data are available in the Internet at http://dnb.d-nb.de.

Zugl.: Maastricht University, Dissertation, 2014

Copyright Shaker Verlag 2014

All rights reserved. No part of this publication may be reproduced, stored in a retrieval system, or transmitted, in any form or by any means, electronic, mechanical, photocopying, recording or otherwise, without the prior permission of the publishers.

Printed in Germany.

ISBN 978-3-8440-2273-5

ISSN 0945-0890

Shaker Verlag GmbH • P.O. BOX 101818 • D-52018 Aachen

Phone: 0049/2407/9596-0 • Telefax: 0049/2407/9596-9

Internet: www.shaker.de • e-mail: info@shaker.de 


\section{Contents}

$\begin{array}{lll}\text { Chapter } 1 & \text { Introduction } & 7\end{array}$

Chapter 2 Chorioamnionitis: a multiorgan disease of the fetus?

Gantert, M., Been, J.V., Gavilanes, A.W., Garnier, Y., Zimmermann, L.J., Kramer, B.W.

J Perinatol. 2010 Oct; 30 Suppl: S21-30

Chapter 3 Lipopolysaccharide-induced chorioamnionitis is confined to one amnionitic compartment in twin pregnant sheep.

Gantert, M., Jellema, R.K., Heinemann, H., Gantert, J., Collins, J.J.P., Seehase, M., Lambermont, V.A.C., Keck, A., Garnier, Y., Zimmermann, L.J.I., Kadyrov, M., Gavilanes, A.W.D., Kramer, B.W. Neonatology. 2012;102:81-88

Chapter 4 Increased EEG delta frequency corresponds to chorioamnionitisrelated brain injury.

Gavilanes, A.W., Gantert, M., Strackx, E., Zimmermann, L.J., Seeldrayers, S., Vles, J.S., Kramer, B.W.

Front Biosci (Schol Ed). 2010 Jan 1; 2: 432-8

Chapter 5 Increased number of cerebellar granule cells and astrocytes in the internal granule layer in sheep following prenatal intra-amniotic injection of lipopolysaccharide.

Strackx, E., Gantert, M., Moers, V., van Kooten, I.A., Rieke, R., Hürter, H., Lemmens, M.A., Steinbusch, H.W., Zimmermann, L.J., Vles, J.S., Garnier, Y., Gavilanes, A.W., Kramer, B.W.

Cerebellum. 2012 Mar;11(1):132-44

Chapter 6 Chorioamnionitis induced by intraamniotic lipopolysaccharide resulted in an interval-dependent increase in central nervous system injury in the fetal sheep.

Gavilanes, A.W., Strackx, E., Kramer, B.W., Gantert, M., Van den Hove, D., Steinbusch, H., Garnier, Y., Cornips, E., Steinbusch, H., Zimmermann, L.J., Vles, J.

Am J Obstet Gynecol. 2009 Apr;200(4):437.e1-8

Chapter 7 Intravenous lipopolysaccharide-induced pulmonary maturation and structural changes in fetal sheep.

Kramer, B.W., Ladenburger, A., Kunzmann, S., Speer, C.P., Been, J.V., van Iwaarden, J.F., Zimmermann, L.J., Gantert, M., Garnier, Y. Am J Obstet Gynecol. 2009 Feb;200(2):195.e1-10

Chapter 8 Effects of in utero endotoxemia on the ovine fetal brain: A model for schizophrenia?

Gantert, M., Kreczmanski, P., Kuypers, E., Jellema, R., Strackx, E., Bastian, N., Gavilanes, A.W., Zimmermann, L.J., Garnier, Y.,

Schmitz, C., Kramer, B.W.

Front Biosci (Elite Ed). 2012 Jun 1;4:2845-53

Chapter 9 Summary and Outlook 
Acknowledgement

Curriculum vitae

List of Publications 
Chapter 1

Introduction 


\section{Introduction}

Contrary to progress in antenatal care, preterm birth remains a major issue across all health care systems. In the Western world, preterm birth accounts for 5 to $13 \%$ of all live birth ${ }^{1,2}$. Even in countries with highly developed health care systems like Germany the preterm birth rate increased steadily from 7.6 to $9.2 \%$ in the last two decades. In some African countries preterm birth rises up to $18 \%$ and an estimated 14.9 million babies were born preterm world wide in $2010^{3}$. Preterm birth accounts for more than $25 \%$ of neonatal mortality worldwide ${ }^{4}$.

The causes of preterm birth can generally be divided in two major groups: Preterm birth preceded by spontaneous preterm labour or PPROM, and medically indicated preterm birth. The larger group is the one of spontaneous preterm labour and PPROM which is often associated with intrauterine inflammation, or chorioamnionitis $^{1,2}$. A very close relationship between chorioamnionitis and spontaneous preterm birth exists ${ }^{2}$. The proportion of preterm infants exposed to chorioamnionitis therefore increases up to $60-80 \%$ at 24-26 weeks of gestation ${ }^{3,4}$.

Both the maternal and fetal immune system are involved in chorioamnionitis as shown by associations between polymorphisms in cytokine genes and the risk of chorioamnionitis with preterm labour ${ }^{5-7}$. The resulting fetal response to chorioamnionitis has been described as the fetal inflammatory response syndrome $(\mathrm{FIRS})^{8,9}$. Adverse neonatal outcome in newborn infants have been linked in many studies with chorioamnionitis. The most pronounced effects were often detected in infants with FIRS. Many studies have focussed on respiratory and neurological outcome, but additional fetal sequelae of chorioamnionitis have been described in several other organ systems. In addition, the effects of chorioamnionitis on health and disease may extend well beyond the neonatal period ${ }^{1,2}$.

Chorioamnionitis can be caused by different bacteria and other pathogens. The clinical situation is very difficult to assess and study since we do not know when chorioamnionitis starts, which bacteria cause chorioamnionitis and how the fetus responds or adapts to the exposure to infection. Therefore animal models may be very useful to study how antenatal exposure to inflammation may affect organ development ${ }^{7-10}$. Sheep have the advantage that the organ development of the lung, gut and brain are very similar to the human situation ${ }^{11}$. The size of the animals allows two distinct approaches to study the fetal response to exposure to antenatal proinflammatory stimuli. 
Endotoxin/Lipopolysaccharide from E.coli was used to cause a chorioamnionitis in time-mated pregnant sheep ${ }^{12}$. LPS rapidly induced a sterile chorioamnionitis after ultrasound guided injection into the amniotic cavity ${ }^{13}$. This model is very robust with tested doses from $1 \mathrm{mg}$ to $100 \mathrm{mg}$ provoking comparable fetal inflammatory responses ${ }^{14}$. The fetal well-being was not impaired during chorioamnionitis as assessed in a chronically catheterized experimental set up ${ }^{15}$. The lung, skin and gut were in direct contact with the amniotic fluid and the LPS. In the lung, a local inflammatory response rapidly changed not only the microvasculature structure ${ }^{16}$, but also caused aberrant elastin deposition in the fetal lung ${ }^{17}$ and matured alveolar macrophages ${ }^{18}$. LPS-induced chorioamnionitis induced therefore a cascade of lung injury, pulmonary inflammation, and remodelling in the fetal lung ${ }^{19,20}$. These structural changes in addition to the reduced expression of growth factors in the fetal lung after chorioamnionitis ${ }^{21}$ resulted in a similar histologic picture to bronchopulmonary dysplasia with alveolar and microvascular simplification ${ }^{16,}{ }^{22}$ The effects of chorioamnionitis were not mediated by cortisol $^{12}$.

A second model studies the fetal response to systemic endotoxin injected intravenously. In this model catheters are placed surgically and allow the collection of fetal blood and vital parameters ${ }^{23,24}$. This model is representing a systemic endotoxemia where the fetal organs are being exposed from the endothelial site to endotoxin.

\section{Aim and outline of the thesis}

Our research group has developed several sheep models to study both the effects of chorioamnionitis and endotoxemia / sepsis on the fetal brain and lung 1, 7, 8, 10, 23-33. I have tested in preterm sheep two separate approaches to study these entities:

- Ultrasound guided injection of lipopolysaccharide (LPS) into the amniotic cavity to induce chorioamnionitis.

- Chronic catheters into the fetus to give LPS systemically (endotoxemia). 


\section{In chapter 2 the clinical literature and the experimental literature were reviewed} for separate organ systems. We outlined the role of chorioamnionitis in the developing fetus and summarized the resulting symptoms and its severe consequences as a multiorgan disease ${ }^{1}$.

In chapter 3 the aim was to study the confinement of chorioamnionitis in twin pregnancies.

LPS administered via amniocentesis to only one amniotic cavity showed remarkable effects at the affected sheep fetus but not at the co-twin ${ }^{25}$.

Related to human multiple pregnancies these findings may help to encourage clinicians to consider delayed-interval delivery as an option. When chorioamnionitis presents with clinical signs and multiple pregnancies are around the borders of survivability it would be of major interest if only one compartement is affected and chorioamnionitis does not affect the other compartment.

Chorioamnionitis is a major predictor of a complicated neonatal clinical course and a poor neurological outcome $\mathrm{i}^{10,26,34-36}$. Newborns previously exposed to antenatal inflammation are difficult to identify. Most of the time clinical signs of chorioamnionitis are lacking especially in preterms when first care takes all heroic efforts of neonatologists. The early detection of neuronal dysfunction in newborns is of particular interest as it might have a diagnostic and prognostic value. Previously we studied chorioamnionitis in the sheep model to investigate the link between antenatal inflammation and neurological injury ${ }^{8}$.

In chapter 4 the function of the fetal brain after ultrasound guided LPS administration into the amniotic cavity was studied. We hypothesized that the neonatal brain function was affected after intra-uterine exposure to inflammation. This investigation demonstrated a relationship between brain dysfunction and chorioamnionitis-related injury in non-anesthetized preterm sheep via intrapartal measurements of electro encephalogram (EEG) delta frequency ${ }^{28}$.

Clinical data shows that choriamnionitis is mainly related to cerebral white matter damage, including disseminated and focal necrosis, cystic lesions, and cerebral palsy $^{37-41}$. Cerebellar injury due to chorioamnionitis is often underestimated, especially in its non-motor function. There is more and more evidence that the 
cerebellum is also involved in cognitive and affective disorders ${ }^{4<-40}$. A disturbed development of the cerebellum during pregnancy and its subsequent neonatal damage may play a role in long-lasting motor, cognitive and other behavioural changes. Almost half of the preterm infants with cerebral palsy show abnormalities in the cerebellum ${ }^{47,48}$.

In chapter $\mathbf{5}$ we studied morphological alterations in the cerebellum subsequent to chorioamnionitis in fetal sheep by asking the question whether chorioamnionitis affected the cerebellum in utero ${ }^{49}$. The cerebellum is especially vulnerable during late gestation, since this is the period of active proliferation and migration of cerebellar granule cells ${ }^{50}$. In human neonates, high concentrations of cytokines, like tumor necrosis factor $\alpha$, Interleukin 6 and Interleukin $1 \beta$, in the cord blood and the amniotic fluid increase the risk for periventricular leukomalacia and higher levels of proinflammatory cytokines are expressed in the damaged areas of the brain ${ }^{51,52}$. Animal studies also provide evidence that the antenatal administration of endotoxins, like LPS, causes a higher systemic cytokine expression, leading to cerebral apoptotic cell death and gliosis in different animal species ${ }^{53-60}$. Pro-inflammatory cytokines induce a multi-organ fetal inflammatory response syndrome leading to reactive astrogliosis and the loss of mainly immature oligodendrocytes ${ }^{61,62}$. Because of its vulnerability at late gestation the cerebellum seems to be quite susceptible to injury and impaired development induced by chorioamnionitis, especially in ex-preterm infants ${ }^{44,46,63,64}$. Chorioamnionitis might interfere with normal development of the cerebellar granule cells and other cerebellar cell populations, such as the Purkinje cells. We hypothesized that chorioioamnionitis causes changes in the granule cell number and / or Purkinje cell number, associated with astrocytic changes, in the near-term fetal cerebellum in a clinical relevant experimental animal model.

The predominantly studied central nervous system pathology is the cerebral periventricular white matter disease, which results in permanent structural brain damage and severe long lasting neurodevelopmental impairment, such as periventricular leukomalacia and cerbral palsy ${ }^{65,66}$. Cortical and subcortical gray matter and cerebellum (chapter 5) are affected as well, contributing to a complex long-term neurologic morbidity ${ }^{35,67}$. 
In chapter 6 we asked whether other brain regions beside the cerebral white matter were affected by chorioamnionitis ${ }^{27}$.

We analyzed apoptotic cells and cell types in the brain, cerebellum, and the spinal cord by flow cytometry. In this study we again administered LPS into the amniotic cavity. This approach avoids the superimposed hypoxic ischemia that is seen in animals, which receive LPS intravenously ${ }^{24}$. The applied experimental time window corresponds to approximately 28 weeks of human central nervous system maturation, which is the most vulnerable period for the human brain to develop white matter desease ${ }^{60,68-70}$.

FIRS is the consequent sequel of chorioamnionitis ${ }^{1}$. Antenatal inflammation may induce a chronic inflammatory response in fetal airways and pulmonary tissue, which has been associated with later development of bronchopulmonary dysplasia (BPD) ${ }^{71}$. BPD is considered to be an impairment of growth and development of the alveoli and microvasculature aggravated by pulmonary and systemic inflammation postnatally ${ }^{71}$, 72 . For example, elastin fibers marking the future site of new alveoli were disrupted in infants and animal models of BPD ${ }^{73}$.

In chapter 7 we hypothesized that fetal systemic inflammation induced by intravenous LPS would affect lung development in utero ${ }^{29}$. We focused on lung maturation and lung structure by measuring Interleukin 6 in the bronchoalverolar lavage, pro-surfactant and surfactant protein $\mathrm{B}$. In addition to these observations we showed the deposition of elastin fibers at sites of septation also as a sign of disturbed lung structure in an animal model.

The neurological outcome after preterm birth is also linked to the development of several disorders in later life, one of which is schizophrenia ${ }^{1,74,75}$. In addition, infections during the second trimester of pregnancy were identified to play a role in the etiopathogenesis of schizophrenia ${ }^{76,77}$. Post mortem studies showed various neuropathological findings in the anterior cingulate cortex of the brains from patients with schizophrenia ${ }^{78-80}$. This area is part of the limbic system and is the central location for visceral regulation processes and higher cognitive processes like memory, attentiveness, affect regulation, concentration and pain ${ }^{81}$. Magnet resonance tomography studies showed that the largest loss of cortical volume in the brains of patients suffering from schizophrenia can be found in the cingulate cortex ${ }^{82}$. As infections during pregnancy seem to play a role in development of schizophrenia, 
we hypothesized that fetal exposure to infection in utero could result in cytoarchitectural changes in the fetal anterior cingulate cortex, similar to the pathogenesis seen in patients with schizophrenia (chapter 8 ). We again used the sheep model in which LPS was injected intravenously in instrumented fetal lambs 30. We aimed to establish an animal model to investigate more about schizophrenia where most perceptions result from post mortem studies.

Finally, in chapter 9, the thesis is summarized. The versatility of our animal models is outlined and future applications are provided. 


\section{References:}

1. Gantert M, Been JV, Gavilanes AW, Garnier Y, Zimmermann LJ, Kramer BW. Chorioamnionitis: a multiorgan disease of the fetus? J Perinatol 2010;30 Suppl:S21-30.

2. Goldenberg RL, Culhane JF, lams JD, Romero R. Epidemiology and causes of preterm birth. Lancet 2008;371:75-84.

3. Blencowe $\mathrm{H}$, Cousens $\mathrm{S}$, Oestergaard $\mathrm{MZ}$, et al. National, regional, and worldwide estimates of preterm birth rates in the year 2010 with time trends since 1990 for selected countries: a systematic analysis and implications. Lancet 2012;379:216272.

4. Lawn JE, Osrin D, Adler A, Cousens S. Four million neonatal deaths: counting and attribution of cause of death. Paediatr Perinat Epidemiol 2008;22:410-6.

5. Bersani I, Thomas W, Speer CP. Chorioamnionitis--the good or the evil for neonatal outcome? J Matern Fetal Neonatal Med 2012;25 Suppl 1:12-6.

6. Czikk MJ, McCarthy FP, Murphy KE. Chorioamnionitis: from pathogenesis to treatment. Clin Microbiol Infect 2011;17:1304-11.

7. Kramer BW. Chorioamnionitis - new ideas from experimental models. Neonatology 2011;99:320-5.

8. Kramer BW, Moss TJ, Willet KE, et al. Dose and time response after intraamniotic endotoxin in preterm lambs. Am J Respir Crit Care Med 2001;164:982-8.

9. Petit E, Abergel A, Dedet B, Subtil D. [The role of infection in preterm birth]. J Gynecol Obstet Biol Reprod (Paris) 2012;41:14-25.

10.Jellema RK, Lima Passos V, Zwanenburg A, et al. Cerebral inflammation and mobilization of the peripheral immune system following global hypoxia-ischemia in preterm sheep. J Neuroinflammation 2013;10:13.

11.Wolfs TG, Jellema RK, Turrisi G, Becucci E, Buonocore G, Kramer BW. Inflammation-induced immune suppression of the fetus: a potential link between chorioamnionitis and postnatal early onset sepsis. J Matern Fetal Neonatal Med 2012;25 Suppl 1:8-11.

12.Eklind S, Mallard C, Leverin AL, et al. Bacterial endotoxin sensitizes the immature brain to hypoxic--ischaemic injury. Eur J Neurosci 2001;13:1101-6.

13.Saha RN, Liu X, Pahan K. Up-regulation of BDNF in astrocytes by TNF-alpha: a case for the neuroprotective role of cytokine. J Neuroimmune Pharmacol 2006;1:212-22.

14.Cui Q, Yin Y, Benowitz LI. The role of macrophages in optic nerve regeneration. Neuroscience 2009;158:1039-48.

15. Mallard $\mathrm{C}$, Hagberg $\mathrm{H}$. Inflammation-induced preconditioning in the immature brain. Semin Fetal Neonatal Med 2007;12:280-6.

16.Polam S, Koons A, Anwar M, Shen-Schwarz S, Hegyi T. Effect of chorioamnionitis on neurodevelopmental outcome in preterm infants. Arch Pediatr Adolesc Med 2005;159:1032-5.

17. Ogunyemi D, Murillo M, Jackson U, Hunter N, Alperson B. The relationship between placental histopathology findings and perinatal outcome in preterm infants. J Matern Fetal Neonatal Med 2003;13:102-9.

18.Fung G, Bawden K, Chow P, Yu V. Chorioamnionitis and outcome in extremely preterm infants. Ann Acad Med Singapore 2003;32:305-10.

19.Dammann O, Leviton A. Inflammation, brain damage and visual dysfunction in preterm infants. Semin Fetal Neonatal Med 2006;11:363-8. 
20.Dammann O, Brinkhaus MJ, Bartels DB, et al. Immaturity, perinatal inflammation, and retinopathy of prematurity: a multi-hit hypothesis. Early Hum Dev 2009;85:325-9.

21.Williams FL, Visser TJ, Hume R. Transient hypothyroxinaemia in preterm infants. Early Hum Dev 2006;82:797-802.

22. De Felice $C$, Bagnoli $F$, Toti $P$, et al. Transient hypothyroxinemia of prematurity and histological chorioamnionitis. J Perinat Med 2005;33:514-8.

23. Garnier $Y$, Coumans AB, Jensen A, Hasaart TH, Berger R. Infection-related perinatal brain injury: the pathogenic role of impaired fetal cardiovascular control. J Soc Gynecol Investig 2003;10:450-9.

24. Garnier Y, Coumans A, Berger R, Jensen A, Hasaart TH. Endotoxemia severely affects circulation during normoxia and asphyxia in immature fetal sheep. J Soc Gynecol Investig 2001;8:134-42.

25.Gantert M, Jellema RK, Heineman $H$, et al. Lipopolysaccharide-Induced Chorioamnionitis Is Confined to One Amniotic Compartment in Twin Pregnant Sheep. Neonatology 2012;102:81-8.

26.Berger R, Garnier Y, Jensen A. Perinatal brain damage: underlying mechanisms and neuroprotective strategies. J Soc Gynecol Investig 2002;9:319-28.

27. Gavilanes AW, Strackx E, Kramer BW, et al. Chorioamnionitis induced by intraamniotic lipopolysaccharide resulted in an interval-dependent increase in central nervous system injury in the fetal sheep. Am J Obstet Gynecol 2009;200:437 e1-8.

28. Gavilanes AW, Gantert M, Strackx E, et al. Increased EEG delta frequency corresponds to chorioamnionitis-related brain injury. Front Biosci (Schol Ed) 2010;2:432-8.

29.Kramer BW, Ladenburger A, Kunzmann S, et al. Intravenous lipopolysaccharideinduced pulmonary maturation and structural changes in fetal sheep. Am J Obstet Gynecol 2009;200:195 e1-10.

30.Gantert M, Kreczmanski P, Kuypers E, et al. Effects of in utero endotoxemia on the ovine fetal brain: A model for schizophrenia? Front Biosci (Elite Ed) 2012;4:2845-53.

31.Kramer BW. Antenatal inflammation and lung injury: prenatal origin of neonatal disease. J Perinatol 2008;28 Suppl 1:S21-7.

32. Kramer BW, Jobe $\mathrm{AH}$. The clever fetus: responding to inflammation to minimize lung injury. Biol Neonate 2005;88:202-7.

33.Kunzmann S, Collins JJ, Kuypers E, Kramer BW. Thrown off balance: the effect of antenatal inflammation on the developing lung and immune system. Am J Obstet Gynecol 2013.

34.Dammann O, Leviton A, Bartels DB, Dammann CE. Lung and brain damage in preterm newborns. Are they related? How? Why? Biol Neonate 2004;85:305-13.

35. Thompson DK, Warfield SK, Carlin JB, et al. Perinatal risk factors altering regional brain structure in the preterm infant. Brain 2007;130:667-77.

36. Wu YW. Systematic review of chorioamnionitis and cerebral palsy. Ment Retard Dev Disabil Res Rev 2002;8:25-9.

37.De Vries LS, Van Haastert IL, Rademaker KJ, Koopman C, Groenendaal F. Ultrasound abnormalities preceding cerebral palsy in high-risk preterm infants. $J$ Pediatr 2004;144:815-20.

38. Inder TE, Anderson NJ, Spencer C, Wells S, Volpe JJ. White matter injury in the premature infant: a comparison between serial cranial sonographic and MR findings at term. AJNR Am J Neuroradiol 2003;24:805-9. 
39. Nelson KB, Willoughby RE. Infection, inflammation and the risk of cerebral palsy. Curr Opin Neurol 2000;13:133-9.

40.Volpe JJ. Cerebral white matter injury of the premature infant-more common than you think. Pediatrics 2003;112:176-80.

41.Yoon $\mathrm{BH}$, Park $\mathrm{CW}$, Chaiworapongsa $\mathrm{T}$. Intrauterine infection and the development of cerebral palsy. BJOG 2003;110 Suppl 20:124-7.

42.Allin $M$, Matsumoto $H$, Santhouse $A M$, et al. Cognitive and motor function and the size of the cerebellum in adolescents born very pre-term. Brain 2001;124:60-6.

43. Hoppenbrouwers SS, Schutter DJ, Fitzgerald PB, Chen R, Daskalakis ZJ. The role of the cerebellum in the pathophysiology and treatment of neuropsychiatric disorders: a review. Brain Res Rev 2008;59:185-200.

44.Limperopoulos C, Bassan H, Gauvreau K, et al. Does cerebellar injury in premature infants contribute to the high prevalence of long-term cognitive, learning, and behavioral disability in survivors? Pediatrics 2007;120:584-93.

45.Limperopoulos C, Robertson RL, Sullivan NR, Bassan H, du Plessis AJ. Cerebellar injury in term infants: clinical characteristics, magnetic resonance imaging findings, and outcome. Pediatr Neurol 2009;41:1-8.

46.Parker J, Mitchell A, Kalpakidou A, et al. Cerebellar growth and behavioural \& neuropsychological outcome in preterm adolescents. Brain 2008;131:1344-51.

47.Bodensteiner JB, Johnsen SD. Cerebellar injury in the extremely premature infant: newly recognized but relatively common outcome. J Child Neurol 2005;20:139-42.

48.Johnsen SD, Bodensteiner JB, Lotze TE. Frequency and nature of cerebellar injury in the extremely premature survivor with cerebral palsy. J Child Neurol 2005;20:60-4.

49. Strackx E, Gantert M, Moers V, et al. Increased number of cerebellar granule cells and astrocytes in the internal granule layer in sheep following prenatal intraamniotic injection of lipopolysaccharide. Cerebellum 2012;11:132-44.

50.Rees S, Harding R. The effects of intrauterine growth retardation on the development of the Purkinje cell dendritic tree in the cerebellar cortex of fetal sheep: a note on the ontogeny of the Purkinje cell. Int J Dev Neurosci 1988;6:4619.

51.Kadhim H, Tabarki B, Verellen G, De Prez C, Rona AM, Sebire G. Inflammatory cytokines in the pathogenesis of periventricular leukomalacia. Neurology 2001;56:1278-84.

52. Yoon BH, Romero R, Jun JK, et al. Amniotic fluid cytokines (interleukin-6, tumor necrosis factor-alpha, interleukin-1 beta, and interleukin-8) and the risk for the development of bronchopulmonary dysplasia. Am J Obstet Gynecol 1997;177:825-30.

53. Cai Z, Pan ZL, Pang Y, Evans OB, Rhodes PG. Cytokine induction in fetal rat brains and brain injury in neonatal rats after maternal lipopolysaccharide administration. Pediatr Res 2000;47:64-72.

54.Duncan JR, Cock ML, Suzuki K, Scheerlinck JP, Harding R, Rees SM. Chronic endotoxin exposure causes brain injury in the ovine fetus in the absence of hypoxemia. J Soc Gynecol Investig 2006;13:87-96.

55. Gilles FH, Averill DR, Jr., Kerr CS. Neonatal endotoxin encephalopathy. Ann Neurol 1977;2:49-56.

56. Gilles FH, Leviton A, Kerr CS. Endotoxin leucoencephalopathy in the telencephalon of the newborn kitten. J Neurol Sci 1976;27:183-91.

57.Nitsos I, Rees SM, Duncan J, et al. Chronic exposure to intra-amniotic lipopolysaccharide affects the ovine fetal brain. J Soc Gynecol Investig 2006;13:239-47. 
58.Rousset $\mathrm{Cl}$, Chalon S, Cantagrel S, et al. Maternal exposure to LPS induces hypomyelination in the internal capsule and programmed cell death in the deep gray matter in newborn rats. Pediatr Res 2006;59:428-33.

59. Yoon $\mathrm{BH}$, Kim CJ, Romero R, et al. Experimentally induced intrauterine infection causes fetal brain white matter lesions in rabbits. Am J Obstet Gynecol 1997; $177: 797-802$.

60.Kuypers E, Ophelders D, Jellema RK, Kunzmann S, Gavilanes AW, Kramer BW. White matter injury following fetal inflammatory response syndrome induced by chorioamnionitis and fetal sepsis: lessons from experimental ovine models. Early Hum Dev 2012;88:931-6.

61.Bell MJ, Hallenbeck JM, Gallo V. Determining the fetal inflammatory response in an experimental model of intrauterine inflammation in rats. Pediatr Res 2004;56:541-6.

62.Leviton A, Gilles F. Ventriculomegaly, delayed myelination, white matter hypoplasia, and "periventricular" leukomalacia: how are they related? Pediatr Neurol 1996;15:127-36.

63. Limperopoulos C, Soul JS, Gauvreau K, et al. Late gestation cerebellar growth is rapid and impeded by premature birth. Pediatrics 2005;115:688-95.

64.Nosarti C, Giouroukou E, Healy E, et al. Grey and white matter distribution in very preterm adolescents mediates neurodevelopmental outcome. Brain 2008;131:205-17.

65.Back SA, Riddle A, McClure MM. Maturation-dependent vulnerability of perinatal white matter in premature birth. Stroke 2007;38:724-30.

66. Leviton A, Paneth N, Reuss ML, et al. Maternal infection, fetal inflammatory response, and brain damage in very low birth weight infants. Developmental Epidemiology Network Investigators. Pediatr Res 1999;46:566-75.

67.Shah DK, Anderson PJ, Carlin JB, et al. Reduction in cerebellar volumes in preterm infants: relationship to white matter injury and neurodevelopment at two years of age. Pediatr Res 2006;60:97-102.

68. Back SA. Recent advances in human perinatal white matter injury. Prog Brain Res 2001;132:131-47.

69.Back SA, Riddle A, Hohimer AR. Role of instrumented fetal sheep preparations in defining the pathogenesis of human periventricular white-matter injury. J Child Neurol 2006;21:582-9.

70.Duncan JR, Cock ML, Scheerlinck JP, et al. White matter injury after repeated endotoxin exposure in the preterm ovine fetus. Pediatr Res 2002;52:941-9.

71.Speer CP. Inflammation and bronchopulmonary dysplasia: a continuing story. Semin Fetal Neonatal Med 2006;11:354-62.

72. Jobe AH, Bancalari E. Bronchopulmonary dysplasia. Am J Respir Crit Care Med 2001;163:1723-9.

73. Bland RD. Neonatal chronic lung disease in the post-surfactant era. Biol Neonate 2005;88:181-91.

74.Limosin F, Rouillon F, Payan C, Cohen JM, Strub N. Prenatal exposure to influenza as a risk factor for adult schizophrenia. Acta Psychiatr Scand 2003;107:331-5.

75.Suvisaari J, Haukka J, Tanskanen A, Hovi T, Lonnqvist J. Association between prenatal exposure to poliovirus infection and adult schizophrenia. Am J Psychiatry 1999;156:1100-2.

76.Adams W, Kendell RE, Hare EH, Munk-Jorgensen P. Epidemiological evidence that maternal influenza contributes to the aetiology of schizophrenia. An analysis of Scottish, English, and Danish data. Br J Psychiatry 1993;163:522-34. 
77.McGrath JJ, Pemberton MR, Welham JL, Murray RM. Schizophrenia and the influenza epidemics of 1954, 1957 and 1959: a southern hemisphere study. Schizophr Res 1994;14:1-8.

78. Harrison PJ. Neurochemical alterations in schizophrenia affecting the putative receptor targets of atypical antipsychotics. Focus on dopamine (D1, D3, D4) and 5-HT2a receptors. Br J Psychiatry Suppl 1999:12-22.

79. Heckers S. Neuropathology of schizophrenia: cortex, thalamus, basal ganglia, and neurotransmitter-specific projection systems. Schizophr Bull 1997;23:403-21.

80. Jakob H, Beckmann H. Gross and histological criteria for developmental disorders in brains of schizophrenics. J R Soc Med 1989;82:466-9.

81.Carter CS, Mintun M, Nichols T, Cohen JD. Anterior cingulate gyrus dysfunction and selective attention deficits in schizophrenia: [15O]H2O PET study during single-trial Stroop task performance. Am J Psychiatry 1997;154:1670-5.

82. Goldstein JM, Goodman JM, Seidman LJ, et al. Cortical abnormalities in schizophrenia identified by structural magnetic resonance imaging. Arch Gen Psychiatry 1999;56:537-47. 


\section{Chapter 2}

Chorioamnionitis: a multiorgan disease of the fetus? Gantert, M., Been, J.V., Gavilanes, A.W., Garnier, Y., Zimmermann, L.J., Kramer, B.W. J Perinatol. 2010 Oct; 30 Suppl: S21-30 


\title{
REVIEW
}

\section{Chorioamnionitis: a multiorgan disease of the fetus?}

\author{
M Gantert $^{1,4}$, JV Been ${ }^{2,3,4}$, AWD Gavilanes ${ }^{2,3}$, Y Garnier ${ }^{1}$, LJI Zimmermann ${ }^{2,3}$ and BW Kramer ${ }^{2,3}$ \\ ${ }^{1}$ Department of Obstetrics and Gynecology, Klinikum Osnabrück, Osnabrück, Germany; ${ }^{2}$ Department of Pediatrics, Maastricht \\ University Medical Centre, Maastricht, The Netherlands and ${ }^{3}$ School of Oncology and Developmental Biology, GROW, School of Mental \\ Health and Neuroscience, University of Maastricht, Maastricht, The Netherlands
}

\begin{abstract}
The bacterial infection of chorion and amnion is a common finding in premature delivery and is referred to as chorioamnionitis. As the mother rarely shows symptoms of a systemic inflammation, the course of chorioamnionitis is frequently asymptomatic and chronic. In contrast, the fetal inflammatory response syndrome represents a separate phenomenon, including umbilical inflammation and increased serum levels of proinflammatory cytokines in the fetus. Ascending maternal infections frequently lead to systemic fetal inflammatory reaction. Clinical studies have shown that antenatal exposure to inflammation puts the extremely immature neonates at a high risk for worsening pulmonary, neurological and other organ development. Interestingly, the presence of chorioamnionitis is associated with a lower rate of neonatal mortality in extremely immature newborns. In the following review, the pathogeneses of inflammation-associated perinatal morbidity are outlined. The concept of fetal multiorganic disease during intrauterine infection is introduced and discussed.

Journal of Perinatology (2010) 0, 000-000. doi:10.1038/jp.2010.96
\end{abstract}

Keywords: antenatal inflammation; organ injury; development; repair; adverse outcome

\section{Introduction}

Despite substantial progress in antenatal care, preterm birth remains a major health issue across the globe. In the Western world, preterm birth accounts for 5 to $13 \%$ of all live births, with important regional differences. ${ }^{1}$ The incidence of preterm birth continues to rise steadily, exposing the society to increasing medical and social expenses. ${ }^{1}$

Roughly, the causes of preterm birth can be divided into two groups: indicated preterm birth and preterm birth preceded by spontaneous preterm labor or preterm prelabor rupture of

Correspondence: Dr BW Kramer, Department of Pediatrics, Maastricht University Medical Center, School of Oncology and Developmental Biology, P. Debyelaan 25, Maastricht 6202 AZ, The Netherlands.

E-mail: b.kramer@mumc.nl

This paper resulted from the Evidence vs Experience in Neonatal Practices conference, 19 to 20 June 2009, sponsored by Dey, LP.

${ }^{4}$ These authors contributed equally to this work. membranes (PPROM). Obviously, in the former group the direct cause is iatrogenic and may relate to fetal or maternal indications for intervention. These include severe intrauterine growth retardation, and maternal pre-eclampsia and hypertension, elevated liver enzymes, low platelets (HELLP) syndrome. On the other hand, preterm deliveries in the larger group of spontaneous preterm labor and PPROM are often associated with intrauterine inflammation or chorioamnionitis. ${ }^{1,2}$ A close association between chorioamnionitis and spontaneous preterm delivery exists. ${ }^{2}$ As a result, the proportion of preterm infants exposed to chorioamnionitis increases with decreasing gestational age to up to $80 \%$ below 28 weeks of gestation. ${ }^{3,4}$

Ascending bacterial invasion of the uterine cavity is thought to be the most common route of infection, although bacteria are identified only in the minority of cases. ${ }^{2}$ Organisms most frequently associated with chorioamnionitis are mainly of low virulence, including Ureaplasma spp. and Mycoplasma spp. ${ }^{2,5}$ Both the maternal and fetal immune system have an important role in chorioamnionitis, given the shown associations between polymorphisms in immunoregulatory genes and the risk of chorioamnionitis and preterm labor. ${ }^{6,7}$ A large subset of chorioamnionitis cases remain clinically silent. These may be diagnosed by culture or proteomic profiling of the amniotic fluid, by microbial culture or footprinting, or by histological examination of the placenta after birth. ${ }^{5}$ The latter is generally regarded as the 'gold standard' in the diagnosis of chorioamnionitis. 5 More serious cases of chorioamnionitis may become clinically apparent and cause both general (fever, leukocytosis and raised C-reactive protein) and local symptoms (uterine tenderness and vaginal discharge). Although a combination of these symptoms is often given the syndromic description 'clinical chorioamnionitis', the overlap with the histological diagnosis of chorioamnionitis has been shown to be only modest. ${ }^{8}$

In chorioamnionitis, the presence of fetal signs of inflammation, such as funisitis or elevated cord blood interleukin-6 (IL-6), is thought to reflect the more serious side of the continuum. ${ }^{9}$ When intrauterine inflammation is present, the fetus may be exposed through direct contact with amniotic fluid or through the placental-fetal circulation. The consequent fetal 
response to chorioamnionitis has been referred to as the fetal inflammatory response syndrome (FIRS). ${ }^{9}$ Many studies have associated chorioamnionitis with adverse neonatal outcome in newborn infants and the most pronounced effects were often present in infants with signs of FIRS. Although earlier studies have focused mainly on the respiratory and neurological outcomes, additional fetal sequelae of chorioamnionitis have more recently been described in several other organ systems. Moreover, evidence is increasing that the effects of chorioamnionitis on health and disease may extend well beyond the neonatal period. ${ }^{10}$ In the current review we aim to give an overview on the concept of chorioamnionitis as a multiorgan disease of the fetus, and discuss potential long-term consequences and therapeutic options for early intervention.

\section{Multiorgan overview \\ Brain}

Clinical observations. Specific stages of brain development could be affected at different gestational ages with different prognoses that manifest throughout the entire lifespan. In term and preterm newborns in particular, perinatal brain damage is a fundamental cause of developmental delay and lifelong neurological disabilities, such as mental retardation, cerebral palsy as well as school and behavioral difficulties. In addition, perinatal brain injury might increase the risk for the development of psychiatric disorders such as schizophrenia later in life. ${ }^{11}$

Chorioamnionitis and vasculitis in the umbilical cord (funisitis) have a high incidence in preterm deliveries and are probably the most important risk factor of both preterm labor and birth, and preterm cerebral white matter disease (WMD) (Figure 1). Furthermore, hypoxia-ischemia in association with chorioamnionitis markedly increases the vulnerability of the immature brain to the deficits mentioned above. ${ }^{12}$ Diffuse or focal WMD, usually described as periventricular leukomalacia, has been shown to be the predominant feature of brain damage in premature newborns of $<32$ weeks of gestation. ${ }^{11}$ Magnetic resonance imaging studies at corrected term age showed that $21 \%$ of extreme preterm infants have moderate-to-severe WMD, and this was predictive of cerebral palsy at the corrected age of 2 years. ${ }^{13}$ In clinical studies, antenatal exposure to inflammation has been associated with an increased risk for periventricular leukomalacia and cerebral palsy. ${ }^{14-16}$ Moreover, neurodevelopmental delay has been linked with previous exposure to chorioamnionitis by some studies, although others have failed to reproduce these findings. ${ }^{10}$

Animal experimental evidence. Experimentally, inflammatory processes - induced by intra-amniotic or intravenous fetal endotoxin administration - impair myelination. ${ }^{17}$ We showed

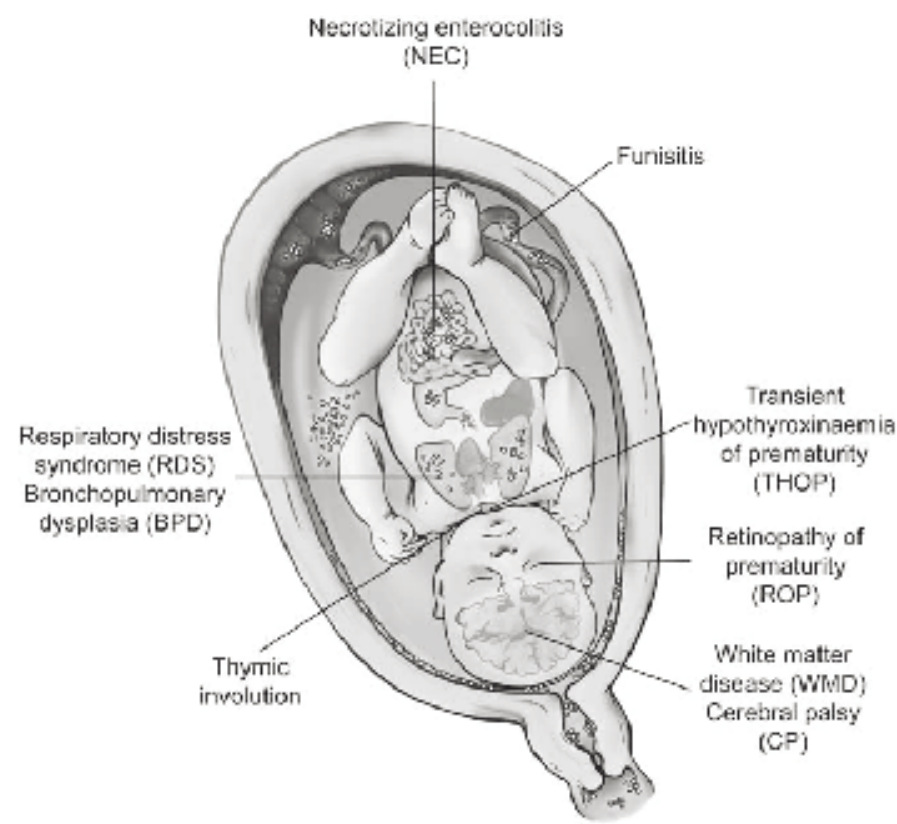

Figure 1 Chorioamnionitis as a multiorgan disease of the fetus. The fetus is being exposed to contaminated amniotic fluid that is aspirated and/or slicked by the fetus. The direct and indirect exposure has been associated with effects on several organs that are depicted in the figure. 
global central nervous system compromise after chorioamnionitis induced by the intra-amniotic administration of lipopolysaccharide (LPS) in the fetal sheep. ${ }^{18}$ Chorioamnionitis induced microglial activation, astrogliosis and apoptotic cell death and differentially affected the whole ovine central nervous system. Regional responses varied as a function of its maturational stage; for example, brain and cerebellar, but not spinal premyelinating oligodendrocytes, were found to be vulnerable at the gestational age of 125 days (term being 150 days). ${ }^{18}$ In addition, Garnier et al. ${ }^{19}$ showed microglial activation in the periventricular and subcortical white matter and increased S100B protein blood levels in a model of intravenous fetal LPS administration at a gestational age of 107 days.

The activated microglia have a central role in the pathogenesis of WMD. Inflammation-mediated impairment of oligodendrocyte progenitor cell development into myelinating, mature oligodendrocytes is mainly caused by the influence of the native activated microglia. ${ }^{20}$ The activated microglia in the diffuse white matter lead to the apoptotic death of the developing oligodendrocytes by two mechanisms. First, in addition to the systemic upregulated proinflammatory cytokines, the diffuse microglial production of proinflammatory cytokines, for example, tumor necrosis factor- $\alpha$ (TNF- $\alpha$ ), IL-1, IL-6 and interferon- $\gamma$, affects mainly the cerebral fetal white matter oligodendrocytes, ${ }^{18}$ and secondarily induces neuronal loss and impaired neuronal guidance, $^{21}$ with high levels of proinflammatory cytokines. ${ }^{22}$ Although low cytokine levels are crucial for the maturation and differentiation of oligodendrocyte precursors into myelinating mature oligodendrocytes, high levels of proinflammatory cytokines, as found in inflamed fetal brains, inhibit this process. ${ }^{23,24}$ In addition, proinflammatory cytokines may affect the central nervous system by increasing the permeability of the developing blood brain barrier exclusively observed in the cerebral white matter, ${ }^{25}$ and by impairing the cerebral blood flow. ${ }^{26}$ Second, developing oligodendrocytes are injured by reactive oxygen species and reactive nitrogen species generated by either oligodendrocyte glutamatergic excitotoxicity or microglial activation. The activated microglia generate free radicals and induce the ultimate death of the antioxidant-deficient immature oligodendrocytes. ${ }^{27}$ Combined, these two processes result in morphological white matter lesions and the impairment of myelination, one of the most serious complications of WMD in preterm infants. ${ }^{28}$

Pathogenetically important is the fact that the immature fetal brain becomes sensitized to hypoxia-ischemia during antenatal infection. There is a sensitization of the fetal brain to a subsequent hypoxic-ischemic insult after intraperitoneal or intracisternal application of bacterial endotoxins. ${ }^{29,30}$ Here also, premyelinating oligodendrocyte injury takes place. In addition to a reduction in myelination, this leads to a secondary loss of small volumes of brain cortical and deep gray matter. ${ }^{21}$ This observation is of great clinical relevance as a fetal inflammatory response is frequently associated with perinatal hypoxia-ischemia. $^{11}$

Recently, a new effect of neuroinflammation was revealed. Neuroinflammation is not only neurotoxic, as already shown, but also beneficial for neural repair. ${ }^{31}$ For instance, TNF- $\alpha$ might lead to structural repair through the upregulation of astroglial brain-derived neurotrophic factor ${ }^{31}$ and macrophages can be involved in optic axonal regeneration. ${ }^{32}$ Furthermore, LPS-induced sublethal inflammation may affect developing central nervous system vulnerability, offering neuroprotection to a severe hypoxic-ischemic insult in the 7-day-old rat. This preconditioning by LPS is associated with upregulation of endogenous corticosterone and with cerebral gene regulation and merits further research. ${ }^{33}$

Eye

Retinopathy of prematurity (ROP) is a disease of the eye that affects prematurely born infants. It is a disorganized growth of retinal blood vessels that may result in scarring and retinal detachment (Figure 1). ROP may be mild and often resolves spontaneously, but it may lead to blindness in serious cases. Both oxygen toxicity and relative hypoxia can contribute to its development. An association with chorioamnionitis was shown by several groups. ${ }^{34-39}$ Moreover, chorioamnionitis correlated positively with severity of ROP in a recent study, ${ }^{39}$ an effect that was only partly attributable to a lower gestational age. Currently, low gestational age and both prenatal and postnatal inflammatory mechanisms often co-occur and seem to contribute importantly to the development of ROP. ${ }^{39}$

\section{Thyroid}

Thyroid hormones are required for normal development of the brain. Transient hypothyroxinemia of prematurity is the most common thyroid dysfunction in preterm infants and is defined by temporary low levels of T4, T3, and normal or low thyroid-stimulating hormone (Figure 1). Low T4 levels in preterm infants are associated with persistent neurodevelopmental deficits in cognitive and motor function. ${ }^{40}$ De Felice et al. ${ }^{41}$ tested the hypothesis that transient hypothyroxinemia of prematurity was associated with histological chorioamnionitis and showed a previously unrecognized relationship with chorioamnionitis.

\section{Thymus}

Recent evidence indicates that chorioamnionitis is associated with a significant decrease in thymic size because of an acute thymic involution in very low birth weight preterm infants (Figure 1). Although fetal thymus size is decreased in women with PPROM and chorioamnionitis, the measurement of the fetal thymus (for example, using ultrasound) might give additional information in subclinical cases. ${ }^{42,43}$ Di Naro et al ${ }^{44}$ suggested that fetal 
thymus involution in preterm labor patients was strongly associated with funisitis, as the histological manifestation of the FIRS.

In addition, significant morphological changes are present in the thymus that include increased organ complexity, severe reduction of thymocytes, and monocytic and macrophagic infiltration of Hassall's bodies. ${ }^{45}$ We have shown using the model of endotoxin-induced chorioamnionitis how the induction of a fetal inflammatory response resulted in changes in the thymus composition with respect to CD4-, CD8- and CD4/CD25- positive $\mathrm{T}$ lymphocytes. The latter $\mathrm{T}$ lymphocytes are regulatory $\mathrm{T}$ lymphocytes that have a major role in the initiation and resolution of inflammation. ${ }^{46}$ The relevance of these changes for postnatal life remains to be shown.

\section{Lungs}

Clinical observations. Preterm birth is highly associated with respiratory distress syndrome (RDS), caused by structural and functional immaturity of the newborn lung. A modulating role of intrauterine exposure on lung immaturity has been recognized for many years ${ }^{47}$ (Figure 1). Watterberg et $a l^{48}$ were the first to show an intriguing ambivalent association between chorioamnionitis and respiratory morbidity. In ventilated preterm infants they were able to show a decrease in RDS but a subsequent increase in chronic lung injury (bronchopulmonary dysplasia (BPD)) after chorioamnionitis. ${ }^{48}$ Many studies since then have reproduced the association between intrauterine inflammation and decreased RDS incidence, as reviewed recently. ${ }^{47}$ Fetal signs of chorioamnionitis have been shown to have an additional effect on RDS reduction, suggesting a 'dose'-dependent response. ${ }^{4}$ However, we have not been able to reproduce these findings. ${ }^{8}$

Despite a reduction in acute respiratory problems, several early human studies have shown chorioamnionitis to be associated with a paradoxical increase in chronic lung disease of prematurity. ${ }^{47,48}$ However, more recent studies show considerable heterogeneity regarding this association. ${ }^{47}$ Part of the inconsistency among studies may be explained by the imprecise diagnosis of both RDS and BPD. Moreover, several confounders affect the relationship between chorioamnionitis and BPD. The most obvious one is gestational age, which is inversely correlated with the incidence of both entities. Thus, chorioamnionitis-exposed infants may be at a higher risk for BPD merely because of their lower gestational age. However, recent epidemiological studies give an intriguing additional explanation and support a 'secondary hit' hypothesis. In these particular studies, chorioamnionitis was associated with a decreased rather than increased risk for BPD in preterm infants. ${ }^{3,49}$ On one hand, the effect was reversed when adjusted for mechanical ventilation, ${ }^{3,50}$ and on the other, chorioamnionitis-exposed infants who were mechanically ventilated for more than a week were at an increased risk of BPD. ${ }^{49}$ We have recently shown that alveolar epithelial repair mechanisms are less effective in ventilated preterm infants with chorioamnionitis, providing a potential underlying mechanism for the above mentioned association. ${ }^{51}$ In addition, postnatal sepsis also highly increased BPD risk in infants with chorioamnionitis in both studies. ${ }^{3,49}$ Recently, we provided evidence for a potential role of reduced surfactant efficacy in infants with severe chorioamnionitis, associated with increased BPD susceptibility. ${ }^{52}$

These observations suggest that after intrauterine inflammation, preterm lungs are more susceptible to secondary injury, leading to chronic lung disease. Clearly, additional studies are needed to investigate this complex association (Figure 2).

Although there is now compelling evidence that chorioamnionitis affects lung development and neonatal pulmonary outcome, little is known about the effects in term newborns and beyond the neonatal period (Figure 1). One small study reported an association between chorioamnionitis and severe pulmonary hypertension, as measured by nitric oxide use. ${ }^{53}$ Follow-up data are available from two studies. ${ }^{54,55}$ In a trial of postnatal hydrocortisone, chorioamnionitis was not associated with changes in the use of supplemental oxygen, bronchodilators or steroids at 18 to 22 months. ${ }^{54}$ However, Kumar et al. ${ }^{55}$ recently reported an association between chorioamnionitis and both recurrent wheezing and physician-diagnosed asthma. This suggests that intrauterine exposure to inflammation may indeed have long-term adverse respiratory effects. ${ }^{10}$

\section{Animal experimental evidence: maturation and}

injury. Clinical observations have generated the concept that antenatal exposure to inflammation may have positive and/or negative effects on preterm lung function and development. ${ }^{47,56}$ However, the presence of chorioamnionitis may be an underlying factor that is modulated by additional factors in its importance for clinical outcomes such as RDS and BPD. The role of mechanical ventilation for the development of BPD in the presence of chorioamnionitis has been highlighted above. Ruptured membranes as surrogate for fetal infection, high concentrations of IL-6 in the cord blood as a sign for systemic inflammation ${ }^{57}$ and colonization with Ureaplasma spp. ${ }^{58}$ all independently predict a low risk for RDS. However, the Alabama Preterm Birth study further differentiated between the effects of histological chorioamnionitis (as reducing the risk of RDS) and the presence of ureaplasma/mycoplasma-positive cord blood cultures (as having no effect on RDS). ${ }^{59}$

Given the complexity of clinical exposures in duration and bacterial agents, animal models are useful to study how fetal exposure to inflammation affects the fetal lung. Bry et al. ${ }^{60}$ discovered that the intra-amniotic injection of IL-1 improved lung pressure-volume curves and induced mRNA for the surfactant proteins in rabbit fetuses. Sheep have been used to overcome the relative short period of gestation in small animals. Intra-amniotic injections of LPS from Escherichia coli and IL-1 caused inflammation of the chorioamnion and amniotic fluid with increased cell numbers and cytokine concentrations. ${ }^{61-63}$ The indicators of inflammation were also increased in the fetal lung 


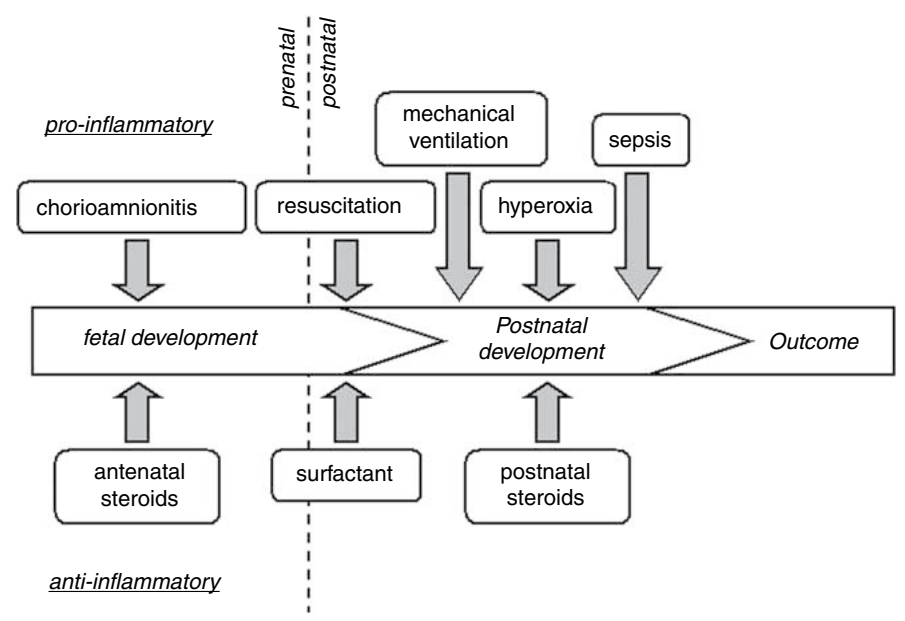

Figure 2 Schematic overview of the inflammatory and anti-inflammatory stimuli that the fetus and the preterm baby are exposed to. The intensity and the time point of exposure may affect the long-term development and outcome.

within $5 \mathrm{~h}$ and recruitment of neutrophils into the fetal airways was detected within $12 \mathrm{~h}^{64}$ The cytokines and inflammatory cells reached their peak after 3 days. The injury to the epithelium of the fetal lung resulted in a permeability defect and apoptosis followed by an increase in proliferation during resolution. ${ }^{64,65}$ This injury response was accompanied by an increase of surfactant protein mRNAs, ${ }^{62,63}$ thinning of alveolar wall ${ }^{66}$ and increased phospholipid concentrations ${ }^{65}$ for several weeks. ${ }^{67}$ The lung parenchyma decreased by activation of matrix metalloproteinases. ${ }^{68}$ As a result, the fetal lung has a more mature lung structure with more surfactant and better compliance improving gas exchange. The effects of early-response proinflammatory cytokines such as TNF- $\alpha,{ }^{69}$ IL- 6 and IL- -8 on pulmonary inflammation were minimal. Inflammation is, however, essential for the induction of the lung maturational changes, which was shown by the fetal administration of an antibody against CD18 blocking the recruitment of inflammatory cells into the airways. ${ }^{70}$ The lung inflammation could be induced by LPS from periodontal organisms, ${ }^{71}$ but a synthetic agonist for Toll-like receptor (TLR)-2 did not cause a consistent fetal lung inflammation. ${ }^{72}$ Intraamniotic injections of endotoxin at 60 to 80 days of gestational age (40 to $55 \%$ of gestation) resulted in fetal lung inflammation at 125 days (term 150 days). ${ }^{73}$ The experimental sheep work therefore suggests that the immature fetus can mount inflammation after exposure to some proinflammatory stimuli, with subsequent structural changes suggestive of lung maturation. However, the alveolarization of these fetuses was reduced similar to the mild phenotype of BPD, showing that the alveolar development can be intrauterinely impaired by inflammation. ${ }^{66}$ The number of alveoli decreases with an increase in individual size, indicating alveolar simplification. The simplification is, however, not limited to the alveoli. Within 2 days of intra-amniotic injection of LPS, endothelial nitric oxide synthase decreased and LPS-induced cytokines known to inhibit vascular development such as interferon- $\gamma$-inducible protein 10 and transforming growth factor- $\beta$ increased. ${ }^{74,75}$ Growth factors for vascular development, such as vascular endothelial growth factor and its receptors, rapidly decreased after the initiation of fetal pulmonary inflammation. ${ }^{74}$ Most interestingly, the intra-amniotic injection of IL- $1 \alpha$ did not cause alveolar or vascular abnormalities, as shown in LPS, but lung maturation. ${ }^{76}$ The central question for the fetus remains how the naive innate immune system of the fetus actively controls the inflammation and injury. ${ }^{77}$

Animal experimental evidence: immunomodulation. Although the fetus can initiate an inflammatory response at early gestation to LPS, the response is not mature as fetal sheep mounted no response to TNF- $\alpha$ and TLR agonists. We learned that the intra-amniotic endotoxin exposure induced parallel responses of maturation and tolerance in the innate immune system. The fetal lung has virtually no alveolar macrophages or interstitial monocytes until late in gestation. ${ }^{78}$ In addition, the monocytes from the fetal lung show little to no response to endotoxin or TNF- $\alpha$ in cytokine or reactive oxygen species production, which is in line with monocyte immaturity. ${ }^{78}$ The administration of intra-amniotic LPS induced the cascade of maturation of alveolar macrophages in the fetal lung with expression of granulocyte-macrophage colony-stimulating factor and the expression of transcription factor PU.1 in the monocytes. ${ }^{79}$ Within 4 days after initiation of inflammation, large numbers of alveolar macrophages appear in the fetal lung, which respond 
in vitro to LPS and TNF- $\alpha$. The response in vitro is comparable to the response of alveolar macrophages from adult sheep. Intra-amniotic endotoxin induced a maturation of immature monocytes to alveolar macrophages that populate the airspace and are responsive to TLR agonists. ${ }^{79,80}$ We then asked whether a second intra-amniotic LPS administration would amplify the fetal inflammatory response..$^{81}$ There was no increase in proinflammatory cytokine mRNA or in cell numbers after a second administration of LPS in vivo. The lung monocytes/macrophages did not respond to an additional stimulus with endotoxin or other proinflammatory stimuli in vitro either. ${ }^{81-83}$ The fetal cells became mature and LPS tolerant in a simultaneous way. The tolerance was not limited to the inducing proinflammatory stimuli of LPS, but comprised other TLR agonists as well. ${ }^{82}$ The inertness of the inflammatory response may be essential for fetal survival in a proinflammatory environment such as chorioamnionitis. ${ }^{77}$ The molecular mechanisms and the clinical implications are just beginning to be studied and understood.

\section{Cardiovascular system}

A possible mechanism through which chorioamnionitis may predispose to adverse neurological outcome is cardiovascular instability. However, human reports of postnatal markers of circulatory disturbance have been inconsistent. Associations between chorioamnionitis and decreased blood pressure, ${ }^{84}$ occurrence of hypotension ${ }^{85}$ and increased use of supportive therapy have all been described. ${ }^{86}$ Moreover, umbilical cord levels of IL-6 have been shown to correlate inversely with postnatal blood pressure in chorioamnionitis-exposed infants. ${ }^{84}$ However, other studies have failed to reproduce these findings. ${ }^{87}$ In a large cohort, we have recently shown that the tendency toward lower blood pressure after chorioamnionitis is explained by the presence of confounding factors such as gestational age or antenatal steroids. ${ }^{88}$ Moreover, we were unable to show a relationship between chorioamnionitis and postnatal hypotension or use of supportive therapy. ${ }^{88}$

Although at this stage clinical studies are not conclusive regarding the association between antenatal inflammation and postnatal circulatory disturbance, animal studies clearly show cardiovascular instability in utero after exposure to proinflammatory stimuli. In pregnant ewes, intravenous administration of LPS induced placental hypoperfusion, causing chronic hypoxemia, moderate acidemia and cardiotocography changes. ${ }^{89,90}$ Subsequently, a pulmonary hyperperfusion and a decrease in cerebral oxygen transport developed. The latter correlated with an inflammatory reaction of the subcortical regions and periventricular white matter similar to that observed in premature newborns below $1500 \mathrm{~g}$ birth weight after intrauterine infection. ${ }^{17,19}$ Taken together, current evidence suggests that intrauterine exposure to inflammation may cause postnatal circulatory disturbance and may thus contribute to the development of brain injury in the preterm newborn.
Sepsis

Many studies have identified both clinical and histological chorioamnionitis as independent risk factors for early-onset sepsis. ${ }^{8,59,91-93}$ The association seems to be augmented by additional prolonged presence of PPROM..$^{91}$ These observations are not surprising given the alleged infectious etiology of chorioamnionitis. Less straightforward is the clinical observation that the association with early-onset sepsis seems strongest when additional fetal signs of inflammation are absent. ${ }^{8,59,92,94}$ Increased use of maternal antibiotics in cases with fetal inflammation could explain part of this association. We tested this hypothesis in a cohort previously described, in which chorioamnionitis without fetal involvement was associated with early-onset sepsis. Addition of maternal administration of antibiotics as a covariate to the original model resulted in a reduction of significance from $P=0.04$ to 0.06 of the association between chorioamnionitis without fetal involvement and early-onset sepsis, although administration of maternal antibiotics itself was not a significant factor (Table 1). The implication of this finding is very intriguing. This may suggest that part of this previously reported association may be because of the less use of antibiotics when compared with chorioamnionitis-exposed infants with fetal involvement. However, a clear trend toward increased risk of early-onset sepsis remained for infants without fetal involvement, warranting the need for additional studies to resolve this issue. This is, in particular, needed as animal experiments with LPS-induced chorioamnionitis have revealed a profound effect on the local and systemic innate immune system of fetuses. A single exposure matured the fetal immune system with respect to secondary stimuli such as LPS or TNF- $\alpha$. Repetitive injections induced a paralysis of the fetal immune system that may be a risk factor for subsequent sepsis. ${ }^{81-83}$

\section{Adrenal glands}

Chorioamnionitis has been shown to be associated with an increase in serum cortisol levels after birth in infants not exposed to antenatal steroids. ${ }^{95,96}$ Similarly, increased adrenal gland volume and a correlation between fetal plasma cortisol and IL-6 levels have been observed after chorioamnionitis ${ }^{97,98}$ (Figure 1). Additional analyses suggested an association between cortisol levels and shorter time to delivery. ${ }^{98}$ Together, these data indicate that chorioamnionitis elicits a stress response in the fetus that may contribute to the initiation of preterm delivery. Moreover, given the important role of steroid hormones in lung maturation, this may be one of the mechanisms responsible for the reduction in RDS observed after intrauterine inflammation. ${ }^{47}$

\section{Liver}

The liver is part of the fetal hematopoiesis that is mostly extramedullar during the last trimester of gestation. Fetal liver granulopoiesis is, however, at a very low level within the sinusoids, 
Table 1 Multivariable models for prediction of early-onset sepsis

\begin{tabular}{|c|c|c|c|c|}
\hline \multirow[t]{2}{*}{ Factor } & \multicolumn{2}{|c|}{ Original model ${ }^{\mathrm{a}}$} & \multicolumn{2}{|c|}{ Model+antibiotics } \\
\hline & OR $(95 \% \mathrm{CI})$ & P-value & OR $(95 \% \mathrm{CI})$ & P-value \\
\hline \multicolumn{5}{|l|}{ Chorioamnionitis (ref $=$ no chorio) } \\
\hline Chorioamnionitis (maternal side only) & $2.22(1.02-4.83)$ & 0.04 & $2.15(0.96-4.80)$ & 0.06 \\
\hline Chorioamnionitis +fetal involvement & $0.86(0.39-1.92)$ & 0.72 & $0.81(0.33-1.97)$ & 0.64 \\
\hline Gestational age (per week increase) & $0.82(0.67-1.01)$ & 0.07 & $0.82(0.67-1.02)$ & 0.07 \\
\hline Birth weight (per kg increase) & $0.29(0.09-0.98)$ & 0.047 & $0.28(0.08-0.97)$ & 0.45 \\
\hline Maternal antibiotics & - & - & $1.13(0.53-2.39)$ & 0.75 \\
\hline
\end{tabular}

Abbreviations: CI, confidence interval; OR, odds ratio.

${ }^{a}$ Original model was by Been $\mathrm{et} \mathrm{al}{ }^{8}$

Estimated ORs based on multiple logistic regression models for prediction of early-onset sepsis

but an early and substantial increase can be observed during infection. ${ }^{99}$ Thus, Pfisterer et al. ${ }^{100}$ and Stallmach and Karoly1 101 described these morphologic alterations in fetal liver to be helpful in the diagnosis of chorioamnionitis. ${ }^{100,101}$ We found in an animal model of sheep that chorioamnionitis can induce the transcription of acute-phase response genes in the fetal liver. ${ }^{102}$ The liver seems to be involved in the initiation and response to chorioamnionitis beyond reactions to hematopoiesis.

\section{Intestines}

Necrotizing enterocolitits is a serious and dreaded complication of prematurity. Recently, the development of spontaneous intestinal perforation and necrotizing enterocolitits has been associated with FIRS, of which the mechanisms remain unclear ${ }^{59,103}$ (Figure 1). The pathogenesis is considered to be multifactorial, in which impaired gut barrier function and immune dysfunction have a major role. ${ }^{104}$ In the animal model, our research group showed that both prematurity and inflammation in utero affect the maturation of the fetal gut predisposing to postnatal intestinal pathology. To prove our hypothesis, the distributions of the tight junctional protein zonula occludens protein 1 (Z0-1) expression, as well as TLR-4, MD-2 mRNA, myeloperoxidase the expressing cells, T lymphocytes and $\gamma \delta$ T cells were assessed. Furthermore, contractility of third-generation mesenteric arteries in the absence and presence of nitric oxide and the endothelial nitric oxide synthase expression were studied. This study shows that bacterial toxins impair maturation of tight junctions during gestation. A poor tight junctional distribution suggests an easy access of microbial toxins to the mucosa and the inner layers of the gut ante- and postnatally. We summarized that both prematurity and chorioamnionitis are associated with impaired development of the intestinal innate immune defense, the mucosal barrier and the vascular function. Although these developmental disorders are all related to neonatal intestinal pathology and necrotizing enterocolitits, the clinical effect can only be estimated.59,103
The immature gut of preterm babies is a risk factor on its own, which is further aggravated by the presence of antenatal inflammation induced by endotoxin. ${ }^{105}$

\section{Skin}

Recently Kim et al. ${ }^{106}$ observed leukocytic infiltrates into the superficial dermis in newborn infants exposed to chorioamnionitis with increased expression of TLR-2 and TLR-4. TLRs recognize microbial products and initiate an immune response. Thus, their group showed for the first time that fetal dermatitis can be detected and is part of chorioamnionitis. ${ }^{106}$

\section{Summary and perspective}

The outlined clinical, epidemiological and experimental data point to the central role of antenatal fetal infection in the pathogenesis of chronic lung disease, brain damage and various multiorgan alterations (Figure 1). Inflammation-associated changes in organ function are complex (Figure 2). The short-term benefits may have detrimental long-term effects. The role of the immune system, which is induced and which modulates and exerts the inflammatory response and which may be detrimental on its own, needs further study. This is particularly true as the available clinical data do not point to a single intervention (Figure 2). For example, the available data on antibiotic treatment in the ORACLE trials have to be considered with caution, as the treatment with erythromycin is known to yield insufficient concentrations in the fetus. ${ }^{107-109}$ Therefore, new trials with adequate antibiotic coverage of the fetus have to be initiated.

In this context, ascending genital tract infections are critically involved. Pathological vaginal flora may induce premature labor and PPROM with the potential for an acute progressive or a chronic indolent chorioamnionitis. With the progress of the infection or inflammation, a fetal systemic inflammatory reaction may develop. This is typically documented by funitis or funisitis 
in the histological examination or in the serum. When chorioamnionitis induces a systemic inflammatory reaction in the pregnant woman, a clinical chorioamnionitis with maternal fever and elevated inflammation protein markers in the maternal compartment develops. On the other hand, detection of a funisitis describes a fetal inflammatory reaction that can be documented biochemically through inflammation markers in the fetal or neonatal serum. Here it is of pivotal significance that a dramatic increase in fetal or neonatal morbidity takes place with a fetal inflammatory reaction as opposed to a primarily maternal inflammation with a chorioamnionitis. The clinical treatment in this context is far from being optimal. Data analysis, which is stratified according to the presence of chorioamnionitis and/or funisitis, needs to be carried out and subsequent studies should take the histology into account. In future, the characterization of the fetal inflammatory response will have a crucial effect on performing adequate interventions to lower the incidence of perinatally the morbidity and mortality of affected children.

\section{Conflict of interest}

The authors declare no conflict of interest.

\section{References}

1 Goldenberg RL, Culhane JF, Iams JD, Romero R. Epidemiology and causes of preterm birth. Lancet 2008; 371: 75-84.

2 Goldenberg RL, Hauth JC, Andrews WW. Intrauterine infection and preterm delivery. N Engl J Med 2000; 342: 1500-1507.

3 Lahra MM, Beeby PJ, Jeffery HE. Intrauterine inflammation, neonatal sepsis, and chronic lung disease: a 13-year hospital cohort study. Pediatrics 2009; 123: 1314-1319.

4 Lahra MM, Beeby PJ, Jeffery HE. Maternal versus fetal inflammation and respiratory distress syndrome: a 10-year hospital cohort study. Arch Dis Child Fetal Neonatal Ed 2009; 94: F13-F16.

5 Faye-Petersen OM. The placenta in preterm birth. J Clin Pathol 2008; 61 $1261-1275$.

6 Annells MF, Hart PH, Mullighan CG, Heatley SL, Robinson JS, McDonald HM. Polymorphisms in immunoregulatory genes and the risk of histologic chorioamnionitis in Caucasoid women: a case control study. BMC Pregnancy Childbirth 2005; 5: 4 .

7 Holst D, Garnier Y. Preterm birth and inflammation-The role of genetic polymorphisms. Eur J Obstet Gynecol Reprod Biol 2008; 141: 3-9.

8 Been JV, Rours IG, Kornelisse RF, Lima Passos V, Kramer BW, Schneider TA et al. Histologic chorioamnionitis, fetal involvement, and antenatal steroids: effects on neonatal outcome in preterm infants. Am J Obstet Gynecol 2009; 201(6): 587.e1-587.e8.

9 Gotsch F, Romero R, Kusanovic JP, Mazaki-Tovi S, Pineles BL, Erez 0 et al. The fetal inflammatory response syndrome. Clin Obstet Gynecol 2007; 50: 652-683.

10 Been JV, Kramer BW, Zimmermann LJ. In utero and early-life conditions and adult health and disease. $N$ Engl J Med 2008; 359: 1523-1524

11 Berger R, Garnier Y. Pathophysiology of perinatal brain damage. Brain Res Brain Res Rev 1999; 30: 107-134

12 Sarkar S, Kaplan C, Wiswell TE, Spitzer AR. Histological chorioamnionitis and the risk of early intraventricular hemorrhage in infants born $<$ or $=28$ weeks gestation. J Perinatol 2005; 25: 749-752.
13 Woodward LJ, Anderson PJ, Austin NC, Howard K, Inder TE. Neonatal MRI to predict neurodevelopmental outcomes in preterm infants. N Engl J Med 2006; 355 685-694

14 Wu YW, Colford Jr JM. Chorioamnionitis as a risk factor for cerebral palsy: a meta-analysis. JAMA 2000; 284: 1417-1424.

15 Leviton A, Paneth N, Reuss ML, Susser M, Allred EN, Dammann 0 et al. Maternal infection, fetal inflammatory response, and brain damage in very low birth weight infants. Developmental Epidemiology Network Investigators. Pediatr Res 1999; 46: $566-575$.

16 Wu YW, Escobar GJ, Grether JK, Croen LA, Greene JD, Newman TB. Chorioamnionitis and cerebral palsy in term and near-term infants. JAMA 2003; 290: 2677-2684.

17 Back SA, Volpe JJ. Cellular and molecular pathogenesis of periventricular white matter damage. Ment Retard Dev 1997; 3: 96-107.

18 Gavilanes AW, Strackx E, Kramer BW, Gantert M, Van den Hove D, Steinbusch H et al. Chorioamnionitis induced by intraamniotic lipopolysaccharide resulted in an interval-dependent increase in central nervous system injury in the fetal sheep. Am J Obstet Gynecol 2009; 200: 437 e431-e438.

19 Garnier Y, Berger R, Alm S, von Duering MU, Coumans AB, Michetti F et al. Systemic endotoxin administration results in increased S100B protein blood

levels and periventricular brain white matter injury in the preterm fetal sheep. Eur J Obstet Gynecol Reprod Biol 2006; 124: 15-22.

20 Malaeb S, Dammann 0. Fetal inflammatory response and brain injury in the preterm newborn. J Child Neurol 2009; 24: 1119-1126.

21 Leviton A, Gressens P. Neuronal damage accompanies perinatal white-matter damage. Trends Neurosci 2007; 30: 473-478.

22 Kadhim H, Tabarki B, De Prez C, Sebire G. Cytokine immunoreactivity in cortical and subcortical neurons in periventricular leukomalacia: are cytokines implicated in neuronal dysfunction in cerebral palsy? Acta Neuropathol 2003; 105: 209-216.

23 Feldhaus B, Dietzel ID, Heumann R, Berger R. Effects of interferon-gamma and tumor necrosis factor-alpha on survival and differentiation of oligodendrocyte progenitors. J Soc Gynecol Investig 2004; 11: 89-96.

24 Haider S, Knofler M. Human tumour necrosis factor: physiological and pathological roles in placenta and endometrium. Placenta 2008; 30: 111-123.

25 Stolp HB, Dziegielewska KM, Ek CJ, Habgood MD, Lane MA, Potter AM et al. Breakdown of the blood-brain barrier to proteins in white matter of the developing brain following systemic inflammation. Cell Tissue Res 2005; 320: 369-378.

26 Feng SY, Phillips DJ, Stockx EM, Yu VY, Walker AM. Endotoxin has acute and chronic effects on the cerebral circulation of fetal sheep. Am J Physiol Regul Integr Comp Physiol 2009; 296: R640-R650.

27 Khwaja 0, Volpe JJ. Pathogenesis of cerebral white matter injury of prematurity. Arch Dis Child Fetal Neonatal Ed 2008; 93: F153-F161

28 Dammann 0, Kuban KC, Leviton A. Perinatal infection, fetal inflammatory response, white matter damage, and cognitive limitations in children born preterm. Ment Retard Dev Disabil Res Rev 2002; 8: 46-50.

29 Coumans AB, Middelanis JS, Garnier Y, Vaihinger HM, Leib SL, Von Duering MU et al. Intracisternal application of endotoxin enhances the susceptibility to subsequent hypoxic-ischemic brain damage in neonatal rats. Pediatr Res 2003; 53: 770-775

30 Eklind S, Mallard C, Leverin AL, Gilland E, Blomgren K, Mattsby-Baltzer I et al. Bacterial endotoxin sensitizes the immature brain to hypoxic-ischaemic injury. Eur J Neurosci 2001; 13: 1101-1106.

31 Saha RN, Liu X, Pahan K. Up-regulation of BDNF in astrocytes by TNF-alpha: a case for the neuroprotective role of cytokine. J Neuroimmune Pharmacol 2006; $\mathbf{1}$ : 212-222.

32 Cui Q, Yin Y, Benowitz LI. The role of macrophages in optic nerve regeneration. Neuroscience 2009; 158: 1039-1048.

33 Mallard C, Hagberg H. Inflammation-induced preconditioning in the immature brain. Semin Fetal Neonatal Med 2007; 12: 280-286.

34 Rocha G, Proenca E, Quintas C, Rodrigues T, Guimaraes H. [Chorioamnionitis and neonatal morbidity]. Acta Med Port 2006; 19: 207-212. 
35 Polam S, Koons A, Anwar M, Shen-Schwarz S, Hegyi T. Effect of chorioamnionitis on neurodevelopmental outcome in preterm infants. Arch Pediatr Adolesc Med 2005; 159: $1032-1035$.

36 Ogunyemi D, Murillo M, Jackson U, Hunter N, Alperson B. The relationship between placental histopathology findings and perinatal outcome in preterm infants. J Matern Fetal Neonatal Med 2003; 13: 102-109.

37 Fung G, Bawden $\mathrm{K}$, Chow $\mathrm{P}$, Yu V. Chorioamnionitis and outcome in extremely preterm infants. Ann Acad Med Singapore 2003; 32: 305-310.

38 Dammann 0, Leviton A. Inflammation, brain damage and visual dysfunction in preterm infants. Semin Fetal Neonatal Med 2006; 11: 363-368.

39 Dammann 0, Brinkhaus MJ, Bartels DB, Dordelmann M, Dressler F, Kerk J et al. Immaturity, perinatal inflammation, and retinopathy of prematurity: a multi-hit hypothesis. Early Hum Dev 2009; 85: 325-329.

40 Williams FL, Visser TJ, Hume R. Transient hypothyroxinaemia in preterm infants Early Hum Dev 2006; 82: 797-802.

41 De Felice C, Bagnoli F, Toti P, Musaro MA, Peruzzi L, Paffetti P et al. Transient hypothyroxinemia of prematurity and histological chorioamnionitis. J Perinat Med 2005; 33: 514-518.

42 Yinon Y, Zalel Y, Weisz B, Mazaki-Tovi S, Sivan E, Schiff E et al. Fetal thymus size as a predictor of chorioamnionitis in women with preterm premature rupture of membranes. Ultrasound Obstet Gynecol 2007; 29: 639-643.

43 De Felice C, Toti P, Santopietro R, Stumpo M, Pecciarini L, Bagnoli F. Small thymus in very low birth weight infants born to mothers with subclinical chorioamnionitis. J Pediatr 1999; 135: 384-386.

44 Di Naro E, Cromi A, Ghezzi F, Raio L, Uccella S, D’Addario V et al. Fetal thymic involution: a sonographic marker of the fetal inflammatory response syndrome. Am J Obstet Gynecol 2006; 194: 153-159.

45 Toti P, De Felice C, Stumpo M, Schurfeld K, Di Leo L, Vatti R et al. Acute thymic involution in fetuses and neonates with chorioamnionitis. Hum Patbol 2000; 31 $1121-1128$

46 Kramer BW, Kallapur SG, Moss TJ, Nitsos I, Polglase GP, Newnham JP et al. Modulation of fetal inflammatory response on exposure to lipopolysaccharide by chorioamnion, lung, or gut in sheep. Am J Obstet Gynecol 2010; 202(1): 77.el-77.e9

47 Been JV, Zimmermann LJ. Histological chorioamnionitis and respiratory outcome in preterm infants. Arch Dis Child Fetal Neonatal Ed 2009; 94: F218-F225.

48 Watterberg KL, Demers LM, Scott SM, Murphy S. Chorioamnionitis and early lung inflammation in infants in whom bronchopulmonary dysplasia develops. Pediatrics 1996; 97: 210-215.

49 Van Marter LJ, Dammann 0, Allred EN, Leviton A, Pagano M, Moore M et al. Chorioamnionitis, mechanical ventilation, and postnatal sepsis as modulators of chronic lung disease in preterm infants. J Pediatr 2002; 140: 171-176.

50 Been JV, Zimmermann LJ. Chorioamnionitis and chronic lung disease in preterm infants. Pediatrics 2009, http://pediatrics.aappublications.org/cgi/eletters/123/5/1314.

51 Been JV, Zimmermann LJ, Debeer A, Kloosterboer N, Van Iwaarden JF Bronchoalveolar lavage fluid from preterm infants with chorioamnionitis inhibits alveolar epithelial repair. Respir Res 2009; 10: 116

52 Been JV, Rours IG, Kornelisse RF, Jonkers F, de Krijger RR, Zimmermann LJ. Chorioamnionitis alters the response to surfactant in preterm infants. J Pediatr 2010; 156(1): $10-15 . e 1$

53 Woldesenbet M, Rosenfeld CR, Ramilo 0, Johnson-Welch S, Perlman JM. Severe neonatal hypoxic respiratory failure correlates with histologic chorioamnionitis and elevated concentrations of IL-6, IL-8 and CRP. Arch Dis Child Fetal Neonatal Ed 2008; 93: F413-F417

54 Watterberg KL, Shaffer ML, Mishefske MJ, Leach CL, Mammel MC, Couser RJ et al. Growth and neurodevelopmental outcomes after early low-dose hydrocortisone treatment in extremely low birth weight infants. Pediatrics 2007; 120: 40-48.

55 Kumar R, Yu Y, Story RE, Pongracic JA, Gupta R, Pearson C et al. Prematurity, chorioamnionitis, and the development of recurrent wheezing: a prospective birth cohort study. J Allergy Clin Immunol 2008; 121: 878-884 e876.
56 Kramer BW, Kallapur S, Newnham J, Jobe AH. Prenatal inflammation and lung development. Semin Fetal Neonatal Med 2009; 14: 2-7.

57 Shimoya K, Taniguchi T, Matsuzaki N, Moriyama A, Murata Y, Kitajima $\mathrm{H}$ et al. Chorioamnionitis decreased incidence of respiratory distress syndrome by elevating fetal interleukin-6 serum concentration. Hum Reprod 2000; 15: 2234-2240.

58 Hannaford K, Todd DA, Jeffery H, John E, Blyth K, Gilbert GL. Role of ureaplasma urealyticum in lung disease of prematurity. Arch Dis Child Fetal Neonatal Ed 1999; 81: F162-F167.

59 Andrews WW, Goldenberg RL, Faye-Petersen 0, Cliver S, Goepfert AR, Hauth JC. The Alabama Preterm Birth study: polymorphonuclear and mononuclear cell placental infiltrations, other markers of inflammation, and outcomes in 23- to 32-week preterm newborn infants. Am J Obstet Gynecol 2006; 195: 803-808

60 Bry K, Lappalainen U, Hallman M. Intraamniotic interleukin-1 accelerates surfactant protein synthesis in fetal rabbits and improves lung stability after premature birth J Clin Invest 1997; 99: 2992-2999.

61 Willet KE, Kramer BW, Kallapur SG, Ikegami M, Newnham JP, Moss TJ et al. Intra-amniotic injection of IL-1 induces inflammation and maturation in fetal sheep lung. Am J Physiol Lung Cell Mol Physiol 2002; 282: L411-L420.

62 Kramer BW, Moss TJ, Willet KE, Newnham JP, Sly PD, Kallapur SG et al. Dose and time response after intraamniotic endotoxin in preterm lambs. Am J Respir Crit Care Med 2001; 164: 982-988

63 Kallapur SG, Willet KE, Jobe AH, Ikegami M, Bachurski CJ. Intra-amniotic endotoxin: chorioamnionitis precedes lung maturation in preterm lambs. Am J Physiol Lung Cell Mol Physiol 2001; 280: L527-L536.

64 Kramer BW, Kramer S, Ikegami M, Jobe AH. Injury, inflammation, and remodeling in fetal sheep lung after intra-amniotic endotoxin. Am J Physiol Lung Cell Mol Physiol 2002; 283: L452-L459.

65 Jobe AH, Newnham JP, Willet KE, Moss TJ, Gore Ervin M, Padbury JF et al. Endotoxin-induced lung maturation in preterm lambs is not mediated by cortisol. Am J Respir Crit Care Med 2000; 162: 1656-1661

66 Willet KE, Jobe AH, Ikegami M, Newnham J, Brennan S, Sly PD. Antenatal endotoxin and glucocorticoid effects on lung morphometry in preterm lambs. Pediatr Res 2000 48: $782-788$.

67 Kallapur SG, Kramer BW, Moss TJ, Newnham JP, Jobe AH, Ikegami M et al. Maternal glucocorticoids increase endotoxin-induced lung inflammation in preterm lambs. Am J Physiol Lung Cell Mol Physiol 2003; 284: L633-L642.

68 Sweet DG, Huggett MT, Warner JA, Moss TJ, Kloosterboer N, Halliday HL et al. Maternal betamethasone and chorioamnionitis induce different collagenases during lung maturation in fetal sheep. Neonatology 2008; 94: 79-86.

69 Ikegami M, Moss TJ, Kallapur SG, Mulrooney N, Kramer BW, Nitsos I et al. Minimal lung and systemic responses to TNF-alpha in preterm sheep. Am J Physiol Lung Cell Mol Physiol 2003; 285: L121-L129.

70 Kallapur SG, Moss TJ, Ikegami M, Jasman RL, Newnham JP, Jobe AH. Recruited inflammatory cells mediate endotoxin-induced lung maturation in preterm fetal lambs. Am J Respir Crit Care Med 2005; 172: 1315-1321

71 Newnham JP, Shub A, Jobe AH, Bird PS, Ikegami M, Nitsos I et al. The effects of intra-amniotic injection of periodontopathic lipopolysaccharides in sheep. $A m J$ Obstet Gynecol 2005; 193: 313-321

72 Hillman NH, Moss TJ, Nitsos I, Kramer BW, Bachurski CJ, Ikegami M et al. Toll-like receptors and agonist responses in the developing fetal sheep lung. Pediatr Res 2008; 63: $388-393$.

73 Moss TJ, Newnham JP, Willett KE, Kramer BW, Jobe AH, Ikegami M. Early gestational intra-amniotic endotoxin: lung function, surfactant, and morphometry. Am J Respir Crit Care Med 2002; 165: 805-811.

74 Kallapur SG, Bachurski CJ, Le Cras TD, Joshi SN, Ikegami M, Jobe AH. Vascular changes after intra-amniotic endotoxin in preterm lamb lungs. Am J Physiol Lung Cell Mol Physiol 2004; 287: L1178-L1185.

75 Kunzmann S, Speer CP, Jobe AH, Kramer BW. Antenatal inflammation induced TGF-betal but suppressed CTGF in preterm lungs. Am J Physiol Lung Cell Mol Physiol 2007; 292: L223-L231. 
76 Sosenko IR, Kallapur SG, Nitsos I, Moss TJ, Newnham JP, Ikegami M et al. IL-1 alpha causes lung inflammation and maturation by direct effects on preterm fetal lamb lungs. Pediatr Res 2006; 60: 294-298.

77 Kramer BW, Jobe AH. The clever fetus: responding to inflammation to minimize lung injury. Biol Neonate 2005; 88: 202-207.

78 Kramer BW, Jobe AH, Ikegami M. Monocyte function in preterm, term, and adult sheep. Pediatr Res 2003; 54: 52-57.

79 Kramer BW, Joshi SN, Moss TJ, Newnham JP, Sindelar R, Jobe AH et al. Endotoxininduced maturation of monocytes in preterm fetal sheep lung. Am J Physiol Lung Cell Mol Physiol 2007; 293: L345-L353.

80 Cheah FC, Pillow JJ, Kramer BW, Polglase GR, Nitsos I, Newnham JP et al. Airway inflammatory cell responses to intra-amniotic lipopolysaccharide in a sheep model of chorioamnionitis. Am J Physiol Lung Cell Mol Physiol 2009; 296: L384-L393.

81 Kramer BW, Ikegami M, Moss TJ, Nitsos I, Newnham JP, Jobe AH. Endotoxin-induced chorioamnionitis modulates innate immunity of monocytes in preterm sheep. Am J Respir Crit Care Med 2005; 171: 73-77.

82 Kramer BW, Kallapur SG, Moss TJ, Nitsos I, Newnham JP, Jobe AH. Intra-amniotic LPS modulation of TLR signaling in lung and blood monocytes of fetal sheep. Innate Immun 2009; 15: 101-107.

83 Kallapur SG, Jobe AH, Ball MK, Nitsos I, Moss TJ, Hillman NH et al. Pulmonary and systemic endotoxin tolerance in preterm fetal sheep exposed to chorioamnionitis. J Immunol 2007; 179: 8491-8499.

84 Yanowitz TD, Jordan JA, Gilmour CH, Towbin R, Bowen A, Roberts JM et al. Hemodynamic disturbances in premature infants born after chorioamnionitis: association with cord blood cytokine concentrations. Pediatr Res 2002; 51: 310-316.

85 Lee SY, Ng DK, Fung GP, Chow CB, Shek CC, Tang PM et al. Chorioamnionitis with or without funisitis increases the risk of hypotension in very low birthweight infants on the first postnatal day but not later. Arch Dis Child Fetal Neonatal Ed 2006; 91 : F346-F348.

86 Furukawa S, Sameshima H, Ikenoue T. Circulatory disturbances during the first postnatal 24 hours in extremely premature infants 25 weeks or less of gestation with histological fetal inflammation. J Obstet Gynaecol Res 2008; 34: 27-33.

87 Laughon M, Bose C, Allred E, O'Shea TM, Van Marter LJ, Bednarek F et al. Factors associated with treatment for hypotension in extremely low gestational age newborns during the first postnatal week. Pediatrics 2007; 119: 273-280.

88 Been JV, Kornelisse RF, Rours IG, Passos VL, De Krijger RR, Zimmermann LJ. Early postnatal blood pressure in preterm infants: effects of chorioamnionitis and timing of antenatal steroids. Pediatr Res 2009; 66: 571-576.

89 Coumans AB, Garnier Y, Supcun S, Jensen A, Berger R, Hasaart TH. The effects of lowdose endotoxin on the umbilicoplacental circulation in preterm sheep. J Soc Gynecol Investig 2004; 11: 289-293.

90 Garnier Y, Coumans A, Berger R, Jensen A, Hasaart TH. Endotoxemia severely affects circulation during normoxia and asphyxia in immature fetal sheep. J Soc Gynecol Investig 2001; 8: 134-142.

91 Klinger G, Levy I, Sirota L, Boyko V, Reichman B, Lerner-Geva L. Epidemiology and risk factors for early onset sepsis among very-low-birthweight infants. Am J Obstet Gynecol 2009; 201: 38 e31-e36.

92 Park CW, Moon KC, Park JS, Jun JK, Romero R, Yoon BH. The involvement of human amnion in histologic chorioamnionitis is an indicator that a fetal and an intra-amniotic inflammatory response is more likely and severe: clinical implications. Placenta 2009; 30: 56-61.

93 Soraisham AS, Singhal N, McMillan DD, Sauve RS, Lee SK. A multicenter study on the clinical outcome of chorioamnionitis in preterm infants. Am J Obstet Gynecol 2009; 200: 372 e $371-\mathrm{e} 376$.

94 Mehta R, Nanjundaswamy S, Shen-Schwarz S, Petrova A. Neonatal morbidity and placental pathology. Indian J Pediatr 2006; 73: 25-28.

95 Falkenberg ER, Davis R0, DuBard M, Parker Jr CR. Effects of maternal infections on fetal adrenal steroid production. Endocr Res 1999; 25: 239-249.

96 Watterberg KL, Scott SM, Naeye RL. Chorioamnionitis, cortisol, and acute lung disease in very low birth weight infants. Pediatrics 1997; 99: E6.

97 Buhimschi CS, Turan OM, Funai EF, Azpurua H, Bahtiyar MO, Turan S et al. Fetal adrenal gland volume and cortisol/dehydroepiandrosterone sulfate ratio in inflammation-associated preterm birth. Obstet Gynecol 2008; 111: 715-722.

98 Yoon BH, Romero R, Jun JK, Maymon E, Gomez R, Mazor M et al. An increase in fetal plasma cortisol but not dehydroepiandrosterone sulfate is followed by the onset of preterm labor in patients with preterm premature rupture of the membranes. Am J Obstet Gynecol 1998; 179: 1107-1114.

99 Papadopoulos N, Simopoulos C, Sigalas J, Kotini A, Cheva A, Tamiolakis D. Induction of hepatic hematopoiesis with tenascin- $C$ expression during the second trimester of development. Eur J Obstet Gynecol Reprod Biol 2004; 113: 56-60.

100 Pfisterer C, Faber R, Horn LC. Chorioamnionitis-induced changes of fetal extramedullar hematopoiesis in the second trimester of gestation. Is diagnosis from fetal autopsy possible? Virchows Arch 2005; 446: 150-156.

101 Stallmach T, Karolyi L. Augmentation of fetal granulopoiesis with chorioamnionitis during the second trimester of gestation. Hum Pathol 1994; 25: 244-247.

102 Wilson TC, Bachurski CJ, Ikegami M, Jobe AH, Kallapur SG. Pulmonary and systemic induction of SAA3 after ventilation and endotoxin in preterm lambs. Pediatr Res 2005; 58: 1204-1209.

103 Ragouilliaux CJ, Keeney SE, Hawkins HK, Rowen JL. Maternal factors in extremely low birth weight infants who develop spontaneous intestinal perforation. Pediatrics 2007; 120: e1458-e1464

104 Neu J, Mshvildadze M, Mai V. A roadmap for understanding and preventing necrotizing enterocolitis. Curr Gastroenterol Rep 2008; 10: 450-457.

105 Wolfs TG, Buurman WA, Zoer B, Moonen RM, Derikx JP, Thuijls G et al. Endotoxin induced chorioamnionitis prevents intestinal development during gestation in fetal sheep. PLoS One 2009; 4: e5837.

106 Kim YM, Romero R, Chaiworapongsa T, Espinoza J, Mor G, Kim CJ. Dermatitis as a component of the fetal inflammatory response syndrome is associated with activation of Toll-like receptors in epidermal keratinocytes. Histopathology 2006; 49 : 506-514.

107 Kenyon SL, Taylor DJ, Tarnow-Mordi W. Broad-spectrum antibiotics for spontaneous preterm labour: the ORACLE II randomised trial. ORACLE Collaborative Group. Lancet 2001; 357: 989-994.

108 Kenyon SL, Taylor DJ, Tarnow-Mordi W. Broad-spectrum antibiotics for preterm, prelabour rupture of fetal membranes: the ORACLE I randomised trial. ORACLE Collaborative Group. Lancet 2001; 357: 979-988.

109 Briggs GG, Freeman RK, Yaffe SJ. Drugs in Pregnancy and Lactation, 8th edn. Lippincott: Philadelphia, 2007. 


\section{Chapter 3}

Lipopolysaccaride-induced chorioamnionitis is confined to one amnionitic compartment in twin pregnant sheep.

Gantert, M., Jellema, R.K., Heinemann, H., Gantert, J., Collins, J.J.P., Seehase, M., Lambermont, V.A.C., Keck, A., Garnier, Y., Zimmermann, L.J.I., Kadyrov, M., Gavilanes, A.W.D., Kramer, B.W. Neonatology. 2012;102:81-88 


\title{
Lipopolysaccharide-Induced Chorioamnionitis Is Confined to One Amniotic Compartment in Twin Pregnant Sheep
}

\author{
Markus Gantert ${ }^{\mathrm{a}}$ e $\quad$ Reint K. Jellema ${ }^{\mathrm{a}}$ Heike Heineman ${ }^{\mathrm{a}} \quad$ Julia Gantert $^{\mathrm{b}}$ \\ Jennifer J.P. Collins ${ }^{a}$ Matthias Seehase ${ }^{a}$ Verena A.C. Lambermont ${ }^{a}$ \\ Alexander Keck ${ }^{c}$ Yves Garnier ${ }^{c}$ Luc J.I. Zimmermann ${ }^{a} \quad$ Mahmed Kadyrov $^{d}$ \\ A.W. Danilo Gavilanes ${ }^{a}$ Boris W. Kramer ${ }^{\mathrm{a}}$

\begin{abstract}
${ }^{a}$ Department of Pediatrics, School for Mental Health and Neuroscience, School for Oncology and Developmental Biology, Maastricht University Medical Center, Maastricht, The Netherlands; ${ }^{b}$ Department of Obstetrics and Gynecology, St. Elisabeth-Krankenhaus Köln, Cologne, 'Department of Obstetrics and Gynecology, Klinikum Osnabrück, Osnabrück, ${ }^{\mathrm{d}}$ Department of Cytopathology Heinrich-Heine-University Düsseldorf, Düsseldorf, and
\end{abstract} \\ e GynMünster - Clinic for Surgical Gynecology, Münster, Germany
}

\section{Key Words}

Chorioamnionitis - Twin pregnancy $\cdot$ Delayed interval delivery $\cdot$ Preterm birth

\begin{abstract}
Background: Chorioamnionitis is a major risk factor for preterm birth in multifetal pregnancies. However, there is little clinical data whether chorioamnionitis is restricted to one amniotic compartment in multifetal pregnancies. Objective: To explore whether chorioamnionitis is confined to the exposed compartment and does not cross to the unaffected fetus in twin pregnancy. Methods: In twin pregnant sheep, one of the twins was exposed to either 2 or 14 days of intraamniotic lipopolysaccharide (LPS) while the co-twin was exposed to either 2 or 14 days of intra-amniotic saline ( $n=3$ for each exposure). Singletons were included in this study to compare the grade of inflammation with twins. All fetuses were delivered at 125 days of gestation (term $=150$ days). Chorioamnionitis was confirmed by histological examina-
\end{abstract}

\section{KARGER}

Fax +41 613061234

E-Mail karger@karger.ch

www.karger.com

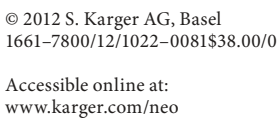

tion. Lung inflammation was assessed by cell count in bronchoalveolar lavage. Lung compliance was assessed at 40 $\mathrm{cm} \mathrm{H}_{2} \mathrm{O}$. Results were compared using analysis of variance (ANOVA) with a post-hoc Tukey analysis. Results: Inflammation in placenta, membranes and lung of LPS-exposed twins was significantly higher after 2 and 14 days of exposure when compared to the saline-exposed co-twins. Lung compliance in LPS-exposed twins was significantly increased after 14 days when compared to saline-exposed co-twins. Intrauterine LPS exposure increased lung compliance and inflammation in the membranes, placenta and lung to the same extent in twins as in singletons. Conclusion: In twin pregnant sheep, inflammation of the membranes, placenta and fetal lung was strictly limited to the exposed fetus in the amniotic compartment in which the LPS was injected.

Copyright $\odot 2012$ S. Karger AG, Basel

M. Gantert and R.K. Jellema contributed equally to this work. 


\section{Introduction}

Preterm birth is the leading cause of perinatal morbidity and mortality in developed countries [1]. Most preterm infants survive due to advancing clinical support, but they are at high risk of neurodevelopmental impairment $[2,3]$ and respiratory $[4]$ and gastrointestinal $[5,6]$ complications [7]. Intrauterine infection of the fetal membranes, as documented by histologic findings or culture is a frequent cause of preterm birth and is referred to as chorioamnionitis [1]. Chorioamnionitis can trigger a fetal immune response syndrome, which can initiate labor by increased uterine contractility and preterm premature rupture of the membranes [8]. The diagnosis of chorioamnionitis is an established risk factor for adverse outcome such as bronchopulmonary dysplasia, neonatal sepsis and injury to the neonatal brain, particularly cystic periventricular leukomalacia and later development of cerebral palsy and intraventricular hemorrhage $[9,10]$.

The risk of preterm birth is increased in multiple pregnancies irrespective of additional risk factors such as chorioamnionitis [1]. Clinical findings show that in the majority of cases, histological chorioamnionitis in twin pregnancy affects the presenting fetus [11, 12]. Under these circumstances clinicians have to decide whether delivery of the second fetus can be delayed to reduce morbidity associated with preterm birth. Delayed-interval delivery may be an option in a twin pregnancy complicated by chorioamnionitis if the inflammation is confined to only one amniotic compartment as reported by Bollen and Padwick [13] and Watson and McNelis [14]. Unfortunately, there is little evidence that shows whether chorioamnionitis crosses from the affected compartment to the unaffected compartment.

Therefore, we performed a study in twin pregnant sheep and exposed only one amniotic compartment to lipopolysaccharide (LPS) to induce histological chorioamnionitis. We hypothesized that LPS-induced histological chorioamnionitis would be confined to the exposed compartment and not affect the neighboring fetus.

\section{Methods}

\section{Animals and Surgery}

This study was approved by the Animal Ethical Committee of Maastricht University (the Netherlands). Twin fetuses of timemated Texel ewes were randomized to be exposed to intra-amniotic LPS or saline for 2 or 14 days. In the 2 -day exposure group, three twin pregnancies were included in which one of the twins was exposed to intra-amniotic LPS $(n=3)$ while the co-twin was exposed to intra-amniotic saline $(\mathrm{n}=3)$. Similarly, in the 14 -day exposure group, three twin pregnancies were included in which one of the twins was exposed to intra-amniotic LPS $(n=3)$ and the co-twin received intra-amniotic saline $(n=3)$. Singleton fetuses of time-mated Texel ewes were randomly assigned to receive 2 days of saline $(n=4), 2$ days of LPS $(n=4), 14$ days of saline $(\mathrm{n}=4)$ and 14 days LPS $(\mathrm{n}=4)$. Singleton fetuses were included in this study to ensure that there is no difference in the fetal responses between singletons and twins. All fetuses were delivered at 125 days of gestation (see fig. 1).

All LPS-exposed animals received an intra-amniotic injection of $10 \mathrm{mg}$ of LPS as previously described [15], which was purchased from Sigma (Escherichia coli 055:B5; Sigma Chemical, St. Louis, Mo., USA). All fetuses were delivered via cesarean section under epidural and local anesthesia. The fetuses were sacrificed by lethal intravenous injection of pentobarbital immediately after birth. The study was completed in one breeding season over a period of 2.5 months.

\section{Chorioamnionitis}

Placentomes (maternal caruncle and fetal cotyledon) with membranes were removed immediately after sacrifice and fixed for $24 \mathrm{~h}$ in $4 \%$ phosphate-buffered formaldehyde and then embedded in paraffin. The inflammation score was determined by two blinded reviewers on serial sections of $5 \mu \mathrm{m}$ thickness. The amount of inflammation in the membranes and placentomes was graded in a blinded fashion by scoring three sections from each animal as zero (no inflammatory cells in tissue), 1 (a few cells), 2 (moderate leukocyte infiltration) and 3-4 (large numbers of inflammatory cells in tissue). Average scores for tissue were calculated for each animal based on four different high-power fields.

\section{Lung Compliance and Inflammation}

Pulmonary assessment was done in a blinded fashion. Immediately after sacrifice, the thorax of the lamb was opened, the right lung was inflated with air at $40 \mathrm{~cm} \mathrm{H}_{2} \mathrm{O}$ for 1 min and maximal lung gas volume was recorded. Lung gas volumes were corrected for the compliance of the system. Lungs were subsequently removed from the thorax. Bronchoalveolar lavages (BAL) were performed on the left lung by filling with $0.9 \%$ saline at $4{ }^{\circ} \mathrm{C}$ until visually distended and repeated 5 times. Absolute cell counts were obtained using a Neugebauer chamber. Differential counts were performed on a cytospin after May-Grünwald staining [16].

\section{Data Analysis}

Statistical analysis was performed with PASW Statistics 18 (SPSS Inc., Chicago, Ill., USA). Graphical presentation of data was performed with Graphpad Prism version 5. All values are represented as means $( \pm$ SEM). Values between experimental groups and between twins and singletons were compared using analysis of variance (ANOVA) with a post-hoc Tukey analysis; $\mathrm{p} \leq 0.05$ was used to denote statistical significance.

\section{Results}

\section{Baseline Characteristics}

One twin-pregnant ewe in the 14-day exposure group spontaneously aborted both fetuses 3 days after LPS in- 
Fig. 1. Study design. Six twin pregnancies were randomized into a 2-day $(n=3)$ and 14 -day $(\mathrm{n}=3)$ exposure group. Within the 2-day and 14-day exposure group, one fetus of the twin received intra-amniotic (i.a.) LPS ( $n=3)$ while the co-twin received saline $(\mathrm{n}=3)$. One twin pregnancy in the 14-day group aborted spontaneously. The aborted fetuses were not included in any analysis. Singleton fetuses were randomized into a 2-day LPS $(\mathrm{n}=4), 2$-day saline $(\mathrm{n}=4), 14$-day LPS $(\mathrm{n}=4)$ and 14-day saline $(n=4)$ experimental group.

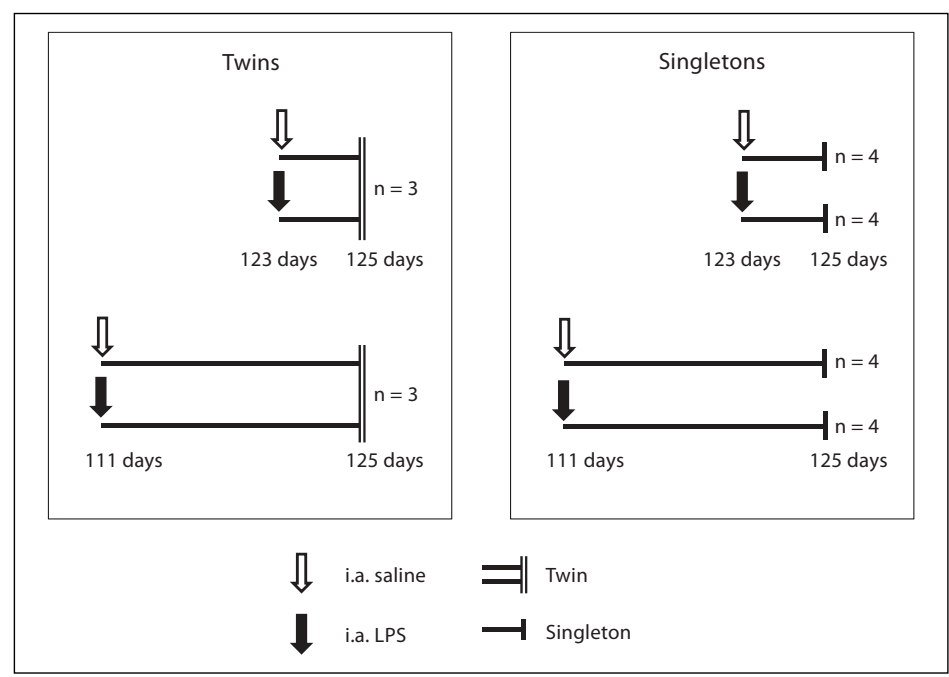

Table 1. Fetal weight

\begin{tabular}{lllll}
\hline & 2-day saline & 2-day LPS & 14-day saline & 14-day LPS \\
\hline Twin fetal weight, g & $2,440 \pm 111$ & $2,370 \pm 200$ & $2,275 \pm 475$ & $2,175 \pm 475$ \\
Singleton fetal weight, $g$ & $2,400 \pm 105$ & $2,483 \pm 87$ & $2,626 \pm 174$ & $2,724 \pm 399$ \\
\hline
\end{tabular}

Values are means \pm SEM. Weight of twin and singleton fetuses did not differ significantly between experimental groups using a one-way ANOVA with Tukey's post hoc test.

jection. The aborted fetuses were not included in any analysis. No further abnormalities in the fetuses were found upon autopsy. Fetal weight after delivery did not differ significantly between control and LPS-exposed animals within the twins and singletons (table 1). There was no significant difference in fetal weight between singletons and twins.

\section{Chorioamnionitis}

Inflammatory scores of the membranes and the placenta were obtained after 2 and 14 days of exposure to saline or LPS. In comparison to the saline-treated cotwin, 2-day LPS exposure significantly increased the inflammatory score of the membranes: 2-day saline $=0.17$ $( \pm 0.17)$ versus 2 -day LPS $=2.60( \pm 0.40), \mathrm{p}<0.001$ (fig. $2 \mathrm{a})$. After 14 days of LPS exposure, the inflammatory score of the membranes significantly increased from $0.25( \pm 0.25)$ in saline-treated twins to $2.50( \pm 0.50)$ in LPS-exposed cotwins $(\mathrm{p}<0.001)$. In singletons, LPS exposure significantly increased the inflammatory response in the membranes when compared with saline-exposed singletons: 2-day saline $=0.25( \pm 0.14)$ versus 2 -day LPS $=2.20( \pm 0.29)$, $\mathrm{p}=0.001$; and 14 -day saline $=0.38( \pm 0.24)$ versus 14 -day LPS $=2.75$ (0.25), $\mathrm{p}=0.002$ (fig. 2b).

A similar pattern was recorded in the histological analyses of the placenta. Compared to twins exposed to saline, LPS injection rapidly induced an inflammatory response in the placenta of the co-twin after 2 days: 2-day saline $=0.17( \pm 0.17)$ versus 2 -day LPS $=2.33( \pm 0.44)$, $p=0.003$. Twins exposed to LPS or saline over 14 days showed the same pattern: 14 -day saline $=0.00( \pm 0.00)$ versus 14 -day $L P S=2.50( \pm 0.50), p=0.006$. Singletons showed the same pattern in inflammatory cell scores of the placenta as twins: 2 -day saline $=0.00( \pm 0.00)$ versus 


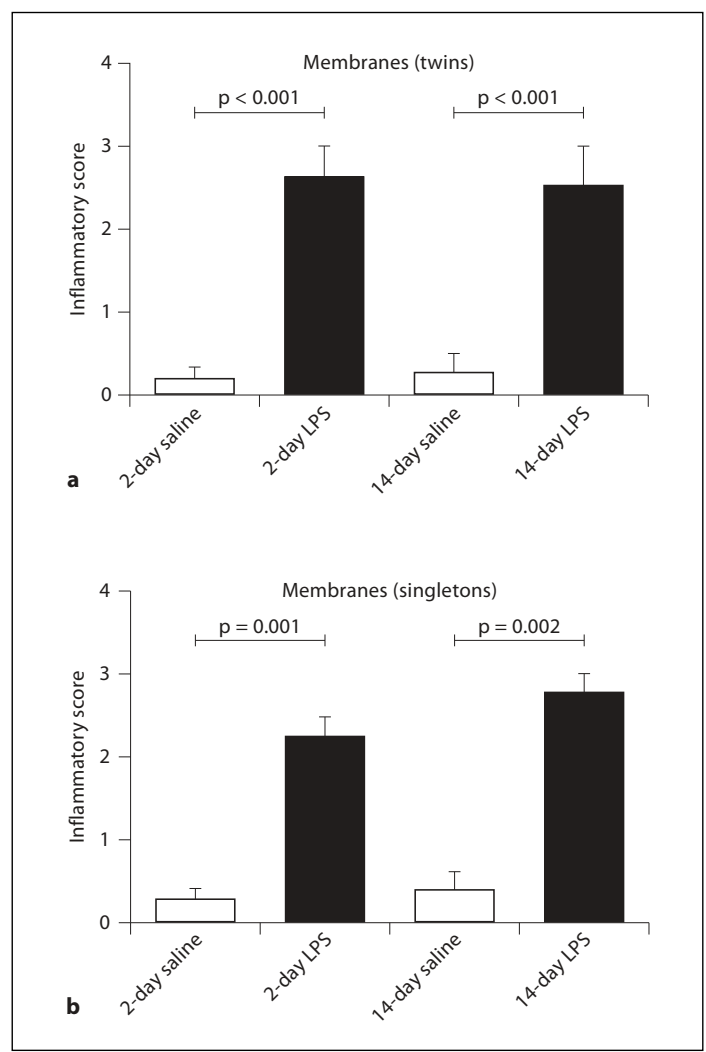

Fig. 2. Inflammatory scores of the membranes. In twins (a) and singletons (b), the inflammatory score of the membranes increased after 2 days of LPS exposure compared to controls and did not further increase in the 14-day groups. Inflammatory scores were similar between twins and singletons. Twin 2-day saline $(\mathrm{n}=3)$, twin 2-day LPS $(\mathrm{n}=3)$, twin 14-day saline $(\mathrm{n}=2)$, twin 14-day LPS $(n=2)$, singleton 2-day saline $(n=4)$, singleton 2-day LPS $(\mathrm{n}=4)$, singleton 14-day saline $(\mathrm{n}=4)$ and singleton 14-day LPS $(n=4)$. $p$ values of ANOVA with post-Tukey test are shown.

2-day LPS $=2.63( \pm 0.24), \mathrm{p}=0.001 ;$ and 14-day saline $=$ $0.13( \pm 0.13)$ versus 14 -day LPS $=2.50( \pm 0.50), \mathrm{p}=0.001$ (fig. 3b). Inflammatory changes in the membranes and placenta were confirmed with the score by Redline et al. (data not shown) [17].

\section{Lung Inflammation}

Lung inflammation was assessed by counting neutrophils in the BAL. In comparison to the twin control fe-

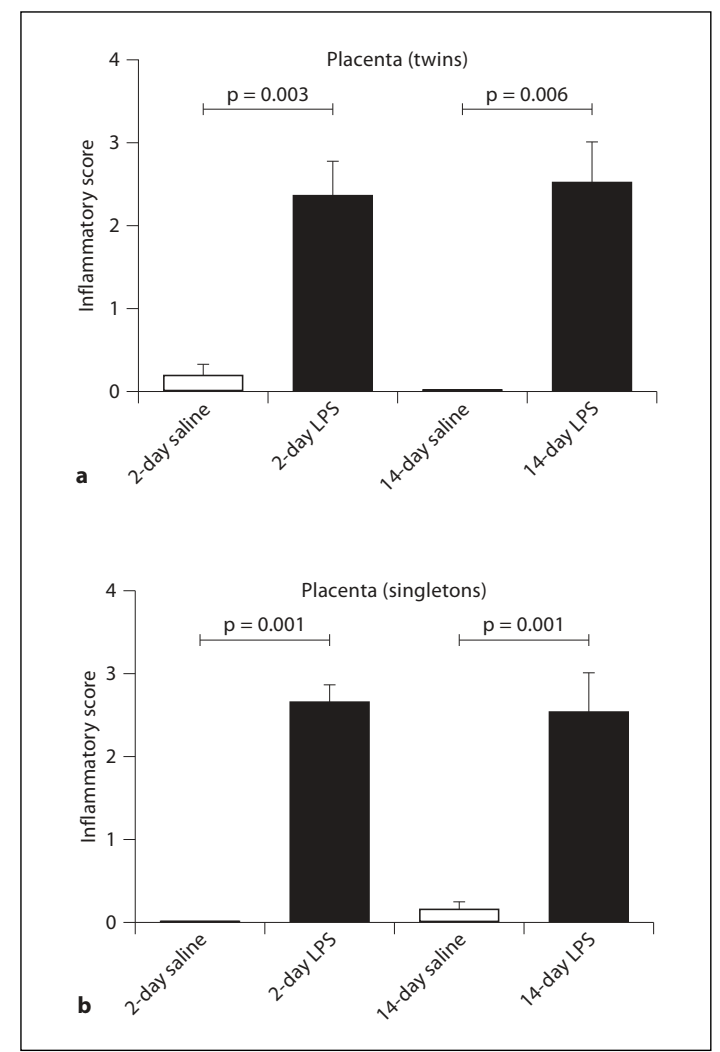

Fig. 3. Inflammatory scores of the placenta. Inflammatory scores of the placenta significantly increased in 2-day and 14-day LPSexposed twin (a) and singleton (b) fetuses compared to controls. No statistical difference in inflammation of the placenta was detected between twins and singletons. Twin 2-day saline $(\mathrm{n}=3)$, twin 2-day LPS $(\mathrm{n}=3)$, twin 14-day saline $(\mathrm{n}=2)$, twin 14-day LPS $(\mathrm{n}=2)$, singleton 2 -day saline $(\mathrm{n}=4)$, singleton 2 -day LPS $(\mathrm{n}=4)$, singleton 14-day saline $(\mathrm{n}=4)$ and singleton 14-day LPS $(\mathrm{n}=4)$. $\mathrm{p}$ values of ANOVA with post-Tukey test are shown.

tuses, LPS injection into the amniotic cavity recruited significantly more neutrophils into the fetal lung (corrected for fetal body weight) after 2 days: 2 -day saline $=3.06 \times$ $10^{4}\left( \pm 1.25 \times 10^{4}\right)$ versus 2 -day LPS $=4.43 \times 10^{7}( \pm 1.31$ $\left.\times 10^{7}\right), p=0.014$ (fig. $4 \mathrm{a}$ ). After 14 days of LPS exposure, the neutrophil count in the BAL increased from $1.25 \times$ $10^{4}\left( \pm 5.00 \times 10^{2}\right)$ in saline-treated twins to $4.30 \times 10^{7}$ $\left( \pm 1.50 \times 10^{7}\right)$ in LPS-exposed co-twins, $p=0.073$ (fig. $4 \mathrm{a}$ ). This difference did not reach significance, most likely due 


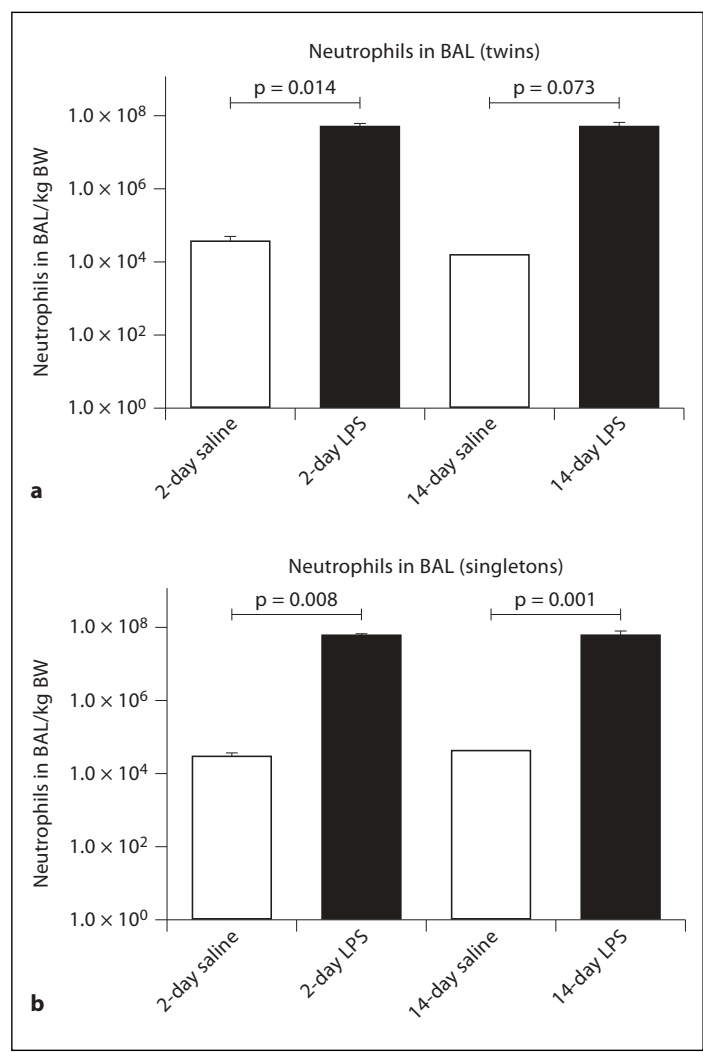

Fig. 4. Neutrophil counts in BAL. Neutrophil counts in BAL increased significantly after 2-day LPS exposure in both twin (a) and singleton (b) fetuses. Differences in neutrophil count in BAL after 14 days of LPS exposure did not reach significance in twins, whereas it did in singletons. Twin and singleton experimental groups did not differ significantly. Results are shown on a log scale. Twin 2-day saline $(\mathrm{n}=3)$, twin 2-day LPS $(\mathrm{n}=3)$, twin 14day saline $(\mathrm{n}=2)$, twin 14-day LPS $(\mathrm{n}=2)$, singleton 2-day saline $(\mathrm{n}=4)$, singleton 2 -day LPS $(\mathrm{n}=4)$, singleton 14 -day saline $(\mathrm{n}=$ 4) and singleton 14-day LPS $(\mathrm{n}=4)$. $\mathrm{kg}$ BW = kilogram body weight. $\mathrm{p}$ values of ANOVA with post-Tukey test are shown.

to the spontaneous abortion of one twin in the 14-day group. The pulmonary inflammatory response in singletons was similar to the pulmonary inflammation in twin pregnancy: 2 -day saline $=2.48 \times 10^{4}\left( \pm 4.85 \times 10^{3}\right)$ versus 2 -day LPS $=5.13 \times 10^{7}\left( \pm 3.79 \times 10^{6}\right), \mathrm{p}=0.008$; and 14-day saline $=3.28 \times 10^{4}\left( \pm 4.42 \times 10^{3}\right)$ versus 14 -day LPS $=4.93 \times 10^{7}\left( \pm 1.14 \times 10^{7}\right), \mathrm{p}=0.001$ (fig. $\left.4 \mathrm{~b}\right)$.

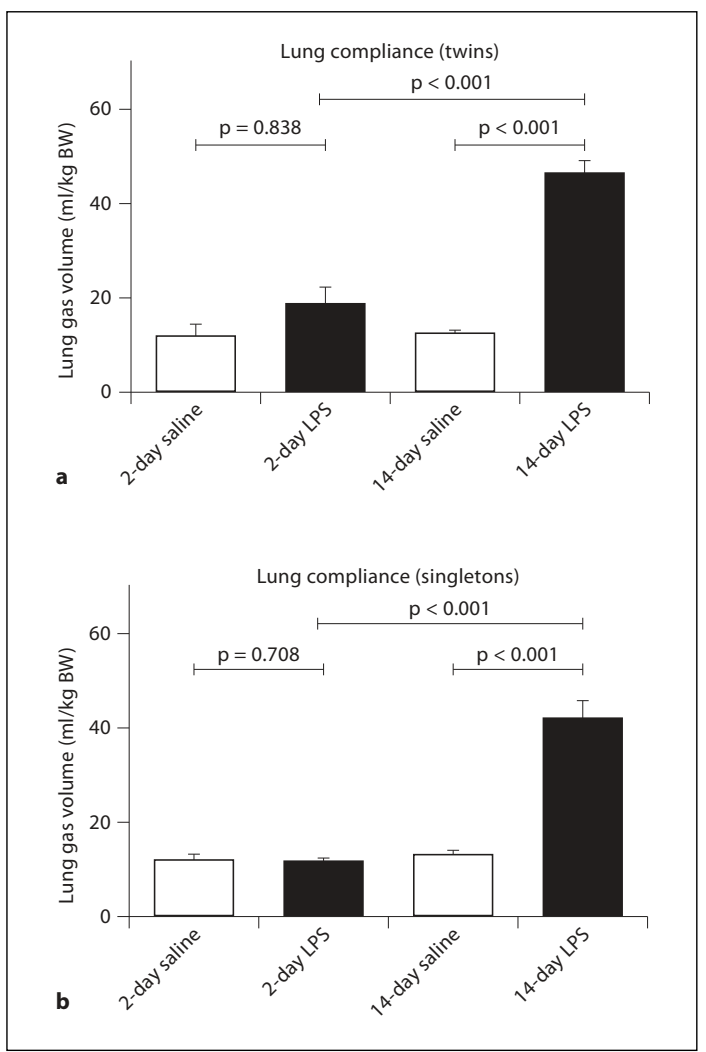

Fig. 5. Lung compliance as measured by maximum lung gas volume at $40 \mathrm{~cm} \mathrm{H}_{2} \mathrm{O}$. Lung compliance of twin (a) and singleton (b) fetuses was not significantly increased after 2 days compared to controls. Lung compliance was increased in both twins and singletons after 14 days of LPS exposure compared to controls. Lung compliance values were not statistically different between twins and singletons. Twin 2-day saline $(\mathrm{n}=3)$, twin 2-day LPS $(\mathrm{n}=3)$, twin 14-day saline $(n=2)$, twin 14-day LPS $(n=2)$, singleton 2-day saline $(\mathrm{n}=4)$, singleton 2 -day LPS $(\mathrm{n}=4)$, singleton 14 -day saline $(\mathrm{n}=4)$ and singleton 14-day LPS $(\mathrm{n}=4)$. $\mathrm{kg} \mathrm{BW}=$ kilogram body weight. $p$ values of ANOVA with post-Tukey test are shown.

\section{Lung Compliance}

Lung compliance was studied by measuring maximum lung gas volumes at $40 \mathrm{~cm} \mathrm{H}_{2} \mathrm{O}$. There was no significant increase in lung gas volume in twins after 2 days of intra-amniotic LPS exposure when compared to saline-treated co-twins: 2 -day saline $=11.4( \pm 3.1)$ versus 2 -day LPS $=18.0( \pm 4.3), \mathrm{p}=0.838$ (fig. 5a). Similarly, in 
singletons lung compliance was not altered by 2 -day LPS exposure: 2 -day saline $=11.2( \pm 1.7)$ versus 2 -day LPS $=$ $11.0( \pm 0.8) ; \mathrm{p}=0.708$. These findings are in line with previous results [16]. Lung compliance was significantly higher after 14 days of LPS exposure compared to the 14day saline controls in both twins [14-day saline $=11.7$ $( \pm 1.0)$ versus 14 -day LPS $=46.0( \pm 3.2), \mathrm{p}<0.001]$ and singletons $[14$-day saline $=12.2( \pm 1.4)$ versus 14 -day LPS $=41.5$ ( \pm 4.2$), \mathrm{p}<0.001$; fig. 5a, b]. In addition, lung compliance was significantly increased after 14 days of LPS exposure compared to 2 days of LPS in both twins $(\mathrm{p}<0.001)$ and singletons $(\mathrm{p}<0.001)$.

\section{Twins versus Singletons}

With respect to lung compliance and inflammation in the membranes, placenta and lung, no statistical differences between twin animals in the saline group and singleton animals in the saline group were found. The same is true for twin animals with 2 days of LPS versus singleton animals with 2 days LPS, and for twin animals with 14 days of LPS versus singleton animals with 14 days LPS (data not shown).

\section{Discussion}

In summary, we assessed in dichorial twin pregnant sheep whether LPS-induced chorioamnionitis was confined to the exposed compartment without crossing to the adjacent compartment affecting the second fetus. We found that inflammatory cells in the placenta, membranes and neutrophils in BAL of fetuses exposed to LPS were significantly higher when compared to the saline exposed co-twin. After 14 days of intrauterine exposure to inflammation, the lung gas volume was significantly increased in all animals exposed to chorioamnionitis. LPS-exposed twins showed similar responses with respect to increases in lung gas volume and number of neutrophils in BAL fluid as LPS-exposed singletons. Intraamniotic LPS injection resulted in histologic chorioamnionitis and lung maturation as indicated by increased lung compliance. This inflammatory response was thus strictly limited to the exposed compartment leaving the unexposed fetus unaffected.

The time-points analyzed in this study and the dose of LPS were chosen based on previous findings which showed that $10 \mathrm{mg}$ of intra-amniotic LPS induces an acute inflammatory response which persists for several weeks [16]. We have therefore chosen a rather short period ( 2 days) after induction of inflammation and a lon- ger period (14 days) to assess both effects. In this study we used LPS as a reliable and reproducible inducer of fetal inflammation with well-described fetal effects [16] to test if the fetal inflammation was confined to the exposed compartment. The relevance of LPS in modeling chorioamnionitis is further underlined by the finding of Romero et al. [18] that concentrations of bacterial endotoxin are higher in the amniotic fluid in women with preterm premature rupture of the membranes in labor than in women with premature rupture of the membranes who were not in labor.

Testing live bacteria as a source of chorioamnionitis was beyond the scope of this study. Live bacteria induce a higher variability of fetal responses which mandates larger animal numbers [19]. After this initial study on the confinement of LPS-induced inflammation to one compartment, an experiment with live bacteria may be indicated; however, the question as to which bacteria should be used is not straightforward since most isolates from chorioamnionitis are multibacterial [20].

These results raise the question whether clinicians should attempt to prolong twin pregnancies complicated by chorioamnionitis in the presenting fetus in order to improve the outcome of the nonpresenting fetus. Several studies have shown that delayed interval delivery can improve neonatal outcome when retained fetuses are compared with firstborn fetuses [21-28]. These data indicate that delayed interval delivery may improve neonatal outcome, although there is still a considerable number of neonatal and maternal complications to be expected [29].

In the above-mentioned studies, chorioamnionitis was often an exclusion criterion. As soon as chorioamnionitis was diagnosed after enrollment in the study, it was an indication for immediate delivery of both fetuses [22-24]. Clinical evidence, however, shows that in $40-67 \%$ of twin pregnancies with preterm birth, a positive amniotic fluid culture is found in only one of the two compartments. This is predominantly the presenting one, indicating that in twin pregnancies the presenting fetus is most often affected by chorioamnionitis $[11,12]$. This implicates that the risk of developing postnatal complications associated with chorioamnionitis (i.e. bronchopulmonary dysplasia, early-onset sepsis, cystic periventricular leukomalacia, cerebral palsy and intraventricular hemorrhage) may be higher in the presenting fetus than in the nonpresenting fetus. This assumption needs confirmation in large databases. The association between chorioamnionitis and increased risk for bronchopulmonary dysplasia and earlyonset sepsis, however, may be explained by the fact that intrauterine exposure to inflammation may cause impair- 
ment of the fetal immune system and damage to epithelial barriers making exposed fetuses more vulnerable to postnatal complications [30].

Physiology and maturation of fetal sheep is highly representative of the human situation, making sheep a suitable translational animal model for research in perinatology. The extrapolation to the human situation is, however, cautioned since the sheep have a uterus bicornis with a dichorial twin pregnancy. To the best of our knowledge, this is the first study that provides evidence that LPS-induced chorioamnionitis in multiple sheep pregnancies is strictly limited to the amniotic cavity in which chorioamnionitis is initiated.

Interestingly, a study by Kim et al. [31] showed that microbial invasion of the amniotic cavity does not follow widespread infection of chorioamniotic membranes, but precedes it. This study result can imply that chorioamnionitis does not readily spread over the membranes, which would make it less likely in a twin pregnancy that one chorioamniotic compartment infects the adjacent compartment by spreading over the membranes. However, we cannot draw this conclusion from our present study since no living bacteria were used to induce chorioamnionitis. Moreover, a study by Moss et al. [32] showed that the chorioamnion was an effective barrier to endotoxin entry into the amniotic fluid when LPS was injected in the subchorionic space. In contrast, in vitro experiments show that some bacteria can readily invade the chorioamnion from the maternal site [33].

Our study has several limitations. One limitation is the limited number of animals per group; however, this is acceptable given the clear responses after LPS-induced chorioamnionitis. The fact that LPS is inert may raise the question whether the same results would have been obtained if live bacteria (i.e. Ureaplasma parvum) had been injected. Furthermore, our observation period was limited to 14 days of intrauterine exposure to inflammation in twins. However, we already know from singleton studies that the pulmonary and placental inflammation persists for a long period of time [34]. In addition, we suffered one spontaneous abortion which was not included in any analysis.

In conclusion, our findings provide evidence that LPSinduced chorioamnionitis in twin sheep pregnancies is exclusively confined to the exposed compartment and does not affect the co-twin compartment. These observations may support the decision to delay delivery in multifetal pregnancies complicated by chorioamnionitis affecting only one fetus since reports suggest that delayed delivery in multifetal pregnancies complicated by chorioamnionitis can be successful. It would be advisable to support expectant management in delivery of the second fetus by careful assessment of the nonpresenting amniotic cavity for signs of infection or inflammation. This may create a good chance of decreasing morbidity and mortality of the second twin in multiple pregnancies in case of preterm birth of the first twin due to chorioamnionitis.

\section{Acknowledgements}

This study was funded by Veni BWK 016.096.141 from the Dutch Scientific Research Organization and the Pediatrics Foundation of Maastricht University Medical Center. The funders had no role in the study design, data collection and analysis, decision to publish, or preparation of the manuscript.

We thank Dr. Alan H. Jobe for the inspirational discussion.

\section{Disclosure Statement}

None of the authors have a conflict of interest.

\section{References}

$\checkmark 1$ Goldenberg RL, et al: Epidemiology and causes of preterm birth. Lancet 2008;371:7584.

2 Faroogi A, et al: Chronic conditions, functional limitations, and special health care needs in 10- to 12-year-old children born at 23 to 25 weeks' gestation in the 1990s: a Swedish national prospective follow-up study. Pediatrics 2006;118:e1466-e1477.

3 Hagberg B, et al: Changing panorama of cerebral palsy in Sweden. VIII. Prevalence and origin in the birth year period 1991-1994. Acta Paediatrica 2001;90:271-277.
4 Doyle LW, et al: Bronchopulmonary dysplasia in very low birth weight subjects and lung function in late adolescence. Pediatrics 2006; 118:108-113.

5 Fitzgibbons SC, et al: Mortality of necrotizing enterocolitis expressed by birth weight categories. J Pediatr Surg 2009;44:10721075, discussion 1075-1076.

-6 Uauy RD, et al: Necrotizing enterocolitis in very low birth weight infants: biodemographic and clinical correlates. National Institute of Child Health and Human Development Neonatal Research Network. J Pediatr 1991;119:630-638.
7 Saigal S, Doyle LW: An overview of mortality and sequelae of preterm birth from infancy to adulthood. Lancet 2008;371:261-269.

8 Gotsch F, et al: The fetal inflammatory response syndrome. Clin Obstet Gynecol 2007; 50:652-683.

-9 Thomas W, Speer CP: Chorioamnionitis: important risk factor or innocent bystander for neonatal outcome? Neonatology 2011;99: 177-187.

10 Gantert M, et al: Chorioamnionitis: a multiorgan disease of the fetus? J Perinatol 2010; 30 (suppl):S21-S30. 
11 Mazor M, et al: Intraamniotic infection in patients with preterm labor and twin pregnancies. Acta Obstet Gynecol Scand 1996;75: 624-627.

12 Romero R, et al: Infection and labor. VI. Prevalence, microbiology, and clinical significance of intraamniotic infection in twin gestations with preterm labor. Am J Obstet Gynecol 1990;163:757-761.

13 Bollen B, Padwick M: Delayed delivery of second twin after chorioamnionitis and abortion of first twin at 21 weeks gestation. Eur J Obstet Gynecol Reprod Biol 2000;93: 109-110.

14 Watson WJ, McNelis T: Delayed interval delivery: infection is not an absolute contraindication. Am J Perinatol 1998;15:387-388.

15 Jobe AH, et al: Endotoxin-induced lung maturation in preterm lambs is not mediated by cortisol. Am J Respir Crit Care Med 2000; 162:1656-1661.

16 Kramer BW, et al: Dose and time response after intraamniotic endotoxin in preterm lambs. Am J Respir Crit Care Med 2001;164: 982-988.

17 Redline RW, et al: Amniotic infection syndrome: nosology and reproducibility of placental reaction patterns. Pediatr Dev Pathol 2003;6:435-448.

18 Romero R, et al: Labor and infection. II. Bacterial endotoxin in amniotic fluid and its relationship to the onset of preterm labor. Am J Obstet Gynecol 1988;158:1044-1049.
19 Kramer BW: Chorioamnionitis - new ideas from experimental models. Neonatology 2011;99:320-325.

20 Onderdonk AB, et al: Detection of bacteria in placental tissues obtained from extremely low gestational age neonates. Am J Obstet Gynecol 2008;198:110.el-e7.

21 Abboud P, Gallais A, Janky E: Intentional delayed delivery in twin pregnancy. Two additional cases and literature review. Eur J Ob stet Gynecol Reprod Biol 1997;75:139-143.

22 Arabin B, van Eyck J: Delayed-interval delivery in twin and triplet pregnancies: 17 years of experience in 1 perinatal center. Am J Obstet Gynecol 2009;200:154.el-8.

23 Farkouh LJ, et al: Delayed-interval delivery: extended series from a single maternal-feta medicine practice. Am J Obstet Gynecol 2000; 183:1499-1503.

24 Fayad S, et al: Delayed delivery of second twin: a multicentre study of 35 cases. Eur J Obstet Gynecol Reprod Biol 2003;109:16-20.

25 Oyelese Y, et al: Delayed interval delivery in twin pregnancies in the United States: im pact on perinatal mortality and morbidity. Am J Obstet Gynecol 2005;192:439-444.

26 Roman AS, et al: Maternal and neonatal outcomes after delayed-interval delivery of multifetal pregnancies. Am J Perinatol 2011;28: 91-96.
27 Rosbergen $\mathrm{M}$, et al: Long-term and shortterm outcome after delayed-interval delivery in multi-fetal pregnancies. Eur J Obstet Gynecol Reprod Biol 2005; 122:66-72.

28 Zhang J, et al: Delayed interval delivery and infant survival: a population-based study. Am J Obstet Gynecol 2004;191:470-476.

29 Livingston JC, et al: Second-trimester asynchronous multifetal delivery results in poor perinatal outcome. Obstet Gynecol 2004 103:77-81

30 Wolfs TG, et al: Inflammation-induced immune suppression of the fetus: a potential link between chorioamnionitis and postnatal early onset sepsis. J Matern Fetal Neonatal Med 2012, E-pub ahead of print.

-31 Kim MJ, et al: Widespread microbial invasion of the chorioamniotic membranes is a consequence and not a cause of intra-amniotic infection. Lab Invest 2009;89:924-936.

32 Moss TJ, et al: Chorioamnionitis induced by subchorionic endotoxin infusion in sheep. Am J Obstet Gynecol 2003;189:1771-1776.

33 Galask RP, et al: Bacterial attachment to the chorioamniotic membranes. Am J Obstet Gynecol 1984;148:915-928.

-34 Kallapur SG, et al: Chronic endotoxin exposure does not cause sustained structural abnormalities in the fetal sheep lungs. Am J Physiol Lung Cell Mol Physiol 2005; 288:L966-L974. 


\section{Chapter 4}

Increased EEG delta frequency corresponds to chorioamnionitis-related brain injury.

Gavilanes, A.W., Gantert, M., Strackx, E.,

Zimmermann, L.J., Seeldrayers, S., Vles, J.S., Kramer, B.W.

Front Biosci (Schol Ed). 2010 Jan 1; 2: 432-8 


\title{
Increased EEG delta frequency corresponds to chorioamnionitis-related brain injury
}

\begin{abstract}
Antonio Wenceslao Danilo Gavilanes ${ }^{1,3}$, Markus Gantert ${ }^{4}$, Eveline Strackx ${ }^{1,2,3}$, Luc J. Zimmermann ${ }^{1}$, Saskia Seeldrayers ${ }^{5}$, Johan S. H. Vles ${ }^{2}$, Boris W. Kramer ${ }^{1,3}$

${ }^{1}$ Departments of Pediatrics, Neonatology, Maastricht University Medical Center, ${ }^{2}$ Child Neurology, Maastricht University Medical Center, in collaboration with the School for Oncology and Developmental Biology (GROW), Faculty of Health, Medicine and Life Sciences Maastricht University, The Netherlands, ${ }^{3}$ School of Mental Health and Neuroscience, Faculty of Health, Medicine and Life Sciences, Maastricht University and European Graduate School of Neuroscience (EURON), The Netherlands, ${ }^{4}$ Department of Obstetrics and Gynecology, Klinikum Osnabrück, Osnabrück, Germany and ${ }^{5}$ Animal Laboratory, Maastricht University Medical Center, Maastricht, The Netherlands
\end{abstract}

\section{TABLE OF CONTENTS}

1. Abstract

2. Introduction

3. Materials and methods

3.1. Animals and surgical procedures

3.2. Intrapartal EEG data sampling and off-line analysis

3.3. Flow cytometric analysis

3.4. Statistical analysis

4. Results

4.1. CFAM amplitude

4.2. CFAM frequency

4.3. FACS activated microglia

4.4. FACS apoptotic cell death

5. Discussion

4.5. CFAM vs. FACS variables

5.1. Clinical relevance of antenatal inflammation

5.2. Inflammatory CNS impact

5.3. CFAM registration

5.4. EEG amplitude analysis

5.5. EEG delta frequency analysis

5.6. Methodological EEG drawbacks and study limitations

5.7. Final remarks

6. Acknowledgements

6. References

\section{ABSTRACT}

We evaluated the impact of chorioamnionitis on the intrapartal EEG delta frequency in the non-anesthetized preterm sheep. $10 \mathrm{mg}$ intra-amniotic LPS or saline were given 2 or 14 days before preterm birth at gestational day 125. Lambs were delivered by Caesarean section under local anesthesia. A 5-minute EEG depicted delta activity and amplitude, and the relationship between EEG delta activity and both the white matter (WM) and cortical microglial activation and apoptosis was analyzed. EEG delta activity was increased significantly in the 14-day LPS preterm fetuses compared to both preterm control and 2day LPS animals $(\mathrm{p}<0.05)$. No differences were seen between controls and the 2-day LPS fetuses. A direct association was demonstrated between EEG delta activity and both cortical microglial activation $(\mathrm{r}=0,645, \mathrm{p}=$ $0,024)$ and apoptosis $(r=0,580, p=0,048)$, and between delta and WM activated microglia $(r=0,742, p=0,006)$ and apoptosis $(r=0,777, p=0,003)$. This study is the first to show a relationship between brain dysfunction and chorioamnionitis-related injury at birth.

\section{INTRODUCTION}

Chorioamnionitis and the resulting fetal inflammatory response syndrome are common in extremely preterm infants, affecting different organs like the lungs and the central nervous system (CNS) (1-3). Consequently, chorioamnionitis is a major predictor of both a complicated neonatal clinical course and a poor neurological long-term outcome (4-7). The identification of newborns previously exposed to antenatal inflammation remains difficult, especially if no clinical signs are present immediately after birth. The early detection of neuronal dysfunction in those newborns is of particular interest as it might have a diagnostic and prognostic value.

Previously we studied chorioamnionitis in the sheep model to investigate the link between antenatal inflammation and neurological injury $(8,9)$. In that study, we established for the first time that chorioamnionitis induces a global CNS inflammatory response and increased apoptosis of the white matter (WM) as well as the cortical and subcortical gray matter (GM) in the preterm fetal 


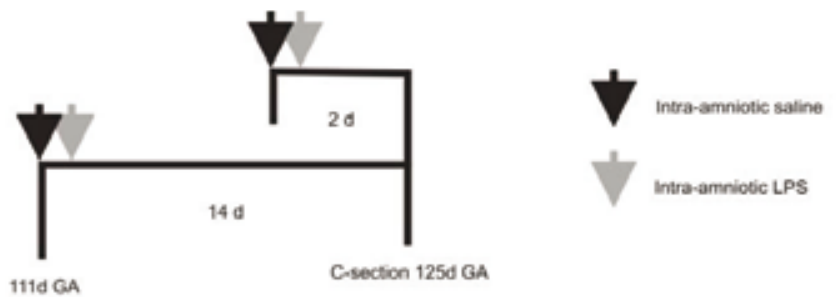

A

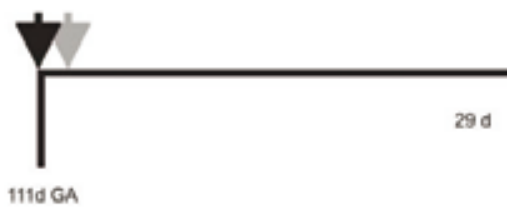

29 d

\section{B}

Figure 1. Schematic overview of the experimental design. Chorioamnionitis was induced by intra-amnionitic LPS administration at 123d GA (2-day LPS, $n=6$ ) and at $111 \mathrm{~d}$ GA (14-day LPS, $n=5$ ); (control saline, $n=7$ ). Ewes delivered preterm at 125d GA.

sheep. The brain was found to be more vulnerable than the cerebellum and the spinal cord, which may be due to their specific stage of maturation (8).

The present study further developed this model of antenatal inflammatory CNS injury by focusing on the effects on the peripartal EEG. We studied the effects of endotoxin induced chorioamnionitis at low gestational age (GA) by intra-amniotic lipopolysaccharide (LPS) administration and subsequent delivery at $125 \mathrm{~d}$ GA $(70 \%$ of full-term gestation). This specific gestational age corresponds to approximately 27 weeks of human CNS maturation, a vulnerable period of the human brain to develop WM disease (10). A 5-minute peripartal EEG was registered on a Cerebral Function Analysing Monitor (CFAM) as described elsewhere, providing detailed information about the amplitude and the frequencies of EEG activity (11). Interestingly, the well-established dominance of slow EEG frequency waves (delta frequency) in the immature brain supports its use as marker of neuronal function (12). The ewes did not receive general anesthesia for the Caesarean section, to avoid the alteration of the cerebral metabolism by systemic anesthesia during the CFAM registration, whereas the fetuses were maintained on placental circulation by the ex-utero intrapartum treatment (EXIT) procedure, assuring stable systemic hemodynamics. This allowed for a representative registration of early neuronal functional changes detected by CFAM. We hypothesized an LPS interval-related effect on the intrapartal EEG as well as a positive correlation between the EEG delta activity and the severity of CNS inflammation and injury in the LPS groups (8).

\section{MATERIALS AND METHODS}

\subsection{Animals and surgical procedures}

The study was performed according to the guidelines of the Animal Care Committee of the University of Maastricht, which approved the protocol. Time-mated
Texel ewes with singleton fetuses were randomly assigned to groups of five animals, to receive a single dose of $10 \mathrm{mg}$ endotoxin (Escherichia coli 055:B5; Sigma Chemical, St. Louis, MO) resuspended in saline or the equivalent volume of saline for control by ultrasound guided intra-amniotic injections, as previously described (9). Chorioamnionitis was induced at a GA of 110 or $111 \mathrm{~d}$ and at $123 \mathrm{~d}$ GA. Animals were sacrificed at the GA of $125 \mathrm{~d} 2$ days $(n=6)$ or 14 days $(n=5)$ after exposure to chorioamnionitis. The GA of $125 \mathrm{~d}$ is comparable with a human GA of approximately 27 weeks (Figure 1).

Pregnant ewes delivered by Caesarean section under subcutaneous infiltration of $4 \%$ lidocaine. The fetal head was exteriorized while feto-maternal circulation was preserved by the EXIT procedure. Five minutes after delivery of the head the umbilical cord was clamped and cut, and the fetal sheep was fully delivered. Fetuses were sacrificed by a lethal injection of pentobarbital after EEG registration, while measurements of cord arterial blood gases were performed. Ewes were killed by a lethal injection of pentobarbital.

\subsection{Intrapartal EEG data sampling and off-line analysis}

EEG data were collected for 5 minutes immediately after delivery of the fetal head by a CFAM system, which was developed and used in the University Hospital of Maastricht (11). No systemic drugs were given before or during the recordings. Four shielded stainlesssteel subcutaneous scalp electrodes (two parietal, one frontal and one reference electrode) were placed. The threechannel EEG (P3/F0 (left hemisphere), P4/F0 (right hemisphere) and $\mathrm{P} 3 / \mathrm{P} 4$, international 10-20 system) registration was processed off-line. This includes weighted digital band filtering between 2 and $15 \mathrm{~Hz}$, rectification, logarithmic amplitude compression, and smoothing of the signal. Intervals of two seconds were analyzed off-line by the computer yielding means EEG amplitude (bandwidth, 


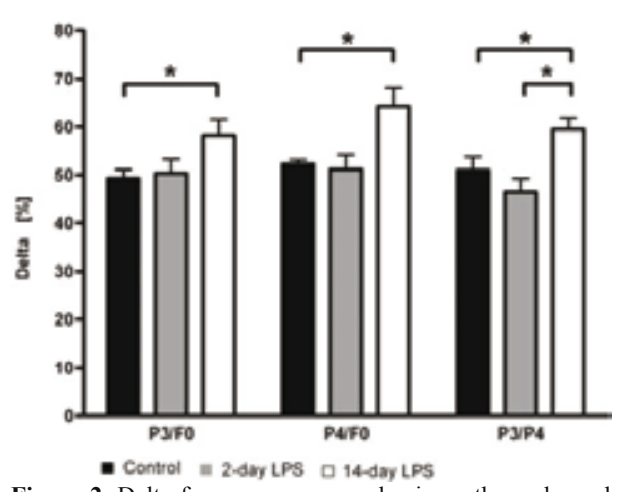

Figure 2. Delta frequency measured suing a three-channel EEG (P3/F0 (left hemisphere), P4/F0 (right hemisphere) and $\mathrm{P} 3 / \mathrm{P} 4$, international 10-20 system). Symmetrical enhancement of delta frequency [in \%] in the 14-day LPS fetuses at $125 \mathrm{~d}$ GA (control $\mathrm{n}=7$; 2-day LPS, $\mathrm{n}=6$; 14-day LPS, $\mathrm{n}=5$ ). Data represents means \pm SEM (One-way ANOVA and post-hoc Bonferroni $* \mathrm{p}<0.05$ )

minimal and maximal) and relative delta [1-3.5 $\mathrm{Hz}]$, theta $[3.5-7.5 \mathrm{~Hz}]$, alpha $[7.5-13 \mathrm{~Hz}]$ and beta [13$27 \mathrm{~Hz}]$ spectral analysis. The power values for each frequency are expressed as a percentage of the mean total power, allowing comparisons across animals. Only the biparietal P3/P4 delta frequency was further analyzed and correlated with previously reported morphological data in the preterm groups (8). We used this original singlechannel biparietal CFAM recording, because it represents the global electrocortical activity.

\subsection{Flow cytometric analysis}

WM and cortical samples of the preterm groups (125d GA) were run on a FACScalibur flow cytometry system (FACS, BD Biosciences, New Jersey, USA), equipped with an argon ion laser $(488 \mathrm{~nm})$. Analysis was done using the Cell Quest Pro software (BD Biosciences, New Jersey, USA). AnnexinV / propidium iodide and OX42 staining, detecting apoptotic cells and activated microglia respectively, were reported by the authors (8). We correlated these data with the P3/P4 delta frequency percentage registered in those animals at birth (control, $\mathrm{n}=3$; 2-day LPS, n=5; 14-day LPS, n=4).

\subsection{Statistical analysis}

Data were analyzed using a multivariate ANOVA (represented as mean \pm SEM). Significant effects were analyzed by post-hoc Bonferroni corrections. Pearson's correlation coefficients were computed to quantify the relationship between the EEG and the FACS variables. The accepted level of significance was $p<0.05$. All calculations were done using Statistical Package for Social Sciences (SPSS 15.0 software).

\section{RESULTS}

There was no influence of gender, singleton/twin or weight on any of the analyzed variables. The cord arterial blood $\mathrm{pH}$ was significantly decreased in the 14-day LPS animals $(\mathrm{p}<0.001$; control $(\mathrm{n}=3) \mathrm{pH} 7.39( \pm 0.02)$ vs.14-day LPS group $(\mathrm{n}=4) \mathrm{pH} 7.22( \pm 0.04))$. A significant decrease in base excess $(\mathrm{mmol} / \mathrm{L})$ was shown in the 14-day LPS group compared to controls $(\mathrm{p}<0.001$; control $(\mathrm{n}=3)-2.4( \pm 0.38), 14$-day LPS group $(\mathrm{n}=4)-$ $7.10( \pm 0.83))$ (data not shown).

\subsection{CFAM amplitude}

Means for the maximal, minimal and bandwidth P3/P4 CFAM amplitude were unchanged in the 2 and 14day LPS groups, compared with the control group (e.g. control preterm $(\mathrm{n}=7)$ maximal mean $5.75 \mu$ volts $( \pm 0.28)$, 2-day LPS group $(\mathrm{n}=6)$ maximal mean $6.0 \mu$ volts $( \pm 0.22)$ vs. 14-day LPS group $(\mathrm{n}=5)$ maximal mean $5.95 \mu$ volts $( \pm$ $0.83)$ ). All amplitude recordings were symmetrical and seizures were not present (data not shown).

\subsection{CFAM frequency}

The percentage of delta frequency in the 14-day LPS group ( $\mathrm{n}=5$ ) was significantly increased compared to both 2-day LPS $(n=6)$ and the saline treated groups $(n=7)$ $(\mathrm{p}<0.05 ; 59.50 \%( \pm 2.15), 47.50 \%( \pm 2.42)$ vs. $51.00 \%( \pm$ 1.89), respectively) (Figure 2). Again asymmetrical spectral power recordings were not seen.

\subsection{FACS activated microglia}

Activated microglia were detected by OX42. Its percentage was very low in the saline group $(n=3,0.8 \%$ $1.6 \%)$ as previously reported [9]. In the WM and cortical GM the percentage of activated microglia was significantly higher in the 2-day LPS group $(n=5,2.5 \%-5 \%)$ than in the saline group. There was an even higher increase in the proportion of activated microglia in the 14-day LPS group $(n=4,3.2 \%-6.8 \%)$ (data not shown).

\subsection{FACS apoptotic cell death}

The percentage of apoptotic cells was determined by AnnexinV+/PI- staining. It increased significantly in the 14-day LPS group ( $n=4,28 \%-46 \%)$ compared to the saline group $(\mathrm{n}=3,12 \%-23 \%)$ in both the WM and GM as previously reported [9]. In the cortex, again the percentage of apoptotic cells was higher in the 2-day LPS group $(n=5)$.

\subsection{CFAM vs. FACS variables}

The Pearson correlation coefficient showed a significant positive correlation between delta frequency and the cortical activated microglia percentage $(r=0.645, p: 0.024)$ (Figure 3A). A significant positive correlation between the delta frequency and WM activated microglia percentage $(\mathrm{r}=$ $0.742, p=0.006$ ) was found as well (Figure 3B). Furthermore, a significant positive correlation was found between the relative delta frequency and the cortical apoptosis $(r=0.580, p$ $=0.048$ ) (Figure 3C). Finally, a significant correlation was observed between delta frequency and WM apoptosis percentages $(r=0.777, p=0.003)$ (Figure 3D).

\section{DISCUSSION}

The central finding of this study is that chorioamnionitis induced by intra-amniotic LPS causes preterm EEG alterations including a substantial 

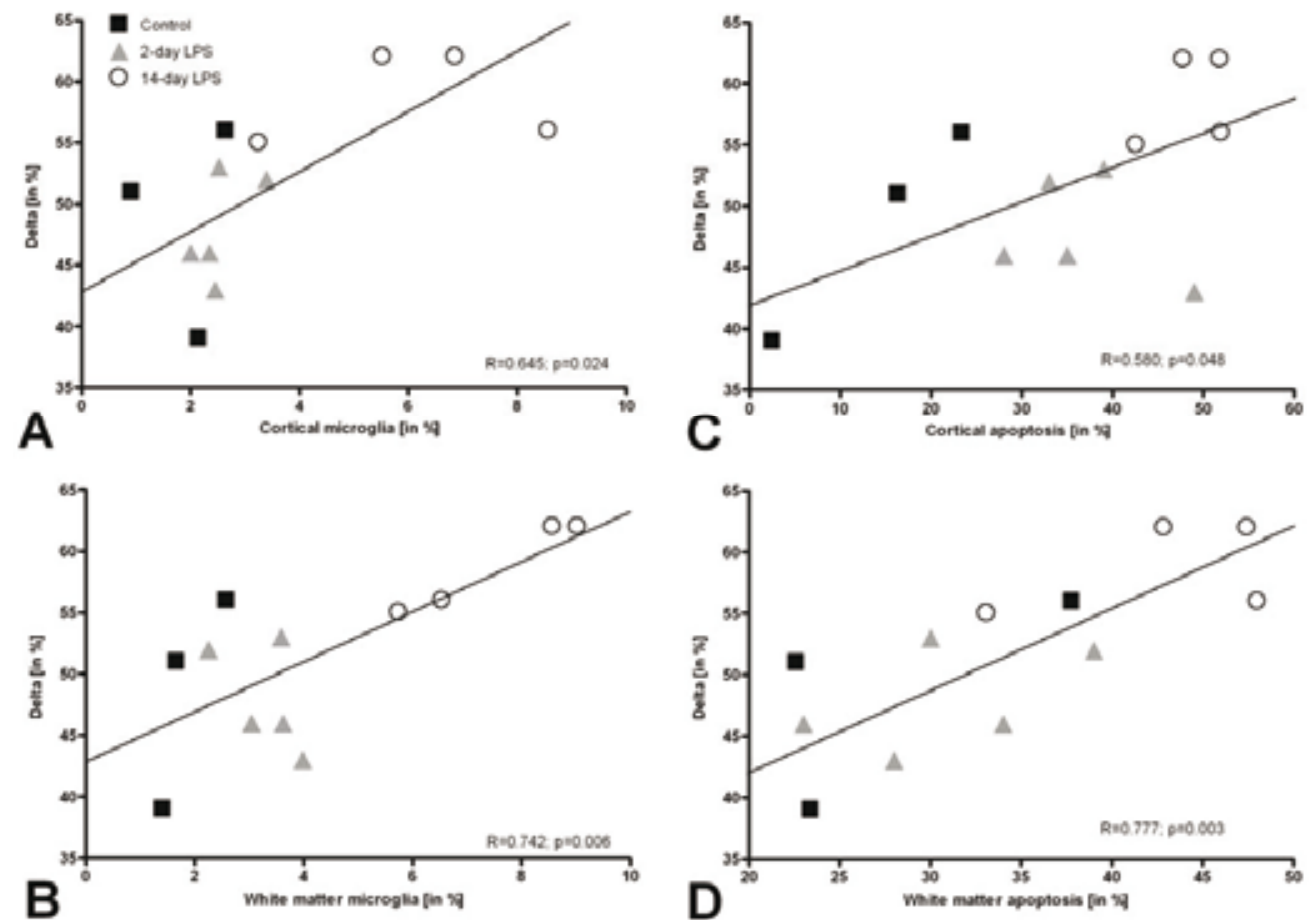

Figure 3. The Pearson correlation coefficient data. (A) Correlation between the delta frequency [in \%] and cortical activated microglia [in \%] in the preterm fetal sheep at a gestational age of 125 days $(\mathrm{R}=0.645, \mathrm{p}=0.024)$. (B) Correlation between the delta frequency [in \%] and white matter activated microglia [in \%] in the preterm fetal sheep at a gestational age of 125 days $(\mathrm{R}=0.742$, $\mathrm{p}=0.006$ ). (C) Correlation between the delta frequency [in \%] and cortical apoptosis [in \%] in the preterm fetal sheep at a gestational age of 125 days $(\mathrm{R}=0.580, \mathrm{p}=0.048)$. (D) Correlation between the delta frequency [in \%] and white matter apoptosis [in \%] in the preterm fetal sheep at a gestational age of 125 days $(R=0.645, p=0.024)($ Control $n=3$, 2-day LPS $n=5$ and 14 -day LPS $n=4)$.

enhancement of the delta frequency. In addition, preterm white matter and cortical microglial activation and apoptotic cell death significantly correlated with this functional variable. This finding was interval-dependent, meaning that the 14-day LPS fetuses were affected most. These findings support the concept that enhancement of the delta frequency may serve as a marker of inflammatory CNS injury as early as at birth.

\subsection{Clinical relevance of antenatal inflammation}

Preterm birth is by far the most important adverse outcome of pregnancy. It is inversely correlated with histological chorioamnionitis with an overall incidence of $30 \%$ prior to 34 weeks of gestation (1). In addition, preterm birth at an extremely early gestational age is associated with an even higher rate of histological chorioamnionitis (up to $80 \%$ ) and funisitis (up to $25 \%$ ) $(2,3)$. Furthermore, preterm newborns affected by systemic inflammation/infection show increased risk of neonatal morbidity and mortality as well as a higher risk to develop chronic pathologies like lung disease and encephalopathy. Considering the impact of these deficits throughout the entire lifespan of an individual and baring the social and economic costs in mind, a full understanding of the impact of antenatal inflammation on CNS development is crucial.

\subsection{Inflammatory CNS impact}

The effects of LPS are mediated through binding to the LPS binding receptor CD14, facilitating the activation of toll-like receptor 4 (TLR4). Interaction of LPS with TLR4 initiates a cascade of cellular events, including activation of the transcription factor nuclear factor - kappa $\mathrm{B}$, which in turn leads to the transcription of proinflammatory cytokines (13-15). A prolonged fetal exposure to these pro-inflammatory cytokines may be caused by a sustained cellular inflammatory response in the amniotic fluid up to seven days after $10 \mathrm{mg}$ IA LPS administration, as shown in this model by Kramer et al. (9). The route of these pro-inflammatory cytokines from the amniotic fluid to the brain, causing brain inflammation, is 
not very well understood. In the brain, the native proinflammatory cytokines production by astrocytes and microglia as well as the systemic cytokine transfer can induce glutamatergic excitotoxicity and the release of nitric oxide and reactive oxygen species. These processes are known to cause mainly oligodendrocyte apoptosis and myelin degeneration (WM disease), which are involved in the pathogenesis of permanent injury to the developing brain (16). We recently found that besides WM disease, both cortical and subcortical gray matter injury contribute to the global CNS injury in the 125-day-old preterm fetuses (9). In the present study, we correlated part of the FACS data on brain WM and cortical activated microglia and apoptosis reported in that study with the EEG delta wave activity assessed in the same preterm animals at birth. By doing so, we linked, for the first time, representative data on both the CNS inflammation and secondary apoptotic changes with a functional marker (delta frequency) at birth.

\subsection{CFAM registration}

CFAM is a quantitative EEG registration in which the EEG signal is filtered and selectively amplified. EEG amplitude and relative spectral power analysis was assessed using the CFAM monitor developed in our institution (10). EEG measurements were performed over a period of 5 minutes.

\subsection{EEG amplitude analysis}

The background EEG amplitude registered by the CFAM has been widely described in several neonatal pathological conditions, and it is mainly used as a predictor of neurological outcome after hypoxic-ischemic encephalopathy in full-term infants (17). This study showed an unchanged CFAM amplitude in the fetuses exposed to chorioamnionitis compared to controls.

\subsection{EEG delta frequency analysis}

This study focused on the relative changes in the spectral power and analyzed the delta frequency for several reasons. First, the neonatal basic low frequency EEG predominantly consists of the slow delta band (12). Preterm control fetal sheep for instance, have a relative delta of $51.00 \%( \pm 1.89)$. Secondly, an increase in delta frequency activity is associated with low levels of consciousness, severe hypocarbia, seizures disorders, cerebral trauma, post-hypoxic encephalopathy and brain ischaemia (18). In the present work, delta frequency percentage increased markedly in the 14-day LPS preterm group. Third, increased low frequency EEG activity has been reported as the consequence of the sleep-promoting (somnogenic) effects of interleukins in rats, presumably by activation of the hypothalamic preoptic area, which is a primary sleep regulatory center $(19,20)$. Fourth, neonatal (intensive) care data on EEG spectral analysis have been reported by several authors. Inder et al. demonstrated that low spectral edge frequency (SEF), assessed one to three weeks postnatally in a heterogeneous group of preterm infants was a predictor of brain WM compromise at the corrected term age (21). However, Wong et al. could not reproduce these SEF findings in term infants suffering from hypoxicischemic encephalopathy, 17 to 96 hours postnatally (22).
Finally, Thaler et al. suggested that lower SEF might serve as a marker for fetal distress during episodes of variable decelerations (23).

Since its first report by Maynard in 1979, CFAM spectral analysis has been limited to the detection of neonatal seizures and to monitoring acute neurological pathologies in the older pediatric intensive care population (2427). Experimental CFAM data in the preterm fetal sheep have been scarce and non conclusive $(28,29)$. Our previous CFAM studies demonstrated altered delta spectral changes in the newborn piglet subjected to either progressive hypotension or graded hypoxia $(30,31)$. Both studies showed that delta frequency augmentation correlated with impaired cerebral and systemic oxygenation and hemodynamics in the anesthetized newborn brain. There are no data from clinical or experimental studies demonstrating objectively antenatal inflammatory brain injury using the enhancement of delta frequency detected at birth.

The present study shows a significant positive correlation between cortical and WM microglia activation and apoptosis and delta frequency in the preterm LPS animals. These data demonstrate that chorioamnionitis affects the structural-functional organization of the preterm brain in a LPS interval-dependent manner.

\subsection{Methodological EEG drawbacks and study limitations}

$\mathrm{PH}, \mathrm{PaCO} 2$ and $\mathrm{PaO} 2$ measurements in cord blood were only performed at the moment of delivery, whereas the CFAM registration was performed for 5 minutes. This made it impossible to measure other physiological variables, such as fetal heart rate, eye movements or breathing patterns. Additionally, this 5-minute timeframe made both the appropriate evaluation of EEG continuity and the classification of cyclic behavior of the fetal EEG by discriminating between high-voltage slow activity and low-voltage fast activity EEG impossible. However, limiting the time from uterine incision to delivery allowed a representative EEG amplitude and frequency registration. Given the fact that neither systemic anesthetics nor uterine relaxation were used during the EXIT procedure, an appropriate uteroplacental support was maintained.

Whether the differences between the groups may have been caused by 1) the length of intra-amniotic LPS exposure (2 vs. 14-day interval), 2) the stage of fetal neurodevelopment at the time of LPS exposure (E111d vs. E123d), or 3) both cannot be distinguished on the basis of the design of this study. However, we think it is likely that both the duration of exposure (up to 14-days) and the developmental stage (gestational age) at the time of LPS administration accounted for the given impact. Finally, despite the small number of animals examined, strong and significant correlations were seen between delta frequency and FACS variables (Figure 3A-B).

\subsection{Final remarks}

The duration of chorioamnionitis was positively correlated with the grade of apoptosis, microglial activation 
and the shift to lower frequency EEG in the preterm fetuses. This findings are highly relevant as they for the first time document morphological and electrophysiological evidence of a CNS compromise at birth secondary to chorioamnionitis. Furthermore, it offers evidence of the potential diagnostic and prognostic value of EEG delta frequency by identifying those newborns who are at risk. The relationship between inflammatory brain injury and functional abnormalities as indicated by the significant enhanced EEG delta band, has to be further validated in human newborns.

\section{ACKNOWLEDGEMENTS}

We thank the animal laboratory team (University of Maastricht), under the leadership of Joyce Suykx, for their helpful assistance during the experiments. We thank Dr. P. Degraeuwe, MUMC, for excellent suggestions for data analysis.

\section{REFERENCES}

1. Lahra, M. M. \& H. E. Jeffery: A fetal response to chorioamnionitis is associated with early survival after preterm birth. Am J Obstet Gynecol, 190, 147-51 (2004)

2. Pacora, P., T. Chaiworapongsa, E. Maymon, Y. M. Kim, R. Gomez, B. H. Yoon, F. Ghezzi, S. M. Berry, F. Qureshi, S. M. Jacques, J. C. Kim, N. Kadar \& R. Romero: Funisitis and chorionic vasculitis: the histological counterpart of the fetal inflammatory response syndrome. J Matern Fetal Neonatal Med, 11, 18-25 (2002)

3. Yoon, B. H., R. Romero, J. S. Park, M. Kim, S. Y. Oh, C. J. Kim \& J. K. Jun: The relationship among inflammatory lesions of the umbilical cord (funisitis), umbilical cord plasma interleukin 6 concentration, amniotic fluid infection, and neonatal sepsis. Am J Obstet Gynecol, $183,1124-9(2000)$

4. Dammann, O., A. Leviton, D. B. Bartels \& C. E. Dammann: Lung and brain damage in preterm newborns. Are they related? How? Why? Biol Neonate, 85, 305-13 (2004)

5. Thompson, D. K., S. K. Warfield, J. B. Carlin, M. Pavlovic, H. X. Wang, M. Bear, M. J. Kean, L. W. Doyle, G. F. Egan \& T. E. Inder: Perinatal risk factors altering regional brain structure in the preterm infant. Brain, 130, 667-77 (2007)

6. Wu, Y. W.: Systematic review of chorioamnionitis and cerebral palsy. Ment Retard Dev Disabil Res Rev, 8, 25-9 (2002)

7. Wu, Y. W., G. J. Escobar, J. K. Grether, L. A. Croen, J. D. Greene \& T. B. Newman: Chorioamnionitis and cerebral palsy in term and near-term infants. Jama, 290, 2677-84 (2003)

8. Gavilanes, A. W. D., E. Strackx, B. W. Kramer, M. Gantert, D. L. A. Van den Hove, H. P. Steinbusch, Y.
Garnier, E. Cornips, H. W. M. Steinbusch, L. Zimmermann \& J. S. H. Vles: Maturation-related differences in the response of CNS to endotoxin-induced chorioamnionitis in fetal sheep. Am J Obstet Gynecol, 200, (4):437.e1-8 (2009)

9. Kramer, B. W., T. J. Moss, K. E. Willet, J. P. Newnham, P. D. Sly, S. G. Kallapur, M. Ikegami \& A. H. Jobe: Dose and time response after intraamniotic endotoxin in preterm lambs. Am J Respir Crit Care Med, 164, 982-8 (2001)

10. Back, S. A., A. Riddle \& A. R. Hohimer: Role of instrumented fetal sheep preparations in defining the pathogenesis of human periventricular white-matter injury. J Child Neurol, 21, 582-9 (2006)

11. Reulen, J. P., A. W. Gavilanes, D. van Mierlo, C. Blanco, F. Spaans \& J. S. Vles: The Maastricht Cerebral Monitor (MCM) for the neonatal intensive care unit. J Med Eng Technol, 23, 29-37 (1999)

12. Victor, S., R. E. Appleton, M. Beirne, A. G. Marson \& A. M. Weindling: Spectral analysis of electroencephalography in premature newborn infants: normal ranges. Pediatr Res, 57, 336-41 (2005)

13. Elovitz, M. A., C. Mrinalini \& M. D. Sammel: Elucidating the early signal transduction pathways leading to fetal brain injury in preterm birth. Pediatr Res, 59, 50-5 (2006)

14. Ling, Z., Q. A. Chang, C. W. Tong, S. E. Leurgans, J. W. Lipton \& P. M. Carvey: Rotenone potentiates dopamine neuron loss in animals exposed to lipopolysaccharide prenatally. Exp Neurol, 190, 373-83 (2004)

15. Wang, X., C. I. Rousset, H. Hagberg \& C. Mallard: Lipopolysaccharide-induced inflammation and perinatal brain injury. Semin Fetal Neonatal Med, 11, 343-53 (2006)

16. Ramsey, P. S., J. M. Lieman, C. G. Brumfield \& W Carlo: Chorioamnionitis increases neonatal morbidity in pregnancies complicated by preterm premature rupture of membranes. Am J Obstet Gynecol, 192, 1162-6 (2005)

17. Spitzmiller, R. E., T. Phillips, J. Meinzen-Derr \& S. B. Hoath: Amplitude-integrated EEG is useful in predicting neurodevelopmental outcome in full-term infants with hypoxic-ischemic encephalopathy: a meta-analysis. $J$ Child Neurol, 22, 1069-78 (2007)

18. Fisch, B. J.: Bilaterally synchronous slow waves. In: Spehlmanss's EEG primer. Ed: B. J. Finsch. Elsevier Science B.V., Amsterdam, The Netherlands (1991)

19. Lancel, M., J. Cronlein, P. Muller-Preuss \& F. Holsboer: Lipopolysaccharide increases EEG delta activity within non-REM sleep and disrupts sleep continuity in rats. Am J Physiol, 268, R1310-8 (1995)

20. Baker, F. C., S. Shah, D. Stewart, C. Angara, H. Gong, R. Szymusiak, M. R. Opp \& D. McGinty: Interleukin 1beta enhances non-rapid eye movement sleep and increases c- 


\section{EEG delta activity in chorioamnionitis}

Fos protein expression in the median preoptic nucleus of the hypothalamus. Am J Physiol Regul Integr Comp Physiol, 288, R998-R1005 (2005)

21. Inder, T. E., L. Buckland, C. E. Williams, C. Spencer, M. I. Gunning, B. A. Darlow, J. J. Volpe \& P. D. Gluckman: Lowered electroencephalographic spectral edge frequency predicts the presence of cerebral white matter injury in premature infants. Pediatrics, 111, 27-33 (2003)

22. Wong, F. Y., C. P. Barfield \& A. M. Walker: Power spectral analysis of two-channel EEG in hypoxic-ischaemic encephalopathy. Early Hum Dev, 83, 379-83 (2007)

23. Thaler, I., R. Boldes \& I. Timor-Tritsch: Real-time spectral analysis of the fetal EEG: a new approach to monitoring sleep states and fetal condition during labor. Pediatr Res, 48, 340-5 (2000)

24. Aziz, S. S., S. J. Wallace, J. F. Murphy, C. P. Sainsbury \& O. P. Gray: Cotside EEG monitoring using computerised spectral analysis. Arch Dis Child, 61, 242-6 (1986)

25. Maynard, D. E.: Development of the CFM: the Cerebral Function Analysing Monitor (CFAM) Ann Anesthesiol Fr, 20, 253-5 (1979)

26. Murdoch-Eaton, D., M. Darowski \& J. Livingston: Cerebral function monitoring in paediatric intensive care: useful features for predicting outcome. Dev Med Child Neurol, $43,91-6(2001)$

27. Tasker, R. C., S. G. Boyd, A. Harden \& D. J. Matthew: The cerebral function analysing monitor in paediatric medical intensive care: applications and limitations. Intensive Care Med, 16, 60-8 (1990)

28. Keunen, H., J. S. Vles, J. L. Van Reempts, D. Gavilanes \& T. H. Hasaart: Effect of repetitive umbilical cord occlusions on neuronal brain activity measured by the cerebral function analyzing monitor and histologic outcome in immature fetal sheep. J Soc Gynecol Investig, 7, 218-23 (2000)

29. Symmes, D., J. W. Prichard \& L. I. Mann: Spectral analysis of fetal sheep EEG during hypoxia. Electroencephalogr Clin Neurophysiol, 29, 511-5 (1970)

30. Gavilanes, A. W., J. S. Vles, K. von Siebenthal, J. P. Reulen, F. H. Nieman, R. van Sprundel \& C. E. Blanco: Electrocortical brain activity, cerebral haemodynamics and oxygenation during progressive hypotension in newborn piglets. Clin Neurophysiol, 112, 52-9 (2001)

31. Gavilanes, A. W., J. S. Vles, K. von Siebenthal, R. van Sprundel, J. P. Reulen \& C. E. Blanco: Neonatal electrocortical brain activity and cerebral tissue oxygenation during nonacidotic, normocarbic and normotensive graded hypoxemia. Clin Neurophysiol, 115, 282-8 (2004)

Key Words: Chorioamnionitis, Fetal Inflammation, Neurological Development, LPS, EEG, CFAM, CNS, EXIT procedure
Send correspondence to: Antonio Wenceslao Danilo Gavilanes, Dept. of Pediatrics, Maastricht University Medical Center, PO Box 5800, 6200 AZ Maastricht, The Netherlands, Tel: 31-43 3876061, Fax: 31-43 3875246, Email: danilo.gavilanes@mumc.nl

http://www.bioscience.org/current/vol2S.htm 


\section{Chapter 5}

Increased number of cerebellar granule cells and astrocytes

in the internal granule layer in sheep following prenatal intra-amniotic injection of

lipopolysaccharide.

Strackx, E., Gantert, M., Moers, V., van Kooten, I.A., Rieke, R., Hürter, H., Lemmens, M.A., Steinbusch, H.W., Zimmermann, L.J., Vles, J.S., Garnier, Y.,

Gavilanes, A.W., Kramer, B.W.

Cerebellum. 2012 Mar;11(1):132-44 


\section{Increased cerebellar granule cell number in sheep following prenatal injection of lipopolysaccharide}

Eveline Strackx ${ }^{1,2}$, Marcus Gantert ${ }^{3}$, Imke A.J. van Kooten ${ }^{1}$, Rebecca Rieke ${ }^{1,2}$, Hanna Hürter $^{1,2}$, Marijke A.M. Lemmens ${ }^{1}$, Harry W.M. Steinbusch ${ }^{1}$, L.J.I. Zimmermann ${ }^{2}$, Johannes SH Vles ${ }^{4}$, Yves Garnier ${ }^{3}$, A.W. Danilo Gavilanes ${ }^{1,2 \#}$ and Boris W. Kramer ${ }^{1,2}$

${ }^{1}$ Department of Neuroscience and European Graduate School of Neuroscience (EURON), Maastricht University, Maastricht, Netherlands, ${ }^{2}$ Department of Pediatrics/Neonatology, Maastricht University Medical Center, Maastricht, The Netherlands, ${ }^{3}$ Department of Obstetrics \& Gynecology, Klinikum Osnabrück, Osnabrück, Germany, ${ }^{4}$ Department of Child Neurology, Maastricht University Medical Center, Maastricht, The Netherlands

${ }^{\#}$ Corresponding author

A.W. Danilo Gavilanes, MD, PhD Maastricht University Medical Center Department of Pediatrics

P. Debyelaan 25 6202 AZ Maastricht The Netherlands

$\mathrm{Ph}:+31-43-387-7246$

Fax: +31-43-387-5246

E-mail:danilo.gavilanes@mumc.nl 


\begin{abstract}
Introduction: Chorioamnionitis is an important problem in perinatology today, leading to brain injury and neurological handicaps. Yet, cerebellar injury due to chorioamnionitis is often overlooked. Therefore, this study aimed to determine if chorioamnionitis causes cerebellar morphological alterations.
\end{abstract}

Methods: Chorioamnionitis was induced by an intra-amniotic injection of lipopolysaccharide (LPS) at a gestational age (GA) of 110 days. At GA 140 days, we investigated the mean total and layer-specific volume and the mean total granule cell (GCs) and Purkinje cell (PC) number in the cerebelli of LPS exposedand control animals, using high precision design-based stereology. Astrogliosis was assessed in the grey matter and white matter (WM) using a GFAP staining combined with grey value image analysis.

Results: The present study showed preserved volumes of the total cerebellum as well as of the molecular layer (ML), outer and inner granular cell layers (OGL and IGL respectively) and WM. Interestingly, compared to controls, the LPS exposedbrains showed a statistically significant increase $(+20.4 \%)$ in the mean total number of GCs, whereas the PCs did not show any difference between the groups. In addition, LPS exposedanimals showed signs of astrogliosis specifically in the IGL.

Conclusion: An intra-amniotic injection of LPS causes morphological changes in the sheep offspring cerebellum at full-term birth. These cerebellar changes might account for some of the motor or non-motor deficits seen in neonates from compromised pregnancies.

Keywords: chorioamnionitis, LPS, intraamniotic, fetal, cerebellum, granule cell loss, astrocytes, stereology 
Abbreviations:

$\begin{array}{ll}\text { GA } & \text { gestational age } \\ \text { GCs } & \text { granule cells } \\ \text { GD } & \text { gestational day } \\ \text { GFAP } & \text { glial fibrillary acidic protein } \\ \text { IGL } & \text { inner granular layer } \\ \text { IL } & \text { interleukin } \\ \text { INF } & \text { interferon } \\ \text { LPS } & \text { lipopolysaccharide } \\ \text { ML } & \text { molecular layer } \\ \text { NF-KB } & \text { nuclear factor kappa B } \\ \text { OGL } & \text { outer granular layer } \\ \text { PC } & \text { Purkinje cells } \\ \text { TLR } & \text { toll-like receptor } \\ \text { TNFa } & \text { tumor necrosis factor alfa } \\ \text { WM } & \text { white matter }\end{array}$




\section{Introduction}

Chorioamnionitis is an important problem in obstetrics today, affecting $20 \%$ of term pregnancies and up to $60 \%$ of preterm deliveries [1]. In addition, chorioamnionitis is associated with premature rupture of membranes and premature labor and delivery [2-4]. It is an important risk factor for adverse outcome, including permanent brain injury and neurological handicaps. Recent clinical data showed that chorioamnionitis is mainly related to cerebral white matter (WM) damage, including disseminated and focal necrosis, cystic lesions, and cerebral palsy [5-9].

The mechanisms by which intrauterine inflammation might cause fetal brain injury are not fully known yet. In human neonates, high concentrations of cytokines, like tumor necrosis factor $\alpha$ (TNF $\alpha$ ), Interleukin (IL) 6 and IL1 $\beta$, in the cord blood and the amniotic fluid increase the risk for periventricular leukomalacia [10] and higher levels of pro-inflammatory cytokines are expressed in the damaged areas of the brain [11, 12]. Animal studies also provide evidence that the antenatal administration of endotoxins, like lipopolysaccharide (LPS), causes a higher systemic cytokine expression, leading to cerebral apoptotic cell death and gliosis in different animal species [13-19]. Therefore, it is though that pro-inflammatory cytokines induce a multi-organ fetal inflammatory response syndrome leading to reactive astrogliosis and the loss of mainly immature oligodendrocytes [20, 21].

Despite the growing body of evidence linking intrauterine inflammation with an adverse neurological outcome, the exact consequences on the central nervous system remain unclear. In particular, cerebellar injury is often overlooked. Research evaluating the role of the cerebellum, especially in non-motor function, is still in its infancy, but there is good evidence that the cerebellum is also involved in cognitive and affective disorders [22-26]. It seems likely that a disturbed development of the cerebellum during pregnancy and its subsequent neonatal damage may play a role in long-lasting motor, cognitive and other behavioral changes.

It is important to know that almost half of the preterm infants with cerebral palsy show abnormalities in the cerebellum [27, 28]. Moreover, the cerebellum is especially vulnerable during late gestation, since this is the period of active proliferation and migration of cerebellar granule cells [29]. Consequently, it is becoming increasingly clear now that injury and impaired development of the cerebellum may be associated with chorioamnionitis, especially in ex-preterm infants [22, 25, 30, 31]. Harmful events, like chorioamnionitis, in this period might potentially interfere with normal 
development of the cerebellar granule cells. In addition, other cerebellar cell population, such as the Purkinje cells, may be influenced by an altered granule cell development [32]. Therefore, it is important to further identify the pathological changes of fetal inflammation in the cerebellum in a clinical relevant experimental animal model. We hypothesize that chorioamnionitis causes changes in the granule cell number and/or Purkinje cell number, associated with astrocytic changes, in the near-term fetal cerebellum.

In this study, we used an intra-amniotic injection of LPS in an ovine model for chorioamnionitis. LPS is a component of a gram-negative bacterial cell wall, which is responsible for most inflammatory responses in common bacterial infections. This model was chosen for several reasons. First, the injection of LPS, especially intravenously, is often associated with circulatory changes in the fetus, causing a secondary hypoxia-ischemia which might contribute to brain damage as well [33, 34]. However, intra-amniotic LPS can cause brain damage in the absence of the superimposed hypoxic-ischemic effect $[19,35,36]$. Second, fetal systemic inflammation has previously been characterized and is well described in this model. An intra-amniotic LPS injection caused an increase in interferon (IFN)Y, IL6 and IL8 in the cord plasma as well as an increase in TNF- $\alpha$ in the spleen [37]. Third, sheep have a long gestation, with several developmental anatomical and functional aspects of the fetal brain comparable to the humans. In this study, LPS was injected at 110 days of ovine gestation which is more or less similar to 28 weeks in human fetus.

The purpose of this study was to determine if chorioamnionitis, induced by an intra-amniotic LPS injection, caused changes in cerebellar volumes and neuron numbers. To achieve this, $10 \mathrm{mg}$ of LPS was injected intra-amniotically at 110 days of gestation (term $\approx 147$ days). At 140 days, cerebellar volumes, granule cell number and Purkinje cell numbers were assessed using design-based stereology and astrogliosis was determined using a semi-quantitative image analysis method. 


\section{Materials and Methods}

\section{Animals}

All experimental procedures were approved by the Animal Ethics Board of the University of Maastricht according to Dutch governmental regulations. Time-mated pregnant Texel ewes with singleton pregnancies were randomly assigned to the different groups. LPS was administered ultrasound-guided injections as previously described [38]. Each ewe received a single dose of $10 \mathrm{mg}$ LPS (Escherichia coli 055:B5; Sigma-Aldrich, St. Louis, MO, USA) at gestational day (GD) 110. Before administration, the endotoxin was solubilized in $2 \mathrm{ml}$ saline and filtered through a $0.45 \mu \mathrm{m}$ filter. Intra-amniotic injections were given into the amniotic cavity using ultrasound guidance. Control animals were treated identically, but were injected with a single dose of saline into the amniotic fluid. Preterm lambs were delivered at GD 140 (term is $\approx$ GD147) by Caesarean section, and sacrificed by decapitation.

\section{Tissue processing}

After opening the skull, brains were removed rapidly and halved in the mediosaggital line. The left cerebellum was immersion-fixed in $4 \%$ formalin for 3 months, cryoprotected $(10 \%, 20 \%$, and finally $30 \%$ sucrose in $0.1 \mathrm{M}$ Tris- $\mathrm{HCl}$ buffer $24 \mathrm{~h}$ per solution at $4^{\circ} \mathrm{C}$ ), embedded in Tissue-tek $\AA$ (Sakura Finetek), quickly frozen and stored at $-80^{\circ} \mathrm{C}$ until further processing. Complete series of $50 \mu \mathrm{m}$-thick coronal sections were cut on a cryostate (Leica CM 3050; Leica, Nussloch, Germany). These sections were used for immunohistochemistry (GFAP).

The right cerebellum was frozen on a metal block in melting liquid nitrogen, and stored at $-80{ }^{\circ} \mathrm{C}$ until further processing. The cerebellum was entirely cut into complete series of $100 \mu \mathrm{m}$-thick coronal sections on a cryostate (Leica CM 3050; Leica, Nussloch, Germany). These series of sections were then divided into subseries of every 2 nd section, yielding 2 series of 11 to 14 sections containing the cerebellum per animal. These sections were used for stereological analyses (Hoechst and Nissl staining).

\section{Immunohistochemistry}

Another series of every twelfth section of the left cerebellum was collected for immunohistochemical detection of glial fibrillary acidic protein (GFAP). Immunohistochemistry was carried out in a free floating manner. Briefly, GFAP labeling was conducted by incubating the sections 24 hours with primary antibody (rabbit anti-GFAP; 1:1600; DAKO, Glostrup, Denmark) at room temperature after rinsing with $0.01 \mathrm{M}$ Tris-Buffered Saline (TBS) and 0.01M Tris-Buffered Saline with $0.2 \%$ Triton $\mathrm{X}-100$ (TBS-T) and blocking endogenous peroxidise activity with $0.3 \%$ 
$\mathrm{H}_{2} \mathrm{O}_{2}$. Following incubation and rinsing with $0.01 \mathrm{M}$ TBS and TBS-T the sections were incubated in biotyinylated seconday IgG antibodies (biotinylated donkey anti-rabbit IgG, 1:1800; Jackson, West Grove, PA, USA) for 2 hours at room temperature (RT), followed by ABC-kit (2 hours at RT; Vectastain, Burlingame, CA, USA). The sections were then simultaneously incubated with 3,3'-Diaminobenzidine (Sigma, Ulthoorn, Netherlands) containing $0.03 \% \mathrm{H}_{2} \mathrm{O}_{2}$ in Tris- $\mathrm{HCl}$ for $5 \mathrm{~min}$ at RT. Sections were rinsed with TBS and TBS-T, mounted on gelatinized glass slides, and dried overnight at RT. After dehydration the sections were coverslipped using DePeX (Serva, Heidelberg, Germany).

\section{Stereological analysis}

One series of every twelfth section of the right cerebellum was collected, mounted on glass slides (Superfrost Plus, Menzel, Braunschweig, Germany), dried, defatted with Triton $\mathrm{x}-100$ (0.025\%; $20 \mathrm{~min}$; Merck) and stained with cresyl violet (0.01\%, $5 \mathrm{~min})$. Slides were mounted and coverslipped using DePex (Serva, Heidelberg, Germany). These sections were used for volume measurements of the whole cerebellum and its layers, and for the total number of granule cells in the inner granular cell layer (IGL). See figure $2 \mathrm{~A}$ and $\mathrm{B}$ for an examples of Nissl stained sections.

Another series of every twelfth section of the right cerebellum was collected, mounted on glass slides (Superfrost Plus, Menzel, Braunschweig, Germany), dried, and $15 \mathrm{~min}$ post-fixed using Somogy fixation (0.2 M phosphate buffer, $20 \%$ paraformaldehyde (PF), picric acid, and $25 \%$ glutaraldehyde $(\mathrm{pH} 7.4))$. After rinsing, sections were stained 30 min with Hoechst (1:500, Sigma Chemical Co., St. Louis, $\mathrm{MO}$, USA) and mounted with $80 \%$ glycerol in TBS. These sections were used for investigation of the total number of Purkinje Cells (PCs). See figure 1B for an example of a Purkinje cell and see figures $2 C$ and $D$ for an example of the Hoechst staining.

All stereologic analyses were performed with a computerized stereology workstation, consisting of a modified light microscope (Olympus BX50 with PlanApo objective $1.25 \times$ [numerical aperture (N.A.) $=0.04$ ] and UPlanApo objective $20 \times$ [oil; N.A. = 0.8]; Olympus, Tokyo, Japan), motorized specimen stage for automatic sampling (Ludl Electronics; Hawthorne, NY, USA), CCD color video camera (HVC20AMP; Hitachi, Tokyo, Japan), and stereology software (Stereolnvestigator; MBF Bioscience, Williston, VT, USA). Using NissI stained sections of the right cerebellum, delineations for volume measurements of regions within the cerebellum, i.e. the inner and outer granular cell layer (IGL and OGL respectively), molecular layer (ML), and WM were analyzed using the Cavalieri's principle $[39,40]$ and point counting $[40$, 41]using a $1.25 x$ objective. De delineation is shown in figure $1 \mathrm{~A}$. Total numbers of granule cells in the IGL (using Nissl stained sections) and PCs (using sections 
stained with Hoechst) were estimated with the Optical Fractionator [40, 42]. All neurons whose nucleus top came into focus within unbiased virtual counting spaces distributed in a systematic-random fashion throughout the delineated regions were counted $[40,41]$. Then, total neuron numbers were calculated from the numbers of counted neurons and the corresponding sampling probability. All details of the stereological analysis are summarized in table 1.

\section{Glial Fibrillary acidic protein (GFAP) image analysis}

It was impossible to differentiate accurately between individual GFAP-positive cell bodies, because of a high astrocytes density. Therefore, it was not possible to use design-based stereology for this analysis. Therefore, GFAP immunohistochemistry in the IGL, the ML and the WM was measured by a semi-quantitative method. Three photographs were taken from each stained section within the different layers with the Olympus AX70 microscope connected to a digital camera (F-view, Olympus, Tokyo, Japan). To correct for potential variability in lighting conditions, all images were collected under identical conditions. Photographs were analyzed, using their corresponding average grey values (ranging from 0-black to 255-white) and the \%area positive for GFAP staining, obtained with the $\mathrm{NIH}$ ImageJ software (http://rsb.info.nih.gov/ij/). Using a trial and error method, a threshold value was selected and kept the same for all measurements. Blood vessels, tissue out of focus or artifacts were excluded.

\section{Photography}

Photomicrographs shown in Figures 1 and 2 were produced by digital photography a MBF Bioscience Stereo Investigator Confocal Spinning Disk (SI-SD) system (MBF Bioscience; Williston, VT), consisting of a modified Olympus BX51 fluorescence microscope (Olympus, Tokyo, Japan) with UPlanSApo objectives 4x (N.A. = 0.16), $10 \times(N . A .=0.4), 20 \times(N . A .=X X)$ and $60 \times(N . A=0.9)$; Olympus $)$, customized spinning disk unit (Olympus), computer-controlled excitation and emission filter wheels (Olympus), three-axis high-accuracy computer-controlled stepping motor specimen stage (4x4 Grid Encoded Stage; Ludl Electronic Products, Hawthorne, NY), linear z-axis position encoder (Ludl), ultra-high sensitivity monochrome electron multiplier CCD camera (1,000 × 1,000 pixels, C9100-02; Hamamatsu Photonics, Hamamatsu City, Japan) and controlling software (MBF Bioscience). On average approximately 170 images were captured for the composite in each Fig. $1 \mathrm{~A}$, and $\mathrm{XX}$ images for the composite in each Fig. 1B. These images were made into one montage using the Virtual Slice module of the Stereolnvestigator software. The final figure was constructed using Corel Photo-Paint v.11 and Corel Draw v.11 (Corel, Ottawa, Canada). Only minor adjustments of contrast and brightness were made, 
without altering the appearance of the original materials.

\section{Statistical analysis}

Mean and standard error of the mean were calculated for both LPS injected and control animals for all investigated parameters. For each parameter normality was tested using a Kolmogorov-Smirnov test. All results were distributed normally. Comparisons between LPS injected and control animals were performed using generalized linear model multivariate analysis (MANOVA), with diagnosis as fixed factor and the gender as covariate. Statistical significance was established at $p<0.05$. Calculations were performed using Statistical Package for the Social Sciences (SPSS; Version 15.0 for Windows; SPSS, Chicago, IL, USA) and GraphPad Prism (Version 4.0 for Windows, GraphPad software, San Diego, CA, USA. 


\section{Results}

\section{Volume measurements}

The total cerebellum including the outer granular layer (OGL), the inner granular layer (IGL), the molecular layer (ML) and the WM of the LPS exposed and control animals were identified on all analyzed sections showing these regions according to figure 1. Figure 4 depicts the mean volumes of the total cerebellum (fig $4 a$ ) as well as the OGL (fig4b), the IGL (fig4c), the ML (fig 4d) and the WM (fig 4e). No significant differences were found between the LPS exposed and control animals for any of the areas.

\section{Granule cell and Purkinje cell numbers}

Figure 5 shows the mean number and density of granule cells (GCs; fig 5a-b) and the mean number of Purkinje cells (PC; fig $5 \mathrm{c}$ ). The LPS exposed animals showed a significantly increased mean total number of GCs in the IGL $\left(+20.4 \% ; F_{(1)}=11.3, p=\right.$ $0.015)$, whereas there was no significant difference in the mean total PC number between the two groups. In addition, no alterations were found between the LPS exposed and control animals with respect to the mean density of the GCs and the ratio between GCs and PCs ratio (fig $5 d$ ). The statistical analysis showed no significant effect of the covariate gender on the investigated variables (data not shown).

\section{GFAP immunoreactivity}

Astrocytes showed a strong GFAP immunoreactivity in both cell bodies and processes in brains from LPS injected animals as well as controls, and were found in all layers of the cerebellum, i.e. OGL, ML, IGL and WM, as depicted in figure 3. In figure 6 the results of GFAP immunoreactivity analysis are given. LPS exposed animals showed a significantly lower grey value (0-black and 255-white), meaning a darker staining, than control animals ( $p=0.0268$; fig 6a). In addition, LPS exposed animals also had a higher surface area (\%area) of GFAP-positive astrocytes $(p=0.0436$; fig 6d). 


\section{Discussion}

This study is the first detailed investigation of the effects of chorioamnionitis on neuron numbers in the fetal ovine cerebellum using design-based stereology. Chorioamnionitis, induced by an intra-amniotic LPS injection at 110 days of gestation, resulted in different morphological alterations in the term cerebellum. In detail, chorioamnionitis caused a massive increase $(+20.4 \%)$ in the number of cerebellar granule cells in the inner granular layer, while no alterations were found in the Purkinje cell number or the volume estimates of the different cerebellar layers. In addition, the GFAP immunoreactivity - in terms of grey value and \%area of positive staining - was also increased specifically in the inner granular layer.

Experimental data on the pathological effects of fetal inflammation or infection on the developing cerebellum are extremely scarce and limited to the use of either uteroplacental or fetal LPS administration in sheep [43, 44]. An injection of LPS in the uterine artery during late gestation ( \pm 135 days) resulted in lipid peroxidation in all cerebellar cortical layers and WM, as shown by a strong 4-HNE immunoreactivity and a compromised cerebellar blood-brain barrier as suggested by the extravasation of plasma albumin [43]. In addition, these fetuses showed a dose-dependent increase in the number of GFAP-positive astrocytes in the cerebellar WM and the granular layer and higher numbers of capase 3-positive cells in the WM and molecular layer [43]. In contrast, a fetal intravenous injection of LPS at 93-96 days of gestation merely caused confined WM injury in the absence of obvious grey matter damage [44]. Cerebellar WM injury was demonstrated by the loss of oligodendrocytes, activated microglia and an increased number of caspase 3 and TUNEL-positive cells [44]. As opposed to that study, Duncan and colleagues could not find clear cerebellar WM injury in the same model [45]. The discrepancies between the different injury patterns found in our study and the studies described above might be explained by differences in the experimental set-up, like the timing of the insult with respect to brain maturity or the route and the dose of LPS administration, which were different for all studies. For example, different regions within the central nervous system might be vulnerable during different periods of development.

Because many studies clearly demonstrated that fetal inflammation, and in particular pro-inflammatory cytokines, induced neuronal cell loss, chorioamnionitis in this study was expected to trigger cell death leading to the loss of cerebellar neurons $[38,43,44,46]$. On the contrary, we observed an increase in the number of granule cells in the IGL of the cerebellum. A similar result was previously found in 
hippocampus. Golan et al. reported an increase in hippocampal pyramidal and granular cells in mice offspring after maternal inflammation [47]. The inconsistency of both studies with the current literature might be explained by the different experimental time lines. Most reports studied the acute effects of inflammation shortly after the administration of the toxic agent $[38,43,44,46]$. In our study, however, the analyses were done 30 days after the LPS injection, creating a time frame for the execution of possible recovery processes. Therefore, these rather unexpected findings might reflect the activation of a regenerative process to replace lost cells or an imbalance between developmental proliferation and apoptosis, disturbing proper development. The increase in cerebellar granule cells might be caused by enhanced proliferation, enhanced cell survival or a reduced level of developmental apoptosis. Which of these explanations might hold true awaits further research though. The further use of markers as caspase 3 and Ki67, for respectively apoptosis and proliferation, might provide an indication of whether this balance is altered. Nevertheless, Hutton et al. already demonstrated an increased number of Ki67 proliferative cells in the sheep brain after an utero-placental infection [48]. In addition, a rapid period of cerebellar growth takes place, particularly during the third trimester [30]. This rapid growth phase might render the cerebellum especially vulnerable in this period. Late gestation is also characterized by a prominent proliferation and migration of cerebellar granule cells [49]. Therefore, the possibility that an infectious challenge may be associated with perturbations in normal growth and development by altering the 'proliferation-apoptosis balance' does not seem that farfetched. Of note, apoptotic cell death and proliferation share common events within their biochemical pathways, like c-fos and p53 [50-54]. There is now compelling evidence that apoptosis is a process closely linked to the cell cycle and that cell originally destined to die may transiently re-enter the cell cycle (as reviewed in [55-57]). In this perspective, Bossenmeyer et al. showed that mild hypoxia led to an increased number of neurons by promoting mitotic activity, while severe hypoxia led to a decreased number probably by aborting mitosis and proceeding on to apoptotic death $[52,53]$. A similar situation might be going on with chorioamnionitis.

No changes were found in the mean number of Purkinje cells, which is inconsistent with the current thoughts. It is now generally accepted that Purkinje cells are especially vulnerable in the developing brain. Purkinje damage and cell death has often been reported after asphyxia/hypoxia in experimental animal models and human, as well as after an infectious challenge [43, 58-61]. The absence of changes in the Purkinje cell layer might be explained by the fact that, in sheep, Purkinje cells are already present as a single layer by approximately 100 days of gestation, while 
chorioamnionitis is only induced 10 days later (110GA) [29]. Formation of the inner granule layer, however, takes place within this exact time window with completion of the layer by day 120 of gestation [29].

Although the mechanisms causing fetal cerebellar changes in this model are unidentified, it is generally known that LPS, a pyrogenic component of Gram negative bacteria, induces a downstream cascade of inflammatory responses via toll-like receptor 4 (TLR4) and nuclear factor-kappa B (NF-KB) activation, stimulating macrophages to produce large amounts of cytokines [62-65]. Therefore, the effects of LPS are similar to those observed with infection, but without causing invasion or multiplication of micro-organisms in the body [34,66]. Work by Kallapur et al. and Kramer et al. already demonstrated that an intra-amniotic LPS injection causes chorioamnionitis, as shown by an increased number of granulocytes in the amniotic fluid and the accumulation of inflammatory cells in the chorion/amnion [37, 67]. This histological chorioamnionitis was associated with an enhanced pro-inflammatory cytokine production, such as TNF- $\alpha, \mathrm{IL}-1, \mathrm{IL}-6$ and IL-8, in the chorion/amnion [67]. Systemic inflammation has also been characterized in this model. Kramer et al. showed an increase in IFN- $\gamma, \mathrm{IL}-6$ and IL-8 in the cord plasma as well as an increase in TNF- $\alpha$ in the spleen [37]. Interestingly, chorioamnionitis also induced the maturation of immune cells $[68,69]$. In the brain, the transfer of maternal, placental, amniotic and/or fetal cytokines might take place across an either intact or disrupted blood-brain barrier and native cytokines might be produced by stimulated astrocytes and microglia [70-72]. Conventionally, the main function of these pro-inflammatory cytokines is a contribution in the immune response, but recently it was demonstrated that cytokines may also play an important role in neuron development and function. TNF- $\alpha$ is involved in the regulation of hippocampal development, neuron growth and survival, while IL-1 has shown to affect synaptic plasticity [73-77] and IL-6 has been shown to enhance survival of cultured neurons $[78,79]$. Furthermore, proinflammatory cytokines, like IL-6, elevate the calcium response due to elevated calcium release in the cell [80]. This may lead to increased proliferation of immature cerebellar granule cells as was shown in in vitro experiments [81, 82]. In addition, IL6 shares a common intracellular subunit with neuronal growth factors, like CNTF and LIF, suggesting that the IL-6 might likely affect neuronal development in that way as well $[83,84]$.

Moreover, the increase in granule cell numbers might be regulated by neurotrophic growth factors. For instance, granule cells express BDNF receptors [85, 86] and many studies show that BDNF is critical in the control of granule cell development [87-91]. Both BDNF and NGF are known to be up-regulated after injury and they are 
able to exert protective effects probably as part of a regeneration process [92-94]. Additionally, it is assumed that IGF-I helps granule cells to migrate from the proliferative zone in the EGL to their final destination in the IGL [95]. Overexpression of IGF-I, which is normally synthesized and released by Purkinje cells, stimulates cerebellar overgrowth as indicated the increased number of granule cells, most likely by attenuating apoptosis [96]. Many other factors have nowadays been identified that inhibit granule cell apoptosis or promote survival, like neurotrophic factors 4 and 5 and the excitatory neurotransmitter glutamate [97-99].

Of note, it is often suggested that an intrauterine infection can affect the immature brain, not only by the production of pro-inflammatory cytokines, but also by inducing cerebral hypoperfusion, leading to hypoxic-ischemic brain damage [33, 34, 100, 101]. Previous studies, however, already demonstrated that the intra-amniotic LPS strategy used in this study avoids the superimposed hypoxia-ischemia. As demonstrated by Jobe et al., fetal arterial $\mathrm{pH}$ and arterial carbon dioxide tension were not altered [35] and Nitsos et al did not find changes in fetal oxygen tension and oxygen saturation $[19,36]$. For that reason, it seems unlikely that the cerebellar changes in this study could be partly attributed to hypoxic secondary cardiovascular effects.

Besides neuronal changes, this study also showed an increase in GFAP immunoreactivity giving evidence of clear astrocytic response, specifically in the inner granule cell layer. Astrocytes have been shown to respond to harmful stimuli may times before. Uteroplacental inflammation in sheep also resulted in an increase in the number of GFAP-positive cell bodies in the granule layer [43]. In addition, enhanced GFAP immunoreactivity in the cerebellum was also reported as a reaction to other insults, like hypoxia or chronic placental insufficiency in different fetal animal models $[60,102]$. The precise role of astrogliosis still remains unclear. It has been suggested that astrogliosis is a response to neuronal death to replace the lost neurons for quite some time. Recent evidence suggests, however, that the process of astrogliosis has detrimental effects. Glial tissue might interfere with the normal functioning of neuronal circuits by inhibiting regeneration and causing electrical instability [103]. In contrast, astrogliosis is also suggested to be beneficial. Reactive astrocytes are believed to reestablish a protective barrier, namely the glial limiting membrane. In this way, they may assist injured neurons by stabilizing the surrounding environment, i.e. by producing neurotrophic factors promoting neuronal survival [103, 104]. In addition, neurons are highly dependent on the functioning of astrocytes for nutrition and maintenance of oxygen supply [105]. For that reason, a rise in reactive astrocytes might be important factor during recovery. 
Summarizing, the current data clearly show that chorioamnionitis in the fetal sheep results in important, but paradoxical morphological alterations in the cerebellum. Translation of these in vivo results to the clinical practice is very complex. It is not clear yet, if these cerebellar changes are associated with an adverse neurodevelopmental outcome. Although cerebellar injury is often overlooked, it is now becoming increasingly recognized that cerebellar pathology is linked to an wide range of deficits, like motor, social and cognitive disorders [23, 106, 107]. The cerebellum is also implicated in neuropsychiatric disorders such as autism, schizophrenia, major depression, bipolar disorder, obsessive compulsive disorder and many more (reviewed in [24]). Therefore the cerebellar changes seen in this study might account for some of the motor or non-motor deficits seen in neonates from pregnancies compromised by intrauterine infection and inflammation. 
Table 1. Details of the stereologic analysis procedures.

\begin{tabular}{|l|ccccccc|}
\cline { 2 - 8 } \multicolumn{1}{c|}{} & $\begin{array}{c}\text { Obj. } \\
\mathbf{1}\end{array}$ & $\begin{array}{c}\text { sla-x, } \\
\text { sla-y } \\
{[\mu \mathrm{m}]}\end{array}$ & $\begin{array}{c}\sum \mathrm{P} \\
\text { OGL }\end{array}$ & $\begin{array}{c}\sum \mathrm{P} \\
\text { ML }\end{array}$ & $\begin{array}{c}\sum \mathrm{P} \\
\text { IGL }\end{array}$ & $\begin{array}{c}\sum \mathrm{P} \\
\text { WM }\end{array}$ & $\begin{array}{c}\sum \mathrm{P} \\
\text { Total }\end{array}$ \\
\hline Volumes & $1.25 \mathrm{x}$ & 500 & 9.681 & 13.839 & 25.152 & 9.100 & 57.772 \\
\hline
\end{tabular}

\begin{tabular}{|c|c|c|c|c|c|c|c|c|c|}
\hline & $\begin{array}{c}\text { Obj. } \\
2\end{array}$ & $\begin{array}{l}\text { sln-x, } \\
\text { sln-y } \\
{[\mu \mathrm{m}]}\end{array}$ & $\begin{array}{c}a \\
{\left[\mu m^{2}\right]}\end{array}$ & $\begin{array}{c}\mathrm{h} \\
{[\mu \mathrm{m}]}\end{array}$ & $\begin{array}{c}\mathrm{d} \\
{[\mu m]}\end{array}$ & $\sum O D$ & $\sum N$ & $\begin{array}{c}\mathrm{t} \\
{[\mu \mathrm{m}]}\end{array}$ & $\mathrm{CE}_{\text {pred. }}[\mathrm{n}]$ \\
\hline \multirow{2}{*}{$\begin{array}{l}\text { GCs } \\
\text { PCs }\end{array}$} & $20 x$ & 1700 & 10 & 10 & 4 & 224 & 699 & 8.8 & 0.038 \\
\hline & $20 x$ & 500 & 60 & 60 & 4 & 394 & 466 & 12.9 & 0.046 \\
\hline
\end{tabular}

OGL, outer granular cell layer; ML, molecular layer; IGL, inner granular cell layer; WM, white matter. Obj. 1, objective used for delineating the regions of interest and point counting; sla-x and sla-y, distance between the points used for volume estimates in mutually orthogonal directions $x$ and $y ; \sum P$, average number of points counted; GCs, granule cells; PCs, Purkinje cells; Obj. 2, objective used for counting neurons; sln-x and sln-y, distance between the unbiased virtual counting spaces used for counting neurons in mutually orthogonal directions $x$ and $y$; a and $h$, base and height of the unbiased virtual counting spaces; d, depth within the section at which the unbiased virtual counting spaces were placed; $\Sigma O D$, average number of unbiased virtual counting spaces used; $\sum \mathrm{N}$, average number of neurons counted; $t$, measured actual average section thickness of the sections after histological processing; $\mathrm{CE}_{\text {pred. }}[\mathrm{n}]$, average predicted coefficient of error of the estimated total neuron numbers using the prediction method described by [40]. 

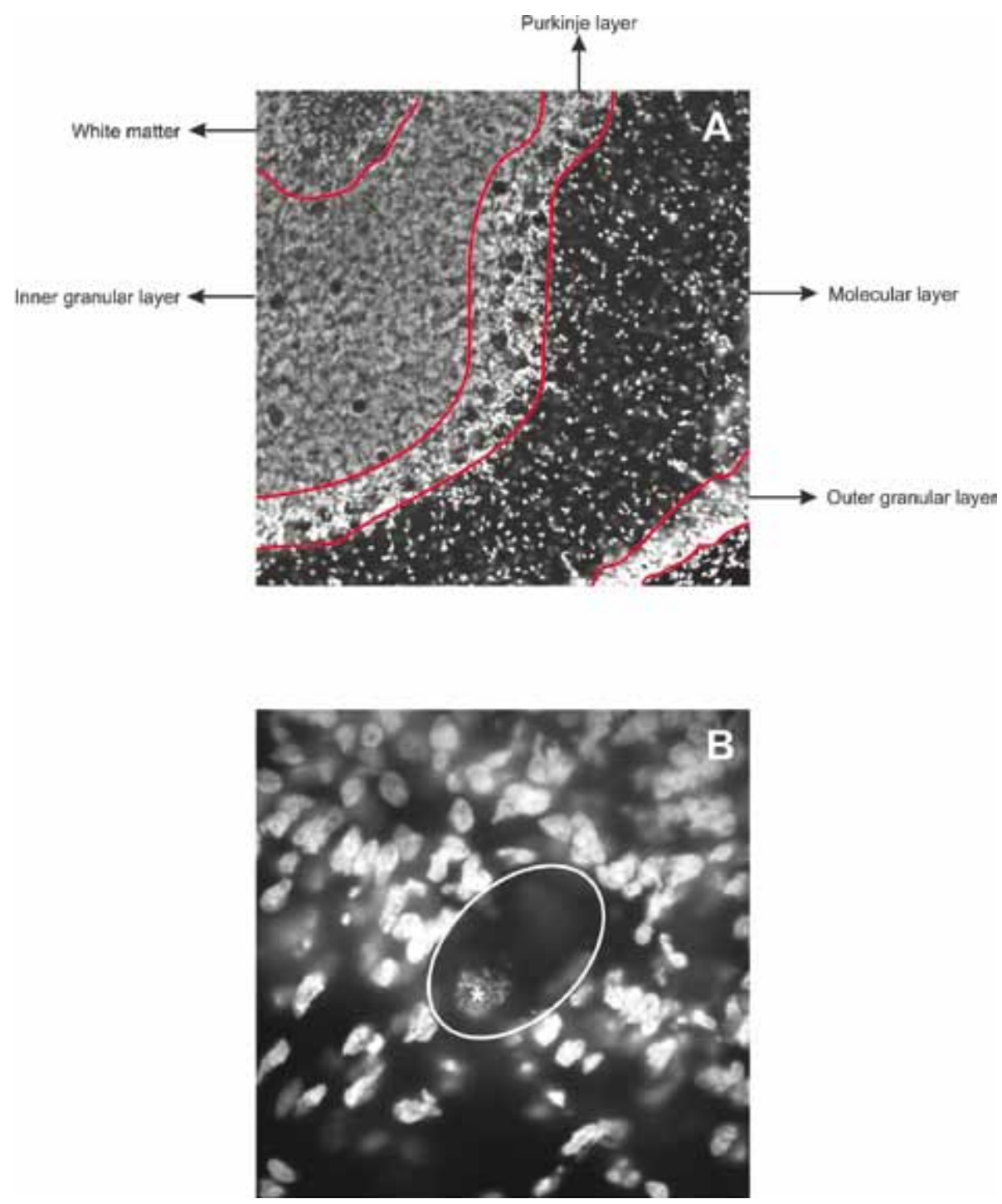

Figure 1. Delineations method

(A) An example of the delineation of the different layers of the cerebellum in a Hoechst stained section. (B) An example of a Purkinje cell in a Hoechst stained section (asterisk is nucleus) 

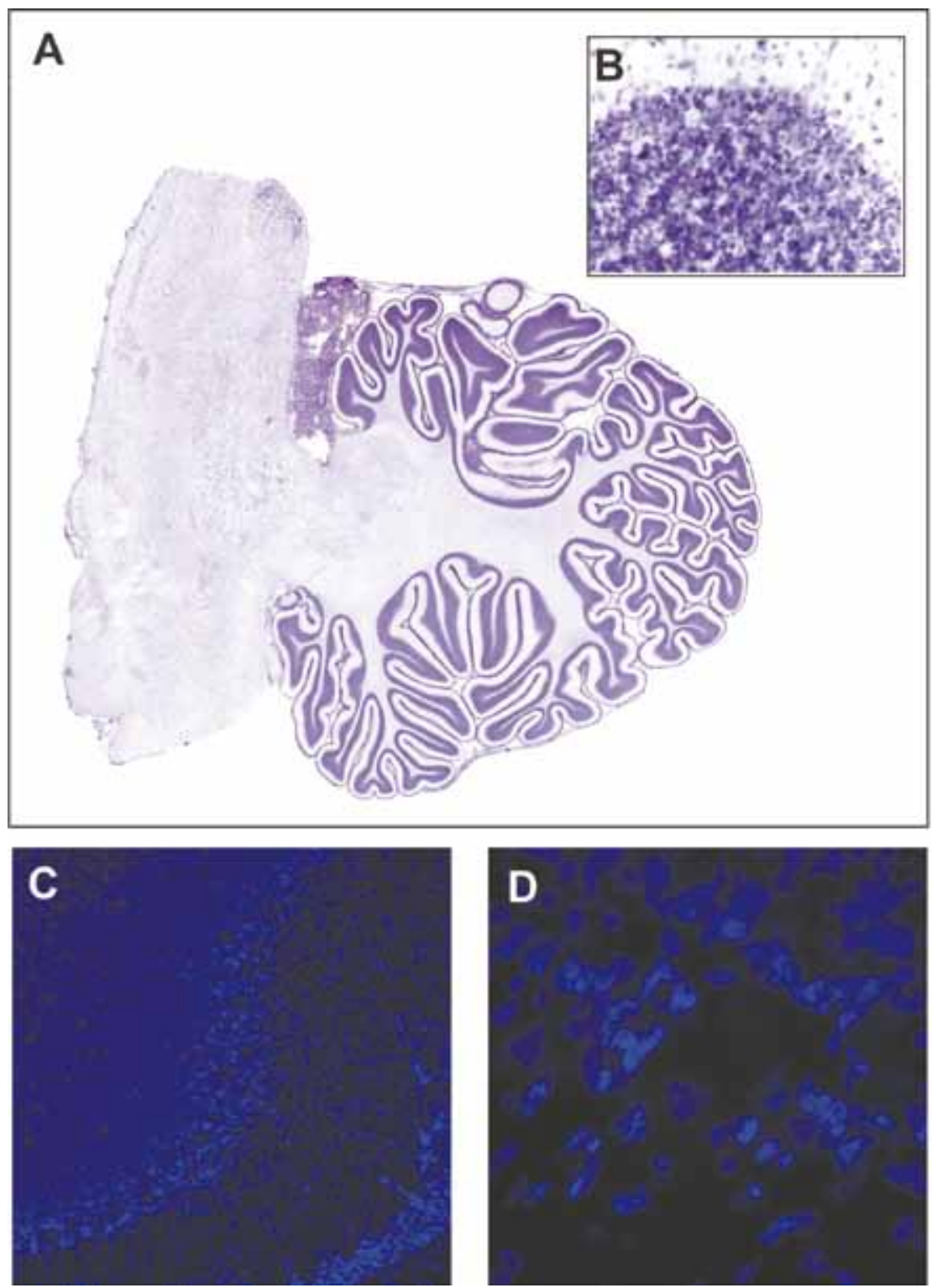

Figure 2. Photomicrographs of Nissl and Hoechst stained sections

(A) An example of a virtual slide of a Nissl stained section of the cerebellum. (B) A 20x magnification example of a Nissl stained section used to count granular cells (C-D) An example of a Hoechst stained section at a low $(20 x ; C)$ magnification showing the different cerebellar layers and high (100x; D) magnification used to count Purkinje cells. 

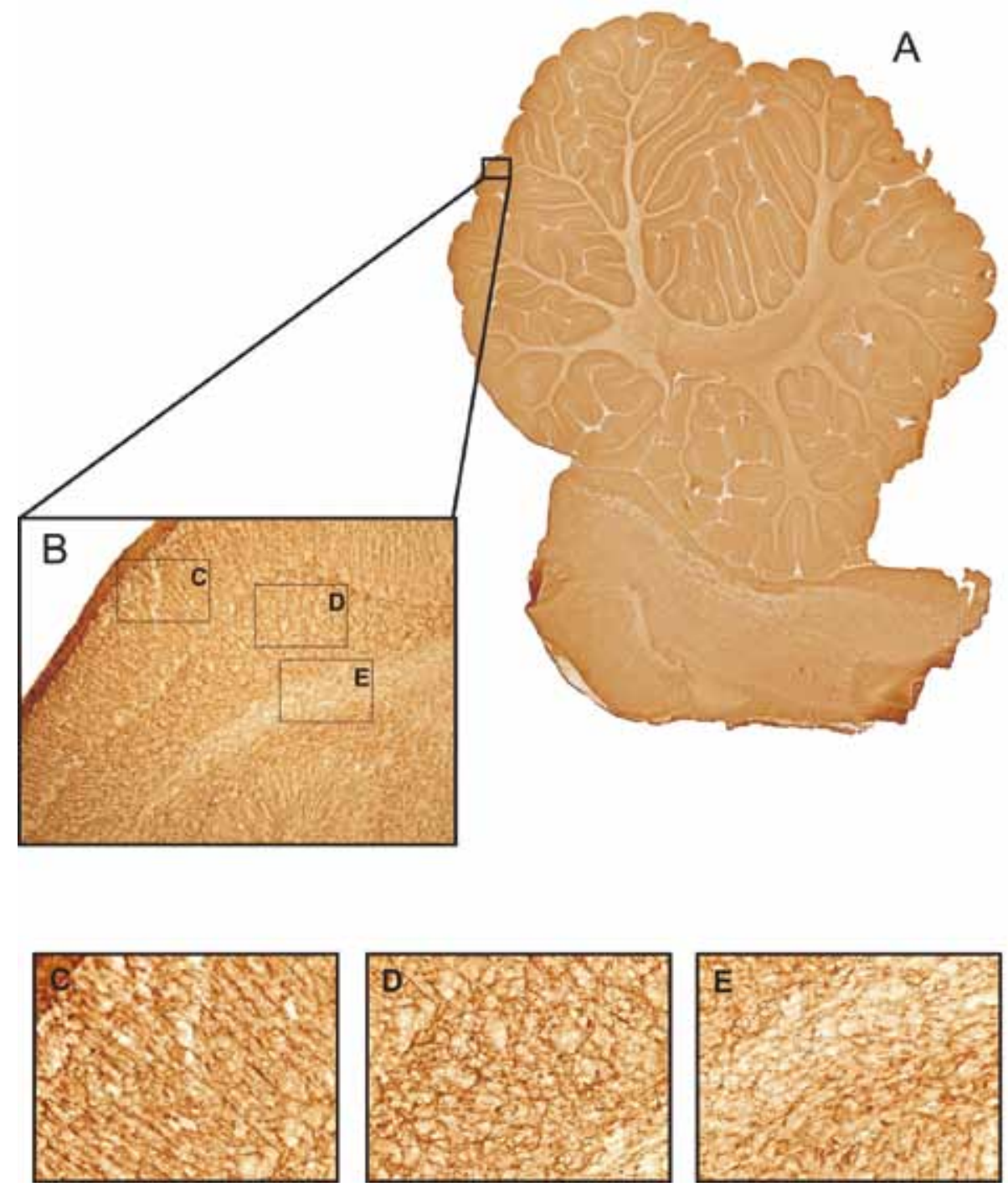

Figure 3. Photomicrographs GFAP

(A) An example of a virtual slide of GFAP stained section of the cerebellum. (B) An example of a 10x magnification photograph of the GFAP staining showing the different layers of the cerebellum. (C-E) High magnification photographs (40x) of the molecular layer with the radial glial fibers (Bergmann glia) (C), the granular layer (D) and the white matter (E). 

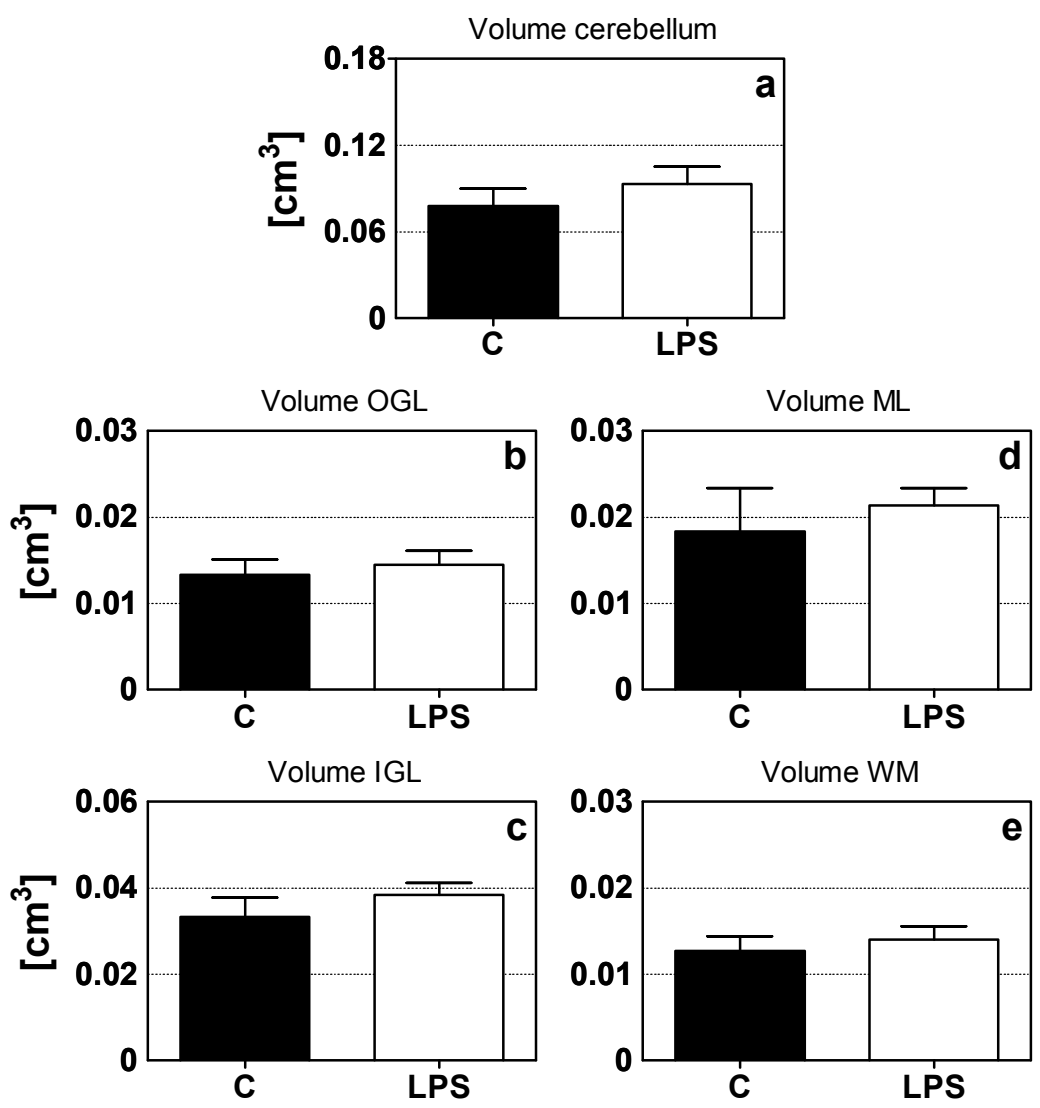

Figure 4. Cerebellar and layer-specific volume measurements

The volumes of the entire cerebellum (a), outer granular cell layer (b), inner granular cell layer (c), molecular layer (d), and white matter (b) of control (closed bars) and LPS exposedanimals (open bars). No significant differences were found between the LPS exposedand the control animals for any of the areas. Abbreviations: OGL: outer ganular layer; IGL: inner granular layer; ML: molecular layer, WM: white matter. 

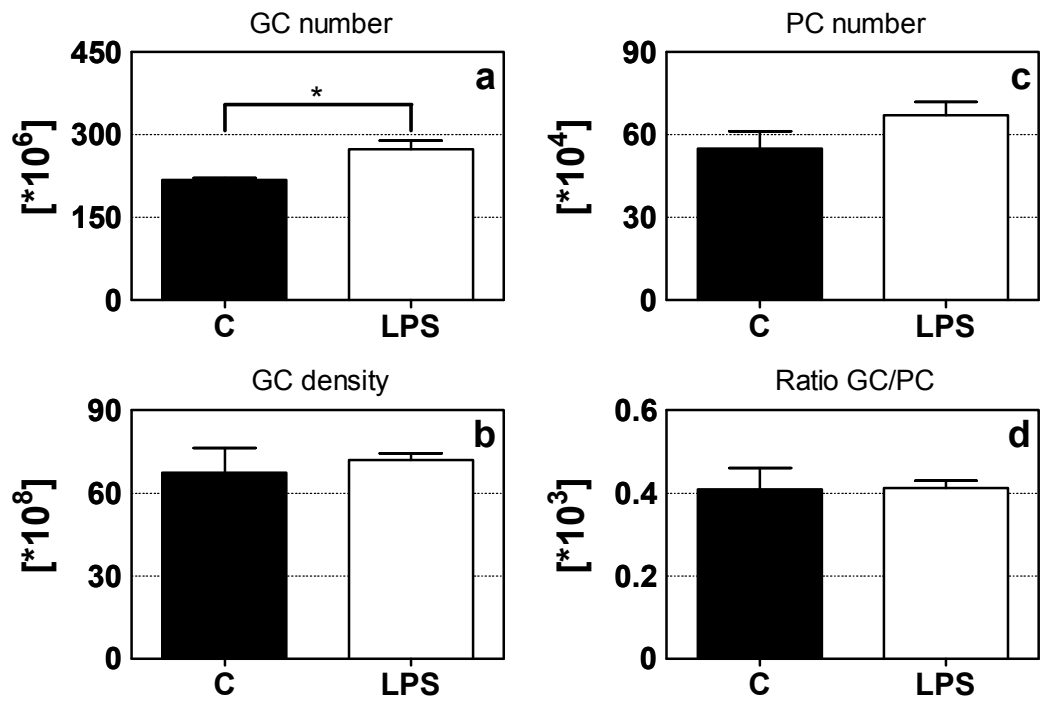

\section{Figure 5. Granule cell and Purkinje cell numbers}

The mean total granule cell number (a) and density (b), mean total Purkinje cell number (c), and the ratio between granule cells/Purkinje cells (d) of control (closed bars) and LPS exposedanimals (open bars). LPS injected animals had significantly more granule cells than control animals. ${ }^{*} p<0.05$; multivariate analysis of variance (MANOVA). Abbreviations: GC: granule cells; PC: Purkinje cells. 

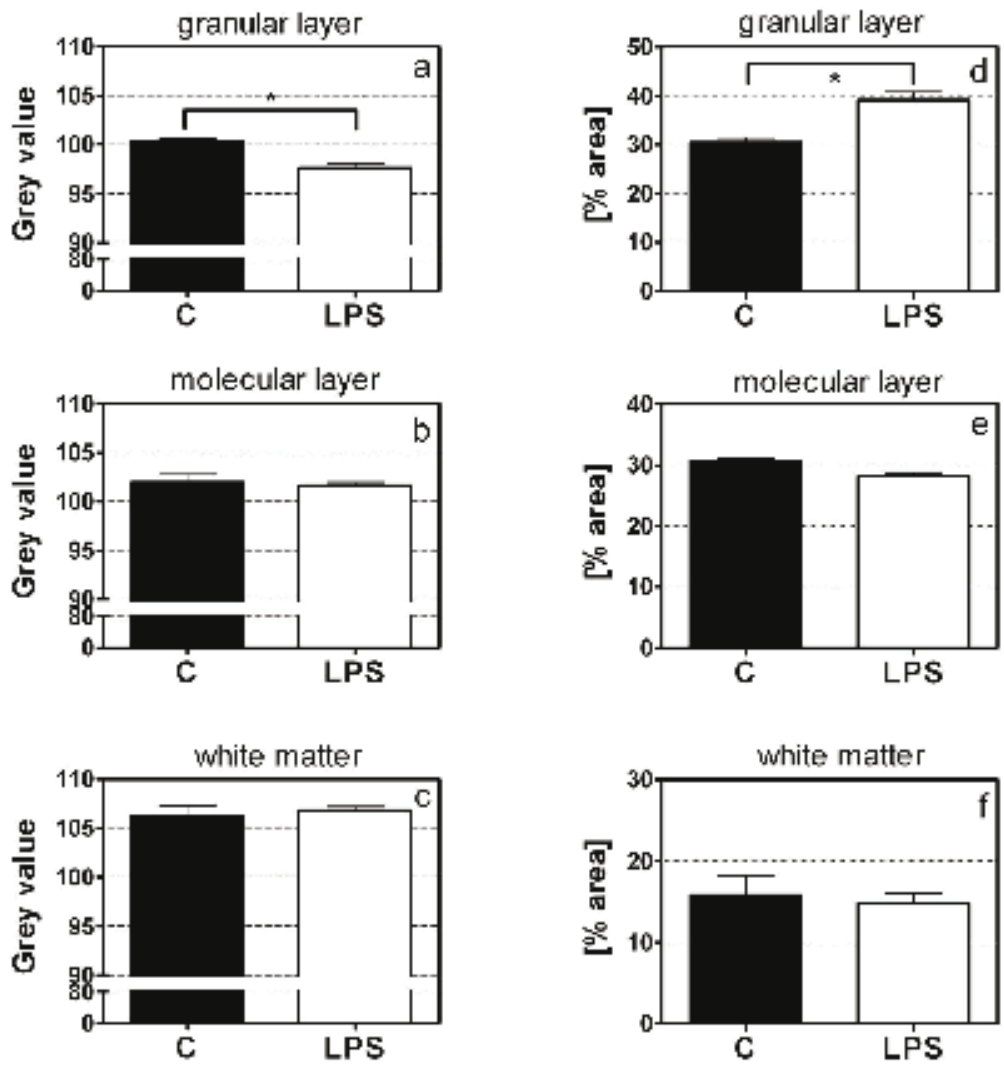

\section{Figure 6. GFAP immunoreactivity}

GFAP immunoreactivity was measured as grey values (a-c) and \% area of positive staining (d-f) in the inner granular layer, molecular layer and white matter. LPS exposedanimals had a significantly lower grey value (a) and a significantly higher \%area (d) of GFAP-positive astrocytes in comparison to control animals. ${ }^{*} p<0.05$; multivariate analysis of variance (MANOVA). 


\section{References}

1. Lahra, M.M. and H.E. Jeffery, A fetal response to chorioamnionitis is associated with early survival after preterm birth. Am J Obstet Gynecol, 2004. 190(1): p. 147-51.

2. Greci, L.S., et al., Is amniotic fluid analysis the key to preterm labor? A model using interleukin-6 for predicting rapid delivery. Am J Obstet Gynecol, 1998. 179(1): p. 1728.

3. Yoon, B.H., et al., Serum C-reactive protein, white blood cell count, and amniotic fluid white blood cell count in women with preterm premature rupture of membranes. Obstet Gynecol, 1996. 88(6): p. 1034-40.

4. Yoon, B.H., et al., Maternal blood C-reactive protein, white blood cell count, and temperature in preterm labor: a comparison with amniotic fluid white blood cell count. Obstet Gynecol, 1996. 87(2): p. 231-7.

5. Yoon, B.H., C.W. Park, and T. Chaiworapongsa, Intrauterine infection and the development of cerebral palsy. Bjog, 2003. 110 Suppl 20: p. 124-7.

6. Nelson, K.B. and R.E. Willoughby, Infection, inflammation and the risk of cerebral palsy. Curr Opin Neurol, 2000. 13(2): p. 133-9.

7. De Vries, L.S., et al., Ultrasound abnormalities preceding cerebral palsy in high-risk preterm infants. J Pediatr, 2004. 144(6): p. 815-20.

8. Inder, T.E., et al., White matter injury in the premature infant: a comparison between serial cranial sonographic and MR findings at term. AJNR Am J Neuroradiol, 2003. 24(5): p. 805-9.

9. Volpe, J.J., Cerebral white matter injury of the premature infant-more common than you think. Pediatrics, 2003. 112(1 Pt 1): p. 176-80.

10. Yoon, B.H., et al., Amniotic fluid inflammatory cytokines (interleukin-6, interleukin1 beta, and tumor necrosis factor-alpha), neonatal brain white matter lesions, and cerebral palsy. Am J Obstet Gynecol, 1997. 177(1): p. 19-26.

11. Kadhim, H., et al., Inflammatory cytokines in the pathogenesis of periventricular leukomalacia. Neurology, 2001. 56(10): p. 1278-84.

12. Yoon, B.H., et al., High expression of tumor necrosis factor-alpha and interleukin-6 in periventricular leukomalacia. Am J Obstet Gynecol, 1997. 177(2): p. 406-11.

13. Gilles, F.H., A. Leviton, and C.S. Kerr, Endotoxin leucoencephalopathy in the telencephalon of the newborn kitten. J Neurol Sci, 1976. 27(2): p. 183-91.

14. Rousset, C.I., et al., Maternal exposure to LPS induces hypomyelination in the internal capsule and programmed cell death in the deep gray matter in newborn rats. Pediatr Res, 2006. 59(3): p. 428-33. 
15. Gilles, F.H., D.R. Averill, Jr., and C.S. Kerr, Neonatal endotoxin encephalopathy. Ann Neurol, 1977. 2(1): p. 49-56.

16. Yoon, B.H., et al., Experimentally induced intrauterine infection causes fetal brain white matter lesions in rabbits. Am J Obstet Gynecol, 1997. 177(4): p. 797-802.

17. Cai, Z., et al., Cytokine induction in fetal rat brains and brain injury in neonatal rats after maternal lipopolysaccharide administration. Pediatr Res, 2000. 47(1): p. 64-72.

18. Duncan, J.R., et al., Chronic endotoxin exposure causes brain injury in the ovine fetus in the absence of hypoxemia. J Soc Gynecol Investig, 2006. 13(2): p. 87-96.

19. Nitsos, I., et al., Chronic exposure to intra-amniotic lipopolysaccharide affects the ovine fetal brain. J Soc Gynecol Investig, 2006. 13(4): p. 239-47.

20. Bell, M.J., J.M. Hallenbeck, and V. Gallo, Determining the fetal inflammatory response in an experimental model of intrauterine inflammation in rats. Pediatr Res, 2004. 56(4): p. 541-6.

21. Leviton, A. and F. Gilles, Ventriculomegaly, delayed myelination, white matter hypoplasia, and "periventricular" leukomalacia: how are they related? Pediatr Neurol, 1996. 15(2): p. 127-36.

22. Limperopoulos, C., et al., Does cerebellar injury in premature infants contribute to the high prevalence of long-term cognitive, learning, and behavioral disability in survivors? Pediatrics, 2007. 120(3): p. 584-93.

23. Limperopoulos, C., et al., Cerebellar injury in term infants: clinical characteristics, magnetic resonance imaging findings, and outcome. Pediatr Neurol, 2009. 41(1): p. 1-8.

24. Hoppenbrouwers, S.S., et al., The role of the cerebellum in the pathophysiology and treatment of neuropsychiatric disorders: a review. Brain Res Rev, 2008. 59(1): p. 185200.

25. Parker, J., et al., Cerebellar growth and behavioural \& neuropsychological outcome in preterm adolescents. Brain, 2008. 131(Pt 5): p. 1344-51.

26. Allin, M., et al., Cognitive and motor function and the size of the cerebellum in adolescents born very pre-term. Brain, 2001. 124(Pt 1): p. 60-6.

27. Bodensteiner, J.B. and S.D. Johnsen, Cerebellar injury in the extremely premature infant: newly recognized but relatively common outcome. J Child Neurol, 2005. 20(2): p. 139-42.

28. Johnsen, S.D., J.B. Bodensteiner, and T.E. Lotze, Frequency and nature of cerebellar injury in the extremely premature survivor with cerebral palsy. J Child Neurol, 2005. 20(1): p. 60-4. 
29. Rees, S. and R. Harding, The effects of intrauterine growth retardation on the development of the Purkinje cell dendritic tree in the cerebellar cortex of fetal sheep: a note on the ontogeny of the Purkinje cell. Int J Dev Neurosci, 1988. 6(5): p. 461-9.

30. Limperopoulos, C., et al., Late gestation cerebellar growth is rapid and impeded by premature birth. Pediatrics, 2005. 115(3): p. 688-95.

31. Nosarti, C., et al., Grey and white matter distribution in very preterm adolescents mediates neurodevelopmental outcome. Brain, 2008. 131(Pt 1): p. 205-17.

32. Jacobson, M., Histogenesis and morphogenesis of cortical cultures, in Developmental neurobiology, M. Jacobson, Editor. 1991, Plenum Press: New York. p. 401-451.

33. Feng, S.Y., et al., Endotoxin has acute and chronic effects on the cerebral circulation of fetal sheep. Am J Physiol Regul Integr Comp Physiol, 2009. 296(3): p. R640-50.

34. Garnier, Y., et al., Endotoxemia severely affects circulation during normoxia and asphyxia in immature fetal sheep. J Soc Gynecol Investig, 2001. 8(3): p. 134-42.

35. Jobe, A.H., et al., Endotoxin-induced lung maturation in preterm lambs is not mediated by cortisol. Am J Respir Crit Care Med, 2000. 162(5): p. 1656-61.

36. Nitsos, I., et al., Fetal responses to intra-amniotic endotoxin in sheep. J Soc Gynecol Investig, 2002. 9(2): p. 80-5.

37. Kramer, B.W., et al., Dose and time response after intraamniotic endotoxin in preterm lambs. Am J Respir Crit Care Med, 2001. 164(6): p. 982-8.

38. Gavilanes, A.W., et al., Chorioamnionitis induced by intraamniotic lipopolysaccharide resulted in an interval-dependent increase in central nervous system injury in the fetal sheep. Am J Obstet Gynecol, 2009. 200(4): p. 437 e1-8.

39. Cavalieri, B., Geometria indivisibilibus continuorum. Bonoiae: Typis Clementis Ferronij. 1635

40. Schmitz, C. and P.R. Hof, Design-based stereology in neuroscience. Neuroscience, 2005. 130(4): p. 813-31.

41. Gundersen, H.J. and E.B. Jensen, The efficiency of systematic sampling in stereology and its prediction. J Microsc, 1987. 147(Pt 3): p. 229-63.

42. West, M.J., L. Slomianka, and H.J. Gundersen, Unbiased stereological estimation of the total number of neurons in thesubdivisions of the rat hippocampus using the optical fractionator. Anat Rec, 1991. 231(4): p. 482-97.

43. Hutton, L.C., M. Castillo-Melendez, and D.W. Walker, Uteroplacental inflammation results in blood brain barrier breakdown, increased activated caspase 3 and lipid peroxidation in the late gestation ovine fetal cerebellum. Dev Neurosci, 2007. 29(4-5): p. 341-54.

44. Dean, J.M., et al., Cerebellar white matter injury following systemic endotoxemia in preterm fetal sheep. Neuroscience, 2009. 160(3): p. 606-15. 
45. Duncan, J.R., et al., White matter injury after repeated endotoxin exposure in the preterm ovine fetus. Pediatr Res, 2002. 52(6): p. 941-9.

46. Conroy, S.M., et al., Interleukin-6 produces neuronal loss in developing cerebellar granule neuron cultures. J Neuroimmunol, 2004. 155(1-2): p. 43-54.

47. Golan, H.M., et al., Specific neurodevelopmental damage in mice offspring following maternal inflammation during pregnancy. Neuropharmacology, 2005. 48(6): p. 903-17.

48. Hutton, L.C., et al., Injury of the developing cerebellum: A brief review of the effects of endotoxin and asphyxial challenges in the late gestation sheep fetus. Cerebellum, 2007: p. 1-10.

49. Berry, M., L.H. Bannister, and S.M. Standring, Nervous system, in Gray's Anatomy, P.L. Williams, Editor. 1995, Churchill Livingstone: Edinburgh. p. 901-1395.

50. Zhang, P., et al., c-fos protein-like immunoreactivity: distribution in the human brain and over-expression in the hippocampus of patients with Alzheimer's disease. Neuroscience, 1992. 46(1): p. 9-21.

51. Crumrine, R.C., A.L. Thomas, and P.F. Morgan, Attenuation of p53 expression protects against focal ischemic damage in transgenic mice. J Cereb Blood Flow Metab, 1994. 14(6): p. 887-91.

52. Bossenmeyer-Pourie, C., et al., Transient hypoxia may lead to neuronal proliferation in the developing mammalian brain: from apoptosis to cell cycle completion. Neuroscience, 1999. 91(1): p. 221-31.

53. Bossenmeyer-Pourie, C., et al., Sequential expression patterns of apoptosis- and cell cycle-related proteins in neuronal response to severe or mild transient hypoxia. Neuroscience, 2002. 114(4): p. 869-82.

54. Yonish-Rouach, E., et al., Wild-type p53 induces apoptosis of myeloid leukaemic cells that is inhibited by interleukin-6. Nature, 1991. 352(6333): p. 345-7.

55. King, K.L. and J.A. Cidlowski, Cell cycle and apoptosis: common pathways to life and death. J Cell Biochem, 1995. 58(2): p. 175-80.

56. Chang, F., et al., Regulation of cell cycle progression and apoptosis by the Ras/Raf/MEK/ERK pathway (Review). Int J Oncol, 2003. 22(3): p. 469-80.

57. Meikrantz, W. and R. Schlegel, Apoptosis and the cell cycle. J Cell Biochem, 1995. 58(2): p. 160-74.

58. Rees, S., et al., The vulnerability of the fetal sheep brain to hypoxemia at midgestation. Brain Res Dev Brain Res, 1997. 103(2): p. 103-18.

59. Castillo-Melendez, M., J.A. Chow, and D.W. Walker, Lipid peroxidation, caspase-3 immunoreactivity, and pyknosis in late-gestation fetal sheep brain after umbilical cord occlusion. Pediatr Res, 2004. 55(5): p. 864-71. 
60. Lee, C., et al., Cerebellar alterations induced by chronic hypoxia: an immunohistochemical study using a chick embryonic model. Brain Res, 2001. 901(12): p. 271-6.

61. Yan, E., et al., Cerebrovascular responses in the fetal sheep brain to low-dose endotoxin. Pediatr Res, 2004. 55(5): p. 855-63.

62. Poltorak, A., et al., Defective LPS signaling in C3H/HeJ and C57BL/10ScCr mice: mutations in TIr4 gene. Science, 1998. 282(5396): p. 2085-8.

63. Wang, X., et al., Lipopolysaccharide-induced inflammation and perinatal brain injury. Semin Fetal Neonatal Med, 2006. 11(5): p. 343-53.

64. Akira, S., TLR signaling. Curr Top Microbiol Immunol, 2006. 311: p. 1-16.

65. Briscoe, T., et al., Activation of NF-kappaB transcription factor in the preterm ovine brain and placenta after acute LPS exposure. J Neurosci Res, 2006. 83(4): p. 567-74.

66. Dziegielewska, K.M., N.A. Andersen, and N.R. Saunders, Modification of macrophage response to lipopolysaccharide by fetuin. Immunol Lett, 1998. 60(1): p. 31-5.

67. Kallapur, S.G., et al., Intra-amniotic endotoxin: chorioamnionitis precedes lung maturation in preterm lambs. Am J Physiol Lung Cell Mol Physiol, 2001. 280(3): p. L527-36.

68. Kallapur, S.G., et al., Pulmonary and systemic endotoxin tolerance in preterm fetal sheep exposed to chorioamnionitis. J Immunol, 2007. 179(12): p. 8491-9.

69. Kramer, B.W., et al., Endotoxin-induced maturation of monocytes in preterm fetal sheep lung. Am J Physiol Lung Cell Mol Physiol, 2007. 293(2): p. L345-53.

70. Yang, G.Y., et al., Tumor necrosis factor alpha expression produces increased bloodbrain barrier permeability following temporary focal cerebral ischemia in mice. Brain Res Mol Brain Res, 1999. 69(1): p. 135-43.

71. Dammann, O. and A. Leviton, Maternal intrauterine infection, cytokines, and brain damage in the preterm newborn. Pediatr Res, 1997. 42(1): p. 1-8.

72. Pang, Y., Z. Cai, and P.G. Rhodes, Effects of lipopolysaccharide on oligodendrocyte progenitor cells are mediated by astrocytes and microglia. J Neurosci Res, 2000. 62(4): p. 510-20.

73. Yang, L., et al., Target depletion of distinct tumor necrosis factor receptor subtypes reveals hippocampal neuron death and survival through different signal transduction pathways. J Neurosci, 2002. 22(8): p. 3025-32.

74. Neumann, $\mathrm{H}$., et al., Tumor necrosis factor inhibits neurite outgrowth and branching of hippocampal neurons by a rho-dependent mechanism. J Neurosci, 2002. 22(3): p. 854-62. 
75. Cunningham, A.J., et al., Interleukin-1 beta (IL-1 beta) and tumour necrosis factor (TNF) inhibit long-term potentiation in the rat dentate gyrus in vitro. Neurosci Lett, 1996. 203(1): p. 17-20.

76. Tancredi, V., et al., Tumor necrosis factor alters synaptic transmission in rat hippocampal slices. Neurosci Lett, 1992. 146(2): p. 176-8.

77. Tancredi, V., et al., The inhibitory effects of interleukin-6 on synaptic plasticity in the rat hippocampus are associated with an inhibition of mitogen-activated protein kinase ERK. J Neurochem, 2000. 75(2): p. 634-43.

78. Brenneman, D.E., et al., Cytokine regulation of neuronal survival. J Neurochem, 1992. 58(2): p. 454-60.

79. Hama, T., et al., Interleukin-6 as a neurotrophic factor for promoting the survival of cultured basal forebrain cholinergic neurons from postnatal rats. Neurosci Lett, 1989. 104(3): p. 340-4.

80. Holliday, J., et al., Cerebellar granule neurons develop elevated calcium responses when treated with interleukin-6 in culture. Brain Res, 1995. 673(1): p. 141-8.

81. Borodinsky, L.N. and M.L. Fiszman, Extracellular potassium concentration regulates proliferation of immature cerebellar granule cells. Brain Res Dev Brain Res, 1998. 107(1): p. 43-8.

82. Mhyre, T.R., D.N. Maine, and J. Holliday, Calcium-induced calcium release from intracellular stores is developmentally regulated in primary cultures of cerebellar granule neurons. J Neurobiol, 2000. 42(1): p. 134-47.

83. Ip, N.Y., et al., CNTF and LIF act on neuronal cells via shared signaling pathways that involve the IL-6 signal transducing receptor component gp130. Cell, 1992. 69(7): p. 1121-32.

84. Kishimoto, T., S. Akira, and T. Taga, Interleukin-6 and its receptor: a paradigm for cytokines. Science, 1992. 258(5082): p. 593-7.

85. Courtney, M.J., K.E. Akerman, and E.T. Coffey, Neurotrophins protect cultured cerebellar granule neurons against the early phase of cell death by a two-component mechanism. J Neurosci, 1997. 17(11): p. 4201-11.

86. Nonomura, T., et al., Signaling pathways and survival effects of BDNF and NT-3 on cultured cerebellar granule cells. Brain Res Dev Brain Res, 1996. 97(1): p. 42-50.

87. Sato, M., K. Suzuki, and S. Nakanishi, Expression profile of BDNF-responsive genes during cerebellar granule cell development. Biochem Biophys Res Commun, 2006. 341(2): p. 304-9.

88. Rocamora, N., et al., Differential expression of brain-derived neurotrophic factor, neurotrophin-3, and low-affinity nerve growth factor receptor during the postnatal 
development of the rat cerebellar system. Brain Res Mol Brain Res, 1993. 17(1-2): p. 1-8.

89. Borghesani, P.R., et al., BDNF stimulates migration of cerebellar granule cells. Development, 2002. 129(6): p. 1435-42.

90. Schwartz, P.M., et al., Abnormal cerebellar development and foliation in BDNF-/mice reveals a role for neurotrophins in CNS patterning. Neuron, 1997. 19(2): p. 26981.

91. Schwartz, P.M., et al., Cerebellar pathology in BDNF -/- mice: the classic view of neurotrophins is changing. Mol Psychiatry, 1998. 3(2): p. 116-20.

92. Sofroniew, M.V., C.L. Howe, and W.C. Mobley, Nerve growth factor signaling, neuroprotection, and neural repair. Annu Rev Neurosci, 2001. 24: p. 1217-81.

93. Zhou, L. and H.D. Shine, Neurotrophic factors expressed in both cortex and spinal cord induce axonal plasticity after spinal cord injury. J Neurosci Res, 2003. 74(2): p. 221-6.

94. Chaisuksunt, V., et al., Expression of regeneration-related molecules in injured and regenerating striatal and nigral neurons. J Neurocytol, 2003. 32(2): p. 161-83.

95. D'Mello, S.R., et al., Induction of apoptosis in cerebellar granule neurons by low potassium: inhibition of death by insulin-like growth factor I and cAMP. Proc Natl Acad Sci U S A, 1993. 90(23): p. 10989-93.

96. Chrysis, D., et al., Insulin-like growth factor-l overexpression attenuates cerebellar apoptosis by altering the expression of $\mathrm{BCl}$ family proteins in a developmentally specific manner. J Neurosci, 2001. 21(5): p. 1481-9.

97. Vaudry, D., et al., Regulators of cerebellar granule cell development act through specific signaling pathways. Science, 2003. 300(5625): p. 1532-4.

98. Skaper, S.D., et al., Neurotrophins rescue cerebellar granule neurons from oxidative stress-mediated apoptotic death: selective involvement of phosphatidylinositol 3kinase and the mitogen-activated protein kinase pathway. J Neurochem, 1998. 70(5): p. 1859-68.

99. Pearson, H., M.E. Graham, and R.D. Burgoyne, Relationship Between Intracellular Free Calcium Concentration and NMDA-induced Cerebellar Granule Cell Survival In Vitro. Eur J Neurosci, 1992. 4(12): p. 1369-1375.

100. Saito, M., et al., Effect of intrauterine inflammation on fetal cerebral hemodynamics and white-matter injury in chronically instrumented fetal sheep. Am J Obstet Gynecol, 2009. 200(6): p. 663 e1-11.

101. Coumans, A.B., et al., The effects of low-dose endotoxin on the umbilicoplacental circulation in preterm sheep. J Soc Gynecol Investig, 2004. 11(5): p. 289-93. 
102. Mallard, E.C., et al., Effects of chronic placental insufficiency on brain development in fetal sheep. Pediatr Res, 1998. 43(2): p. 262-70.

103. Reier, P., Gliosis following CNS injury: the anatomy of astrocytic scars and their influences on axonal elongation. Astrocytes, Cell Biology and Pathology of Astrocytes., ed. V.A. Fedoroff S. 1986, New York: Academic Press. 263-324.

104. Montgomery, D.L., Astrocytes: form, functions, and roles in disease. Vet Pathol, 1994. 31(2): p. 145-67.

105. Magistretti, P.J. and L. Pellerin, Cellular bases of brain energy metabolism and their relevance to functional brain imaging: evidence for a prominent role of astrocytes. Cereb Cortex, 1996. 6(1): p. 50-61.

106. Allen, G. and E. Courchesne, The cerebellum and non-motor function: clinical implications. Mol Psychiatry, 1998. 3(3): p. 207-10.

107. Allen, G. and E. Courchesne, Differential effects of developmental cerebellar abnormality on cognitive and motor functions in the cerebellum: an fMRI study of autism. Am J Psychiatry, 2003. 160(2): p. 262-73. 


\section{Chapter 6}

Chorioamnionitis induced by intraamniotic I

ipopolysaccharide resulted in an interval-dependent increase in central nervous system injury in the fetal sheep.

Gavilanes, A.W., Strackx, E., Kramer, B.W., Gantert, M., Van den Hove, D., Steinbusch, H.,

Garnier, Y., Cornips, E., Steinbusch, H., Zimmermann, L.J., Vles, J.

Am J Obstet Gynecol. 2009 Apr;200(4):437.e1-8 


\title{
Chorioamnionitis induced by intraamniotic lipopolysaccharide resulted in an interval-dependent increase in central nervous system injury in the fetal sheep
}

\author{
A. W. Danilo Gavilanes, MD, PhD; Eveline Strackx, MSc; Boris W. Kramer, MD, PhD; Markus Gantert, MD; \\ Daniël Van den Hove, PhD; Hellen Steinbusch; Yves Garnier, MD, PhD; Erwin Cornips, MD; \\ Harry Steinbusch, PhD; Luc Zimmermann, MD, PhD; Johan Vles, MD, PhD
}

\begin{abstract}
OBJECTIVE: We quantified the impact of chorioamnionitis on both the white and gray matter structures of the preterm ovine central nervous system (CNS).
\end{abstract}

STUDY DESIGN: The CNS was studied at 125 days of gestation, either 2 or 14 days after the intraamniotic administration of $10 \mathrm{mg}$ of lipopolysaccharide (LPS) (Escherichia coli) or saline. Apoptotic cells and cell types were analyzed in the brain, cerebellum, and spinal cord using flow cytometry.

RESULTS: Apoptosis and microglial activation increased in all regions with prolonged exposure to LPS-induced chorioamnionitis.
Astrocytes were increased in the brain and cerebellum of LPS-exposed fetuses but not in the spinal cord. Mature oligodendrocytes decreased in the cerebral and cerebellar white matter, the cerebral cortex, caudate putamen, and hippocampus 14 days after LPS. Neurons in the cerebral cortex, hippocampus, and substantia nigra were reduced 14 days after LPS.

CONCLUSION: Fetal inflammation globally but differentially affected the CNS depending on the maturational stage of the brain region.

Key words: central nervous system, chorioamnionitis, fetal inflammation, lipopolysaccharide, oligodendrocytes

Cite this article as: Gavilanes AWD, Strackx E, Kramer BW, et al. Chorioamnionitis induced by intraamniotic lipopolysaccharide resulted in an interval-dependent increase in central nervous system injury in the fetal sheep. Am J Obstet Gynecol 2009;200:437.e1-437.e8.

\begin{abstract}
Chorioamnionitis (CA) and the corresponding fetal inflammatory response are both inversely related to gestational age in preterm infants, ${ }^{1-3}$ affecting mainly the lungs and the central nervous system (CNS). ${ }^{4-7}$ The predominantly studied CNS pathology is cerebral periventricular white matter (WM) disease (WMD), which results in permanent structural brain damage and severe longlasting neurodevelopmental impairment,
\end{abstract}

such as periventricular leukomalacia., ${ }^{89}$ Cortical and subcortical gray matter (GM) and cerebellum are affected as well, contributing to a complex long-term neurologic morbidity. ${ }^{10,11}$

This study aimed to overcome 2 general drawbacks from the most commonly used experimental paradigms. First, lipopolysaccharide (LPS) is usually given intravenously (IV) to induce fetal inflammation. In addition to fetal inflammation, how-

From the Departments of Pediatrics-Neonatology (Drs Gavilanes, Kramer, and Zimmermann and Ms Strackx), Child Neurology (Ms Strackx and Dr Vles), and Neurosurgery (Dr Cornips), University Hospital Maastricht, in collaboration with the Research Institute of Growth and Development (GROW), Maastricht, The Netherlands; the Faculty of Health, Medicine and Life Sciences, School of Mental Health and Neuroscience, Maastricht University, and European Graduate School of Neuroscience (EURON), Maastricht, The Netherlands (Dr Van den Hove, and Ms Hellen Steinbusch, Mr Harry Steinbusch, and Ms Strackx); and the Department of Obstetrics and Gynecology, University of Köln, Köln, Germany (Drs Gantert and Garnier).

Received May 26, 2008; revised July 20, 2008; accepted Dec. 4, 2008.

Reprints: A. W. Danilo Gavilanes, MD, Department of Pediatrics, Division of Neonatology, Maastricht University Medical Center, PO Box 5800, NL-6200 AZ Maastricht, The Netherlands. danilo.gavilanes@mumc.nl.

The first 2 authors contributed equally to this research.

0002-9378/\$36.00 • ( 2009 Mosby, Inc. All rights reserved. • doi: 10.1016/j.ajog.2008.12.003

ever, this approach also induces important superimposed hypoxia ischemia. ${ }^{12}$ Second, little attention has been paid to other CNS regions besides the cerebral WM. To overcome the first drawback, we studied the sheep CNS pathology after CA by LPS administration into the amniotic fluid. This intraamniotic administration avoids the hemodynamic changes and the secondary postasphyctic encephalopathy induced by fetal IV LPS. ${ }^{13,14}$ In addition, this experimental time window corresponds to approximately 28 weeks of human CNS maturation, which is the most vulnerable period for the human brain to develop WMD. ${ }^{15-17}$ To overcome the second drawback, we studied the regional impact on the developing CNS in different regions of the WM and GM using flow cytometry. We hypothesize both a global CNS impact and a time-related effect after LPS-induced CA.

\section{Materials and Methods Animals and surgical procedures} All experimental procedures were approved by our animal ethics board accord- 


\section{FIGURE 1}

Body and brain weights
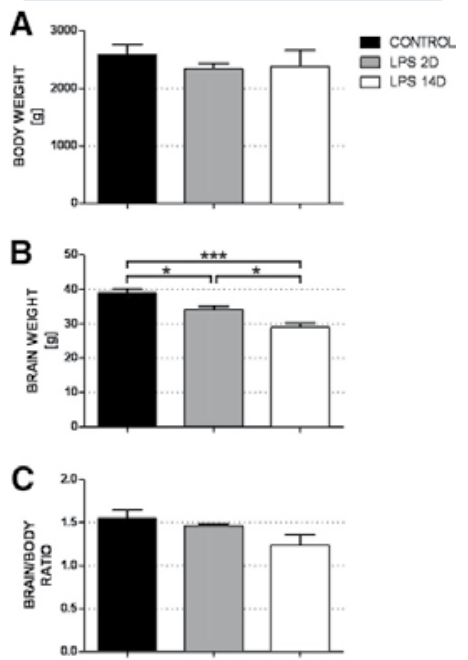

Effect of fetal endotoxin exposure on body and brain weight. A, No significant differences in bodyweight between groups. B, Brain weight was significantly lower in lipopolysaccharide (LPS) 2-day (2D) and 14-day (14D) groups than in control group. C, Endotoxin exposure did not cause any changes in brain to body ratio among 3 groups. Data are represented as mean + SEM. Black bars $=$ control $(n=7)$; gray bars $=$ LPS 2D $(\mathrm{n}=5)$; and white bars = LPS 14D $(\mathrm{n}=$ 6) groups. Multivariate analysis of variance + Bonferroni testing; ${ }^{\star} P<.05$ and ${ }^{* *} P<.001$. Gavilanes. CA induced by intraamniotic LPS resulted in an interval-dependent increase in CNS injury in the fetal sheep. Am J Obstet Gynecol 2009.

ing to Dutch government regulations. Pregnant Texel ewes, bearing both singletons and twins, were housed outdoors. Food and water were provided ad libitum. LPS (10 mg dissolved in $2 \mathrm{~mL}$ sterile and filtered saline) was injected intraamniotically (IA) under ultrasound guidance at day 123 of gestation $(n=5)$ or at day 111 of gestation $(n=6)$. Control saline injection was given at either day 111 or 123 of gestation $(\mathrm{n}=7) .{ }^{18}$ At day 125 of gestation, pregnant ewes were anesthetized and all fetuses were delivered by cesarean section. Fetuses were killed by a lethal injection of pentobarbital. The brain was removed and halved. One half was prepared for flow cytometric analysis.

\section{Tissue preparation}

The cerebral cortex, caudate nucleus and putamen (CPU), hippocampus, frontal periventricular WM, hypothalamus, substantia nigra (SN), C1, T11, and L1 of the spinal cord (SC), and cerebellar cortex and WM were dissected and placed in ice-cold plating medium consisting of Dulbecco's Modified Eagle's medium supplemented with $10 \%$ fetal bovine serum (FBS), penicillin/streptavidin, and glutamate. The tissue was mechanically disrupted using a glass homogenizer. The suspension was centrifuged at $1200 \mathrm{rpm}$ at $4^{\circ} \mathrm{C}$ for $10 \mathrm{~min}$ utes, and the pellet was resuspended in 5 $\mathrm{mL}$ of plating medium. The crude cell suspension was then passed through a $100-\mu \mathrm{m}$ nylon cell strainer to remove large cell clumps. The cells were counted using a cell counting chamber and divided into different microcentrifuge tubes $\left(10^{6}\right.$ cells/ $0.5 \mathrm{~mL} /$ tube). The viability of the cells was monitored using trypan blue staining.

\section{Flow cytometric analysis}

AnnexinV/propidium iodide staining

Apoptotic and necrotic cells were detected with annexinV conjugated to fluorescin (FITC) and propidium iodide (PI) (AnnexinV-FITC Apoptosis Detection Kit; BD Biosciences Pharmingen, Breda, The Netherlands). The cells were washed twice with phosphate buffered saline (PBS), followed by a wash in AnnexinV-binding buffer. Then, all samples $\left(10^{7}\right.$ cells $\left./ 100 \mu \mathrm{L}\right)$ were incubated with $5 \mu \mathrm{L}$ of AnnexinV antibody and 5 $\mu \mathrm{L}$ of PI for 15 minutes at room temperature (RT).

\section{Extracellular staining (0X42)}

OX42 was used to identify activated microglia. The cells were washed twice with staining buffer (PBS $+2 \%$ FBS) by centrifugation at $1200 \mathrm{rpm}$ at $4^{\circ} \mathrm{C}$ and incubated for 30 minutes at RT with the primary antibody: mouse antibovine CD11b/c (clone OX42; AbD Serotec, Huissen, The Netherlands), diluted 1:100 in staining buffer. The cells were washed twice followed by incubation with the secondary antibody: donkey antimouse alexa 488 diluted 1:100 in staining buffer. All samples were washed and kept at $4^{\circ} \mathrm{C}$ in the dark.
Intracellular staining (glial fibrillary acidic protein, $2^{\prime}, 3^{\prime}$-cyclic nucleotide $3^{\prime}$-phosphodiesterase, and antineurofilament 200-kd)

Antiglial fibrillary acidic protein antibodies were used to identify activated astrocytes. Anti-2', $3^{\prime}$-cyclic nucleotide $3^{\prime}$ phosphodiesterase antibodies were used to detect mature oligodendrocytes, whereas antineurofilament 200-kd antibodies were used to detect neurons. Cells were washed twice with staining buffer by centrifugation at $1200 \mathrm{rpm}$ at $4^{\circ} \mathrm{C}$. After washing, cells were fixed with $4 \%$ paraformaldehyde in staining buffer ( $2 \%$ final concentration) for 20 minutes at RT. Permeabilization was done after 2 more washing steps with permeabilization buffer $(0.05 \%$ saponin + $2 \%$ FBS + PBS) for 10 minutes at RT. The cell suspension was then incubated with the primary antibody for 30 or 45 minutes at RT. The antibodies were mouse antiovine $2^{\prime}, 3^{\prime}$-cyclic nucleotide phosphodiesterase (clone 11-5B; Sigma, Munich, Germany); monoclonal antibody 1:200 in permeabilization buffer/rabbit antiovine glial fibrillary acidic protein (Dako, Glostrup, Denmark); and polyclonal antibody 1:200 in permeabilization buffer/ mouse antineurofilament 200-kd (Abcam, Cambridge, UK); and monoclonal antibody 1:100 in permeabilization buffer. After 2 washing steps, the cell suspension was incubated with the secondary antibody (respectively donkey antimouse or donkey antirabbit alexa 488 diluted 1:100 in permeabilization buffer) again for 30 minutes at RT. All samples were washed 2 times and kept at $4^{\circ} \mathrm{C}$ in the dark.

\section{Flow cytometry}

All samples were run on an FACScalibur flow cytometry system (BD Biosciences, San Jose, CA), equipped with an argon ion laser $(488 \mathrm{~nm})$. Analysis was done using the Cell Quest Pro software (BD Biosciences). Forward and sideward light angle scatters were collected from all samples. Using those plots, samples were gated (region $1 ; \mathrm{R} 1$ ) to exclude cell debris and cellular aggregates for further analysis. For each marker, the mean fluorescence intensity and the percentage of positive cells stained above background were measured for a total of 10,000 cells per sample within the gate (R1). The cut- 


\section{FIGURE 2}

\section{Flow cytograms}
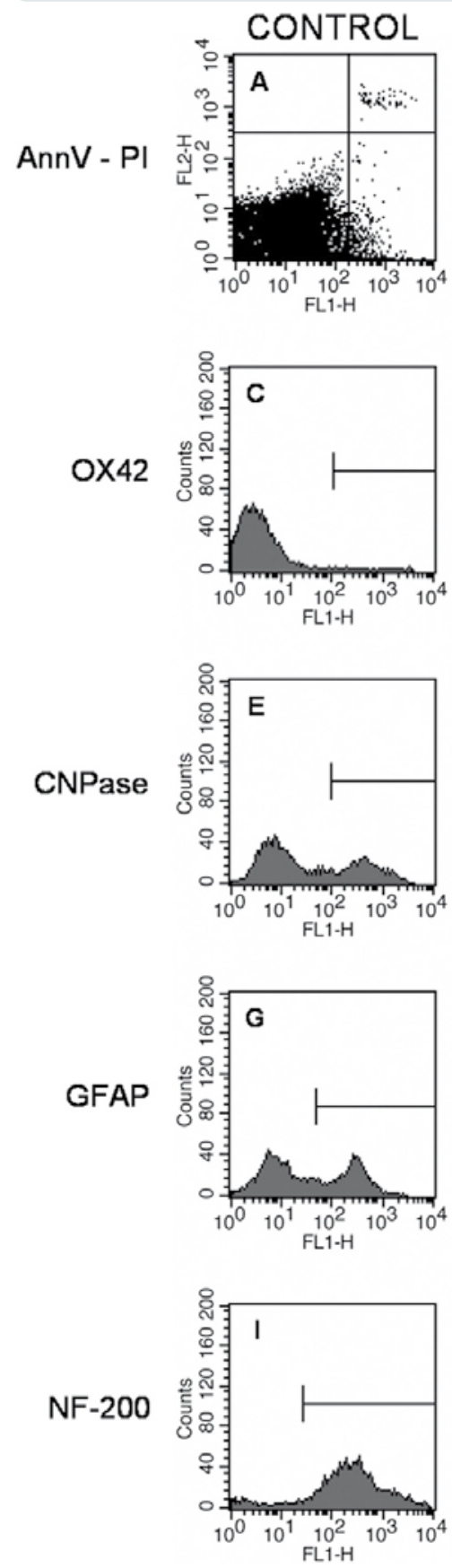
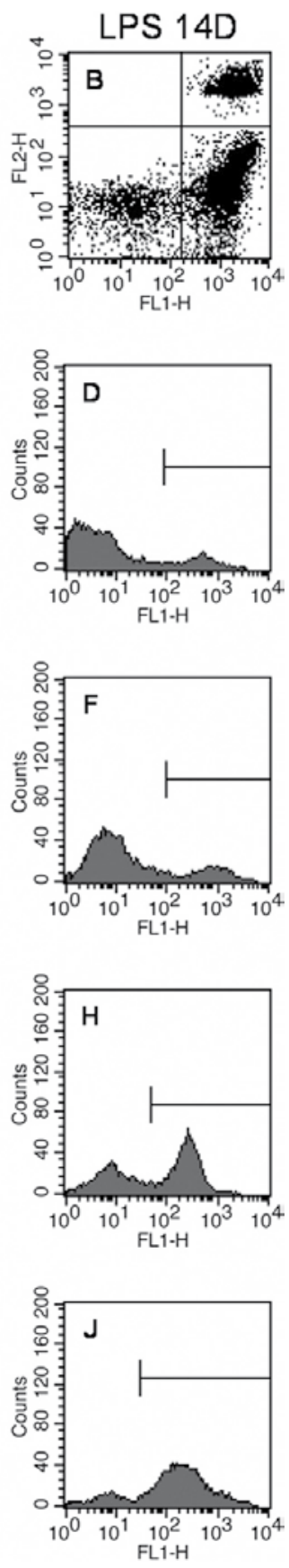

off was defined using control tissue negative for the different markers processed and stained alongside the experimental samples. The mean fluorescence intensity was corrected for autofluorescence using the values from cells only incubated with secondary antibody.

\section{Statistical analysis}

Data were analyzed using a multivariate analysis of variance (mean \pm SEM). Significant effects were analyzed by post hoc Bonferroni corrections. The accepted level of significance was $P<.05$. All calculations were done using software (SPSS 12.0; SPSS, Inc, Chicago, IL).

Representative flow cytograms of control and lipopolysaccharide (LPS) 14-day (14D) animals. Flow cytograms of AnnexinV (AnnV) binding vs propidium iodide (PI) uptake of $\mathbf{A}$, control and B, LPS 14D animals. Four populations of cells are visualized. Viable cells, in lower left quadrant (Q3), are double negative. Apoptotic cells in lower right quadrant $\left(\mathrm{Q}_{4}\right)$ are $\mathrm{AnnV}^{+}$and $\mathrm{Pl}^{-}$. Double-positive cells $\left(\mathrm{AnnV}^{+} / \mathrm{PI}^{+}\right)$are in upper right quadrant (Q2). They are thought to be necrotic or advanced apoptotic. Cells in last quadrant (upper left, Q1) are isolated nuclei or cellular debris. There was significant decrease in number of viable cells in LPS 14D animal as compared with control animal. Further, significant increase in apoptotic (Q4) and necrotic index (Q2) was observed in LPS 14D animal compared with control animal. Flow cytograms of $\mathbf{C}$ and $\mathbf{D}, 0 X 42$, E and $\mathbf{F}, 2^{\prime}, 3^{\prime}$-cyclic nucleotide 3 '-phosphodiesterase (CNPase), $\mathbf{G}$ and $\mathbf{H}$ glial fibrillary acidic protein (GFAP), and $\mathbf{I}$ and $\mathbf{J}$, antineurofilament 200-kd (NF-200) staining of C, E, G, and I, control and D, F, H, and J, LPS $14 \mathrm{D}$ animals. Data were plotted as fluorescence $\left(\mathrm{FL}_{1}\right)$ in function of number of counts. Percentage of positive cells in histograms is indicated by line. There was significant increase in percentage of activated microglia and astrocytes in LPS 14D compared with control animal. Moreover, proportion of mature oligodendrocytes and neurons was lower in LPS 14D animal than in control animal.

Gavilanes. CA induced by intraamniotic LPS resulted in an interval-dependent increase in CNS injury in the fetal sheep. Am J Obstet Gynecol 2009. 


\section{FIGURE 3}

\section{Apoptosis and necrosis}

BRAIN

APOPTOSIS

A

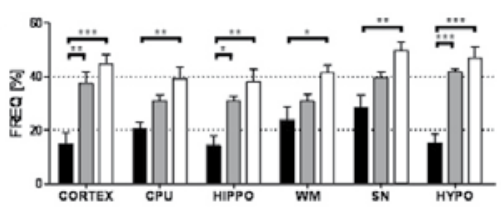

D

\section{NECROSIS}
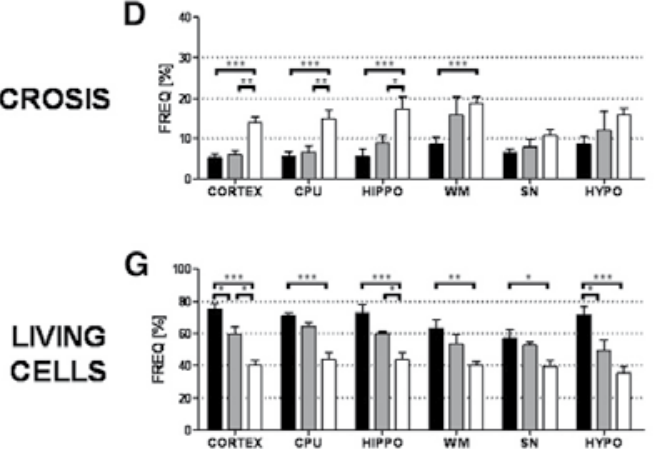

CEREBELLUM

SPINAL CORD

B

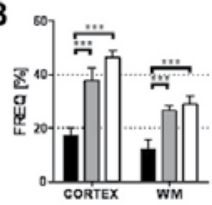

E
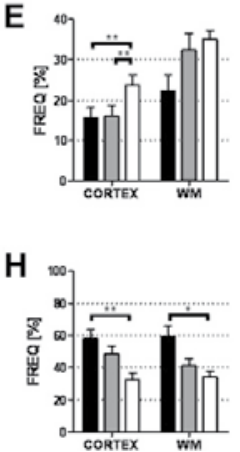

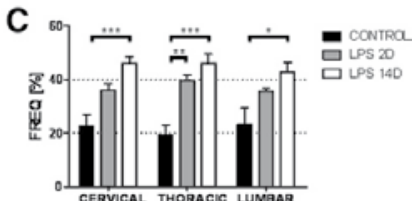

F
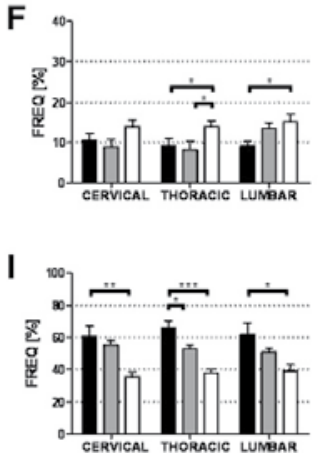

Differences in percentage of apoptotic, necrotic, and living cells in brain, cerebellum, and spinal cord. Percentage of apoptotic cells in A, brain, B, cerebellum, and C, spinal cord. Percentage of necrotic cells in D, brain, E, cerebellum, and F, spinal cord. Percentage of living cells in G, brain, $\mathbf{H}$, cerebellum, and I, spinal cord. Data are represented as mean percentage of positive cells + SEM. Black bars = control $(n=7)$; gray bars = lipopolysaccharide (LPS) 2-day $(\mathrm{n}=5)$; and white bars $=$ LPS 14-day $(\mathrm{n}=6)$ groups. Multivariate analysis of variance + Bonferroni testing; ${ }^{*} P$ $<.05,{ }^{\star \star} P<.01$, and ${ }^{* \star *} P<.001$.

CPU, caudate putamen; HIPPO, hippocampus; hypo, hypothalamus; $S N$, substantia nigra; WM, white matter

Gavilanes. CA induced by intraamniotic LPS resulted in an interval-dependent increase in CNS injury in the fetal sheep. Am J Obstet Gynecol 2009.

\section{Results}

\section{Brain and bodyweight}

The mean body and brain weights of the LPS 2-day $(\mathrm{n}=5)$, LPS 14-day $(\mathrm{n}=$ $6)$, and control $(n=7)$ groups are shown in Figure 1. There were no significant differences in body weight among the 3 groups (Figure 1, A). The mean brain weight of both the LPS 2-day $(P=.031)$ and LPS 14 -day $(P<$ $.001)$ group was significantly lower than the mean brain weight of the control group (Figure 1, B). A significant difference between the LPS 2-day and the LPS 14-day group was shown, with the last group being most affected $(P=$ .048 vs control). The percentage brain of total body weight did not differ significantly between the different groups (Figure 1, C).

\section{Apoptotic and necrotic cell death}

Figure 2, A and B, shows representative examples of the histograms of a control animal and LPS 14-day animal. Percentages of living (Annexin $\mathrm{V}^{-}$and $\mathrm{PI}^{-}$), apoptotic $\left(\right.$Annexin $\mathrm{V}^{+}$and $\mathrm{PI}^{-}$), and necrotic (AnnexinV ${ }^{+}$and $\mathrm{PI}^{+}$) cells are given in Figure 3. Double-negative $\left(\right.$ Annexin $\mathrm{V}^{-} / \mathrm{PI}^{-}$) cells are viable cells (Figure 3, G-I). Values of living cells were significantly lower in the LPS 14-day group (33-43\%) in all CNS areas investigated compared with controls $(57-75 \%)$. Only the cortex, hippocampus, hypothalamus, and the T11 level of the SC showed a significant decrease in the LPS 2-day group. Annexin $\mathrm{V}^{+} / \mathrm{PI}^{-}$cells are considered to be apoptotic cells (Figure 3, A-C). The percentage of apoptotic cells increased significantly in the LPS 14-day group (28-46\%) compared with the saline group (12-23\%) in all regions of interest. In the cortex, hippocampus, hypothalamus, cerebellar cortex, cerebellar WM, and T11 level of the SC, the percentage of apoptotic cells in the LPS 2-day group was higher than in controls. Double-positive cells (Annexin $\mathrm{V}^{+} / \mathrm{PI}^{+}$) are considered to undergo necrosis or advanced apoptosis (Figure 3, D-F). A significant increase in the necrotic index in the LPS 14-day group (14-30\%) in comparison with the saline group (5-22\%) was shown in the cerebral cortex, CPU, hippocampus and periventricular $\mathrm{WM}$ in the brain, T11 and L1 level of SC, and in the cerebellar WM. In addition, there was also a significant increase in the necrotic in- 
FIGURE 4

CNS cell populations

BRAIN

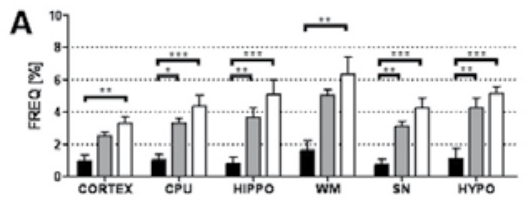

D

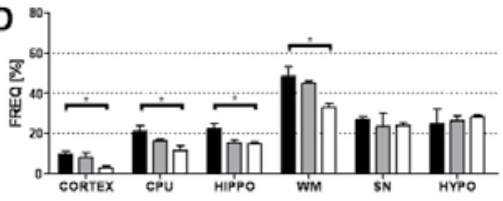

B

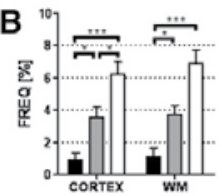

E

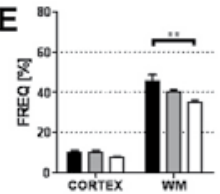

H
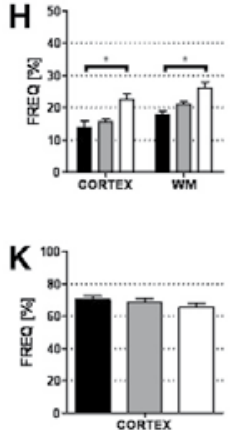

SPINAL CORD
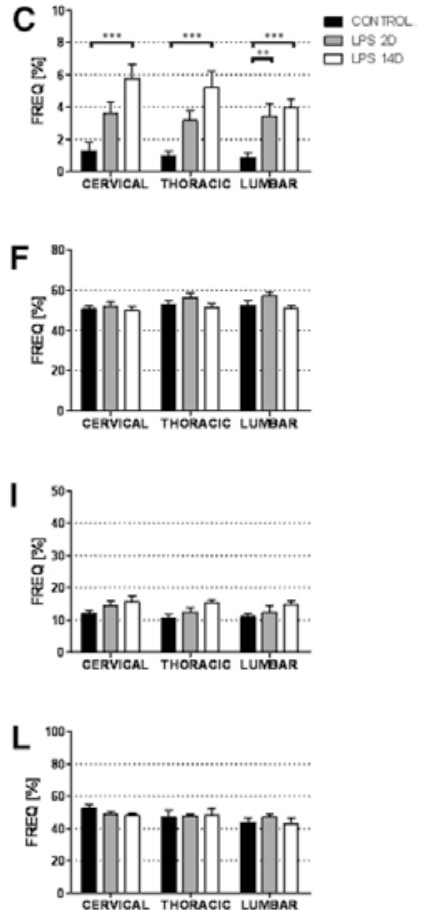

Differences in percentage of microglia, oligodendrocytes, astrocytes, and neurons in brain, spinal cord, and cerebellum. Percentage of microglia in A, brain, $\mathbf{B}$, cerebellum, and $\mathbf{C}$, spinal cord. Percentage of oligodendrocytes in $\mathbf{D}$, brain, $\mathbf{E}$, cerebellum, and $\mathbf{F}$, spinal cord. Percentage of astrocytes in $\mathbf{G}$, brain, $\mathbf{H}$, cerebellum, and $\mathbf{I}$, spinal cord. Percentage of neurons in $\mathbf{J}$, brain, $\mathbf{K}$, cerebellum, and $\mathbf{L}$, spinal cord. Data are represented as mean percentage of positive cells + SEM. Black bars = control $(n=7)$; gray bars = lipopolysaccharide $(\mathrm{LPS}) 2$-day $(\mathrm{n}=5)$; and white bars $=$ LPS 14 -day $(\mathrm{n}=$ 6) groups. Multivariate analysis of variance + Bonferroni testing; ${ }^{\star} P<.05,{ }^{\star \star} P<.01$, and ${ }^{\star \star \star} P<.001$.

CNS, central nervous systems; CPU, caudate putamen; HIPPO, hippocampus; hypo, hypothalamus; SN, substantia nigra; WM, white matter. Gavilanes. CA induced by intraamniotic LPS resulted in an interval-dependent increase in CNS injury in the fetal sheep. Am J Obstet Gynecol 2009.

dex in the cortex, CPU, hippocampus, T11 level of the SC, and cerebellar cortex in the LPS 14-day group compared with the LPS 2-day group. The necrotic index was not different in the SN, hypothalamus, $\mathrm{Cl}$ of the $\mathrm{SC}$, or the cerebellar cortex.

\section{Cell populations}

\section{Activated microglia}

The representative histograms are shown in Figure 2, C and D. The number of activated microglia $\left(\mathrm{OX} 42^{+}\right)$was very low in the saline group $(0.8-1.6 \%)$. In almost all regions (CPU, hippocampus, SN, hypothalamus, L1 level of SC, the cerebellar cortex, and cerebellar WM), the percentage of activated microglia was significantly higher in the LPS 2-day group $(2.5-5 \%)$ than in the saline group. There was an even higher increase in the proportion of activated microglia in the LPS 14-day group (3.2-6.8\%), affecting all areas investigated (Figure 4, A-C).

\section{Mature oligodendrocytes}

The representative histograms are shown in Figure 2, E and F. The values of the mature oligodendrocytes observed were similar for the saline $(9-52 \%)$ and the LPS 2-day (8-57\%) groups for all areas investigated (Figure 4, D-F). In the cortex, CPU, hippocampus, periventricular WM, and cerebellar WM, the proportion of mature oligodendrocytes was much lower in the LPS 14-day group (3-35\%) than in the saline group (9-45\%). All other regions investigated were not affected in the LPS 14day group.

\section{Reactive astrocytes}

The representative plots are shown in Figure 2, G and H. No significant differences were found in the percentage of astrocytes in the LPS 2-day group (12-27\%) compared with the saline group (10-22\%) (Figure 4, G-I). However, in the LPS 14-day group (14-36\%) a 
significant increase in the proportion of astrocytes was observed in all areas of the brain and cerebellum. The SC, in contrast, was not affected.

\section{Neurons}

No significant differences were found in the proportion of neurons between the control (41-82\%) and the LPS 2-day (43$82 \%$ ) groups for any of the areas investigated (Figure 4, J-L); representative histogram is in Figure 2, I and J. In the LPS 14 -day group $(41-73 \%)$, however, the percentages of neurons were significantly lower in the cortex, hippocampus, and SN compared with the control group. No differences were detected in the cerebellum or SC.

There was no influence of sex, singleton/twin, or weight on any of the analyzed variables.

\section{Comment}

$\mathrm{CA}$ resulted in an interval-dependent increase in CNS injury and different regional injury patterns. Microglial activation and apoptotic cell death were increased in all brain, cerebellum, and SC regions in an interval-dependent manner. In addition, most brain regions showed reductions in oligodendrocytes and neurons and an increase in astrocytes, whereas the cerebellum and especially the SC seemed to be less affected. This study is the first to show a global inflammatory response to acute CA in the brain, cerebellum, and SC and a selective vulnerability of the developing regions.

These changes might be explained by the state of CNS maturation at that given gestational age. In the fetal brain, the WM is predominantly affected by systemic inflammation/infection as highlighted by fetal animal experiments in rabbits, guinea pigs, mice, rats, and sheep. ${ }^{19-24}$ Furthermore, CA is associated with both cerebral palsy and WMD seen with neonatal imaging. ${ }^{5,7,25}$ More recent evidence points toward a relationship between WMD and GM abnormalities. ${ }^{11}$ This could explain the permanent neurodevelopmental and intellectual deficits in ex-preterm infants, which are not limited to cerebral palsy. ${ }^{26}$ The use of this model of CA has several advantages, making it clinically more relevant than others. First, the CA-associated systemic inflammation has been previously characterized in this model by Kramer et al. ${ }^{13}$ Second, the IA LPS strategy avoids the superimposed hypoxia ischemia of the IV strategy and the local processes caused by an intracerebral route. ${ }^{12,27}$ Third, species with a long gestation duration, such as human beings and sheep, share several aspects of development and function. In addition, the current study not only focused on brain WMD, but it also analyzed the effect of developmental inflammation on both the cerebral cortical and subcortical GM structures and the cerebellar and SC regions. Experimental data combining all these regions are not available.

The loss of oligodendrocytes, especially in the periventricular and the subcortical WM, has been reported before in intracerebral, IV, intrauterine, and maternal LPS models in different animal species. $^{27-31}$ In addition, a previous study using a similar ovine intraamniotic LPS model also demonstrated a decrease in oligodendrocytes in the areas of extensive focal damage. ${ }^{20}$ In contrast to our study, no global effects were previously found on the density and/or number of mature oligodendrocytes throughout the whole brain. Moreover, our study showed a decreased number of neurons in the cortex, hippocampus, and $\mathrm{SN}$ in the LPS 14-day group compared with the control group, whereas neither the cerebellum nor the SC differed from the control animals. GM and/or neuron-specific damage have not been identified before in intracerebral or IV LPS models. ${ }^{31} \mathrm{Ma}$ ternal administration of LPS in rats, however, led to a loss of tyrosine hydroxylase-positive neurons in the SN of 16month-old offspring. ${ }^{32}$ In addition, maternal LPS caused the loss of pyramidal cells in the hippocampus at the age of 8 months. ${ }^{33}$

Apoptotic cell death was increased in some of the regions in the LPS 2-day group (cortex, hippocampus, hypothalamus, cerebellar cortex, cerebellar WM, and T11) and in all areas studied in the LPS 14-day group. Necrotic cells were also higher in most areas of the LPS 14day group compared with the control group (cortex, CPU, hippocampus, periventricular WM, and cerebellar cortex T11 and L1). In a human postmortem study, apoptosis has already been reported as a contributing mechanism for cell death in infants with WMD. ${ }^{34}$ Garnier et $\mathrm{al}^{35}$ also found evidence of apoptotic cell death, especially in the periventricular WM, in a sheep model for IV LPS. Moreover, an intracervical LPS injection of pregnant rats led to the activation of both the intrinsic and the extrinsic pathway of apoptosis. ${ }^{36}$ One possible explanation for LPS-induced apoptotic cell death could be that LPS causes the up-regulation of the systemic production of tumor necrosis factor (TNF)- $\alpha$, activating the TNF- $\alpha$-caspase pathway and an increased production by microglia and astrocytes in the brain. ${ }^{13,37,38}$ Apoptosis has been reported to affect mainly oligodendrocytes and/or their precursors, ${ }^{34,39}$ but our study suggests that neurons are affected as well.

Microglial activation was increased in all regions of both LPS groups with the exception of cerebral cortex and WM, and the $\mathrm{C} 1$ and $\mathrm{T} 11$ level of SC in the LPS 2-day group. Increased astrocytic activation was observed in all areas of the brain and cerebellum in the LPS 14-day group, whereas the SC was not affected. Similar increases were found in almost all other LPS models, in particular in the cerebral WM. ${ }^{27,29-31}$ Our study shows for the first time general microglial activation or astrogliosis throughout the whole brain. The activation of microglia and astrocytes in the brain may be caused by the entry of systemic inflammatory cells and cytokines through a permeable bloodbrain barrier. Activated microglia and astrocytes respond to an inflammatory insult, which may affect the WM and, second, explain the concomitant selective GM compromise. First, neurons destined for the frontal cerebral cortex migrate through the developing WM and form the subplate during late gestation. ${ }^{40}$ These subplate neurons are the only neuronal element of developing cerebral WM and persist up to 6 months postnatally. ${ }^{26}$ They may guide thalamocortical and cortical axons. ${ }^{26,41}$ In patients with WMD, apoptotic changes are seen in subplate neurons, WM, and cor- 
tex. ${ }^{40}$ Second, oligodendroglial-axonal interactions are critical for axonal and neuronal development. Therefore, the injury to preoligodendrocytes in WMD could contribute neuronal disruption. ${ }^{26}$ This GM compromise has been recently shown by quantitative volumetric magnetic resonance imaging analysis in expreterm infants, where WMD was associated with both a reduced cerebral cortical and basal ganglia volume and with a reduced thalamic volume. ${ }^{42-44}$ In addition, WM and cortical GM volume reductions are correlated with working memory deficits at 2 years of corrected age and hippocampal volume reductions are correlated with a memory impairment in ex-preterm infants at 13 years. ${ }^{45,46}$ Further, qualitative term magnetic resonance imaging analysis with WMD is positively correlated with superimposed GM abnormalities and global deficits at 2 years of corrected age in ex-preterm infants. ${ }^{47}$

Myelination proceeds from caudal in the first trimester of gestation to rostral up until infancy. ${ }^{48}$ This maturational hierarchy is a plausible explanation for the lesser general impact of CA on the SC as compared with the cerebellum and brain, and the unchanged cerebellar neuronal counts in LPS-treated animals. The developing cerebellum is of particular importance because it might not only influence motor control and posture, but also the more complex cognitive processes. ${ }^{49,50}$

In summary, the CNS inflammatory impact was universal, because all subjects of a given group were almost equally affected. The impact was also interval dependent, because damage was more prominent in the 14-day CA group than in the 2-day group. Moreover, the impact showed selective regional differences, meaning that neither astrocytic and neuronal SC changes nor neuronal cerebellar changes were found in either CA group. Whether the differences between groups are caused by: (1) length of intraamniotic LPS exposure (2- vs 14-day interval); (2) stage of fetal neurodevelopment at the time of LPS exposure (day 111 of gestation vs day 123 of gestation); or (3) both cannot be differenti- ated on the basis of the experimental design of this study.

These findings are relevant because this is the first study showing both global WM and GM impact of an acute CA in association with regional differences.

\section{ACKNOWLEDGMENTS}

We thank Dr Vincent Roelfsema and Dr Odette Besancon for their collaboration and the animal laboratory team for their assistance during the experiments. Our special thanks to Prof Marc De Baets for the generous facilitation of the flow cytometry equipment.

\section{REFERENCES}

1. Lahra MM, Jeffery HE. A fetal response to chorioamnionitis is associated with early survival after preterm birth. Am J Obstet Gynecol 2004;190:147-51.

2. Pacora $P$, Chaiworapongsa T, Maymon E, et al. Funisitis and chorionic vasculitis: the histological counterpart of the fetal inflammatory response syndrome. J Matern Fetal Neonatal Med 2002;11:18-25.

3. Yoon BH, Romero R, Park JS, et al. The relationship among inflammatory lesions of the umbilical cord (funisitis), umbilical cord plasma interleukin 6 concentration, amniotic fluid infection, and neonatal sepsis. Am J Obstet Gynecol 2000;183:1124-9.

4. Dammann O, Leviton A, Bartels DB, Dammann $C E$. Lung and brain damage in preterm newborns. Are they related? How? Why? Biol Neonate 2004;85:305-13.

5. Wu YW. Systematic review of chorioamnionitis and cerebral palsy. Ment Retard Dev Disabil Res Rev 2002;8:25-9.

6. Wu YW, Escobar GJ, Grether JK, Croen LA, Greene JD, Newman TB. Chorioamnionitis and cerebral palsy in term and near-term infants. JAMA 2003;290:2677-84.

7. Yoon BH, Romero R, Park JS, et al. Fetal exposure to an intra-amniotic inflammation and the development of cerebral palsy at the age of three years. Am J Obstet Gynecol 2000;182: 675-81.

8. Back SA, Riddle A, McClure MM. Maturation-dependent vulnerability of perinatal white matter in premature birth. Stroke 2007;38: 724-30.

9. Leviton A, Paneth N, Reuss ML, et al. Maternal infection, fetal inflammatory response, and brain damage in very low birth weight infants: developmental epidemiology network investigators. Pediatr Res 1999;46:566-75.

10. Shah DK, Anderson PJ, Carlin JB, et al. Reduction in cerebellar volumes in preterm infants: relationship to white matter injury and neurodevelopment at two years of age. Pediatr Res 2006;60:97-102

11. Thompson DK, Warfield SK, Carlin JB, et al. Perinatal risk factors altering regional brain structure in the preterm infant. Brain 2007;130:667-77.

12. Garnier $Y$, Coumans $A$, Berger R, Jensen $A$, Hasaart TH. Endotoxemia severely affects circulation during normoxia and asphyxia in immature fetal sheep. J Soc Gynecol Investig 2001;8:134-42.

13. Kramer BW, Moss TJ, Willet KE, et al. Dose and time response after intraamniotic endotoxin in preterm lambs. Am J Respir Crit Care Med 2001;164:982-8

14. Nitsos I, Moss TJ, Cock ML, Harding R, Newnham JP. Fetal responses to intra-amniotic endotoxin in sheep. J Soc Gynecol Investig 2002;9:80-5.

15. Back SA. Recent advances in human perinatal white matter injury. Prog Brain Res 2001;132:131-47.

16. Back SA, Riddle A, Hohimer AR. Role of instrumented fetal sheep preparations in defining the pathogenesis of human periventricular white-matter injury. J Child Neurol 2006;21: 582-9.

17. Duncan JR, Cock ML, Scheerlinck JP, et al. White matter injury after repeated endotoxin exposure in the preterm ovine fetus. Pediatr Res 2002;52:941-9.

18. Jobe AH, Newnham JP, Willet KE, et al. Effects of antenatal endotoxin and glucocorticoids on the lungs of preterm lambs. Am J Obstet Gynecol 2000;182:401-8.

19. Elovitz MA, Mrinalini C, Sammel MD. Elucidating the early signal transduction pathways leading to fetal brain injury in preterm birth. $\mathrm{Pe}$ diatr Res 2006;59:50-5.

20. Nitsos I, Rees SM, Duncan J, et al. Chronic exposure to intra-amniotic lipopolysaccharide affects the ovine fetal brain. J Soc Gynecol Investig 2006;13:239-47.

21. Patrick LA, Gaudet LM, Farley AE, Rossiter JP, Tomalty LL, Smith GN. Development of a guinea pig model of chorioamnionitis and fetal brain injury. Am J Obstet Gynecol 2004;191: 1205-11.

22. Poggi SH, Park J, Toso L, et al. No phenotype associated with established lipopolysaccharide model for cerebral palsy. Am J Obstet Gynecol 2005;192:727-33.

23. Ramsey PS, Lieman JM, Brumfield CG, Carlo W. Chorioamnionitis increases neonatal morbidity in pregnancies complicated by preterm premature rupture of membranes. Am J Obstet Gynecol 2005;192:1162-6.

24. Yoon BH, Kim CJ, Romero R, et al. Experimentally induced intrauterine infection causes fetal brain white matter lesions in rabbits. Am J Obstet Gynecol 1997;177:797-802.

25. Yoon BH, Romero R, Yang SH, et al. Interleukin-6 concentrations in umbilical cord plasma are elevated in neonates with white matter lesions associated with periventricular leukomalacia. Am J Obstet Gynecol 1996;174: 1433-40.

26. Volpe JJ. Encephalopathy of prematurity includes neuronal abnormalities. Pediatrics 2005;116:221-5. 
27. Pang Y, Cai Z, Rhodes PG. Disturbance of oligodendrocyte development, hypomyelination and white matter injury in the neonatal rat brain after intracerebral injection of lipopolysaccharide. Brain Res Dev Brain Res 2003;140: 205-14.

28. Lehnardt S, Lachance C, Patrizi S, et al. The toll-like receptor TLR4 is necessary for lipopolysaccharide-induced oligodendrocyte injury in the CNS. J Neurosci 2002;22:2478-86.

29. Mallard C, Welin AK, Peebles D, Hagberg $\mathrm{H}$, Kjellmer I. White matter injury following systemic endotoxemia or asphyxia in the fetal sheep. Neurochem Res 2003;28:215-23.

30. Paintlia MK, Paintlia AS, Barbosa E, Singh I, Singh AK. N-acetylcysteine prevents endotoxin-induced degeneration of oligodendrocyte progenitors and hypomyelination in developing rat brain. J Neurosci Res 2004;78:347-61.

31. Wang X, Rousset Cl, Hagberg $\mathrm{H}$, Mallard C. Lipopolysaccharide-induced inflammation and perinatal brain injury. Semin Fetal Neonatal Med 2006;11:343-53.

32. Ling Z, Chang QA, Tong CW, Leurgans SE, Lipton JW, Carvey PM. Rotenone potentiates dopamine neuron loss in animals exposed to lipopolysaccharide prenatally. Exp Neuro 2004;190:373-83.

33. Golan HM, Lev V, Hallak M, Sorokin Y, Huleihel M. Specific neurodevelopmental damage in mice offspring following maternal inflammation during pregnancy. Neuropharmacology 2005;48:903-17.

34. Chamnanvanakij S, Margraf LR, Burns $D$, Perlman JM. Apoptosis and white matter injury in preterm infants. Pediatr Dev Patho 2002;5:184-9.

35. Garnier $Y$, Berger R, Alm S, et al. Systemic endotoxin administration results in increased S100B protein blood levels and periventricular brain white matter injury in the preterm feta sheep. Eur J Obstet Gynecol Reprod Biol 2006;124:15-22.

36. Sharangpani A, Takanohashi A, Bell MJ. Caspase activation in fetal rat brain following experimental intrauterine inflammation. Brain Res 2008;1200:138-45.

37. Cammer W. Effects of TNFalpha on immature and mature oligodendrocytes and their progenitors in vitro. Brain Res 2000;864:213-9. 38. Eklind S, Hagberg H, Wang X, et al. Effect of lipopolysaccharide on global gene expression in the immature rat brain. Pediatr Res 2006;60:161-8

39. Bell MJ, Hallenbeck JM. Effects of intrauterine inflammation on developing rat brain. J Neurosci Res 2002;70:570-9.

40. Robinson S, Li Q, Dechant A, Cohen ML. Neonatal loss of gamma-aminobutyric acid pathway expression after human perinatal brain injury. J Neurosurg 2006;104:396-408.

41. Kostovic I, Jovanov-Milosevic N. The development of cerebral connections during the first 20-45 weeks' gestation. Semin Fetal Neonatal Med 2006;11:415-22.

42. Inder TE, Warfield SK, Wang H, Huppi PS, Volpe JJ. Abnormal cerebral structure is present at term in premature infants. Pediatrics 2005;115:286-94.

43. Lin $Y$, Okumura A, Hayakawa F, Kato $K$, Kuno T, Watanabe K. Quantitative evaluation of thalami and basal ganglia in infants with periventricular leukomalacia. Dev Med Child Neurol 2001:43:481-5

44. Srinivasan L, Dutta R, Counsell SJ, et al. Quantification of deep gray matter in preterm infants at term-equivalent age using manual volumetry of 3-tesla magnetic resonance images. Pediatrics 2007;119:759-65.

45. Gimenez M, Junque $C$, Narberhaus A, et al. Hippocampal gray matter reduction associates with memory deficits in adolescents with history of prematurity. Neuroimage 2004;23:869-77.

46. Woodward LJ, Edgin JO, Thompson D, Inder TE. Object working memory deficits predicted by early brain injury and development in the preterm infant. Brain 2005;128:2578-87.

47. Woodward LJ, Anderson PJ, Austin NC, Howard K, Inder TE. Neonatal MRI to predict neurodevelopmental outcomes in preterm infants. N Engl J Med 2006;355:685-94.

48. Holland BA, Haas DK, Norman D, BrantZawadzki M, Newton TH. MRI of normal brain maturation. AJNR Am J Neuroradiol 1986;7: 201-8.

49. Hutton LC, Castillo-Melendez M, Walker DW. Uteroplacental inflammation results in blood brain barrier breakdown, increased activated caspase 3 and lipid peroxidation in the late gestation ovine fetal cerebellum. Dev Neurosci 2007;29:341-54.

50. Hutton LC, Yan E, Yawno T, Castillo-Melendez M, Hirst JJ, Walker DW. Injury of the developing cerebellum: a brief review of the effects of endotoxin and asphyxial challenges in the late gestation sheep fetus. Cerebellum 2007;3:1-10 


\section{Chapter 7}

Intravenous lipopolysaccharide-induced pulmonary maturation and structural changes in fetal sheep.

Kramer, B.W., Ladenburger, A., Kunzmann, S., Speer, C.P., Been, J.V., van Iwaarden, J.F., Zimmermann, L.J., Gantert, M., Garnier, Y. Am J Obstet Gynecol. 2009 Feb;200(2):195.e1-10 


\title{
Intravenous lipopolysaccharide-induced pulmonary maturation and structural changes in fetal sheep
}

\author{
Boris W. Kramer, MD, PhD; Andreas Ladenburger, MD; Steffen Kunzmann, MD; \\ Christian P. Speer, MD, FRCPE; Jasper V. Been, MD; J. Freek van Iwaarden, PhD; \\ Luc J. I. Zimmermann, MD, PhD; Markus Gantert, MD; Yves Garnier, MD, PhD
}

BACKGROUND: Antenatal pulmonary inflammation is associated with reduced risk for respiratory distress syndrome but with an increased risk for bronchopulmonary dysplasia (BPD) with impaired alveogenesis.

OBJECTIVE: We hypothesized that fetal systemic inflammation induced by intravenous (IV) lipopolysaccharide (LPS) would affect lung development in utero.

STUDY DESIGN: Twenty-one fetal sheep were instrumented (107 days gestational age). Control fetuses received saline $(N=12)$ and 9 in the study group received $100 \mathrm{ng}$ of LPS IV 3 days after surgery. Animals were assessed for lung maturation and structure after $3(\mathrm{~N}=5)$ and 7 $(\mathrm{N}=4)$ days.
RESULTS: Interleukin- 6 concentration increased in the bronchoalveolar lavage more than 40-fold 3 days after LPS IV. Processing of prosurfactant protein (SP)-B to mature SP-B and increased SP-B concentrations were shown 7 days after LPS IV. Deposition of elastin fibers at sites of septation was disturbed within 3 days after LPS IV.

CONCLUSION: Lung maturation and disturbed lung structure occurred after short-term exposure to fetal inflammation and suggests new targeted therapies for BPD.

Key words: capillary leakage, chorioamnionitis, fetal circulation, surfactant

Cite this article as: Kramer BW, Ladenburger A, Kunzmann S, et al. Intravenous lipopolysaccharide-induced pulmonary maturation and structural changes in fetal sheep. Am J Obstet Gynecol 2009;200:195.e1-195.e10.

$\mathrm{P}$ reterm infants are frequently exposed in utero to inflammation and to bacterial infection of the amniotic fluid and membranes (chorioamnionitis). Recent studies reported an incidence of chorioamnionitis of approximately $60 \%$ in extremely preterm infants. ${ }^{1}$ The exposure to antenatal inflammation may induce a chronic inflammatory response in fetal airways and pulmonary tissue, which has been associated with the later development of bronchopulmonary dysplasia (BPD). ${ }^{2}$
The role of fetal inflammation in the pathogenesis of BPD has been suggested by increased interleukin (IL)-6 concentrations in cord blood. ${ }^{3,4}$ BPD is nowadays considered to be an impairment of the growth and development of the alveoli and microvasculature aggravated by pulmonary and systemic inflammation postnatally. ${ }^{2,5}$ For example, elastin fibers marking the future site of new alveoli were disrupted in infants and animal models of BPD. ${ }^{6}$ Interestingly, the incidence of respiratory distress syndrome

From the Department of Pediatrics (Drs Kramer, Been, van Iwaarden, and Zimmermann), Maastricht University Hospital Center, the Netherlands, and University Children's Hospital, Wuerzburg (Drs Kramer, Kunzmann, Speer, and Ladenburger); the Department of Obstetrics and Gynecology (Drs Gantert and Garnier), University Hospital of Cologne, Cologne; and the Department of Obstetrics and Gynecology (Drs Gantert and Garnier), Klinikum Osnabrueck, Osnabrueck, Germany.

Received March 5, 2008; revised May 30, 2008; accepted Sept. 3, 2008.

Reprints: Boris W. Kramer, MD, PhD, Department of Pediatrics, Academisch Ziekenhuis Maastricht, Postbus 5800,6202 AZ Maastricht, the Netherlands. bkra@paed.azm.nl.

Supported by the Interdisciplinary Center for Clinical Research, Wuerzburg, Germany, Grant A-27; the Universitätsbund Würzburg, the Schuster Stiftung, Frankfurt a.M., Germany; and the Stichting Kindergeneeskunde, and Research School GROW, University of Maastricht, Maastricht, the Netherlands.

0002-9378/\$36.00 • @ 2009 Mosby, Inc. All rights reserved. • doi: 10.1016/j.ajog.2008.09.009 


\section{FIGURE 1}

\section{Experimental design}

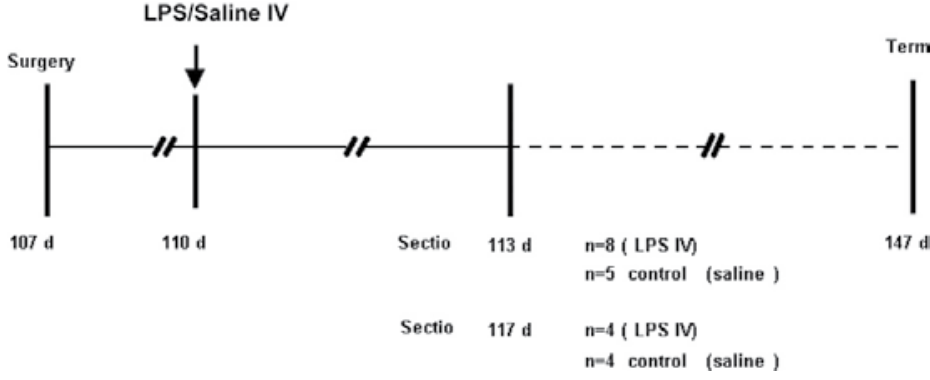

Fetal sheep were chronically instrumented at 107 days (d) of gestation (term is $147 \mathrm{~d}$ ). After surgery, animals were allowed to recover for 3 consecutive d. At gestational d 110 either saline or lipopolysaccharide (LPS) derived from Escherichia coli was injected intravenously (IV). Animals were analyzed 3 or $7 \mathrm{~d}$ after exposure to LPS IV and compared with corresponding control groups. Kramer. Intravenous lipopolysaccharide-induced pulmonary maturation and structural changes in fetal sheep. Am JObstet Gynecol 2009.

for surfactant protein (SP)-B homeostasis, alveolar wall thickness, and compliance as markers of lung maturation and for proliferation, and deposition of elastin fibers to mark future growth of alveoli.

\section{Materials and Methods Animals and surgery}

The animal component of this study was performed at the University of Maastricht, the Netherlands. The experimental protocols were approved by the Animal Medical Ethics Committee of University of Maastricht and met the guidelines of the responsible governmental agencies.

\section{Animal preparation and experimental protocol}

Twenty-one fetal sheep were chronically instrumented at a gestational age (GA) of 106-108 days (term is 147 days) as described previously. ${ }^{15-17}$ Briefly, all ewes received general anesthesia (thiopental sodium $1 \mathrm{~g} / 70 \mathrm{~kg}$ intravenously [IV] for induction, $0.5-1.0 \%$ halothane in a $1: 1$ nitrous oxide and oxygen mixture for maintenance). A midline abdominal incision was performed. The fetal limbs were identified and exteriorized through an incision in the uterus. Polyvinyl catheters (Maxxim Medical BV, Den Bosch, the Netherlands) with $0.75-\mathrm{mm}$ inner diameter and 1.25-mm outer diameter were inserted via a tibial fetal vein and artery of each hind leg and advanced into the caudal vena cava and abdominal aorta, respectively. The fetal skin was closed with cyanoacrylate glue (Cyanolit, Tokyo, Japan). An intrauterine pressure catheter was placed, and the uterus was closed after replacing the lost amniotic fluid with a $0.9 \%$ saline solution at $39^{\circ} \mathrm{C}$. Catheters were filled with heparin (100 IU/mL, Heparin-Natrium; Braun, Melsungen, Germany) and exteriorized through a small incision in the flank of the ewe. Catheters were protected by a pouch sewn to the skin of the ewe. The ewes received $1 \mathrm{~g}$ of ampicillin (Pentrexyl; Bristol-Myers, Woerden, the Netherlands) subcutaneously and 10 $\mu \mathrm{g} / \mathrm{kg}$ body weight of buprenorphine (Temgesic; Schering, Utrecht, the Netherlands) twice a day for 3 consecutive postoperative days. A recovery period of 3 days followed the operation before experiments were started (Figure 1). Fetuses of the control group $(n=9)$ received saline infusion $(5 \mathrm{~mL}$ saline $0.9 \%)$, whereas fetuses of the study group $(\mathrm{n}=12)$ received $100 \mathrm{ng}$ of LPS ( $E$ coli, 0127:B8; Sigma-Aldrich, Frankfurt, Germany) (in $5 \mathrm{~mL}$ saline $0.9 \%$ ) IV at $110 \pm 1$ days GA. Solutions were infused during a period of 10 minutes. Fetal heart rate (FHR) and mean arterial blood pressure (MAP) were continu- ously recorded during the experiment on a personal computer, using a customized hemodynamic data acquisition system (University of Maastricht, Maastricht, the Netherlands).

Blood samples were taken at various time points (ie, $-1,1,3,6,12,24,48$, and 72 hours) from the fetal descending aorta and analyzed for blood gases, acid base balance (AVL 993; Radiometer, Copenhagen, Denmark), hemoglobin concentration, and arterial oxygen saturation of hemoglobin (OSM $2 \mathrm{He}$ moximeter; Radiometer). Animals were grouped as control animals $(\mathrm{N}=12)$ and LPS IV-exposed animals ( $\mathrm{N}=9)(\mathrm{Ta}-$ ble). After the experiment the fetuses were anesthetized with sodium pentobarbitone ( $1 \mathrm{~g} / 70 \mathrm{~kg}$ body weight IV for induction, $0.5-1.0 \%$ halothane in a $1: 1$ nitrous oxide and oxygen mixture for maintenance). Animals were given an overdose of sodium pentobarbitone (150 mg/kg).

\section{Pressure-volume curve and lung processing}

The thorax was opened, the lungs were inflated with air at $40 \mathrm{~cm}$ water pressure for 1 minute, and maximal lung gas volume was recorded. The pressure was sequentially lowered to $20,15,10,5$, and 0 $\mathrm{cm}$ water, and lung gas volumes were recorded 30 seconds after each pressure was reached. Lung gas volumes were corrected for the compliance of the system. Lungs were subsequently removed from the thorax. Bronchoalveolar lavage was performed on the left lung by filling with $0.9 \%$ saline at $4^{\circ} \mathrm{C}$ until visually distended, and repeated 5 times.

\section{IL-6 in the bronchoalveolar lavage fluid}

IL-6 concentration was measured in the bronchoalveolar lavage fluid (BALF) with an ovine specific enzyme-linked immunosorbent assay as previously reported. ${ }^{11}$ Recombinant ovine IL- 6 was used as a standard, which was the generous gift of Dr Alan H. Jobe, Cincinnati, OH. Measurements were done in duplicate.

\section{Alveolar wall thickness and inflammation in the fetal lung}

The right upper lobe was inflation fixed with $4 \%$ formalin at $30 \mathrm{~cm}$ water pressure. 


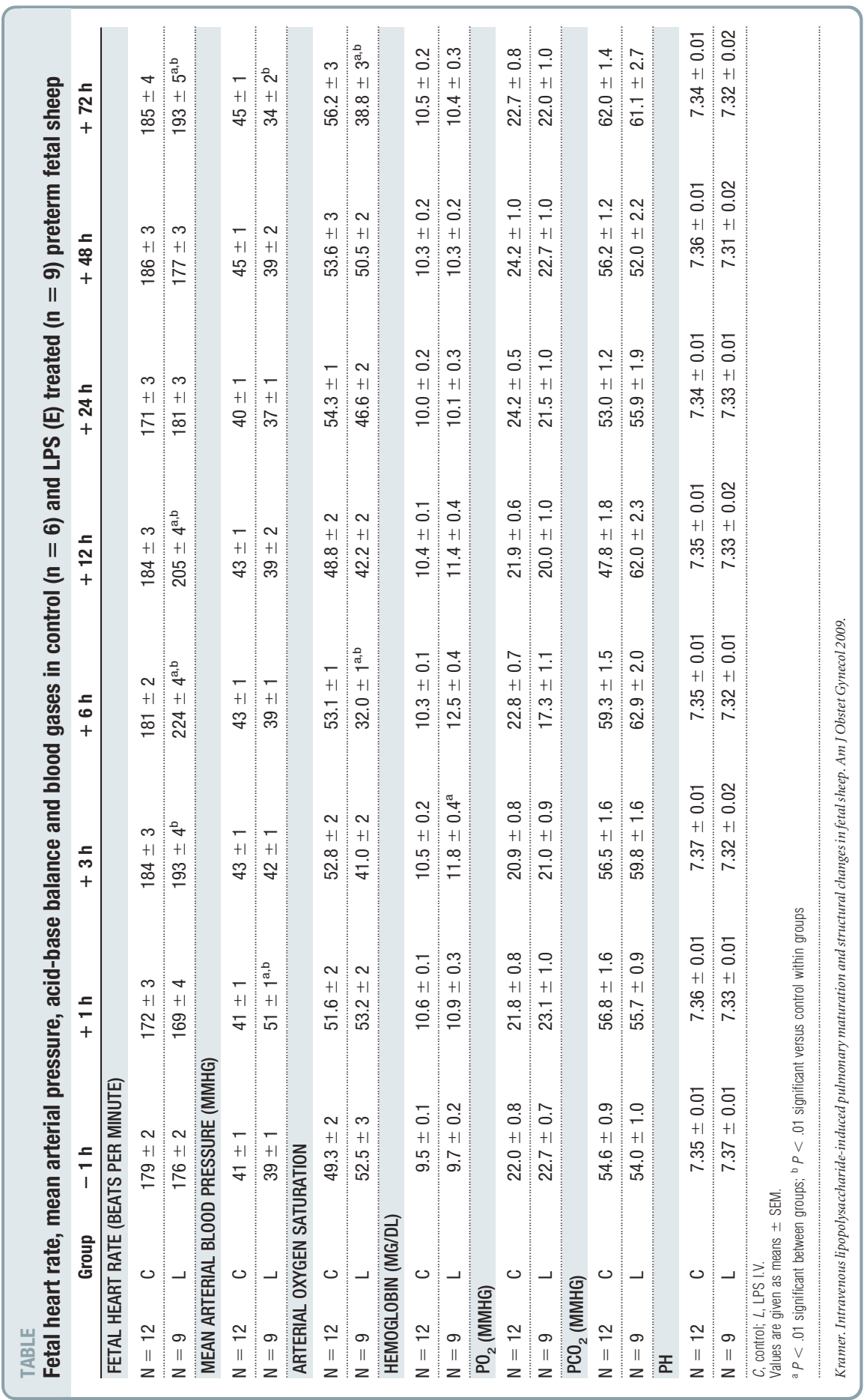


Paraffin tissue sections of $5 \mu \mathrm{m}$ stained with hematoxylin-eosin were analyzed as previously described. ${ }^{18}$ We measured the width of the alveolar walls to quantify thinning of the mesenchyme. This measurement was performed by drawing a line perpendicularly across the distal airspace walls, at the midpoint between the junctions of adjacent airspace walls. We made 60 measurements per tissue section (5 width measurements were made in each of 15 calibrated fields, using a checkerboard sampling scheme to avoid overlapping fields of analysis). ${ }^{19}$ Neutrophils and monocytic cells (monocytes and macrophages) in the airspaces were counted after May-Grünwald staining as previously described. $^{20}$ Six high-power fields were counted in each animal. The average counted neutrophils was calculated for each animal. Comparison was done to the corresponding control group.

\section{Immunohistochemistry}

Immunohistochemistry was done for SP-B and Ki-67. The antibody against ovine SP-B was a generous gift of Dr J. Whitsett, Cincinnati, OH. Lung proliferation was assessed by staining with an antibody against Ki-67, which is an antigen expressed during the cell proliferation cycle but not in resting cells (Dako, Hamburg, Germany).

Sections were treated for 5 minutes in a microwave at $300 \mathrm{~W}$. Endogenous peroxidase activity was removed by incubation with hydrogen peroxide. Nonspecific binding sites for the antibody were blocked with serum. After washing, slides were incubated with the corresponding secondary biotinylated antibody (Vector Laboratories, Burlingame, CA). Avidin and horseradish peroxidase were added (Vector Laboratories). Staining of positive cells was developed with diaminobenzidine. Counterstaining was done with hematoxylin.

We used a 5-step semiquantative scale to analyze immunohistochemistry as previously described. ${ }^{21}$ Two independent observers who were unaware of the identity of the samples did the analysis at $\times 20$ and $\times 40$ magnification. Four to 5 tissue sections of each lung from different regions were analyzed. The average count of all results was calculated for each lung.

\section{FIGURE 2}

Inflammation and neutrophils in fetal lungs
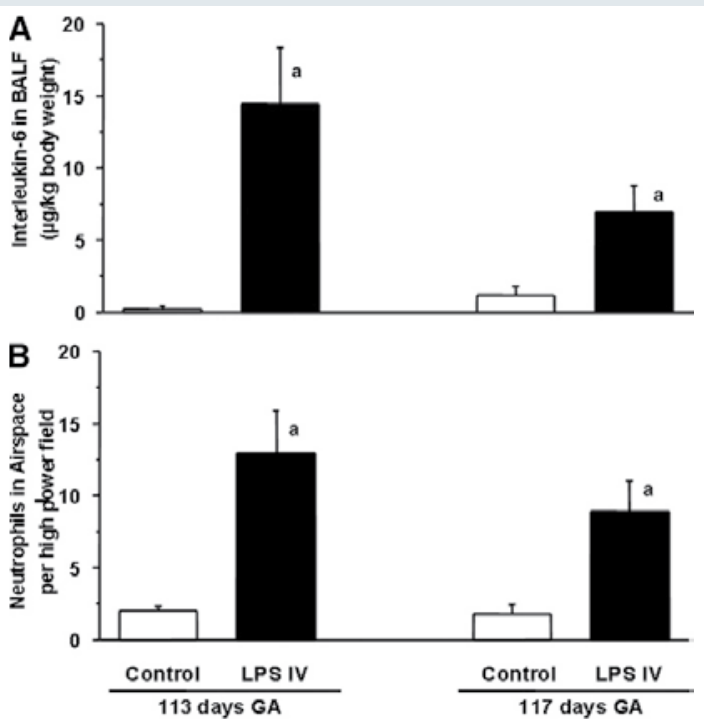

A, Concentration of interleukin (IL)-6 in bronchoalveolar lavage fluid (BALF) was quantified by enzyme-linked immunosorbent assay specific for ovine IL-6. Concentration of IL-6 was more than 70-fold increased 3 days after lipopolysaccharide (LPS) intravenously (IV) in comparison with control animals at 113 days gestational age $(G A)$. Concentration in BALF from control animals at 117 days GA was not significantly higher than in control animals at 113 days GA ( ${ }^{\mathrm{a}} P=.18$ ). IL-6 was higher in BALF from animals 7 days after LPS IV than in control animals ( ${ }^{\mathrm{a}} P<.05$ vs control). B, Neutrophils were counted in airspaces of fetal lungs. Six high-power fields were counted in each animal. Average of counted neutrophils was calculated for each animal. Number of neutrophils increased more than 4-fold 3 days after LPS IV and was increased 7 days after LPS IV in comparison with corresponding control groups ( ${ }^{\mathrm{P}} P<.05$ vs control).

Kramer. Intravenous lipopolysaccharide-induced pulmonary maturation and structural changes in fetal sheep. Am J Obstet Gynecol 2009.

\section{Western blot}

SP-B as a marker of surfactant and lung maturation was measured in BALF. ${ }^{22}$ Sodium dodecylsulfate-polyacrylamide gel electrophoresis for SP-B was carried out using $10-20 \%$ gradient tricine gels (Novex, San Diego, CA). ${ }^{22}$ Samples were electrophoresed along with an ovine SP-B standard under nonreducing conditions and normalized for phospholipids, the major component of surfactant. $^{22}$ Proteins were transferred to polyvinylidene fluoride (PVDF) membranes (Schleicher \& Schuell, Keene, $\mathrm{NH}$ ) for immunoblot analysis using a rabbit anti-SP-B that reacts with both completely $\left(\mathrm{M}_{\mathrm{r}} \sim 16,000\right)$ and partially $\left(M_{\mathrm{r}} \sim 25,000\right)$ processed forms of SP-B (generous gift of Dr J. A. Whitsett, Division of Pulmonary Medicine, Cincinnati Children's Hospital Medical Center, Cincinnati, $\mathrm{OH})$. The PVDF membrane was first blocked with 5\% low-fat milk (wt/vol) in TRIS-buffered saline, pH 7.4, containing $0.1 \%$ (vol/vol) Tween 20 . The antibody was diluted and incubated overnight. Horseradish peroxidase-conjugated goat antirabbit immunoglobulin (Calbiochem, La Jolla, CA) was used as secondary antibody, and enhanced chemiluminescence substrates (Amersham, Arlington Heights, IL) were used to develop the immunoblots. Results were corrected for volume of BALF and sample volume loaded in each lane. Experiments were repeated 3 times. 


\section{FIGURE 3}

\section{Proliferation}
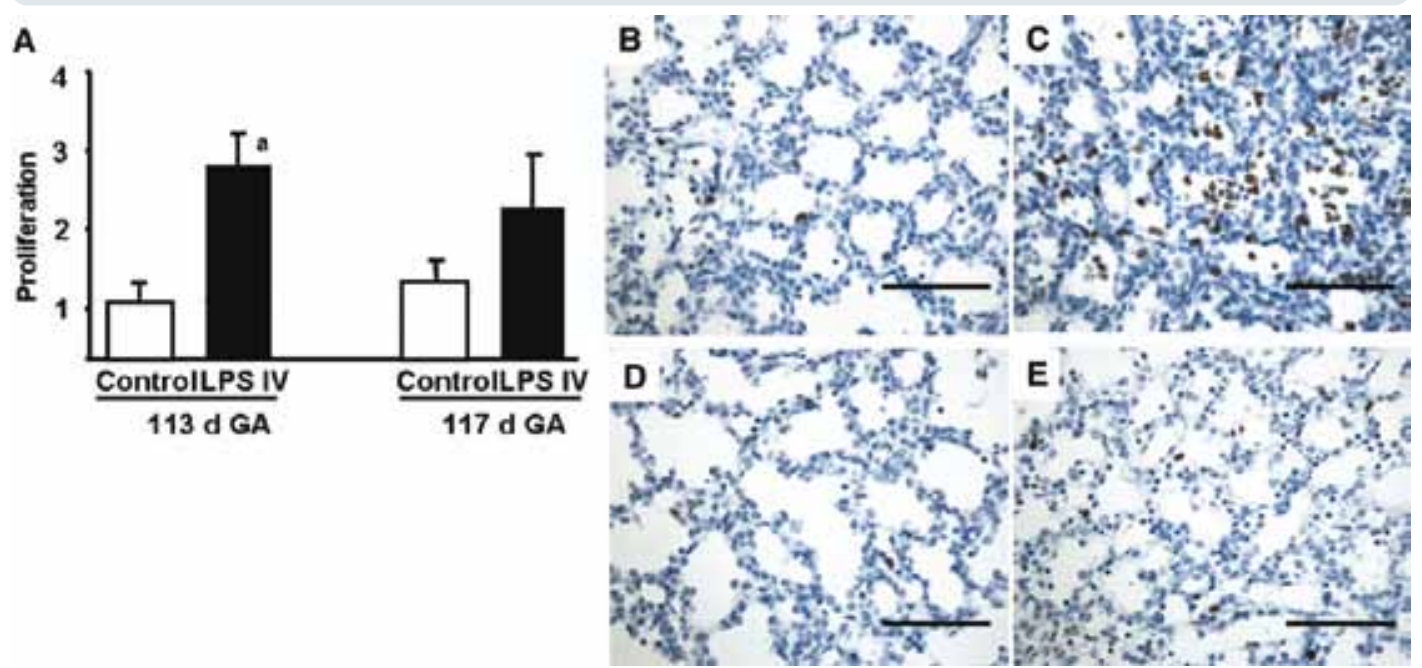

Fetal lungs were stained with Ki-67, a marker that detects cells in proliferation entering phase G1, S, G2, and, M, but not resting cells. A, Semiquantitative analysis of Ki-67-positive cells in fetal lungs. Two-fold increase in proliferating cells was detected 3 days ( $d$ ) after lipopolysaccharide (LPS) intravenously (IV) in comparison with age-matched control group at $113 \mathrm{~d}$ gestational age $(G A)\left({ }^{\mathrm{a}} P<.05\right)$ but not $7 \mathrm{~d}$ after LPS IV. B, Representative sections are depicted for Ki-67 immunohistochemistry in lungs of control animals at $113 \mathrm{~d}$ GA and C, corresponding animals $3 \mathrm{~d}$ after LPS IV as in D, control animals at $117 \mathrm{~d}$ GA and E, animals $7 \mathrm{~d}$ after LPS IV. Scale bar represents $50 \mu \mathrm{m}$.

Kramer. Intravenous lipopolysaccharide-induced pulmonary maturation and structural changes in fetal sheep. Am J Obstet Gynecol 2009.

\section{Total protein}

Total protein was measured in the BALF by the method of Lowry as previously described as a marker for capillary leakage. ${ }^{11}$ Results were calculated per kilogram of body weight.

\section{Elastin fibers}

Elastin fibers were stained with a Hart's resorcin-fuchsin solution. ${ }^{23}$ In short, $5-\mu \mathrm{m}$ paraffin slides were hydrated and stained in a resorcin-fuchsin solution with hydrochloric acid and counterstained with a tartrazine solution. Elastin fibers were stained in black and all other tissue elements in yellow. Slides were analyzed in a blinded fashion in which normal, concentrated deposition of elastin at the tips of secondary crests was recorded in distinction from nonfocal deposition along the epithelium of alveoli. $^{6}$

\section{Data analysis}

Results are given as means \pm SEM. Comparisons between groups were done by analysis of variance with Student-Newman-Keuls test used for post hoc analysis. Significance was accepted at $P<.05$.

\section{Results}

Physiologic variables, blood gases, acid-base balance

All measurements of FHR, MAP, hemoglobin, and blood gases during the control period were in the normal range for chronically prepared fetal sheep of this GA. ${ }^{12}$ There were no significant differences between control and LPS-treated animals at the time point of injection (Table). Unlike in controls, FHR increased 6 hours after LPS injection from $176 \pm 5$ to $224 \pm 11$ beats/min $(27 \% ; P<.05)$, and remained higher than in control animals until it normalized 15 hours after the LPS infusion was started. MAP increased 1 hour after LPS infusion by $24 \%(P<.001)$ and returned to control levels 4-6 hours after LPS administration. Oxygen saturation was lower in the LPS group at 6 hours $(-40 \% ; P$ $<.05$ ) and slowly recovered during the following 24 hours although not completely ( $P<.05$ at 72 hours). There were no significant differences in arterial blood $\mathrm{pH}$ and blood gas parameters between the 2 groups (Table). Birth weights and lung weights were not different at delivery (data not shown).

\section{IL-6 in the BALF}

The concentration of IL- 6 in BALF from control animals at 117 days GA was not significantly higher than in control animals at 113 days GA $(P=.18)$. IL-6 concentration increased 3 days after LPS IV in comparison with control animals at 113 days GA more than 70-fold (Figure 2, A). Seven days after LPS IV, IL-6 was still higher in BALF from endotoxin-exposed animals.

\section{Inflammation in the Fetal Lung}

Pulmonary inflammation was assessed by neutrophils and monocytic cells in the 


\section{FIGURE 4}

\section{Surfactant protein B}
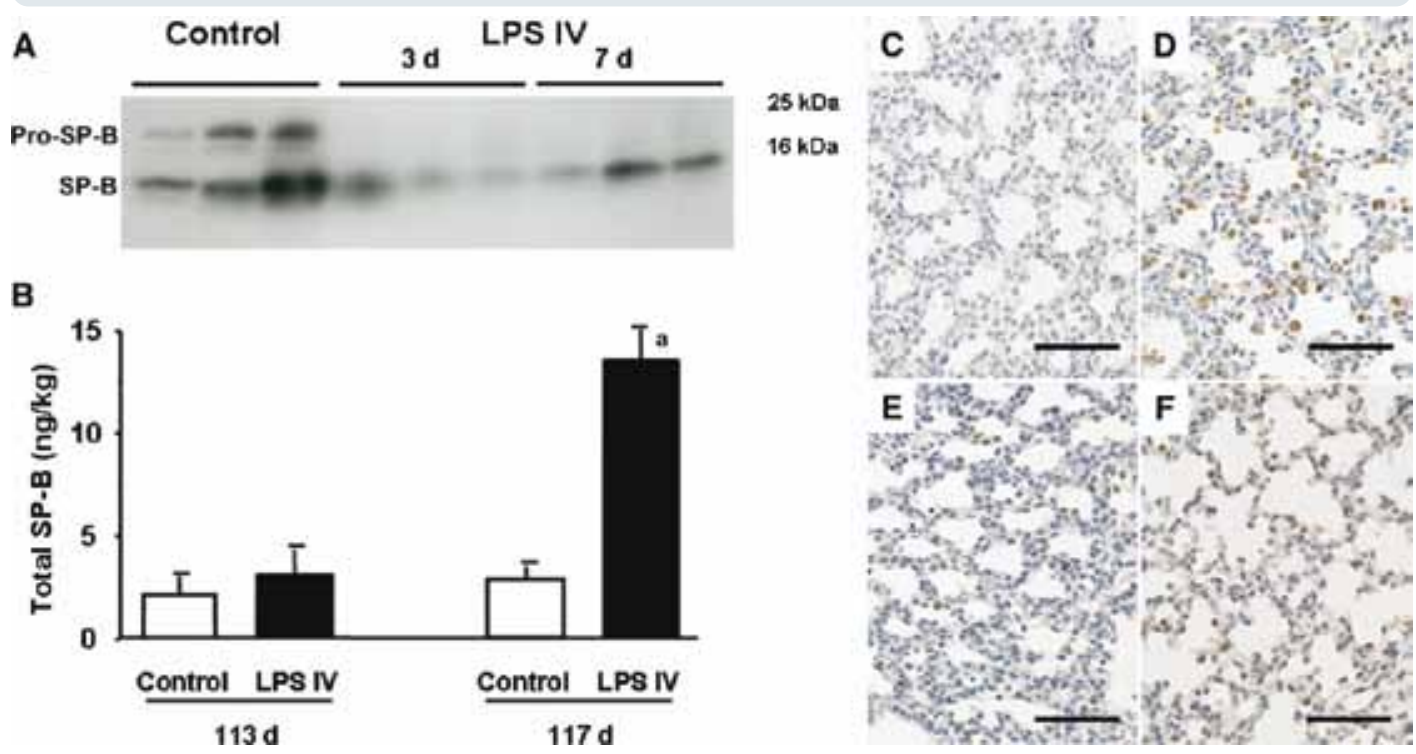

A, Western blot for unprocessed and processed surfactant protein (SP)-B in bronchoalveolar lavage fluid (BALF). Partially processed SP-B (M $\left.\mathrm{M}_{\mathrm{r}} \sim 25,000\right)$ was detected in control animals at both 113 and 117 days (d) gestational age (GA) but not in animals 3 and $7 \mathrm{~d}$ after lipopolysaccharide (LPS) intravenously (IV). Mature SP-B homodimer $\left(\mathrm{M}_{\mathrm{r}} \sim 16,000\right)$ was detected in animals 3 and $7 \mathrm{~d}$ after LPS IV. Concentration of SP-B in BALF varied considerably. B, Total amount of SP-B was, therefore, calculated after adjusting for different sample volume, total volume of BALF, and body weight in each animal. Seven d after LPS IV, SP-B was significantly increased ( ${ }^{\mathrm{a}} P<.05$ vs control animals at $117 \mathrm{~d}$ GA) but not $3 \mathrm{~d}$ after LPS IV. Representative sections detecting SP-B in alveolar type II cells are shown for C, $113 \mathrm{~d}$ GA control animals, D, $3 \mathrm{~d}$ after LPS IV, E, GA control at 117, F, and $7 \mathrm{~d}$ after LPS IV, suggesting that SP-B is increased in alveolar type II cells but not secreted $3 \mathrm{~d}$ after LPS IV.

Kramer. Intravenous lipopolysaccharide-induced pulmonary maturation and structural changes in fetal sheep. Am J Obstet Gynecol 2009.

airspaces of the fetal lungs. Six highpower fields were chosen randomly and counted in each animal. The average number of neutrophils was calculated for each animal. The number of neutrophils increased more than 4 -fold 3 days after LPS IV and was increased 7 days after LPS IV in comparison with the corresponding control groups (Figure 2, B) $(P<.05$ vs control).

\section{Proliferation}

The proliferation was increased 2.8 -fold 3 days after LPS IV but not 7 days after LPS IV in comparison with GA controls (Figure 3). Representative sections are shown from 113 days GA control animals (Figure 3, B) and 3 days after LPS IV (Figure 3, C). Staining for Ki-67 was not increased 7 days after LPS IV (Figure 3, A and $\mathrm{E}$ ) in comparison with the GA control animals at 117 days (Figure 3, D).

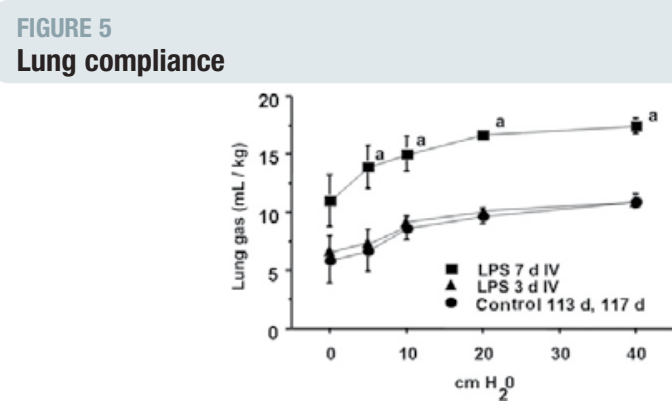

Lungs were isolated and deflation limb of pressure volume curve was performed. Lung gas volumes increased 7 days ( $d$ ) after lipopolysaccharide (LPS) intravenously (IV) but not $3 \mathrm{~d}$ after LPS IV No difference between control animals at 113 and 117 d' gestational age was detected ( ${ }^{a} P<.05$ vs control $113 d, 117 d)$.

Kramer. Intravenous lipopolysaccharide-induced pulmonary maturation and structural changes in fetal sheep. Am J Obstet Gynecol 2009 . 


\section{FIGURE 6}

\section{Alveolar septae}
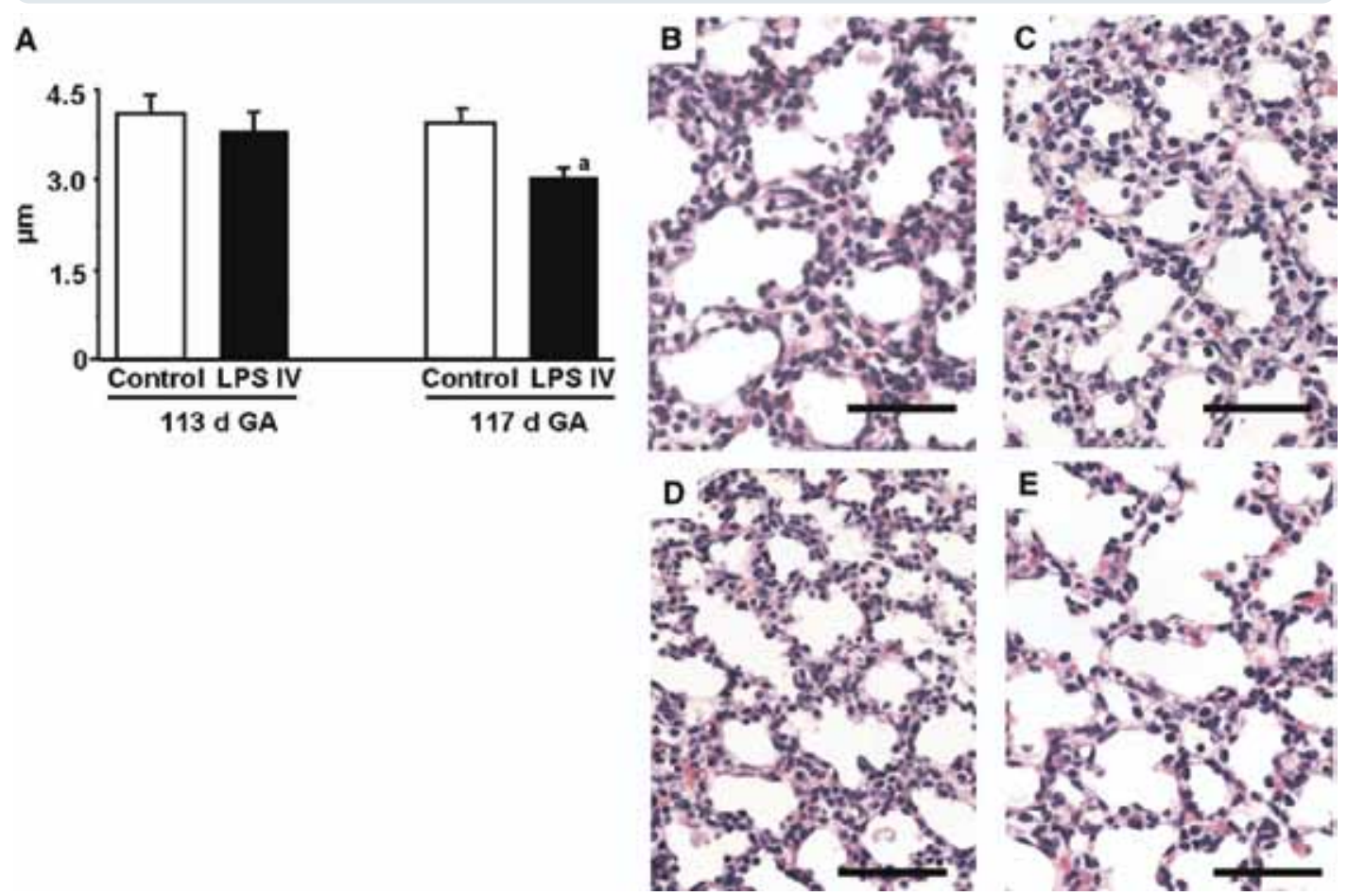

A, Thickness of alveolar septae was measured. No difference found between control animals at 113 days (d) gestational age (GA) and animals $3 \mathrm{~d}$ after lipopolysaccharide (LPS) intravenously (IV). Thickness of alveolar septae was reduced $7 \mathrm{~d}$ after LPS IV in comparison with age-matched control animals at $117 \mathrm{~d} \mathrm{GA}\left({ }^{\mathrm{a}} P<.05\right.$ vs control $\left.117 \mathrm{~d} \mathrm{GA}\right)$. B, Representative sections of hematoxylin-eosin staining of lungs of control animals at $113 \mathrm{~d}$ GA and C, corresponding animals $3 \mathrm{~d}$ after LPS IV as in D, control animals at $117 \mathrm{~d}$ GA and E, animals $7 \mathrm{~d}$ after LPS IV. Scale bar represents $20 \mu \mathrm{m}$. Kramer. Intravenous lipopolysaccharide-induced pulmonary maturation and structural changes in fetal sheep. Am J Obstet Gynecol 2009.

\section{Lung maturation}

Partially processed SP-B $\left(\mathrm{M}_{\mathrm{r}} \sim 25,000\right.$ $\mathrm{Da})$ was detectable in BALF from control animals at 113 and 117 days GA (Figure 4, A). At 3 and 7 days after LPS IV, SP-B was completely processed and the homodimer was exclusively detected $\left(\mathrm{M}_{\mathrm{r}} \sim 16,000\right)$ (Figure $\left.4, \mathrm{~A}\right)$. When calculated relative to body weight, secreted SP-B tripled 7 days after LPS IV in comparison with control animals, whereas there was no increase in SP-B pool size 3 days after LPS IV (Figure 4, B). Representative sections detecting SP-B in alveolar type II cells are shown for 113 days GA control animals (Figure 4, C), 3 days after LPS IV (Figure 4, D), GA control at 117 days
(Figure 4, E), and 7 days after LPS IV (Figure 4, F) showing increased SP-B in alveolar type II cells but not secreted 3 days after LPS IV.

\section{Lung gas volume}

The lung gas volume at $40 \mathrm{~cm}$ water pressure was increased to $17.3 \pm 0.9 \mathrm{~mL} / \mathrm{kg}$ body weight 7 days after LPS IV in comparison with $9.7 \pm 0.7 \mathrm{~mL} / \mathrm{kg} 3$ days after LPS IV or $10.1 \pm 0.3 \mathrm{~mL} / \mathrm{kg}$ in controls with no difference between 113 and 117 days GA (Figure 5).

\section{Lung remodeling}

The mean thickness of the alveolar wall was reduced to $3.6 \pm 0.2 \mu \mathrm{m} 3$ days after LPS IV ( $P>.05$ vs control 113 days GA)
(Figure 6, C) and to $3.2 \pm 0.1 \mu \mathrm{m}(P<$ .05 vs control 117 days GA) 7 days after LPS IV (Figure 6, E) as shown in representative sections. The alveolar walls were thinner in all animals exposed to LPS IV (Figure 6, A) as part of the changes seen in lung maturation. ${ }^{18}$ Alveolar septae were not different in control animals at the 2 different GAs (Figure 6, $\mathrm{B}$ and D).

\section{Alveolar-capillary leakage}

The capillary barrier was impaired as shown by the increase in total protein in the BALF (Figure 7). Total protein increased 2-fold 3 days after LPS IV and 3 -fold 7 days after LPS IV in comparison with age-matched controls. 


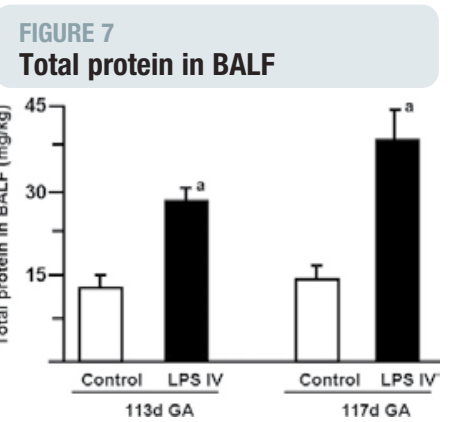

Total protein in bronchoalveolar lavage fluid (BALF). Total protein was quantified as marker for capillary leakage. Total protein was increased 3 and 7 days ( $d$ ) after lipopolysaccharide (LPS) intravenously $(I V$ indicating capillary damage after systemic inflammation ( ${ }^{\mathrm{P}} P<.05$ vs corresponding control animals). GA, gestational age.

Kramer. Intravenous lipopolysaccharide-induced pulmonary maturation and structural changes in fetal sheep. Am J Obstet Gynecol 2009.

\section{Elastin deposition}

The deposition of elastin fibers was altered after exposure to LPS IV (Figure 8). Elastin was located primarily in control animals of 113 (Figure 8, B) and 117 (Figure 8, D) days GA at the distal tips of secondary crests, marking the site where future alveoli will form. In contrast, the elastin fibers in animals exposed to LPS IV were scattered along the wall with lack of definition of secondary crests (Figure 8, C and E). Analysis of the distribution of elastin in the lungs of animals after LPS IV showed decreased deposition of normal elastin fibers in the alveolar crests at both 3 and 7 days after LPS IV (Figure 8, A).

\section{Comment}

The present study investigated the role of systemic fetal inflammation in the pathogenesis of inflammation-associated lung development in utero. We found that intrauterine exposure to LPS IV resulted in pulmonary inflammation and changed the pattern of elastin deposition in future alveolar septae with increased IL- 6 concentrations in the fetal lung.

Remarkably, this intravascular, intrauterine exposure to inflammation was sufficient to affect lung development within 3 days as shown by the elastin deposition of future alveoli. The transient increase in proliferation did not result in a normal deposition of elastin fibers and subsequent normal development. Apparently, the lung inflammation as indicated by increased IL- 6 concentrations was severe enough to negatively affect lung development in utero. The present study suggests that the IL-6 pathway may be relevant in both lung injury and repair after antenatal inflammation. These signaling pathways were (still) activated 3 days after LPS IV although the structural phenotype of increased compliance, reduced alveolar wall thickness, and increase in SP-B concentration were not detectable until 7 days after LPS IV. The increased SP-B expression can be considered in part as lung maturation. However, in vivo and in vitro studies have shown antiinflammatory properties of SP-B and phospholipids. SP-B can limit the inflammation after intratracheal endotoxin instillation. ${ }^{24,25}$ SP-B, SP-C, and phospholipids reduced the transcription of tumor necrosis factor- $\alpha$ in monocytes. ${ }^{26,27}$ In addition, surfactant preparations of SP-B and phospholipids enhanced the phagocytosis of apoptotic cells as part of the resolution of inflammation. ${ }^{28}$ Therefore, the increase in surfactant pool size may have primarily antiinflammatory effects and may be a mechanism of fetal adaptation, which clinically appears as lung maturation and thus optimizes adaptation-and survival-after preterm birth. ${ }^{29}$

The kinetics of lung maturation after IV LPS were not different from intraamniotic LPS administration. ${ }^{11}$ Lung maturation was detectable 7 days but not 3 days after IV LPS. Apparently, the pulmonary immune system is involved in the inflammation-mediated lung maturation. ${ }^{30-32}$ Kallapur et $\mathrm{l}^{31}$ used a monoclonal antibody against CD18 that blocked the recruitment of neutrophils into the alveoli after intraamniotic LPS injection. Lung maturation was mostly ablated in the absence of neutrophils, which suggests an essential role of this cell type in the inflammation-mediated prenatal lung maturation. We, therefore, conclude from this study that systemic fetal inflammation is sufficient to induce lung maturation but does not induce lung maturation faster than intraamniotic LPS. This study demonstrates the importance of systemic inflammation for lung pathology in clinical contexts. The high incidence of chorioamnionitis in preterm births predisposes the fetuses to systemic inflammation and infection. Inflammation has been associated with adverse pulmonary outcomes and higher susceptibility to hypoxic brain injury. ${ }^{33,34}$ Our study showed that systemic inflammation contributed to the prenatal injury and structural changes in the lung of the fetus. Unfortunately, we do not have any data to address the question of whether a single exposure, as in our model, will yield a durable or permanent disruption of alveolar development.

The pivotal effects of antenatal inflammation on lung growth and lung maturation are further complicated by subsequent injuries and prenatal conditioning of the immune system. ${ }^{12}$ Birth with resuscitation, oxygen, mechanical ventilation, barotrauma, and volutrauma might be second hits onto the already injured lung. ${ }^{2,5,35}$ The preterm baby will respond to these postnatal injuries depending on the prenatal conditioning of the immune system. ${ }^{29,30,32,36}$ Repetitive intraamniotic endotoxin injections, for example, decreased the response of fetal monocytes (endotoxin tolerant) in the blood and in the lung. ${ }^{30,37}$ Monocytes did not respond to a second endotoxin stimuli and no inflammatory response was initiated. The effect was not limited to a subgroup of immune cells but endotoxin tolerance was a major risk factor for developing nosocomial infection in intensive care departments. ${ }^{38}$ Systemic inflammation in utero is, therefore, a serious condition that may predispose the fetus-in a wider perspective-to a kind of multiorgan disease with injury of the lung, paralysis of the immune system, and susceptibility to hypoxic brain injury. ${ }^{39}$ All therapeutic approaches will have to balance the beneficial effects on lung maturation on the one hand and the detrimental effects on lung structure on the other hand. 


\section{FIGURE 8}

\section{Elastin deposition in fetal lung}
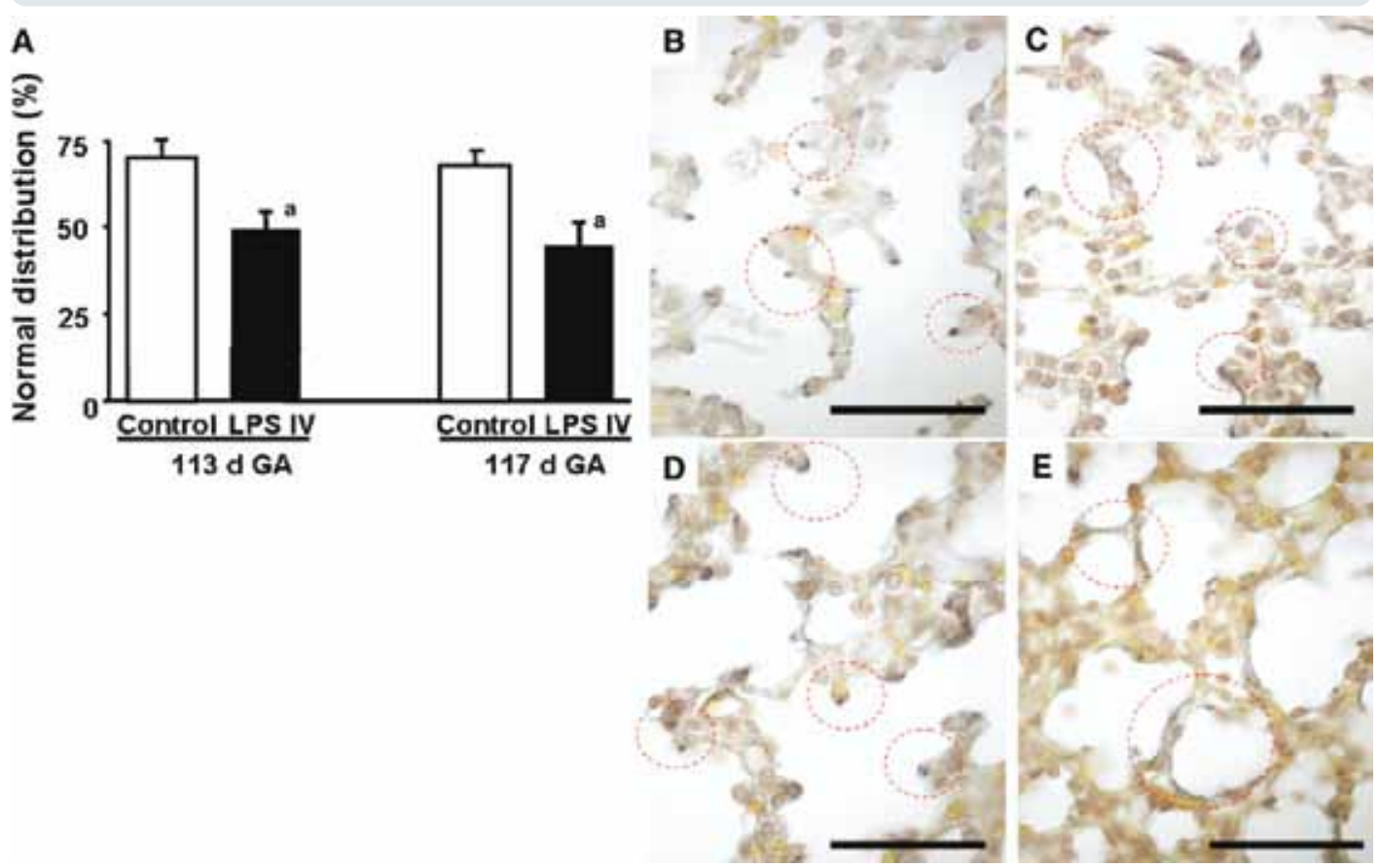

A, Normal, concentrated deposition of elastin at tips of secondary crests was recorded in distinction from outspread deposition along epithelium of alveoli. Normal deposition of elastin was reduced 3 and 7 days (d) after lipopolysaccharide (LPS) intravenously (IV) in comparison with age-matched control animals ( ${ }^{\mathrm{P}}<.05$ ). Representative sections of elastin staining (black) with tartrazine counterstain (yellow) of lungs are shown. B, Normal deposition of elastin was highlighted in red circles in control animals at $113 \mathrm{~d}$ gestational age (GA) in comparison with C, animals $3 \mathrm{~d}$ after LPS IV in which elastin was no longer deposited in tip of secondary crest but was spread out along alveoli. D, Normal deposition of elastin was also predominantly observed in control animals at $117 \mathrm{~d}$ GA but not in E, animals $7 \mathrm{~d}$ after LPS IV. Scale bar represents $10 \mu \mathrm{m}$.

Kramer. Intravenous lipopolysaccharide-induced pulmonary maturation and structural changes in fetal sheep. Am J Obstet Gynecol 2009.

\section{ACKNOWLEDGMENTS}

We thank Michaela Kapp, Daniele Herbst, and Silvia Seidenspinner for excellent technical help.

\section{REFERENCES}

1. Lahra MM, Jeffery HE. A fetal response to chorioamnionitis is associated with early survival after preterm birth. Am J Obstet Gynecol 2004;190:147-51.

2. Speer CP. Inflammation and bronchopulmonary dysplasia: a continuing story. Semin Fetal Neonatal Med 2006;11:354-62.

3. Yoon BH, Romero R, Kim KS, et al. A systemic fetal inflammatory response and the development of bronchopulmonary dysplasia. Am J Obstet Gynecol 1999;181: 773-9.

4. Gomez R, Romero R, Ghezzi F, Yoon BH, Mazor M, Berry SM. The fetal inflammatory response syndrome. Am J Obstet Gynecol 1998;179:194-202.
5. Jobe $A H$, Bancalari E. Bronchopulmonary dysplasia. Am J Respir Crit Care Med 2001;163:1723-9.

6. Bland RD. Neonatal chronic lung disease in the post-surfactant era. Biol Neonate 2005; 88:181-91.

7. Watterberg KL, Demers LM, Scott SM, Murphy S. Chorioamnionitis and early lung inflammation in infants in whom bronchopulmonary dysplasia develops. Pediatrics 1996;97:210-5. 8. Bry K, Lappalainen U, Hallman M. Intraamniotic interleukin-1 accelerates surfactant protein synthesis in fetal rabbits and improves lung stability after premature birth. J Clin Invest 1997;99:2992-9.

9. Jobe AH, Newnham JP, Willet KE, et al. Effects of antenatal endotoxin and glucocorticoids on the lungs of preterm lambs. Am J Obstet Gynecol 2000;182:401-8.

10. Kallapur SG, Willet KE, Jobe AH, Ikegami M, Bachurski CJ. Intra-amniotic endotoxin: chorioamnionitis precedes lung maturation in preterm lambs. Am J Physiol Lung Cell Mol Physiol 2001;280:L527-36.

11. Kramer BW, Moss TJ, Willet KE, et al. Dose and time response after intraamniotic endotoxin in preterm lambs. Am J Respir Crit Care Med 2001;164:982-8.

12. Kramer BW. Antenatal inflammation and lung injury: prenatal origin of postnatal disease. J Perinatol 2008;28:S21-7.

13. Shimoya K, Taniguchi T, Matsuzaki N, et al. Chorioamnionitis decreased incidence of respiratory distress syndrome by elevating fetal interleukin-6 serum concentration. Hum Reprod 2000;15:2234-40.

14. Tauscher MK, Berg D, Brockmann M, Seidenspinner S, Speer CP, Groneck P. Association of histologic chorioamnionitis, increased levels of cord blood cytokines, and intracerebral hemorrhage in preterm neonates. Biol Neonate 2003;83:166-70. 
15. Garnier $Y$, Coumans A, Berger R, Jensen A, Hasaart TH. Endotoxemia severely affects circulation during normoxia and asphyxia in immature fetal sheep. J Soc Gynecol Investig 2001;8:134-42.

16. Garnier $Y$, Coumans AB, Berger R, Hasaart $\mathrm{TH}$. Pulmonary perfusion during lipopolysaccharide (LPS) induced fetal endotoxemia in the preterm fetal sheep. Eur J Obstet Gynecol Reprod Biol 2006;124:150-7.

17. Garnier $Y$, Coumans $A B$, Jensen $A$, Hasaart $T H$, Berger R. Infection-related perinatal brain injury: the pathogenic role of impaired fetal cardiovascular control. J Soc Gynecol Investig 2003;10:450-9.

18. Willet KE, Jobe AH, Ikegami M, Newnham J, Brennan S, Sly PD. Antenatal endotoxin and glucocorticoid effects on lung morphometry in preterm lambs. Pediatr Res 2000;48:782-8.

19. Bolender RP, Hyde DM, Dehoff RT. Lung morphometry: a new generation of tools and experiments for organ, tissue, cell, and molecular biology. Am J Physiol Lung Cell Mol Physiol 1993;265:L521-48.

20. Kramer BW, Jobe AH, Bachurski CJ, Ikegami M. Surfactant protein A recruits neutrophils into the lungs of ventilated preterm lambs. Am J Respir Crit Care Med 2001;163:158-65. 21. Kramer BW, Kaemmerer U, Kapp M, et al. Decreased expression of angiogenic factors in placentas with chorioamnionitis after preterm birth. Pediatr Res 2005;58:607-12.

22. Bachurski CJ, Ross GF, Ikegami M, Kramer $\mathrm{BW}$, Jobe AH. Intra-amniotic endotoxin increases pulmonary surfactant proteins and induces SP-B processing in fetal sheep. Am J
Physiol Lung Cell Mol Physiol 2001;280: L279-85.

23. Bland RD, Albertine $\mathrm{KH}$, Pierce RA, Starcher BC, Carlton DP. Impaired alveolar development and abnormal lung elastin in preterm lambs with chronic lung injury: potential benefits of retinol treatment. Biol Neonate 2003;84: 101-2.

24. Epaud $R$, Ikegami $M$, Whitsett JA, Jobe $A H$, Weaver TE, Akinbi HT. Surfactant protein B inhibits endotoxin-induced lung inflammation. Am J Respir Cell Mol Biol 2003;28:373-8.

25. Ikegami M, Whitsett JA, Martis PC, Weaver TE. Reversibility of lung inflammation caused by SP-B deficiency. Am J Physiol Lung Cell Mol Physiol 2005;289:L962-70.

26. Baur FM, Brenner B, Goetze-Speer B, Neu $S$, Speer CP. Natural porcine surfactant (Curosurf) down-regulates mRNA of tumor necrosis factor-alpha (TNF-alpha) and TNF-alpha type II receptor in lipopolysaccharide-stimulated monocytes. Pediatr Res 1998;44:32-6.

27. Speer CP, Gotze B, Curstedt T, Robertson B. Phagocytic functions and tumor necrosis factor secretion of human monocytes exposed to natural porcine surfactant (Curosurf). Pediatr Res 1991;30:69-74.

28. Kramer BW, Jobe AH, Ikegami M. Monocyte function in preterm, term, and adult sheep. Pediatr Res 2003;54:52-7.

29. Kramer BW, Jobe AH. The clever fetus: responding to inflammation to minimize lung injury. Biol Neonate 2005;88:202-7.

30. Kallapur SG, Jobe AH, Ball MK, et al. Pulmonary and systemic endotoxin tolerance in preterm fetal sheep exposed to chorioamnionitis. J Immunol 2007;179:8491-9.
31. Kallapur SG, Moss TJ, Ikegami M, Jasman RL, Newnham JP, Jobe AH. Recruited inflammatory cells mediate endotoxin-induced lung maturation in preterm fetal lambs. Am J Respir Crit Care Med 2005;172:1315-21.

32. Kramer BW, Joshi SN, Moss TJ, et al. Endotoxin-induced maturation of monocytes in preterm fetal sheep lung. Am J Physiol Lung Cell Mol Physiol 2007;293:L345-53.

33. Dammann O, Leviton A. Inflammation, brain damage and visual dysfunction in preterm in fants. Semin Fetal Neonatal Med 2006;11: 363-8.

34. Hagberg H, Dammann O, Mallard C, Leviton A. Preconditioning and the developing brain. Semin Perinatol 2004;28:389-95.

35. May M, Strobel P, Preisshofen T, Seidenspinner S, Marx A, Speer CP. Apoptosis and proliferation in lungs of ventilated and oxygentreated preterm infants. Eur Respir J 2004; 23:113-21.

36. Kunzmann S, Speer CP, Jobe AH, Kramer BW. Antenatal inflammation induced TGF\{beta\} 1 but suppressed CTGF in preterm lungs. Am J Physiol Lung Cell Mol Physiol 2007; 292:L223-31.

37. Kramer BW, Ikegami M, Moss TJ, Nitsos I, Newnham JP, Jobe AH. Endotoxin-induced chorioamnionitis modulates innate immunity of monocytes in preterm sheep. Am J Respir Crit Care Med 2005;171:73-7.

38. West MA, Heagy W. Endotoxin tolerance: a review. Crit Care Med 2002;30:S64-73.

39. Kramer BW, Garnier Y. Chorioamnionitis-an inflammatory multi-organ response of the fetus? Geburtsh Frauenheilk 2007;67:602-10. 


\section{Chapter 8}

Effects of in utero endotoxemia on the ovine fetal brain:

A model for schizophrenia? Gantert, M.,

Kreczmanski, P., Kuypers, E., Jellema, R., Strackx, E.,

Bastian, N., Gavilanes, A.W., Zimmermann, L.J., Garnier,

Y., Schmitz, C., Kramer, B.W.

Front Biosci (Elite Ed). 2012 Jun 1;4:2845-53 
[Frontiers in Bioscience E4, 2745-2753, June 1, 2012]

Effects of in utero endotoxemia on the ovine fetal brain: A model for schizophrenia?

Markus Gantert $^{1,3}$, Pawel Kreczmanski ${ }^{2}$, Elke Kuypers ${ }^{3}$, Reint Jellema ${ }^{3}$, Eveline Strackx ${ }^{3}$, Nina Bastian ${ }^{4}$, Antonio W.D. Gavilanes $^{3}$, Luc J.I. Zimmermann ${ }^{3}$, Yves Garnier ${ }^{1}$, Christoph Schmitz ${ }^{2,5}$, Boris W. Kramer ${ }^{3}$

${ }^{I}$ Department of Obstetrics and Gynaecology, Klinikum Osnabruck, Osnabruck, Germany, ${ }^{2}$ Department of Psychiatry and Neuropsychology, Division of Cellular Neuroscience, Maastricht University Medical Center, Maastricht, The Netherlands, ${ }^{3}$ Department of Pediatrics, School for Oncology and Developmental Biology, School for Mental Health and Neuroscience, Maastricht University Medical Center, Maastricht, The Netherlands, ${ }^{4}$ Department of Ophthalmology, Bonn University Hospital, Bonn, Germany, ${ }^{5}$ Department of Neuroanatomy, Ludwig-Maximilians University, Munich, Germany

\title{
TABLE OF CONTENTS
}

\author{
1. Abstract \\ 2. Introduction \\ 3. Materials and methods \\ 3.1. Experimental setup of the animal study \\ 3.2. Tissue processing \\ 3.3. Immunohistochemistry \\ 3.4. Nissl staining \\ 3.5. Qualitative and quantitative histological analysis \\ 3.6. Photography \\ 3.7. Statistical analysis \\ 4. Results \\ 5. Discussion \\ 6. Acknowledgements \\ 7. References
}

\section{ABSTRACT}

Infections during pregnancy can adversely affect the development of the fetal brain. This may contribute to disease processes such as schizophrenia in later life. Changes in the (cyto-) architecture of the anterior cingulate cortex (ACC), particularly in GABA-ergic interneurons, play a role in the pathogenesis of schizophrenia. We hypothesized that exposure to infection during pregnancy could result in cyto-architectural changes in the fetal ACC, similar to the pathogenesis seen in schizophrenia. Fetal sheep of 110 days GA (term $=150$ days GA) received an intravenous injection of $100 \mathrm{ng}$ or $500 \mathrm{ng}$ lipopolysaccharide (LPS) or saline as control. After delivery at 113 days GA, the cyto-architecture of the cingulate cortex (CC) was examined by immunohistochemistry. High dose LPS exposure resulted in a decreased density of GFAP-, calbindin D-28K- and parvalbumin-immunoreactive cells in the CC. In addition, these cells and calretinin-immunoreactive cells showed a changed morphology with reduced cell processes. This study provides further evidence that intra-uterine endotoxemia can induce changes in the fetal brain which correspond with changes seen in schizophrenia.

\section{INTRODUCTION}

Infections during pregnancy are a widespread phenomenon and may have serious consequences on the development of the fetus in utero. Chorioamnionitis is a bacterial infection of the placental membranes and amniotic fluid which is highly associated with preterm birth. Often chorioamnionitis presents as a clinically silent infection and is only diagnosed postnatally by histo-pathological analysis of the placenta $(1,2)$. Chorioamnionitis may not only provoke a maternal immune response, but can also induce an inflammatory response of the fetus. The latter can adversely affect the development of the fetal brain leading to pathologies such as periventricular leukomalacia (PVL) and cerebral palsy $(3,4)$. The neurological outcome after preterm birth is also linked to the development of several disorders in later life, one of which is schizophrenia (5-7). In addition, infections during the second trimester of pregnancy were identified to play a role in the etiopathogenesis of schizophrenia $(8,9)$.

Schizophrenic psychoses are a group of diseases that are characterized by the breakup of the personality (10). Emotional stability is disturbed and thinking is highly 
limited. The disease may show a chronic progress or progress in episodes, and often results in persisting changes of personality. A multitude of post mortem studies showed various neuropathological findings in the anterior cingulate cortex (ACC) of the brains from patients with schizophrenia (11-13). The ACC is part of the limbic system and is the central location for visceral regulation processes and higher cognitive processes like memory, attentiveness, affect regulation, concentration, and pain (14). Anatomically, the ACC is located on the cingulate gyrus in the medial cortex area above the corpus callosum. Magnet resonance tomography studies showed that the largest loss of cortical volume in the brains of patients suffering from schizophrenia can be found, amongst others, in the anterior cingulate cortex (15).

On a molecular and structural level, the GABAergic interneurons play a major role in the pathogenesis of schizophrenia. GABA-ergic interneurons, which can be differentiated immunohistochemically by the calciumbinding proteins parvalbumin, calbindin D-28K and calretinin, have an inhibitory function on neuronal circuits and a decisive influence on the cortico-limbic circulation. They contribute to maintenance of synchronized oscillations in neuronal networks, process information from the cortex and the limbic system, and have an influence on gating of sensory information (16). Benes et al. showed a reduced interneuron count and changes in both pyramidal cells and GABA-ergic interneurons in the ACC in schizophrenia (17). Also the prefrontal cortex of schizophrenia patients seems affected with a decreased density of inhibitory neurons which was not seen in patients who suffered from bipolar disease $(18,19)$.

As infections during pregnancy seem to play a role in development of schizophrenia $(8,9)$, we hypothesized that fetal exposure to infection in utero could result in cyto-architectural changes in the fetal ACC, similar to the pathogenesis seen in patients with schizophrenia. To test this hypothesis, we used a sheep model in which lipopolysaccharide (LPS) was injected intravenously in instrumented fetal lambs. Our group has developed several well established sheep models to study both the effects of chorioamnionitis and endotoxemia/sepsis on the fetal brain (20-23). In this study, the (cyto-) architecture of the cingulate cortex (CC) was examined using immunohistochemistry with focus on the different subsets of GABA-ergic interneurons which were shown to play a major role in the pathogenesis of schizophrenia.

\section{MATERIALS AND METHODS}

\subsection{Experimental setup of the animal study}

The animal studies were performed at the University of Maastricht, the Netherlands. The protocol was approved by the Animal Ethics Committee of the University of Maastricht and was in accordance with the guidelines of the responsible governmental agencies. The experimental setup of the animal studies was published previously (24). Briefly, twenty-one fetal sheep with a gestational age (GA) of 106-108 days (term=150 days) were instrumented in utero of which 14 fetuses were included in further analysis for brain structure.

Before the surgical instrumentation, ewes were anaesthetized using sodium thiopental $(1 \mathrm{~g} / 70 \mathrm{~kg}$ body weight intravenously for initiation of anesthesia) and 0.5 $1.0 \%$ halothane (with 1:1 nitrogen oxide and oxygen for maintenance) (25). A midline abdominal incision was performed and the fetal hind legs were identified and exposed by means of incision in the uterus. Polyvinyl catheters (Maxxim Medical BV, Den Bosch, the Netherlands) with an outer diameter of $1.25 \mathrm{~mm}$ and an inner diameter of $0.75 \mathrm{~mm}$ were inserted through a tibial vein or artery in the fetal hind legs up to vena cava inferior or aorta abdominalis. The skin of the fetuses was closed with cyanoacrylate glue (Cyanolit; Toagosei, Tokyo, Japan). Furthermore, an intra-uterine pressure catheter was placed. After closure of the uterus, the lost amniotic fluid was replaced with $0.9 \%$ saline solution (temperature: $39^{\circ}$ C). The protruding catheters were filled with heparin (100 $\mathrm{IU} / \mathrm{ml}$; Heparin-Natrium; Braun, Melsungen, Germany) and directed outwards via a small incision in the flank of the mother where they were collected in a bag sewn to the skin of the ewe. Antibiotics (1g ampicillin, Pentrexyl; BristolMyers, Woerden, the Netherlands) and post-operative pain relief (buprenorphine $10 \mu \mathrm{g} / \mathrm{kg}$ bodyweight, Temgesic; Schering, Netherlands) was provided to all ewes. After a recovery period of three days, the fetuses ( $110 \pm 1$ day GA) received an intravenous bolus injection of lipopolysaccharide (LPS; E.coli O127:B8; Sigma-Aldrich, Saint Louis, MO, USA) of either $100 \mathrm{ng}(\mathrm{n}=4)$ or $500 \mathrm{ng}$ $(\mathrm{n}=5)$ LPS in $5 \mathrm{ml}$ saline solution $(0.9 \%)$. Control animals $(n=5)$ received an intravenous bolus injection of saline. Fetal heart rate and fetal mean arterial pressure were monitored throughout the experiment. Three days after the injection, the ewes were anaesthetized using sodium thiopental (1 g / $70 \mathrm{~kg}$ body weight intravenously for initiation of anesthesia) and $0.5-1.0 \%$ halothane (with $1: 1$ nitrogen oxide and oxygen for maintenance). The fetus was exposed by an incision in the centre line of the abdomen and uterus. The thorax of the fetus was opened and a catheter was inserted into the left ventricle for perfusionfixation with $10 \%$ paraformaldehyde.

\subsection{Tissue processing}

After the fetuses were sacrificed, the fetal brains were removed from the skull. The cerebral hemispheres were separated and the left hemisphere was divided into different brain regions after which they were fixated in $10 \%$ paraformaldehyde. Each region was cryo-protected $(10 \%, 20 \%$ and $30 \%$ sucrose in $0.1 \%$ PBS, $24 \mathrm{~h}$ per solution at $4^{\circ} \mathrm{C}$ ), embedded in Tissue-Tek O.C.T Compound (Sakura; Alphen aan den Rijn, the Netherlands) and deepfrozen. Frontal $50 \mu \mathrm{m}$ thick sections were cut on a cryostate (CM3050; Leica, Wetzlar, Germany) for immunohistochemical and stereological analysis.

\subsection{Immunohistochemistry}

Different subsets of GABA-ergic interneurons were identified by immunoprocessing for calretinin (CR: antibody \#7699/3H, Swant, Bellinzona, Switzerland), calbindin D-28K (CB: antibody \#300, Swant) and 
parvalbumin (PV: antibody \#235, Swant). Anti-GFAP (glial fibrillary acidic protein) antibody (\#G3893, SigmaAldrich) was used to visualize astrocytes. All procedures were performed using the free floating method. Unspecific binding was blocked by incubating the sections in 5\% bovine serum albumin (BSA) for $60 \mathrm{~min}$. Subsequently, the endogenous peroxidase activity was blocked with $7 \%$ H202. After rinsing with Tris-buffered saline (TBS, $p H$ 7,6), sections were incubated for $48 \mathrm{~h}$ at $4^{\circ} \mathrm{C}$ with the diluted primary antibody (calretinin 1:5000, calbindin D28K 1:2000, parvalbumin 1:2000, GFAP 1:5000 in TBS). After rinsing with TBS, the sections were incubated with a secondary biotin-labeled antibody for $2 \mathrm{~h}$ at room temperature. The immunostaining was enhanced with Vectastain ABC peroxidase Elite kit (PK-6200, Vector Laboratories, Burlingame, USA) followed by a 3,3'diaminobenzidine (DAB) staining. Subsequently, the brain sections were rinsed, mounted on glass slides coated with APES (3-aminopropyltriethoxysilane; Sigma-Aldrich) and coverslipped with $80 \%$ glycerol in TBS (26)

\subsection{Nissl staining}

Sections for Nissl staining were mounted on APES-coated glass slides and were allowed to dry. The sections were immersed in $0.01 \%$ cresyl violet for 25 minutes and post-fixed in $100 \%$ ethanol. Finally, slides were coverslipped using DePeX (Serva; Heidelberg, Germany).

\subsection{Qualitative and quantitative histological analysis}

The Nissl-stained slides were used to select the brain sections that contained the CC. Stereological analysis of the density of CR-, CB-, PV- or GFAP-immunoreactive cells in the $\mathrm{CC}$ were performed on a stereology workstation consisting of a modified light microscope (Olympus BX50; Olympus, Tokyo, Japan) with Olympus UPlanApo objectives, motorized specimen stage (Ludl Electronics; Hawthorne, NY, USA), digital measuring sensor for determination of the depth of focus (Ludl Electronics), CCD color video camera (HV-C20AMP; Hitachi, Tokyo, Japan) and stereology software (Stereo Investigator Version 7.00.03; MBF Bioscience, Williston, VT). Virtual threedimensional regions (UVCS) within the $\mathrm{CC}$ were determined within the brain sections in accordance with the criteria of systematic-and-random (SRS) sampling $(27,28)$. Then, CR-, CB, PV- or GFAP-immunoreactive cells were counted within the UVCS according to the principles of design-based stereology. The dimensions of the UVCS were as following: base area: $50 \mu \mathrm{m} \times 50 \mu \mathrm{m}$, distance between the UVCS in XY directions: $100 \mu \mathrm{m}$ for PVimmunoreactive cells, $200 \mu \mathrm{m}$ for CR-, CB- and GFAPimmunoreactive cells (29). For determining cell densities, the total number of counted cells was divided by the total number of analyzed UVCS multiplied by the volume of the UVCS. Analysis of the morphology of the cells was only performed descriptively.

\subsection{Photography}

Photomicrographs were taken using an Olympus DP70 digital camera assembled onto an Olympus AX-70 microscope with CellP software (version 2.3; Soft Imaging System, Münster, Germany).

\subsection{Statistical analysis}

Results are given as means \pm standard error of mean (SEM). The groups were compared using one-way ANOVA with Bonferroni tests for post-hoc analysis. Statistical analysis was performed using GraphPad Prism v4.0 (GraphPad Software, San Diego, CA, USA) Significance was accepted at $\mathrm{p}<0.05$.

\section{RESULTS}

LPS exposure did not induce major changes in the architecture of the CC (Figure 1). In those animals that received a low dose of LPS (100 ng), no changes in the brain (cyto-) architecture were observed. In contrast, intrauterine exposure to high dose of LPS (500 ng) reduced the density of several GABA-ergic interneuron subsets and GFAP-immunoreactive cells, which are mainly astrocytes. Exposure to $500 \mathrm{ng}$ of LPS resulted in a decreased mean density of GFAP-, CB D-28K- and PV-immunoreactive cells (Figure 2). The mean density of CR-immunoreactive cells did not change after LPS exposure.

In addition, descriptive analysis of the sections revealed several morphological changes in the examined cell types. GFAP-immunoreactive cells were present in abundance throughout the cortex of control animals (Figure 3 ). Exposure to high dose of LPS resulted in a reduction of the processes of GFAP-immunoreactive cells, particularly in the perivascular area. CR-immunoreactive multipolar cells were present in all layers of the cortex in the control animals (Figure 4). Animals that were exposed to LPS did not show a reduced density of CR-immunoreactive cells. Instead, descriptive analysis showed a change in the morphology of these cells with more unipolar cells (Figure 4). CB-immunoreactive cells were mainly found in layer II and III of the cortex in control animals (Figure 5). The density of CB-immunoreactive cells was significantly decreased after LPS exposure (Figure 2). Furthermore, the cells seemed to be arranged in clusters what was not seen in the control animals (Figure 5). Exposure to LPS resulted in a decreased density of PV-immunoreactive cells which are normally found in layers III and IV of the cortex (Figure 6).

\section{DISCUSSION}

In the present study, we examined the effects of intravenous LPS exposure on the fetal cingulate cortex. Exposure to a high LPS dose $(500 \mathrm{ng})$ resulted in a decreased density of GFAP-, calbindin D-28K- and parvalbumin-positive cells in the $\mathrm{CC}$ of the fetus. Although several studies already underlined the profound effects of in utero LPS exposure on fetal brain development $(21,23)$, this study is the first to report cyto-architectural changes in GABA-ergic interneuron subsets in the $\mathrm{CC}$. The changes observed in the present study in the ovine fetal brain were detected in a brain region that has been associated with the pathogenesis of schizophrenia. The post- mortem pathologic changes in the brain of schizophrenia patients include, amongst others, (cyto)-architectural changes in the ACC, particularly for GABA-ergic interneurons $(16,30)$. It is of note that the altered pattern of different subsets of GABA-ergic interneurons in the ACC of patients with 


\section{Cortical changes after endotoxemia}

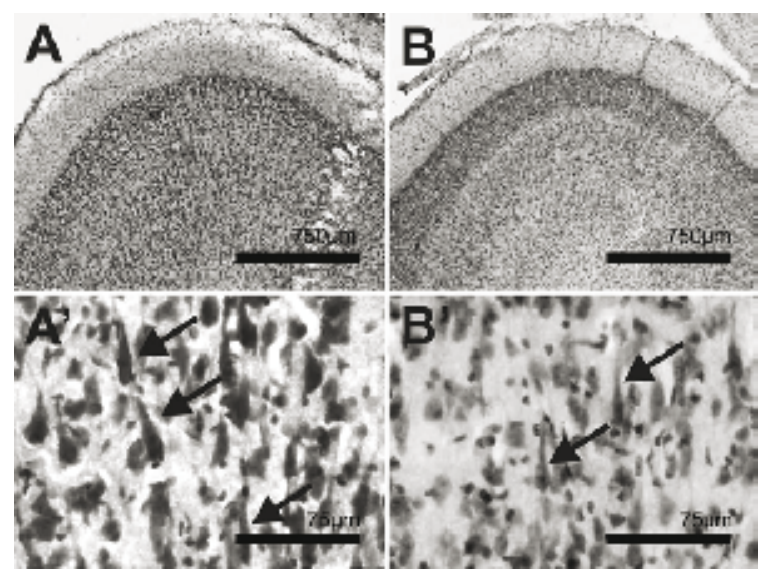

Figure 1. Architecture of the cingulate cortex (CC) after LPS exposure. Representative images of the Nissl-staining on the cingulate cortex (CC) are shown for controls (A) and $500 \mathrm{ng}$ LPS exposed animals (B). LPS exposure did not induce major changes in the architecture of the CC. Arrow: Oblong neurons (similar to von Economo neurons in the human anterior cingulate gyrus).
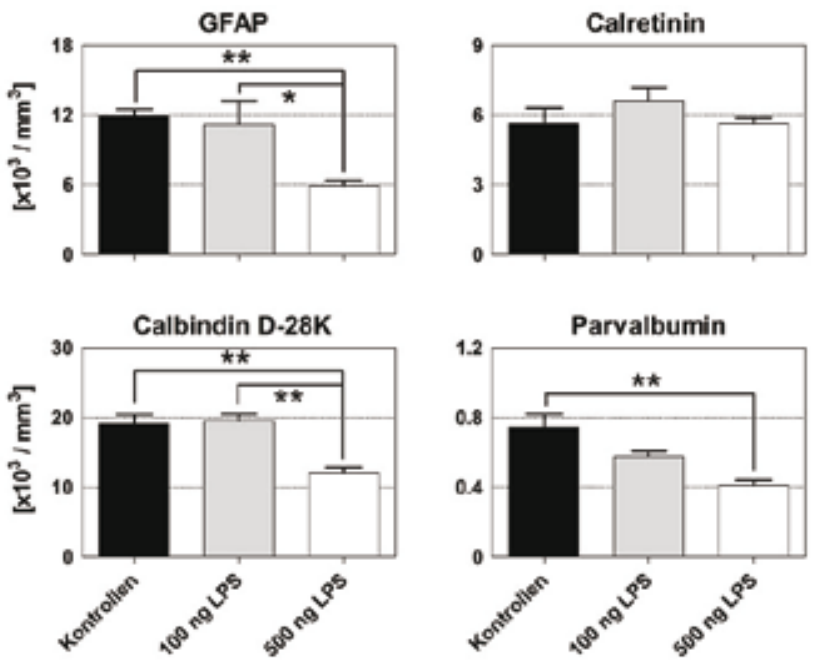

Figure 2. Mean density of GFAP, calretinin, calbinin D-28K and parvalbumin-positive cells in the cingulate cortex (CC) of fetal sheep. At day $110+/-1$ of gestation, the fetuses received either an injection of saline (black bar; controls) or $100 \mathrm{ng}$ lipopolysaccharides (LPS) (grey bar) or $500 \mathrm{ng}$ LPS (white bar). Results of the post-hoc Bonferroni tests on pairwise comparison between the groups with $\mathrm{p}$ values $<0.05$ are shown $(*$ : $<<0.05 ; * * \mathrm{p}<0.01)$.

schizophrenia was confirmed in subsequent studies (31-33), and shows correspondence to the pattern of changes in cell density in the $\mathrm{CC}$ of the fetal sheep after exposure to 500 ng LPS as demonstrated in the present study. As such, this pilot study demonstrates that antenatal factors can play a role in the development of postnatal diseases.

GABA-ergic interneurons play an inhibitory role in neuronal circuits and have a decisive influence on the cortico-limbic circulation (34). Due to the increasing evidence of an impairment of the GABA-ergic interneuron subpopulations in the pathology of schizophrenia, understanding the disturbances of prenatal development and disturbed formation of neuronal circuits during early adult life - when the disease mainly becomes clinically manifest - may provide more insight into the pathophysiology of this disorder (35). There are several underlying pathological mechanisms by which exposure to 


\section{Cortical changes after endotoxemia}

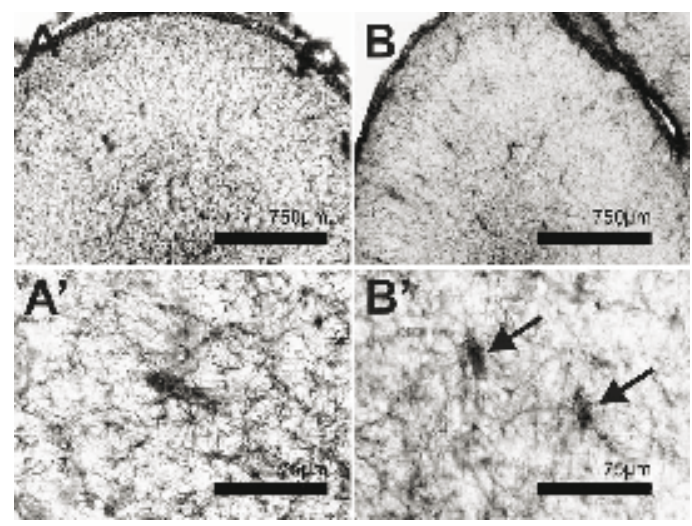

Figure 3. LPS exposure decreased the density of GFAP-positive cells in the cingulate cortex (CC). The reduced density of GFAP-positive cells as well as the reduced GFAP signal within the cell processes is mainly seen in the area of the perivascular astrocytes after exposure to high dose LPS. Representative images of the GFAP-staining on the CC are shown for controls (A) and $500 \mathrm{ng}$ LPS exposed animals (B). Arrow: GFAP-positive cells which show reduced processes.
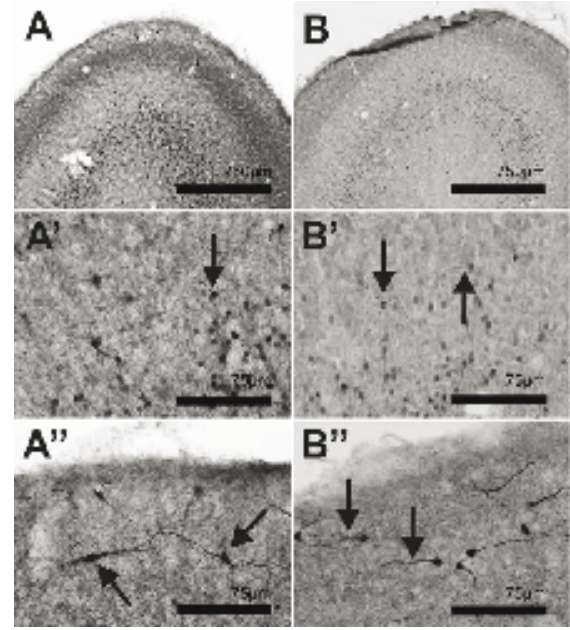

Figure 4. LPS exposure induced changes in the morphology of calretinin-positive cells in the cingulate cortex (CC). The morphology of the calretinin-immunoreactive cells changed from multipolar cells to unipolar cells in the cingulate cortex after exposure to $500 \mathrm{ng}$ LPS. Representative images of calretinin-positive cells are shown for controls (A) and $500 \mathrm{ng}$ LPS exposed animals (B). Arrow: Multipolar (A) vs. unipolar (B) calretinin-positive cells in layer I of the cortex.

infection during fetal development can lead to a similar neuropathology as seen in schizophrenia. The risk to develop a neuropsychiatric disease like schizophrenia could be promoted by a prenatal maternal infection with consecutive cytokine-controlled inflammatory response that may result in a persistent damage to the developing brain $(36,37)$. Here, glia cell reactions represent a possible immune response to inflammatory stimuli and play a decisive role in the developing brain. Glia cells in turn may produce immune modulators (TNF- $\alpha$, IL-1b, IL-6, IL-12, IL-10, TGF- $\beta$ ) and supply nutrients to ripening neurons
(38). Glial dysfunction may therefore also result in neuronal dysfunction $(39,40)$

Rodent models of pre- or neonatal LPS exposure have shown changes in some GABA-ergic interneurons in the hippocampus which were linked to behavioral changes consistent with schizophrenia (41-43). However, no studies address the changes in the $\mathrm{CC}$ which seems to be a key region in the pathology of schizophrenia. This is in part due to the differences in neurospecific stages of development between rodents and humans. As such, rodents are only 


\section{Cortical changes after endotoxemia}

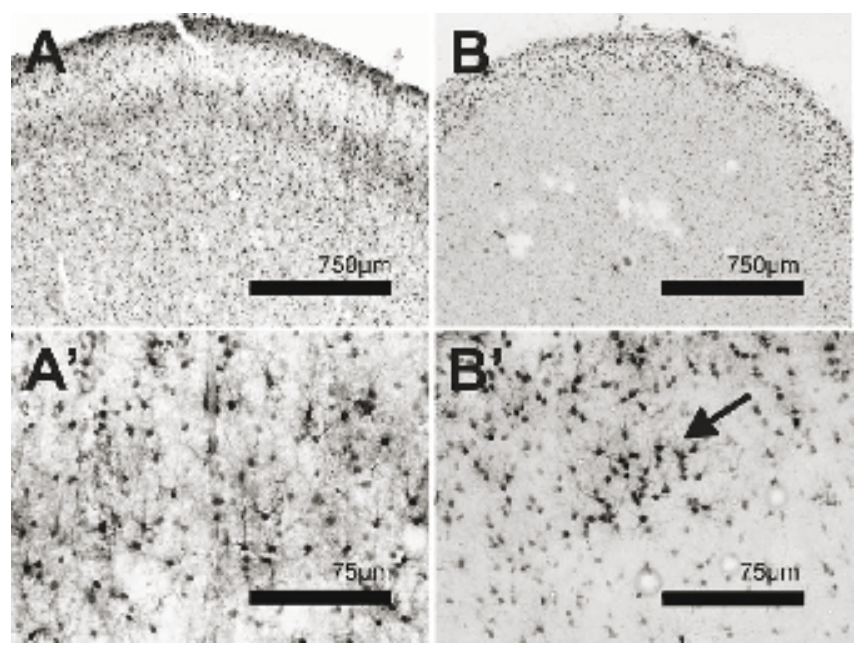

Figure 5. The density of calbindin D-28K-positive cells decreased after LPS exposure in the cingulate cortex (CC). Exposure to high dose LPS (500 ng) decreased the density of calbindin D-28K-immunoreactive cells in the cingulate cortex as well as the allocation of such cells in "clusters" compared to controls. Representative images of calbindin D-28K-positive cells are shown for controls (A) and $500 \mathrm{ng}$ LPS exposed animals (B). Arrow: Clusters of calbindin D-28K-positive cells in LPS exposed animals.

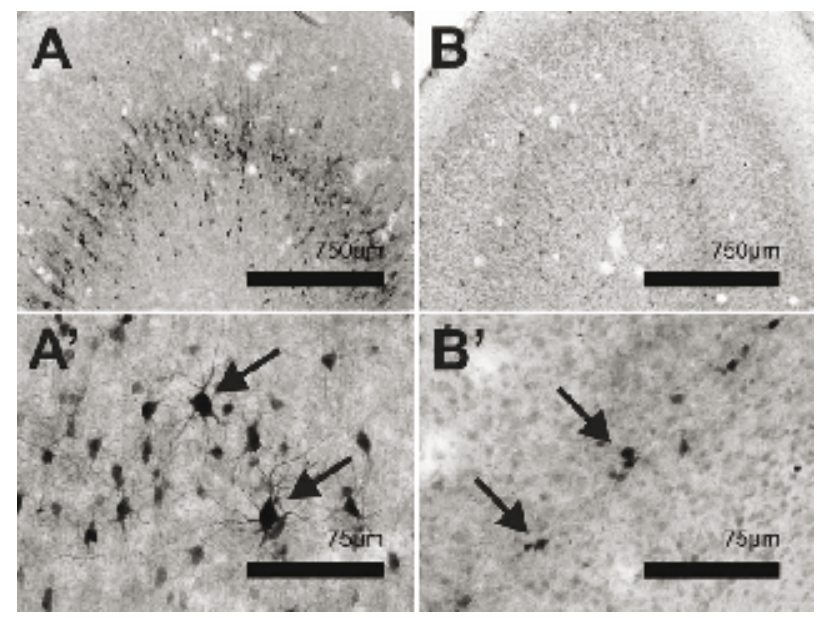

Figure 6. LPS exposure induced changes in the density and morphology of parvalbumin-positive cells in the cingulate cortex (CC). Exposure to high dose LPS (500 ng) decreased the density of parvalbumin-immuoreactive cells as well as loss of immunoreactivity within the cell processes. Representative images of parvalbumin-positive cells are shown for controls (A) and $500 \mathrm{ng}$ LPS exposed animals (B). Arrow: Loss of immunopositivity in the cell processes in LPS exposed animals.

limitedly suitable for creation of an animal model with regard to possible intra-uterine disturbances of brain development during the second trimester of human pregnancy. With regard to prenatal development processes in the brain, sheep show a significantly higher similarity to humans as rodents do.
Accordingly, exposure of fetal sheep to a high dose of LPS on day 110 of gestation could serve as a new animal model for key aspects of the neuropathology of schizophrenia with the adverse event occurring around the end of the second trimester of pregnancy which has been shown be the critical point in time in relation to 
disturbances in the fetal brain development $(8,9)$. However, this pilot study does impose some limitations. The study was conducted with only 14 animals and provides some quantitative measurements and descriptive data. To clarify the role of intra-venous LPS exposure on changes in the ovine fetal GABA-ergic interneuron subsets, further studies will be necessary. At the given moment, only limited information is available concerning behavioral examination of this animal model. However, behavioral similarities between experimentally manipulated animals and specific symptoms of human suffering from a certain neuropsychiatric disease often represent only intuitive criteria for evident application of an animal model. Most importantly, it seems impossible to find an adequate correlate with an animal model for the positive symptoms of schizophrenia (e.g. hallucinations and delusions).

In summary, the results of the present paper suggest that exposure of fetal sheep to intravenous LPS at day $110+/-1$ of pregnancy is a possible new animal model for key aspects of the neuropathology of schizophrenia, with significant benefits as compared to rodent models of the disease.

\section{ACKNOWLEDGEMENTS}

Supported by Veni BWK-016096141 from the Dutch Scientific Research Organization and the Research School for Oncology and Developmental Biology, Maastricht University. The funders had no role in study design, data collection and analysis, decision to publish, or preparation of the manuscript. None of the authors have a conflict of interest.

\section{REFERENCES}

1. Redline RW. Inflammatory responses in the placenta and umbilical cord. Semin Fetal Neonatal Med 11, 296-301 (2006)

2. Benirschke $\mathrm{K}$. The placenta in the litigation process. Am $J$ Obstet Gynecol 162, 1445-8 (1990)

3. Back SA. Perinatal white matter injury: the changing spectrum of pathology and emerging insights into pathogenetic mechanisms. Ment Retard Dev Disabil Res Rev 12, 129-40 (2006)

4. Patrick LA, Smith GN. Proinflammatory cytokines: a link between chorioamnionitis and fetal brain injury. J Obstet Gynaecol Can 24, 705-9 (2002)

5. Suvisaari J, Haukka J, Tanskanen A, Hovi T, Lonnqvist J. Association between prenatal exposure to poliovirus infection and adult schizophrenia. Am J Psychiatry 156, 1100-2 (1999)

6. Limosin F, Rouillon F, Payan C, Cohen JM, Strub N. Prenatal exposure to influenza as a risk factor for adult schizophrenia. Acta Psychiatr Scand 107, 331-5 (2003)

7. Gantert M, Been JV, Gavilanes AW, Garnier Y, Zimmermann LJ, Kramer BW. Chorioamnionitis: a multiorgan disease of the fetus? J Perinatol 30, Suppl:S21$30(2010)$.

8. McGrath JJ, Pemberton MR, Welham JL, Murray RM. Schizophrenia and the influenza epidemics of 1954, 1957 and 1959: a southern hemisphere study. Schizophr Res 14, $1-8(1994)$

9. Adams W, Kendell RE, Hare EH, Munk-Jorgensen P. Epidemiological evidence that maternal influenza contributes to the aetiology of schizophrenia. An analysis of Scottish, English, and Danish data. Br J Psychiatry 163, 522-34 (1993)

10. Mueser KT, McGurk SR. Schizophrenia. Lancet $19 ; 363,2063-72$ (2004)

11. Jakob H, Beckmann H. Gross and histological criteria for developmental disorders in brains of schizophrenics. $J$ R Soc Med 82, 466-9 (1989)

12. Heckers S. Neuropathology of schizophrenia: cortex, thalamus, basal ganglia, and neurotransmitter-specific projection systems. Schizophr Bull 23, 403-21 (1997)

13. Harrison PJ. Neurochemical alterations in schizophrenia affecting the putative receptor targets of atypical antipsychotics. Focus on dopamine (D1, D3, D4) and 5-HT2a receptors. Br J Psychiatry Suppl 38, 12-22 (1999)

14. Carter CS, Mintun M, Nichols T, Cohen JD. Anterior cingulate gyrus dysfunction and selective attention deficits in schizophrenia: [15O]H2O PET study during single-trial Stroop task performance. Am J Psychiatry 154, 1670-5 (1997)

15. Goldstein JM, Goodman JM, Seidman LJ, Kennedy DN, Makris N, Lee H, Tourville J, Caviness VS Jr, Faraone SV, Tsuang MT. Cortical abnormalities in schizophrenia identified by structural magnetic resonance imaging. Arch Gen Psychiatry 56, 537-47 (1999)

16. Benes FM, Berretta S. GABAergic interneurons: implications for understanding schizophrenia and bipolar disorder. Neuropsychopharmacology 25, 1-27 (2001)

17. Benes FM, McSparren J, Bird ED, SanGiovanni JP, Vincent SL. Deficits in small interneurons in prefrontal and cingulate cortices of schizophrenic and schizoaffective patients. Arch Gen Psychiatry 48, 996-1001 (1991)

18. Woo TU, Kim AM, Viscidi E. Disease-specific alterations in glutamatergic neurotransmission on inhibitory interneurons in the prefrontal cortex in schizophrenia. Brain Res 1218, 267-77 (2008)

19. Fung SJ, Webster MJ, Sivagnanasundaram S, Duncan C, Elashoff M, Weickert CS. Expression of interneuron markers in the dorsolateral prefrontal cortex of the developing human and in schizophrenia. Am J Psychiatry $167,1479-88$ (2010) 
20. Gavilanes AW, Gantert M, Strackx E, Zimmermann LJ, Seeldrayers S, Vles JS, Kramer BW. Increased EEG delta frequency corresponds to chorioamnionitis-related brain injury. Front Biosci (Schol Ed) 2,432-8 (2010)

21. Gavilanes AW, Strackx E, Kramer BW, Gantert M, Van den Hove D, Steinbusch H, Garnier Y, Cornips E, Steinbusch $\mathrm{H}$, Zimmermann L, Vles J. Chorioamnionitis induced by intraamniotic lipopolysaccharide resulted in an intervaldependent increase in central nervous system injury in the fetal sheep. Am J Obstet Gynecol 200, 437 e1-8 (2009)

22. Strackx E, Gantert M, Moers V, van Kooten IA, Rieke R, Hurter H, Lemmens MA, Steinbusch HW, Zimmermann LJ, Vles JS, Garnier Y, Gavilanes AW, Kramer BW. Increased Number of Cerebellar Granule Cells and Astrocytes in the Internal Granule Layer in Sheep Following Prenatal Intraamniotic Injection of Lipopolysaccharide. Cerebellum Epub ahead of print (2011)

23. Nitsos I, Rees SM, Duncan J, Kramer BW, Harding R, Newnham JP, Moss TJ. Chronic exposure to intra-amniotic lipopolysaccharide affects the ovine fetal brain. J Soc Gynecol Investig 13, 239-47 (2006)

24. Kramer BW, Ladenburger A, Kunzmann S, Speer CP, Been JV, van Iwaarden JF, Zimmermann LJ, Gantert M, Garnier Y. Intravenous lipopolysaccharide-induced pulmonary maturation and structural changes in fetal sheep. Am J Obstet Gynecol 200, 195 e1-10 (2009)

25. Garnier Y, Coumans AB, Berger R, Hasaart TH Pulmonary perfusion during lipopolysaccharide (LPS) induced fetal endotoxemia in the preterm fetal sheep. Eur $J$ Obstet Gynecol Reprod Biol 124, 150-7 (2006)

26. Kreczmanski P, Schmidt-Kastner R, Heinsen H, Steinbusch HW, Hof PR, Schmitz C. Stereological studies of capillary length density in the frontal cortex of schizophrenics. Acta Neuropathol 109, 510-8 (2005)

27. Schmitz C, Hof PR. Design-based stereology in neuroscience. Neuroscience 130, 813-31 (2005)

28. Schmitz C, Hof PR. Recommendations for straightforward and rigorous methods of counting neurons based on a computer simulation approach. J Chem Neuroanat 20, 93-114 (2000)

29. Takahashi H, Brasnjevic I, Rutten BP, Van Der Kolk N, Perl DP, Bouras C, Steinbusch HW, Schmitz C, Hof PR, Dickstein DL. Hippocampal interneuron loss in an APP/PS1 double mutant mouse and in Alzheimer's disease. Brain Struct Funct 214, 145-60 (2010)

30. Bunney BG, Potkin SG, Bunney WE, Jr. New morphological and neuropathological findings in schizophrenia: a neurodevelopmental perspective. Clin Neurosci 3, 81-8 (1995)

31. Bernstein HG, Krause S, Krell D, Dobrowolny H, Wolter M, Stauch R, Ranft K, Danos P, Jirikowsi GF,
Bogerts B. Strongly reduced number of parvalbuminimmunoreactive projection neurons in the mammillary bodies in schizophrenia: further evidence for limbic neuropathology. Ann N Y Acad Sci 1096,120-7 (2007)

32. Chance SA, Walker M, Crow TJ. Reduced density of calbindin-immunoreactive interneurons in the planum temporale in schizophrenia. Brain Res 1046,32-7 (2005)

33. Druga R. Neocortical inhibitory system. Folia Biol (Praha) 55, 201-17 (2009)

34. Gonzalez-Burgos G, Lewis DA. GABA neurons and the mechanisms of network oscillations: implications for understanding cortical dysfunction in schizophrenia. Schizophr Bull 34, 944-61 (2008)

35. Woo TU, Spencer K, McCarley RW. Gamma oscillation deficits and the onset and early progression of schizophrenia. Harv Rev Psychiatry 18, 173-89 (2010)

36. Brown AS, Patterson PH. Maternal infection and schizophrenia: implications for prevention. Schizophr Bull 37, 284-90 (2010)

37. Meyer U, Schwendener S, Feldon J, Yee BK. Prenatal and postnatal maternal contributions in the infection model of schizophrenia. Exp Brain Res 173, 243-57 (2006)

38. Chew LJ, Takanohashi A, Bell M. Microglia and inflammation: impact on developmental brain injuries. Ment Retard Dev Disabil Res Rev 12, 105-12 (2006)

39. Aschner M, Allen JW, Kimelberg HK, LoPachin RM, Streit WJ. Glial cells in neurotoxicity development. Annu Rev Pharmacol Toxicol 39, 151-73 (1999)

40. Chao CC, Hu S, Peterson PK. Glia, cytokines, and neurotoxicity. Crit Rev Neurobiol 9, 189-205 (1995)

41. Jenkins TA, Harte MK, Stenson G, Reynolds GP. Neonatal lipopolysaccharide induces pathological changes in parvalbumin immunoreactivity in the hippocampus of the rat. Behav Brain Res 205, 355-9 (2009)

42. Baharnoori M, Bhardwaj SK, Srivastava LK. Neonatal Behavioral Changes in Rats With Gestational Exposure to Lipopolysaccharide: A Prenatal Infection Model for Developmental Neuropsychiatric Disorders. Schizophr Bull Epub ahead of print (2010)

43. Nouel D, Burt M, Zhang Y, Harvey L, Boksa P. Prenatal exposure to bacterial endotoxin reduces the number of GAD67- and reelin-immunoreactive neurons in the hippocampus of rat offspring. Eur NeuropsychopharmacolEpub ahead of print (2010) .

Key Words: Chorioamnionitis, Brain development, Schizophrenia, Cingulate cortex, Interneurons, Animal model 


\section{Cortical changes after endotoxemia}

Send correspondence to: Boris W. Kramer, Department of Pediatrics, Maastricht University Medical Center, Postbus 5800, 6202 AZ Maastricht, The Netherlands, Tel: 31-43-387-

4202, Fax: 31-43-387-5246, E-mail: b.kramer@mumc.nl 


\section{Chapter 9}

Summary and Outlook

General discussion 


\section{Summary and Outlook}

Clinical experience and experimental results indicate that fetal exposure to antenatal inflammation has both good and adverse effects on the fetus ${ }^{1}$. In several aspects chorioamnionitis causes damage to the developing fetus for example by inducing a simplification of the lung development ${ }^{2}$. Many organs are affected by the exposure to antenatal inflammation. It is distinguished (chapter 2) that chorioamnionitis induces "a multi-organ disease of the fetus" ${ }^{\text {. }}$.

In order to study mechanisms of disease, animal models of intra-amniotic and intravenous injections were developed. The risk of preterm birth is increased in multiple pregnancies irrespective of additional risk factors such as chorioamnionitis ${ }^{4}$. Clinical findings show that in the majority of cases, histological chorioamnionitis in twin pregnancy affects the presenting fetus ${ }^{5}$. In our sheep model we showed that LPSinduced histological chorioamnionitis is confined to the exposed compartment and does not affect the neighboring fetus (chapter 3 ). Inflammation in placenta, membranes and lung of LPS-exposed twins was significantly higher after 2 and 14 days of exposure when compared to the saline-exposed co-twins ${ }^{6}$. Lung compliance in LPS-exposed twins was significantly increased after 14 days when compared to saline-exposed co-twins. Intrauterine LPS exposure increased lung compliance and inflammation in the membranes, placenta and lung to the same extent in twins as in singletons. Related to human multiple pregnancies these findings may help to encourage clinicians to consider delayed-interval delivery as an option. When chorioamnionitis presents with clinical signs and multiple pregnancies are around the borders of survivability it would be of major interest if only one compartement is affected and chorioamnionitis does not affect the other compartment.

Brain injury after endotoxin exposure

From clinical and epidemiologic studies it is well known that in utero exposure to infection plays an important role in the genesis of fetal or neonatal injury leading to cerebral palsy and chronic lung disease ${ }^{7}$. After chorioamnionitis the incidence of immature neonates with periventricular white matter damage and periventricular or intraventricular hemorrhage is significantly elevated. Perinatal brain injury is usually associated with cerebral ischemia, cerebral hemorrhage, or an ascending intrauterine infection $^{8}$. A variety of studies support the view that cytokines released during intrauterine infection directly cause injury to the immature brain. Preterm infants often exhibit chronic deficits in white matter and cortical maturation.

Although fetal infection / inflammation may contribute to white matter pathology, the factors contributing to cortical changes are largely unknown. Besides cerebral periventricular white matter disease, cortical and subcortical gray matter and cerebellum were affected as well, contributing to a complex long-term neurologic morbidity.

We examined the effect of fetal lipopolysaccharide exposure on white matter and cortical development as assessed by electroencephalography (EEG) in fetal sheep at preterm human equivalent age in chapter $4^{9} .10 \mathrm{mg}$ intra-amniotic LPS or saline were given 2 or 14 days before preterm birth at gestational day 125 . Fetuses were delivered by Caesarean section under local anesthesia. A 5-minute EEG depicted delta activity and amplitude, and the relationship between EEG delta activity and both the white matter and cortical microglial activation and apoptosis was analyzed. EEG delta activity was increased significantly in the 14-day LPS preterm fetuses compared to both preterm control and 2-day LPS animals. No differences were seen 
between controls and the 2-day LPS fetuses. An association was demonstrated between EEG delta activity and both cortical microglial activation and apoptosis. Beyond that a correlation between delta acitivity and white matter activated microglia and apoptosis is shown. This study is the first to show a relationship between brain dysfunction and chorioamnionitis-related injury at birth. Neurological injury in newborns as a result of chorioamnionitis is quite difficult to identify, particularly in absence of clinical signs right after birth. This less invasive procedure in a nonanesthetized fetus could be an easy indicator of encephalopathy.

For decades the cerebellum has been considered as a region of the brain mainly involved in motor behaviour. Spawned by neuroanatomical research and new diagnostic methods of investigation, nowadays the cerebellum seems to contribute to the pathophysiology of psychiatric disorders ${ }^{10}$. In chapter 5 we hypothesized that chorioamnionitis affected the cerebellum as well as other brain areas ${ }^{11}$. A relatively high ratio of premature infants with cerebral palsy, exhibit abnormalities in the cerebellum $^{12}$. It is vulnerable during late gestation, since this is the period of active proliferation and migration of cerebellar granule cells ${ }^{13}$. Adverse neurological outcome as a result of intrauterine inflammation is more and more proven, but the exact consequences on the central nervous system remain unclear. There is nowadays good evidence that the cerebellum is also involved in cognitive and affective disorders ${ }^{10,14-17}$. We hypothesized that chorioamnionitis caused changes in the granule cell number and / or Purkinje cell number, associated with astrocytic changes in the near-term fetal cerebellum. $10 \mathrm{mg}$ LPS was administered intraamniotically as opposed to the intravenously application to minimise circulatory changes in the fetus, causing a secondary hypoxia-ischemia which might contribute to brain damage as well ${ }^{18,19} .30$ days after application (140 days, term $=147$ days) cerebellar volumes, granule cell number and Purkinje cell numbers were assessed using design-based stereology and astrogliosis was determined using a semiquantitative image analysis method. In the outer granular layer, the inner granular layer, the molecular layer, and the white matter of the cerebellum no significant differences were found in the volumes of LPS-exposed versus control animals.

The LPS exposed animals showed a significantly increased mean total number of granule cells in the inner granular layer, whereas there was no significant difference in the mean total Purkinje cell number between the two groups.

Astrocytes showed a strong GFAP immunoreactivity in both cell bodies and processes in brains from LPS injected animals as well as controls, and were found in all layers of the cerebellum. Furthermore, LPS exposed animals showed a stronger immunoreactivity than control animals and had a higher surface area of GFAPpositive astrocytes. This study showed that chorioamnionitis in the fetal sheep resulted in important, morphological alterations in the cerebellum. The clinical impact was complex and needs further investigation. It remains unclear, if these cerebellar changes associated with adverse neurodevelopmental outcome. Finally, cerebellar pathology is more and more linked to a wide range of deficits, like motor, social and cognitive disorders ${ }^{16,20,21}$.

In chapter 6, we quantified the impact of chorioamnionitis on both the white and gray matter structures of the preterm ovine central nervous system ${ }^{22}$. Therefore, apoptotic cells and cell types were analyzed in the brain, cerebellum, and spinal cord using flow cytometry.

Contrary to the most commonly used experimental paradigms, in this study LPS was administered into the amniotic fluid via amniocentesis.Thisintraamniotic 
administration avoids the hemodynamic changes and the secondary postasphyctic encephalopathy induced by fetal intravenously LPS ${ }^{23,24}$. The central nervous system is studied at 125 days of gestation, either 2 or 14 days after $10 \mathrm{mg}$ of LPS. This experimental time window corresponds to approximately 28 weeks of human central nervous system maturation, which is the most vulnerable period for the human brain to develop white matter disease ${ }^{25}$.

Chorioamnionitis resulted in an interval-dependent increase in central nervous system injury and different regional injury patterns. Microglial activation and apoptotic cell death were increased in all brain, cerebellum, and spinal cord regions in an interval-dependent manner. In addition, most brain regions showed reductions in oligodendrocytes and neurons and an increase in astrocytes, whereas the cerebellum and the spinal cord seemed to be less affected. The study shows a global inflammatory response to acute chorioamnionitis in the brain, cerebellum, and spinal cord and a selective vulnerability of the developing regions.

In chapter 7, the role of intravenously endotoxin and thus pulmonary inflammation is outlined. Pulmonary inflammation is associated with reduced risk for respiratory distress syndrome (RDS) but with an increased risk for bronchopulmonary dysplasia (BPD) with impaired alveogenesis. Multiple pre- and postnatal events contribute to the development of BPD in the fetus ${ }^{26}$. Interleukin 6 concentrations in cord blood of inflammated fetuses that develop BPD are increased. BPD is nowadays considered to be an impairment of the growth and development of the alveoli and microvasculature aggravated by pulmonary and systemic inflammation postnatally ${ }^{26}$, 27. After the induction of fetal systemic inflammation it was shown that surfactant protein B (SP-B) homeostasis, alveolar wall thickness, and compliance as markers of lung maturation were significant altered as well as proliferation, and deposition of elastin fibers to mark future growth of alveoli

Partially processed SP-B was detectable in bronchoalveolar lavage fluid (BALF) from control animals at 113 and 117 days GA. At 3 and 7 days after LPS, SP-B was completely processed and the homodimer was exclusively detected. When calculated relative to body weight, secreted SP-B triples 7 days after LPS in comparison with control animals, whereas there was no increase in SP-B pool size 3 days after LPS. The increased SP-B expression after 7 days can be considered in part as lung maturation. However, in vivo and in vitro studies have shown antiinflammatory properties of SP-B and phospholipids. SP-B can limit the inflammation after intratracheal endotoxin instillation ${ }^{28,} 29$. SP-B, SP-C, and phospholipids reduced the transcription of tumor necrosis factor- $\alpha$ in monocytes ${ }^{30,31}$. In addition, surfactant preparations of SP-B and phospholipids enhanced the phagocytosis of apoptotic cells as part of the resolution of inflammation ${ }^{32}$. Therefore, the increase in surfactant pool size may have primarily antiinflammatory effects and may be a mechanism of fetal adaptation, which clinically appears as lung maturation and thus optimizes adaptation - and survival - after preterm birth ${ }^{33}$. The alveolar walls were thinner in all animals exposed to LPS as part of the changes seen in lung maturation. The deposition of elastin fibers was altered after exposure to LPS.

Systemic fetal inflammation seemed to be sufficient to induce lung maturation but did not induce lung maturation faster than intraamniotic LPS. This study demonstrated the importance of systemic inflammation for lung pathology in clinical contexts besides chorio-amnionitis. The high incidence of chorioamnionitis in preterm births predisposes the fetuses to systemic inflammation and infection. Inflammation has been associated with adverse pulmonary outcomes and higher susceptibility to 
hypoxic brain injury. Systemic and non-systemic inflammation contributes to the prenatal injury and structural changes in the lung of the fetus.

In chapter 8 the effects of in utero endotoxemia on the ovine fetal brain particularly the cingulate cortex were examined ${ }^{34}$.

The neurological outcome after preterm birth can have many facets of disorders in later life. Infections during the second trimester of pregnancy were indentified to play a role in the etiopathogenesisofschizophrenic psychoses ${ }^{35,36}$. A multitude of post mortem studies focused on the anterior cingulate cortex as an area of neuropathological disturbances in brains from patients with schizophrenia ${ }^{37-39}$.

High doses of intravenous LPS (500ng) intra-amniotic reduced the density of several GABA-ergic interneuron subsets and GFAP-immunoreactive cells, which are mainly astrocytes. On a molecular and structural level, the GABA-ergic interneurons play a major role in the pathogenesis of schizophrenia. GABA-ergic interneurons, which can be differentiated immunohistochemically by the calciumbinding proteins parvalbumin, calbindin D-28K, and calretinin, have an inhibitory function on neuronal circuits and a decisive influence on the cortico-limbic circulation ${ }^{40}$.

This study is the first to report cyto-architectural changes in GABA-ergic interneuron subsets in the cingulate cortex. The post mortem pathological changes in the brain of schizophrenia patients include cytoarchitectual changes in the anterior cingulate cortex, particularly for GABA-ergic interneurons ${ }^{41,42}$.

The study in chapter 8 shows the strengths and weaknesses of our animal models. The size of the animal and the good representation of the underlying developmental biology make the sheep an excellent model to study antenatal events but the lack of appropriate neurodevelopmental tests in later life in sheep makes a statement on the functional relevance impossible. Therefore, well designed, controlled clinical studies are necessary to translate our findings into the clinical context. The sheep model can still serve as an evaluation of new therapeutic approaches with respect to mechanistic approaches. 


\section{References:}

1. Kramer BW. Antenatal inflammation and lung injury: prenatal origin of neonatal disease. J Perinatol 2008;28 Suppl 1:S21-7.

2. Kuypers E, Collins JJ, Kramer BW, et al. Intra-amniotic LPS and antenatal betamethasone: inflammation and maturation in preterm lamb lungs. Am J Physiol Lung Cell Mol Physiol 2012;302:L380-9.

3. Gantert M, Been JV, Gavilanes AW, Garnier Y, Zimmermann LJ, Kramer BW. Chorioamnionitis: a multiorgan disease of the fetus? J Perinatol 2010;30 Suppl:S21-30.

4. Goldenberg RL, Culhane JF, lams JD, Romero R. Epidemiology and causes of preterm birth. Lancet 2008;371:75-84.

5. Romero R, Shamma F, Avila C, et al. Infection and labor. VI. Prevalence, microbiology, and clinical significance of intraamniotic infection in twin gestations with preterm labor. Am J Obstet Gynecol 1990;163:757-61.

6. Gantert M, Jellema RK, Heineman $H$, et al. Lipopolysaccharide-Induced Chorioamnionitis Is Confined to One Amniotic Compartment in Twin Pregnant Sheep. Neonatology 2012;102:81-8.

7. Garnier $Y$, Coumans $A B$, Jensen $A$, Hasaart $T H$, Berger R. Infection-related perinatal brain injury: the pathogenic role of impaired fetal cardiovascular control. J Soc Gynecol Investig 2003;10:450-9.

8. Berger R, Garnier Y, Jensen A. Perinatal brain damage: underlying mechanisms and neuroprotective strategies. J Soc Gynecol Investig 2002;9:319-28.

9. Gavilanes AW, Gantert M, Strackx E, et al. Increased EEG delta frequency corresponds to chorioamnionitis-related brain injury. Front Biosci (Schol Ed) 2010;2:432-8.

10. Hoppenbrouwers SS, Schutter DJ, Fitzgerald PB, Chen R, Daskalakis ZJ. The role of the cerebellum in the pathophysiology and treatment of neuropsychiatric disorders: a review. Brain Res Rev 2008;59:185-200.

11.Strackx E, Gantert M, Moers V, et al. Increased number of cerebellar granule cells and astrocytes in the internal granule layer in sheep following prenatal intraamniotic injection of lipopolysaccharide. Cerebellum 2012;11:132-44.

12.Johnsen SD, Bodensteiner JB, Lotze TE. Frequency and nature of cerebellar injury in the extremely premature survivor with cerebral palsy. J Child Neurol 2005;20:60-4.

13. Rees $S$, Harding $R$. The effects of intrauterine growth retardation on the development of the Purkinje cell dendritic tree in the cerebellar cortex of fetal sheep: a note on the ontogeny of the Purkinje cell. Int J Dev Neurosci 1988;6:4619.

14.Allin $M$, Matsumoto $H$, Santhouse AM, et al. Cognitive and motor function and the size of the cerebellum in adolescents born very pre-term. Brain 2001;124:60-6.

15.Limperopoulos C, Bassan H, Gauvreau K, et al. Does cerebellar injury in premature infants contribute to the high prevalence of long-term cognitive, learning, and behavioral disability in survivors? Pediatrics 2007;120:584-93.

16.Limperopoulos C, Robertson RL, Sullivan NR, Bassan H, du Plessis AJ. Cerebellar injury in term infants: clinical characteristics, magnetic resonance imaging findings, and outcome. Pediatr Neurol 2009;41:1-8.

17.Parker J, Mitchell A, Kalpakidou A, et al. Cerebellar growth and behavioural \& neuropsychological outcome in preterm adolescents. Brain 2008;131:1344-51. 
18.Feng SY, Phillips DJ, Stockx EM, Yu VY, Walker AM. Endotoxin has acute and chronic effects on the cerebral circulation of fetal sheep. Am J Physiol Regul Integr Comp Physiol 2009;296:R640-50.

19. Garnier Y, Coumans A, Berger R, Jensen A, Hasaart TH. Endotoxemia severely affects circulation during normoxia and asphyxia in immature fetal sheep. J Soc Gynecol Investig 2001;8:134-42.

20.Allen G, Courchesne E. The cerebellum and non-motor function: clinical implications. Mol Psychiatry 1998;3:207-10.

21.Allen G, Courchesne E. Differential effects of developmental cerebellar abnormality on cognitive and motor functions in the cerebellum: an fMRI study of autism. Am J Psychiatry 2003;160:262-73.

22. Gavilanes AW, Strackx E, Kramer BW, et al. Chorioamnionitis induced by intraamniotic lipopolysaccharide resulted in an interval-dependent increase in central nervous system injury in the fetal sheep. Am J Obstet Gynecol 2009;200:437 e1-8.

23. Kramer BW, Moss TJ, Willet KE, et al. Dose and time response after intraamniotic endotoxin in preterm lambs. Am J Respir Crit Care Med 2001;164:982-8.

24.Nitsos I, Moss TJ, Cock ML, Harding R, Newnham JP. Fetal responses to intraamniotic endotoxin in sheep. J Soc Gynecol Investig 2002;9:80-5.

25.Duncan JR, Cock ML, Scheerlinck JP, et al. White matter injury after repeated endotoxin exposure in the preterm ovine fetus. Pediatr Res 2002;52:941-9.

26. Speer CP. Inflammation and bronchopulmonary dysplasia: a continuing story. Semin Fetal Neonatal Med 2006;11:354-62.

27.Jobe AH, Bancalari E. Bronchopulmonary dysplasia. Am J Respir Crit Care Med 2001;163:1723-9.

28.Epaud R, Ikegami M, Whitsett JA, Jobe AH, Weaver TE, Akinbi HT. Surfactant protein $B$ inhibits endotoxin-induced lung inflammation. Am J Respir Cell Mol Biol 2003;28:373-8.

29.Ikegami M, Whitsett JA, Martis PC, Weaver TE. Reversibility of lung inflammation caused by SP-B deficiency. Am J Physiol Lung Cell Mol Physiol 2005;289:L96270.

30.Baur FM, Brenner B, Goetze-Speer B, Neu S, Speer CP. Natural porcine surfactant (Curosurf) down-regulates mRNA of tumor necrosis factor-alpha (TNFalpha) and TNF-alpha type II receptor in lipopolysaccharide-stimulated monocytes. Pediatr Res 1998;44:32-6.

31.Speer CP, Gotze B, Curstedt T, Robertson B. Phagocytic functions and tumor necrosis factor secretion of human monocytes exposed to natural porcine surfactant (Curosurf). Pediatr Res 1991;30:69-74.

32. Kramer BW, Jobe AH, Ikegami M. Monocyte function in preterm, term, and adult sheep. Pediatr Res 2003;54:52-7.

33. Kramer BW, Jobe $\mathrm{AH}$. The clever fetus: responding to inflammation to minimize lung injury. Biol Neonate 2005;88:202-7.

34. Gantert M, Kreczmanski P, Kuypers E, et al. Effects of in utero endotoxemia on the ovine fetal brain: A model for schizophrenia? Front Biosci (Elite Ed) 2012;4:2845-53.

35.Adams W, Kendell RE, Hare EH, Munk-Jorgensen P. Epidemiological evidence that maternal influenza contributes to the aetiology of schizophrenia. An analysis of Scottish, English, and Danish data. Br J Psychiatry 1993;163:522-34.

36. McGrath JJ, Pemberton MR, Welham JL, Murray RM. Schizophrenia and the influenza epidemics of 1954, 1957 and 1959: a southern hemisphere study. Schizophr Res 1994;14:1-8. 
37. Harrison PJ. Neurochemical alterations in schizophrenia affecting the putative receptor targets of atypical antipsychotics. Focus on dopamine (D1, D3, D4) and 5-HT2a receptors. Br J Psychiatry Suppl 1999:12-22.

38. Heckers S. Neuropathology of schizophrenia: cortex, thalamus, basal ganglia, and neurotransmitter-specific projection systems. Schizophr Bull 1997;23:403-21.

39. Jakob H, Beckmann H. Gross and histological criteria for developmental disorders in brains of schizophrenics. J R Soc Med 1989;82:466-9.

40.Benes FM, McSparren J, Bird ED, SanGiovanni JP, Vincent SL. Deficits in small interneurons in prefrontal and cingulate cortices of schizophrenic and schizoaffective patients. Arch Gen Psychiatry 1991;48:996-1001.

41.Benes FM, Berretta S. GABAergic interneurons: implications for understanding schizophrenia and bipolar disorder. Neuropsychopharmacology 2001;25:1-27.

42. Bunney BG, Potkin SG, Bunney WE, Jr. New morphological and neuropathological findings in schizophrenia: a neurodevelopmental perspective. Clin Neurosci 1995;3:81-8. 
Samenvatting 


\section{Nederlandstalige samenvatting}

Klinische observaties en experimentele resultaten tonen aan dat foetale blootstelling aan antenatale inflammatie zowel voordelige als nadelige effecten heeft voor de foetus. Chorioamnionitis brengt schade toe aan de ontwikkelende foetus door bijvoorbeeld het verstoren van de long ontwikkeling. Meerdere organen kunnen aangedaan zijn door blootstelling aan antenatale inflammatie. Daarom wordt nu algemeen aangenomen dat chorioamnionitis een multi-orgaan ziekte in de foetus veroorzaakt (hoofdstuk 2).

Om de verschillende ziekte mechanismes te bestuderen zijn dier modellen van intraamniotische en intraveneuze injecties ontwikkeld. Het risico van vroeggeboorte stijgt bij een meerlingen-zwangerschap onafhankelijk van de aanwezigheid van extra risico factoren zoals chorioamnionitis. Klinische resultaten tonen aan dat histologische chorioamnionitis bij een tweelingzwangerschap in de meerderheid van de gevallen alleen de foetus die blootgesteld wordt aan deze chorioamnionitis, beïnvloedt. In ons schaap model hebben we aangetoond dat LPS-geïnduceerde histologische chorioamnionitis beperkt blijft tot het blootgestelde compartiment en niet de tweede foetus beïnvloedt (hoofdstuk 3). Inflammatie in de placenta, membranen en longen van de LPS-blootgestelde foetus van de tweelingzwangerschap was significant hoger op 2 en 14 dagen na LPS injectie wanneer vergeleken met controle-tweelingen. Ook de long compliantie in LPS-blootgestelde dieren was significant gestegen 14 dagen na blootstelling vergeleken met controle-tweelingen. Intra-uteriene LPS blootstelling veroorzaakte een stijging in long compliantie en inflammatie in de membranen, placenta en longen in dezelfde graad in tweelingen als in eenlingen. Deze bevindingen kunnen daarom mogelijk artsen aanmoedigen om een verlate-interval bevalling te opteren. Wanneer chorioamnionitis zich presenteert met klinische symptomen en de zwangerschapsduur van de meerlingen-zwangerschap aanleunt tegen levensvatbaarheid, kan het van zeer groot belang zijn als 1 of beiden compartiment aangedaan zijn door chorioamnionitis.

\section{Hersenschade na endotoxine blootstelling}

Van klinische en epidemiologische studies is het gekend dat blootstelling aan infecties in de baarmoeder een belangrijke rol speelt in het ontstaan van foetale of neonatale schade wat kan leiden tot cerebrale parese en chronische long ziekte. $\mathrm{Na}$ chorioamnionitis stijgt de incidentie van peri-ventriculaire witte stof schade en periventriculaire of intra-ventriculaire hersenbloedingen in vroeggeboren significant. Perinatale hersen schade is vaak geassocieerd met cerebrale ischemie, cerebrale bloedingen of een intra-uteriene infectie. Verschillende studies suggereren dat cytokines 
die worden geproduceerd tijdens een intra-uteriene infectie direct schade veroorzaken aan het immature brein. Daarom vertonen preterme kinderen vaak chronische problemen met de witte stof ontwikkeling en corticale maturatie. Hoewel foetale infectie/inflammatie kan bijdragen tot witte stof pathologie, is het onbekend welke factoren bijdragen tot de corticale veranderingen. Naast de cerebrale peri-ventriculaire witte stof schade, zijn ook de corticale en subcorticale grijze stof alsook het cerebellum aangedaan, wat bijdraagt tot de complexe lange termijn neurologische morbiditeit in deze kinderen.

In hoofdstuk 4 hebben we het effect van foetale lipopolysaccharide (LPS) blootstelling op de cerebrale witte stof en corticale ontwikkeling onderzocht door middel van elektroencefalografie (EEG) in foetale schapen van wie de ontwikkelingsbiologie overeenstemt met de preterme periode in de mens. $10 \mathrm{mg}$ intra-amniotisch LPS of zoutoplossing werd gegeven 2 of 14 dagen voor vroeggeboorte op een zwangerschapsduur van 125 dagen. De foetussen werden geboren door middel van een keizer snede onder lokale anesthesie. Een 5-minuten durende EEG met delta activiteit en amplitude, microglia activatie en apoptose in de witte en de corticale stof werd geanalyseerd.

EEG delta activiteit was significant gestegen in foetussen blootgesteld aan LPS 14 dagen voor de vroeggeboorte vergeleken met controle en 2-dagen blootgestelde foetussen. Geen verschillen werden opgemerkt tussen controle dieren en 2- dagen LPS blootgestelde dieren. Een associatie werd aangetoond tussen de EEG delta activiteit en corticale microglia activatie en apoptose alsook een correlatie tussen delta activiteit en geactiveerde microglia en apoptose in de witte stof. Deze studie is een van de eersten die een relatie aantoont tussen hersendysfunctie en chorioamnionitis-gerelateerde schade in schapen. Neurologische schade in pasgeborenen als gevolg van chorioamnionitis is zeer moeilijk te identificieren, vooral wanneer er geen klinische indicaties zijn net na de geboorte. Daarom zou deze minder invasieve procedure in een niet-geanestheseerde foetus toegepast kunnen worden voor het opsporen van encefalopathie.

Verschillende decennia al wordt het cerebellum beschouwd als een regio van het brein wat vooral betrokken is bij motorfuncties. Aangestuurd door neuro-anatomisch onderzoek en nieuwe diagnostische methodes, wordt er echter recent gesuggereerd dat het cerebellum bijdraagt in de pathofysiologie van psychiatrische aandoeningen.

In hoofdstuk 5 testen we de hypothese dat het naast de verschillende hersen gebieden ook het cerebellum aangedaan was door intra-uteriene inflammatie. Een relatief hoog percentage van preterme kinderen met cerebrale parese vertonen ook abnormaliteiten in het cerebellum. Het cerebellum is zeer gevoelig tijdens de laatste periode van de zwangerschap aangezien er dan actieve proliferatie en migratie van de cerebellaire granulaire cellen plaatsvindt. Een ongunstige neurologische uitkomst als resultaat van 
blootstelling aan intra-uteriene inflammatie wordt meer en meer aangetoond maar het is nog erg onduidelijk wat de juiste gevolgen zijn voor het centrale zenuwstelsel. Momenteel is er duidelijk bewijs dat ook het cerebellum betrokken is bij cognitieve en affectieve aandoeningen.

Daarom stelden we de hypothese dat chorioamnionitis veranderingen zou veroorzaken in het aantal granulaire en/of Purkinje cellen en astrocyten in het cerebellum van een bijna voldragen foetus. $10 \mathrm{mg}$ LPS werd toegediend intra-amniotisch in tegenstelling tot intraveneus om mogelijke circulatie veranderingen wat secundaire hypoxie-ischemie in de foetus kan veroorzaken, te minimaliseren. 30 dagen na de toediening van LPS (op 140 dagen, a term= 147 dagen) werden de cerebellaire volumes en het aantal granulaire en Purkinje cellen bepaald door middel van stereologie en werd astrogliose gemeten door een semi-kwantitatieve analyse methode. Het volume van de buitenste granulaire laag, de binnenste granulaire laag, de moleculaire laag en de witte stof van het cerebellum was niet verschillend in LPS-blootgestelde dieren vergeleken met controle dieren.

LPS-blootgestelde dieren vertoonden een significante stijging in het gemiddelde totale aantal granulaire cellen in de binnenste granulaire laag maar geen verschil in het gemiddelde totale aantal Purkinje cellen. Astrocyten vertoonden een sterke GFAP immuno-reactiviteit in zowel het cel lichaam als in de dendrieten in de hersenen van LPS-blootgestelde en controle dieren en werden teruggevonden in alle lagen van het cerebellum. LPS-blootgestelde dieren vertoonden een sterkere immuno-reactiviteit van GFAP en had een groter oppervlakte van GFAP-positieve astrocyten vergeleken met controle dieren. Deze studie toonde aan dat blootstelling aan chorioamnionitis in foetale schapen leidde tot belangrijke, morfologische veranderingen in het cerebellum. De klinische impact hiervan is complex en vraagt verdere uitdieping. Het blijft onduidelijk of deze cerebellaire veranderingen geassocieerd zijn met een nadelige neurologische ontwikkeling. Cerebellaire veranderingen wordt meer en meer geassocieerd met een zeer grote variatie aan complicaties zoals motor, sociale en cognitieve aandoeningen.

In hoofdstuk 6 hebben we de impact van chorioamnionitis op zowel witte als grijze stof structuren in het centrale zenuwstelsel van het preterme schaap gekwantificeerd. Hiervoor werden apoptotische cellen en cel types in de hersenen, cerebellum en ruggenmerg geanalyseerd met behulp van flow cytometrie. In tegenstelling tot de meest gebruikte experimentele setups, werd er in deze studie LPS toegediend in het amnion vocht door middel van een amniocentese. Deze intra-amniotische toediening vermijdt hemodynamische veranderingen en secundaire post-asphyxtische encefalopathie wat veroorzaakt wordt door foetale intraveneuze LPS toediening. Het centrale zenuwstelsel werd onderzocht op dag 125 van de zwangerschapsduur 2 of 14 dagen na de toediening van $10 \mathrm{mg}$ LPS. Het experimentele tijdstip in schapen komt overeen met een zwangerschapsduur van 28 weken in de ontwikkeling van het humane centrale 
zenuwstelsel dat de meest gevoelige periode is voor de ontwikkeling van witte stof ziekten bij de mens. Blootstelling aan chorioamnionitis resulteerde in een intervalafhankelijk stijging van centraal zenuwstelsel schade en regionale verschillen in het schade patroon. Microglia activatie en apoptotische cel dood steeg in het brein, cerebellum en ruggenmerg in een interval afhankelijke manier. In de meeste hersenregio's werd er ook een daling van oligodendrocyten en neuronen gezien alsook een stijging van astrocyten. Het cerebellum en ruggenmerg leken minder aangedaan in dit aspect. Deze studie toont een globale inflammatoire reactie aan na acute chorioamnionitis in de hersenen, cerebellum en ruggenmerg en een selectieve gevoeligheid van de ontwikkelende regio's voor deze schadelijke stimulus.

In hoofdstuk 7 werd de rol van intraveneus endotoxine op de long inflammatie verder verdiept. Long inflammatie is geassocieerd verminderd risico op acute respiratoire distress syndroom (RDS) maar een stijging in het risico voor bronchopulmonale dysplasie (BPD) met een verstoorde alveogenese. Verschillende pre- en postnatale factoren kunnen bijdragen tot de ontwikkeling van BPD in de foetus. Interleukine- 6 concentraties in het navelstrengbloed is gestegen in foetussen die later BPD ontwikkelen. BPD wordt momenteel gezien als een verstoorde groei en ontwikkeling van de alveoli en micro-vasculatuur wat verder kan verergerd worden na postnatale pulmonale en/of systemische inflammatie. Foetale systemische inflammatie kan leiden tot veranderingen in surfactant proteïne B (SP-B) homeostase, alveolaire wand dikte en long compliantie, markers van long maturatie alsook proliferatie en depositie van elastine vezels die normaal de groei van toekomstige alveoli aanstuurt.

Deels verwerkt SP-B werd gedetecteerd in de broncho-alveolaire lavage van controle dieren op 113 en 117 dagen zwangerschapsduur. 3 en 7 dagen na LPS blootstelling was het SP-B helemaal verwerkt en werden er alleen nog homodimeer vormen gedetecteerd.

Het uitgescheiden SP-B verdriedubbelde 7 dagen na LPS blootstelling in vergelijking met controle dieren, terwijl er geen stijging in de SP-B secretie werd opgemerkt 3 dagen na blootstelling. De stijging in SP-B expressie na 7 dagen kan gezien worden als deel van de long maturatie processen. In vivo en in vitro studies hebben aangetoond dat SP$B$ en fosfolipiden anti-inflammatoire eigenschappen bezitten. SP-B kan inflammatie veroorzaakt door intra-tracheale toediening van endotoxine, limiteren. SP-B, SP-C en fosfolipiden verminderen de transcriptie van tumor necrosis factor- $\alpha$ in monocyten. Ook stimuleren surfactant preparaties van SP-B en fosfolipiden de fagocytose van apoptotische cellen als deel van de resolutie fase van inflammatie. Hierdoor kan een stijging van de surfactant pool grootte primaire anti-inflammatoire effecten hebben en kan dit werken als een deel van het mechanisme van foetale adaptatie wat klinisch gezien wordt door long maturatie en wat de uiteindelijke adaptatie en dus overleving na vroeggeboorte vergroot. Verder waren de alveolaire wanden in alle dieren blootgesteld 
aan LPS dunner, wat verder ook deel is van de morfologische veranderingen gezien na long maturatie. De depositie van elastine vezels waren alsook veranderd na LPS blootstelling.

Systemische foetale inflammatie lijkt voldoende te zijn om long maturatie te veroorzaken maar niet zo snel als intra-amniotische LPS toediening. Deze studie toonde de belangrijkheid van systemische inflammatie voor de long pathologie aan in de klinische contexten naast chorioamnionitis. De hoge incidentie van chorioamnionitis bij vroeggeboorte verhoogt het risico van de foetus voor systemische inflammatie en infectie. Inflammatie is geassocieerd met negatieve pulmonale klinische uitkomsten en een hogere kwetsbaarheid voor hypoxische hersen schade. Samengevat, systemische en niet-systemische inflammatie dragen bij tot prenatale schade en structurele veranderingen in de longen van de foetus.

In hoofdstuk 8 werden de effecten van endotoxemie in de baarmoeder op de foetale hersenen en voornamelijk de cingulate cortex van preterme schapen onderzocht. De neurologische uitkomst na vroeggeboorte kan zich uiten in vele verschillende aandoeningen in het latere leven. Infecties tijdens het $2^{\text {de }}$ trimester van de zwangerschap lijken een rol te spelen in het ontstaan van schizofrenie. Verscheidende post-mortem studies hebben vooral veranderingen in de anterior cingulate cortex aangetoond als een van de neuropathologische veranderingen in de hersenen van schizofrenie patiënten. Hoge dosissen intraveneuze LPS (500 ng) gegeven tijdens de ontwikkeling verminderde de densiteit van verschillende GABA-nergische interneuron subsets en GFAP-immuno reactieve cellen dat voornamelijk astrocyten zijn. Op een moleculair en structureel niveau spelen de GABA-nergische interneuronen een belangrijke rol in de pathogenese van schizofrenie. GABA-nergische interneuronen, die immunohistochemisch onderscheiden kunnen worden door de calcium-bindende proteïnen parvalbumine, calbindin D-28K en calretenine, hebben een remmende functie op neuronale circuits en een belangrijke invloed op de cortico-limbische circulatie. Deze studie toonde als een van de eerste cyto-architecturale veranderingen aan in de GABAnergische interneuron subsets in de cingulate cortex van preterme schapen. De postmortem pathologische veranderingen in de hersenen van schizofrene patiënten houden ook deze cyto-architecturale veranderingen in de anterieure cingulate cortex in, voornamelijk in de GABA-nergische interneuronen.

De studie in hoofdstuk 8 toont zowel de sterktes als zwaktes aan van onze diermodellen. De grootte van het dier en de duidelijke overeenkomst in de onderliggende ontwikkelingsbiologie maakt het schaap een zeer goed model voor het bestuderen van antenatale gebeurtenissen maar het gebrek aan geschikte neurologische testen in het latere leven maakt uitspraken over de functionele relevantie van bepaalde veranderingen erg moeilijk. Daarom zijn goed ontworpen, gecontroleerde klinische studies nodig om onze bevindingen van in het experimenteel dier model om te 
zetten naar de klinische context. Het schaap model kan nog steeds dienen voor het evalueren van nieuwe therapeutische strategieën en mechanistische interventies. 
Acknowledgement 


\section{Acknowledgement}

My friend, mentor and promoter Prof. Dr. Dr. Boris Kramer offered me the opportunity to pursue my scientific career and to accomplish my $\mathrm{PhD}$ thesis as an external PhD student at the University of Maastricht. I am deeply grateful to him. Working with him has been an honour!

The fact that the research work was done by a German in the Netherlands is not coincidental. The excellent working conditions, the outstanding support by the team, and the eminent sustenance of the animals with high ethical standards made the University of Maastricht the perfect place to accomplish this thesis. I would like to express my gratitude to Dr. Danilo Gavilanes (co-promoter) and Professor Dr. Luc Zimmermann (promoter), Chairman of the Department of Paediatrics, University of Maastricht.

I am also grateful to many people who inspired me, gave me advice and support, and participated in my formation as Obstetrician and Gynecologist: Professor Dr. Jelte de Haan, Professor Dr. Tom Hasaart, Professor Dr. Arne Jensen, Professor Dr. Werner Rath, Dr. Jörg Falbrede, Professor Dr. Peter Mallmann and Dr. Bernd Holthaus.

The main inspiration for this whole project came from Priv.-Doz. Dr. Dr. Yves Garnier. Over many years, he was not only my boss, but also my friend and an example of a dedicated Obstetrician and Gynecologist. I am deeply grateful for his guidance and support and for the decade in which we walked together on a common path.

I also thank Reint Jellema, who joined the team a few years ago. I was able to give him some advice in animal surgery. He, in return, helped me with many tasks that cannot be accomplished by an external.

I am also grateful to many other contributors: Elke Kuypers for analyzing data, for her co-authorship and passion for neuroscience; Heike Heinemann, Verena Lambermont, Matthias Seehase, Jennifer Collins, Eveline Strackx, and Evi Vlassaks for their collaboration in animal work and analysis of tissue; Lilian Kessels, Nico Kloosterboer, and Leon Janssen for technical help; Peggy van den Heuvel who managed correspondence with the university; Joyce Suyk, Sanne Bout, Petra Dijkstra, Frans Slangen, Noortje Peeters, Drs. Saskia Seeldrayers and Dr. Barry Plooijer with whom I spent so many hours in the CPV. Their support was splendid.

Finally, I would like to thank my family. Without my wife, children, and my parents, this work would not have been possible. They all have supported me incredibly. Their patience was inexhaustible! This work is dedicated to my family, especially to my 
father, Dr. Lothar Gantert, pediatrician, who passed away in 2011, and therefore could not see this work finished. 
Curriculum vitae 


\section{Curriculum Vitae}

\section{Markus Bodo Paul Friedrich Gantert}

Name

Year of Birth

Title and position

Children
Markus Gantert

1973

Dr. med., gynaecologist and obstetrician, Head physician

Specialism: special obstetrics and perinatal medicine, MIC II (minimally invasive surgery, level II)

Julia Gantert

Janus Frieder Gantert

Mathilda Mia Gantert

\section{Training and Qualifications}

\begin{tabular}{|c|c|}
\hline rsity & \\
\hline 1993 & Commenced medical degree at the University of Freiburg \\
\hline 1996 & Preclinical examination [Ärztliche Vorprüfung] \\
\hline 1998 & $\begin{array}{l}\text { Clinical examination, stage I [Erster Abschnitt der } \\
\text { Ärztlichen Prüfung] }\end{array}$ \\
\hline 1998-99 & $\begin{array}{l}\text { Year abroad studying at the University of La Laguna, } \\
\text { Tenerife, Spain }\end{array}$ \\
\hline 1999 & $\begin{array}{l}\text { Two months' research for thesis at the Royal Hospital for } \\
\text { Women under Prof. N. Hacker, Sydney, Australia }\end{array}$ \\
\hline 2000 & $\begin{array}{l}\text { Clinical examination, stage II [Zweiter Abschnitt der } \\
\text { Ärztlichen Prüfung] } \\
\text { Awarded doctorate in medicine ("magna cum laude") }\end{array}$ \\
\hline 2001 & $\begin{array}{l}\text { Clinical examination, stage III [Dritter Abschnitt der } \\
\text { Ärztlichen Prüfung] ("good") }\end{array}$ \\
\hline 2002-03 & $\begin{array}{l}\text { Bochum University gynaecology clinic, junior house officer } \\
\text { [Arzt im Praktikum] }\end{array}$ \\
\hline 07/2003 & Registration \\
\hline $\begin{array}{l}08 / 2003- \\
03 / 2004\end{array}$ & $\begin{array}{l}\text { Gynaecology and obstetrics training as } \\
\text { junior doctor [Assistenzarzt] at Aachen University Hospital } \\
\text { Department of Gynaecology and Obstetrics }\end{array}$ \\
\hline $\begin{array}{l}04 / 2004- \\
09 / 2005\end{array}$ & $\begin{array}{l}\text { Gynaecology and obstetrics training as } \\
\text { junior doctor at the Frauenklinik an der Vogelsangstrasse } \\
\text { gynaecology clinic, Kliniken St. Antonius hospital, } \\
\text { Wuppertal }\end{array}$ \\
\hline $\begin{array}{l}10 / 2005- \\
06 / 2008\end{array}$ & $\begin{array}{l}\text { Gynaecology and obstetrics training as research } \\
\text { assistant and junior doctor at the clinic and policlinic for } \\
\text { gynaecology and obstetrics [Klinik und Poliklinik für } \\
\text { Frauenheilkunde und Geburtshilfe], Cologne University } \\
\text { Hospital }\end{array}$ \\
\hline 09/2006 & $\begin{array}{l}\text { Regular and successful participation in animal testing } \\
\text { courses at LMU Munich university }\end{array}$ \\
\hline 05/2007- & Hygiene officer at the clinic and policlinic for gynaecology \\
\hline
\end{tabular}


$06 / 2008$

$06 / 2007-$

09/2007-

$06 / 2008$

07/2008-

$03 / 2010$

04/2010-

$09 / 2010$

$04 / 2010-$

$09 / 2012$

$11 / 2010$

$12 / 2010$

10/2012-

$09 / 2013$

10/2013- and obstetrics, Cologne University Hospital

Gynaecologist and obstetrician

Consultant at the clinic and policlinic for gynaecology

and obstetrics, Cologne University Hospital

Consultant at the gynaecology and obstetrics clinic [Klinik

für Frauenheilkunde und Geburtshilfe] Klinikum Osnabrück $\mathrm{GmbH}$

Consultant at Klinik St. Elisabeth $\mathrm{gGmbH}$ hospital in

Damme, gynaecology and obstetrics department

Member of the GYNMÜNSTER clinic for surgical

gynaecology

Qualified in specialty: special obstetrics and perinatal medicine

MIC II (minimally invasive surgery, level II)

Deputy director of the MIC, Dr. Geisenhofer gynaecology clinic, Munich

Deputy director of the gynaecology department at Airport

Clinic M, Munich

Head of Department of Obstetrics \& Gynaecology

St. Franziskus-Hospital, Ahlen

\section{Membership of Professional Bodies}

2003

Deutsche Gesellschaft für Gynäkologie und Geburtshilfe (DGGG) [German Gynaecology and Obstetrics Association]

Deutsche Gesellschaft für Perinatale Medizin (DGPM)

[German Perinatal Medicine Association]

Deutsch-Spanische- Gesellschaft für Geburtshilfe und Gynäkologie e. V.

[German-Spanish Association for Obstetrics and Gynaecology]

2004

In Training Member of the Society for Gynecologic Investigation (SGI)

[Gynaecological Endoscopy Working Group]

Arbeitsgemeinschaft für Urogynäkologie und plastische Beckenbodenrekonstruktion (AGUB e.V.)

[Working Group on Urogynaecology and Plastic Reconstructive Surgery for the Pelvic Floor] 


\section{List of Publications}




\section{List of Publications}

1. Gantert M, Kreczmanski P, Kuypers E, et al. Effects of in utero endotoxemia on the ovine fetal brain: A model for schizophrenia? Front Biosci (Elite Ed) 2012;4:2845-53.

2. Gantert M, Jellema RK, Heineman H, et al. Lipopolysaccharide-Induced Chorioamnionitis Is Confined to One Amniotic Compartment in Twin Pregnant Sheep. Neonatology 2012;102:81-8.

3. Strackx E, Gantert M, Moers V, et al. Increased number of cerebellar granule cells and astrocytes in the internal granule layer in sheep following prenatal intra-amniotic injection of lipopolysaccharide. Cerebellum 2012;11:132-44.

4. Seehase M, Gantert M, Ladenburger A, et al. Myocardial response in preterm fetal sheep exposed to systemic endotoxinaemia. Pediatr Res 2011;70:242-6.

5. Gantert M, Been JV, Gavilanes AW, Garnier Y, Zimmermann LJ, Kramer BW Chorioamnionitis: a multiorgan disease of the fetus? J Perinatol 2010;30 Suppl:S21-30.

6. Gavilanes AW, Gantert M, Strackx E, et al. Increased EEG delta frequency corresponds to chorioamnionitis-related brain injury. Front Biosci (Schol Ed) 2010;2:432-8.

7. Wolfs TG, Buurman WA, Zoer B, et al. Endotoxin induced chorioamnionitis prevents intestinal development during gestation in fetal sheep. PLoS One 2009;4:e5837.

8. Gavilanes AW, Strackx E, Kramer BW, et al. Chorioamnionitis induced by intraamniotic lipopolysaccharide resulted in an interval-dependent increase in central nervous system injury in the fetal sheep. Am J Obstet Gynecol 2009;200:437 e1-8.

9. Kramer BW, Ladenburger A, Kunzmann S, et al. Intravenous lipopolysaccharide-induced pulmonary maturation and structural changes in fetal sheep. Am J Obstet Gynecol 2009;200:195 e1-10.

10. Garnier Y, Kadyrov M, Gantert M, Einig A, Rath W, Huppertz B. Proliferative responses in the placenta after endotoxin exposure in preterm fetal sheep. Eur J Obstet Gynecol Reprod Biol 2008;138:152-7.

11. Kadyrov M, Garnier Y, Gantert M, Kramer BW, Kaufmann P, Huppertz B. Cytokeratin antibodies as differential markers of trophoblast and fetomaternal syncytial plaques in the sheep placentome. Placenta 2007;28:1107-9.

12. Meier C, Middelanis J, Wasielewski B, et al. Spastic paresis after perinatal brain damage in rats is reduced by human cord blood mononuclear cells. Pediatr Res 2006;59:244-9. 
13. Kohlberger P, Gantert M, Volk-Orlowska T, Kieback DG, Gitsch G. Immunohistochemical detection of lymph node metastases in node-negative breast cancer patients. Anticancer Res 2001;21:697-9. 